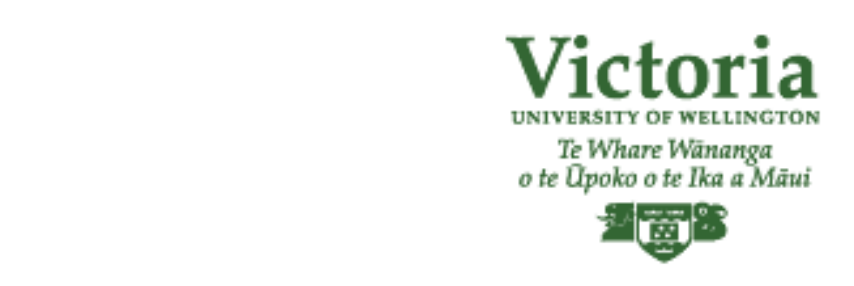

Electric Vehicles in the Pacific Islands?

An Investigation of the Possibilities of Electro-mobility in Samoa

By

Klaus Thoma

2014

A thesis submitted to Victoria University of Wellington, as partial fulfilment of requirements for the degree of Masters of Development Studies

School of Geography, Environment and Earth Sciences Victoria University of Wellington 


\title{
Electric Vehicles in the Pacific Islands? \\ An Investigation of the Possibilities of Electro-mobility in Samoa
}

\begin{abstract}
The identification of alternative transport modes is urgently required as fuel price inflation is adversely affecting Samoa's energy security and increasingly its economic and social well-being. The Samoan government has recognised the society-wide implications of fuel dependency and is moving towards improving fuel use efficiency of the national transport fleet and the identification of viable alternative transport fuels. This research analysed findings from global transport stakeholder organisations and modelled the energy consumption of electric vehicles (BEVs) under Samoan conditions. The results pointed to lower operating cost of BEVs which led to stakeholder support for the eCar pilot project aimed at establishing the feasibility of electro-mobility. The study adopted a postdevelopment approach as it provided information about BEV technology and invited Samoan transport stakeholders to contribute to mutual learning about alternative transport modes via a series of participative workshops. Postdevelopment thinking also pointed to assumptions made under prevailing conceptions of the modernist development project which may see the promotion of electro-mobility in the form of a commercial technology which is unaffordable to the majority of Samoans. The study concludes that in order to make electro-mobility accessible to a wider section of society, the concept of electro-mobility needs to be deconstructed into its components and rebuild to suit Samoa's conception of modernity. This could literally mean BEV retrofit conversions of second hand cars to take advantage of the well documented energy efficiency of the electric motor and discounting the status enhancing ownership of a commercial BEV.
\end{abstract}

Key words: electric vehicles, electro-mobility, electric vehicle retrofits, postdevelopment, renewable energy, externality cost, participative action research, Pacific Islands, Samoa. 


\section{Acknowledgements}

First of all I would like to express my warmest gratitude to my family who not only encouraged me to fulfil one of my old dreams to go back to university and do something practical there but also their support came with the full knowledge that they had to take over many of my jobs on our farm.

My studies as a mature student at the Postgraduate Programme in Development Studies were a rare mixture of stimulation and delight having such a cosmopolitan bunch of students to work and play with. But my special thanks go to my supervisor Professor John Overton who let me explore my unorthodox research ideas in Samoa hoping that I might return eventually and even with a project worthy of his attention.

I have to mention the warm and charming people of Samoa who made my stay on Upolu such a delight. There were too many small and ordinary meetings and interactions to mention which made my stay such an unforgettable experience. The warm reception of the palangi has given me extra motivation to contribute something worthwhile to this lovely country.

Without the support of my colleagues at the Samoan Ministry of Natural Resources and Environment I would not have gained the insights I needed to get ahead in my research. Special thanks go out to Sala Sagato Tuiafiso who shared the dream of reducing fossil fuel dependency in Samoa. Much appreciation goes to my colleague Anne who realised soon enough that I needed a helping hand with finding reports and all that institutional knowledge which only she had on her fingertips. I have appreciated Lillian's help in meeting many stakeholders but I will never forget her scheming in making me appear on my bicycle in front of Samoan TV, something I would have never even dreamt of doing. Thank you Lillian but count on a return prank.

I also want to extent a special thank you to Tutoatasi Setu who took it on herself to drive me to many interview appointments. She obviously did not have much confidence in my bicycle skills and realised soon enough that I was in dire need of some cultural guidance which she passed on in her nonchalant way. 


\section{Table of Contents}

Chapter One: Introduction.................................................................................... 13

1.1 Genesis of the Research Project ........................................................... 13

1.2 Central Research Question ................................................................. 15

1.3 Overview of Thesis Structure................................................................. 17

Chapter Two: The Transport and Energy Sector in Samoa ................................ 20

2.1 Samoa's Cultural and Political Institutions ................................................ 20

2.1.1. Fa'a Samoa: Samoa's way of dealing with outsiders .......................... 20

2.1.2. Contemporary and Independent Samoa......................................... 22

2.1.3 Samoa's Tussle with Globalisation ................................................... 23

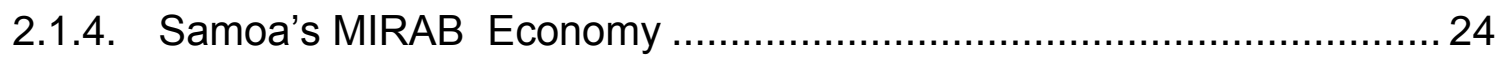

2.2 Socio-economic Aspects of Car ownership ............................................. 27

2.3 Some Macroeconomic Statistics Relating to the Energy Sector .....................28

2.4 Samoa's Transport and Energy Sector .................................................. 30

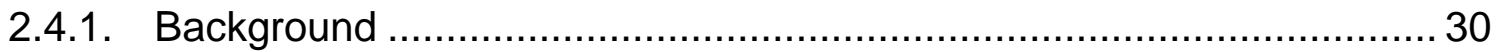

2.4.2. Relevant Policy governing the Transport and Energy Sector ...............33

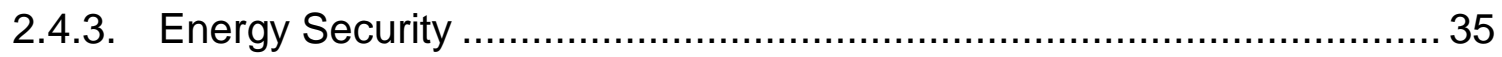

2.4.4. Samoan Renewable Energy Targets ............................................... 37

2.4.5. The Current Situation in the Transport Sector .................................. 40

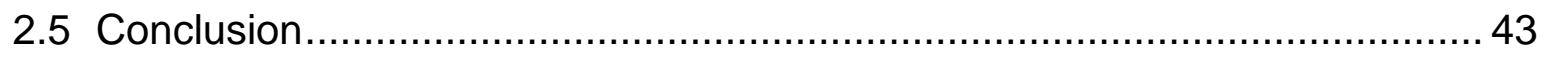

Chapter Three:Developments in Electric Mobility and Relevance for Samoa .. 45

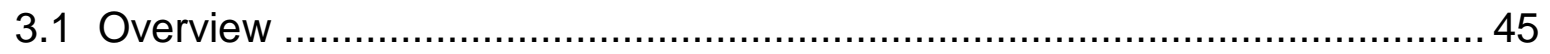

3.2 Economic and Environmental Context of the Transport Sector .................... 46

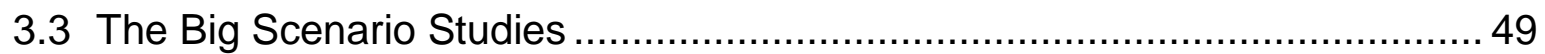

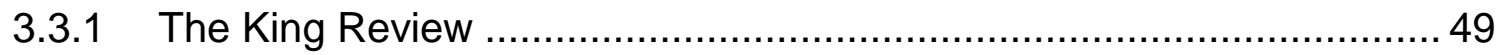

3.3.2 The International Energy Agency 2 Degree Celsius Scenario ...............51

3.3.3 The Renewable Energy Network Survey .......................................... 53 
3.4 Current Status of BEV and PHBEV Technology ….................................56

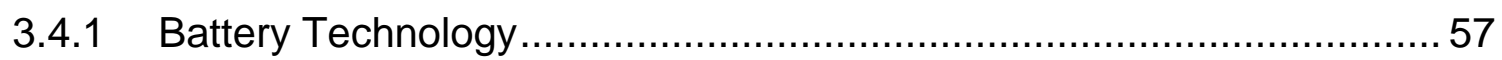

3.4.2 BEV Infrastructure Innovation ...................................................... 58

3.4.3 Some Footprint Comparisons of ICEVs, FCVs, BEVs and PHBEVs .... 60

3.5 The Role of Renewable Energy in the Pacific Island Countries..................... 62

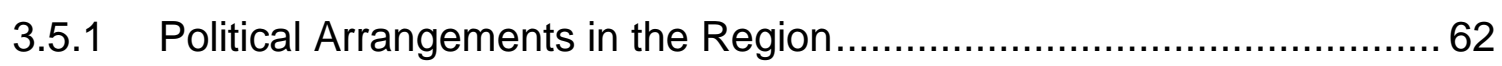

3.5.2 Practical Experiences with Biodiesel ................................................. 63

3.6 Small Island Nations' Experience with Electric Mobility ................................ 65

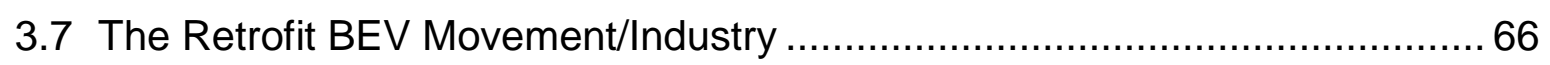

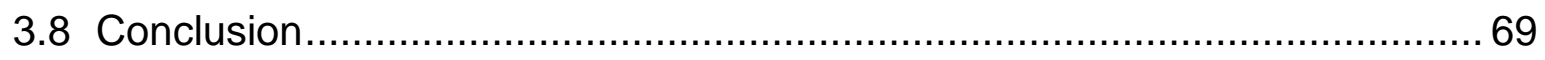

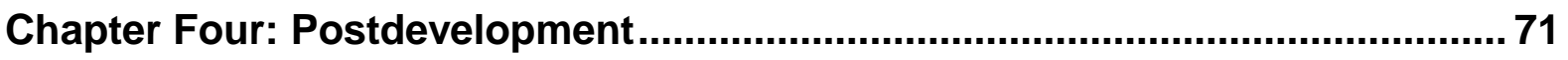

4.1 Background on Postdevelopment Theory ............................................... 72

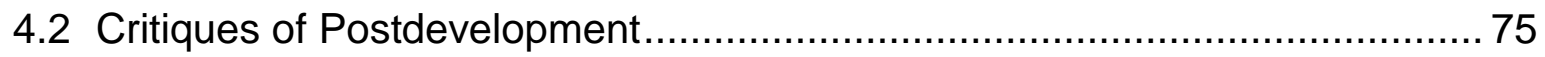

4.3 Postdevelopment in the early 2000s..................................................... 77

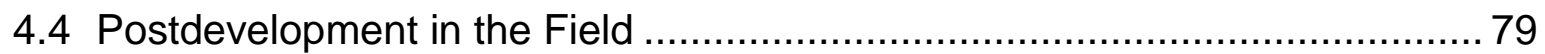

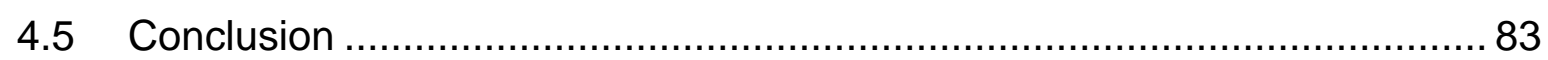

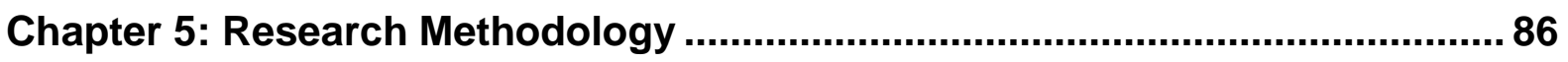

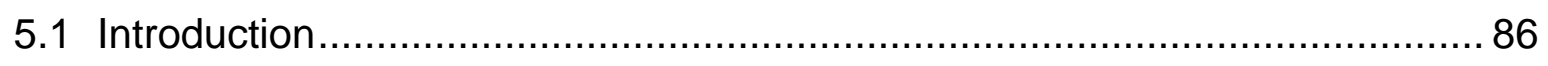

5.2 The Origins of the Participatory Development Paradigm …………................. 86

5.3 Participating in MNRE's Search for Alternative Transport Modes.................. 89

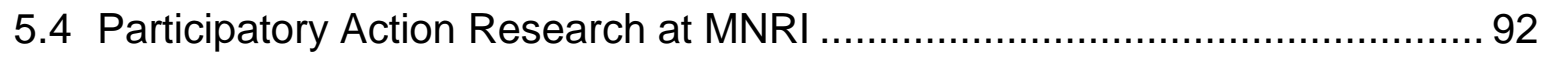

5.5 Applying Postdevelopment Thinking to the Problem of Fuel Dependency ... 93

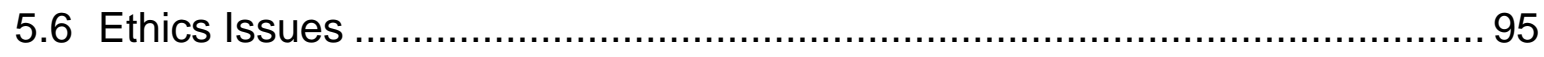

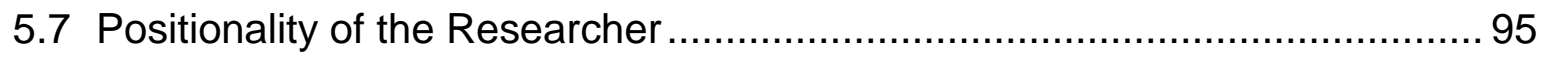

Chapter Six: Discovering Samoa's BEV Possibilities......................................... 99

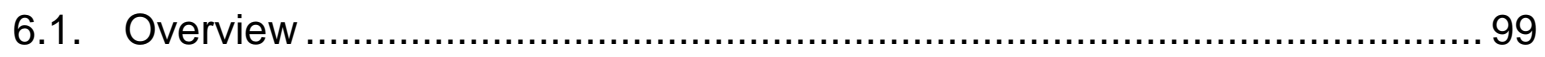




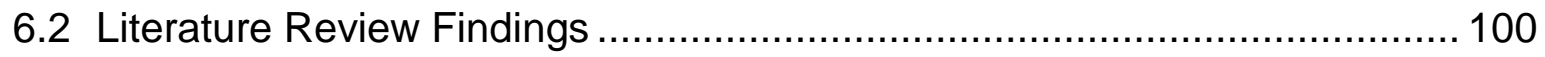

6.2.1 Relevance of Literature Findings for Samoan Legislation................... 101

6.2.2 Samoan Transport Data ............................................................... 103

6.2.3 First Participative Information Workshop ........................................ 106

6.2.4 Follow-up Interviews with Workshop Participants............................. 109

6.2.5 Summary of Findings from Semi-structured Stakeholder Interviews .. 111

6.2.6 Second Participative Workshop and Presentation of Draft eCar Pilot Project ................................................................................ 114

6.2.7. The Draft eCar Pilot Project Proposal.............................................. 115

6.2.8. Cost Benefit Considerations ........................................................... 117

6.3. Preparation of Samoan Government Cabinet Submission ........................ 124

Chapter Seven: Discussion ............................................................................ 127

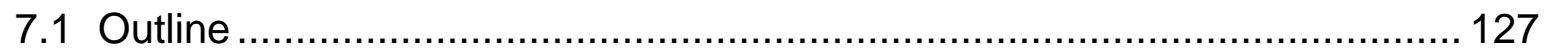

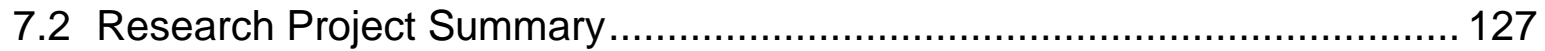

7.3 Transport Policy and Electro-mobility .................................................... 130

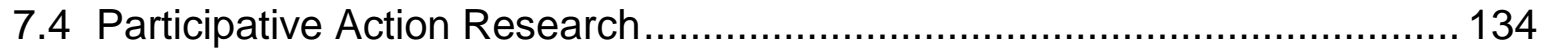

7.5 Reflections on my Postdevelopment Approach ........................................ 138

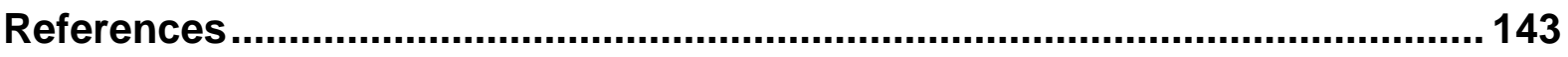

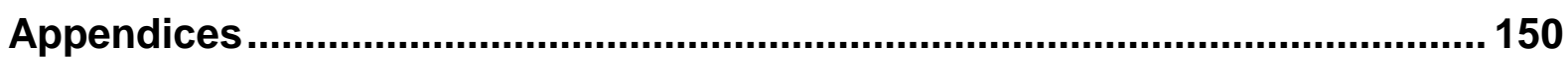

Appendix 1. Interview Documents............................................................ 151

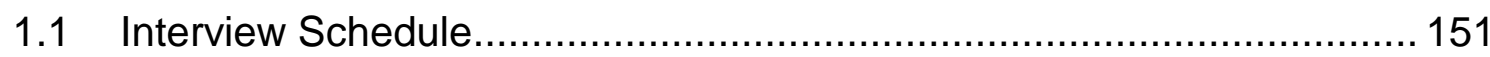

1.2 Consent Form - Consent to Participate in Research ........................... 152

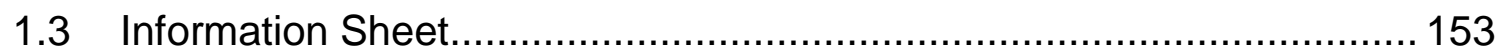

Appendix 2 Power Point Presentation of Second Participative Workshop ......... 155

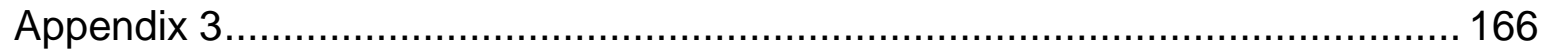

Project Proposal for Project: eCar Pilot Trial ................................................... 189

3.1. eCar Pilot Project Implementation Budget ........................................ 189 
3.2. Implementation Schedule by Month (relative to project commencement date) 


\section{Tables:}

Table 2.3.1: $\quad$ Petroleum Imports as a percentage of total imports and GDP by selected PICs

Table 2.4.1: $\quad$ Fuel price inflation 1999-2012

Table 2.4.2: $\quad$ Electricity cost variation, 2005-2011 32

Table 2.4.3: $\quad$ Ranked top six sources of GHG emissions 34

Table 6.1: $\quad$ Fuel Cost Comparison - CV, BEV and

Biodiesel Blend (BD)

Table 6.2: $\quad$ Transport mode effects on annual transport cost, GHG emissions and foreign exchange savings by a 1000 vehicle fleet.

\section{Figures:}

Figure 2.4.1: Total petroleum consumption by sector, 2011.

Figure 2.4.2: $\quad$ Comparison of retail fuel prices, $\mathrm{T} \$, 2011$.

Figure 2.4.3: Total Generation Cost, sene/kWh after electricity generation upgrade.

Figure 2.4.4: $\quad$ Fuel use changes by type 39

Figure 2.4.5: $\quad$ Samoan vehicle registrations by type 41

Figure 3.1: $\quad$ Government sales targets and BEV/PHBEV production/sales data

Figure 3.2: $\quad$ Greenhouse gas emissions by various alternative transport forms.

Figure 5.1.: $\quad$ Action research stages and iterations

Figure 6.1: $\quad$ Summary of literature review findings instrumental for action research phase.

Figure 6.2: $\quad$ Pay-back times for BEV capital investment based on two inflation scenarios, (US \$).

Figure 6.3: $\quad$ Illustrated Pay-back times for BEV capital investment including internalised externality cost (US \$). 


\section{Photographs:}

Photograph 2.1: Modern cars in central Apia. 40

Photograph 2.2: Public Transport at Apia's Bus Station. 43

Photograph 3.1: Illustration of conversion process of a mid-sized sedan with a picture taken before a conversion and after. $\quad 68$

Photograph 7.1: Projection and re-interpretation of transport technology. 140 


\section{Acronyms used in Text:}

\begin{tabular}{|c|c|}
\hline 2DS & Two Degree Scenario \\
\hline ADO & Automotive Diesel \\
\hline BAU & Business As Usual \\
\hline BEV & Electric Vehicle \\
\hline BEVI & Electric Vehicle Initiative \\
\hline BSE & Barefoot Solar Engineer \\
\hline BDV & Biodiesel Powered Vehicle \\
\hline BBEV & Battery Electric Vehicle \\
\hline CapEx & Capital Expenditure \\
\hline CBA & Cost Benefit Analysis \\
\hline CDM & Clean Development Mechanism \\
\hline $\mathrm{CO}_{2}$ & Carbon Dioxide \\
\hline DPK & $\begin{array}{l}\text { Dual Purpose Kerosene } \\
\text { (jet fuel and domestic cooking) }\end{array}$ \\
\hline EPC & Electricity Power Corporation \\
\hline FCV & Fuel Cell Vehicle \\
\hline FSM & Federated States of Micronesia \\
\hline Gal & 1 American gallon $=3.78$ litres \\
\hline GEF & Global Environment Facility \\
\hline GDP & Gross Domestic Product \\
\hline GFC & Global Financial Crisis \\
\hline GHG & Greenhouse Gases \\
\hline GoS & Government of Samoa \\
\hline GNI & Gross National Income \\
\hline GWh & Giga Watt Hours \\
\hline IEA & International Energy Agency \\
\hline ICE & Internal Combustion Engine \\
\hline \multirow[t]{2}{*}{ ICEV } & Internal Combustion \\
\hline & Engine Vehicle \\
\hline KWh & Kilowatt hour \\
\hline $\mathrm{Lb}$ & American pound $=0.4535 \mathrm{~kg}$ \\
\hline
\end{tabular}

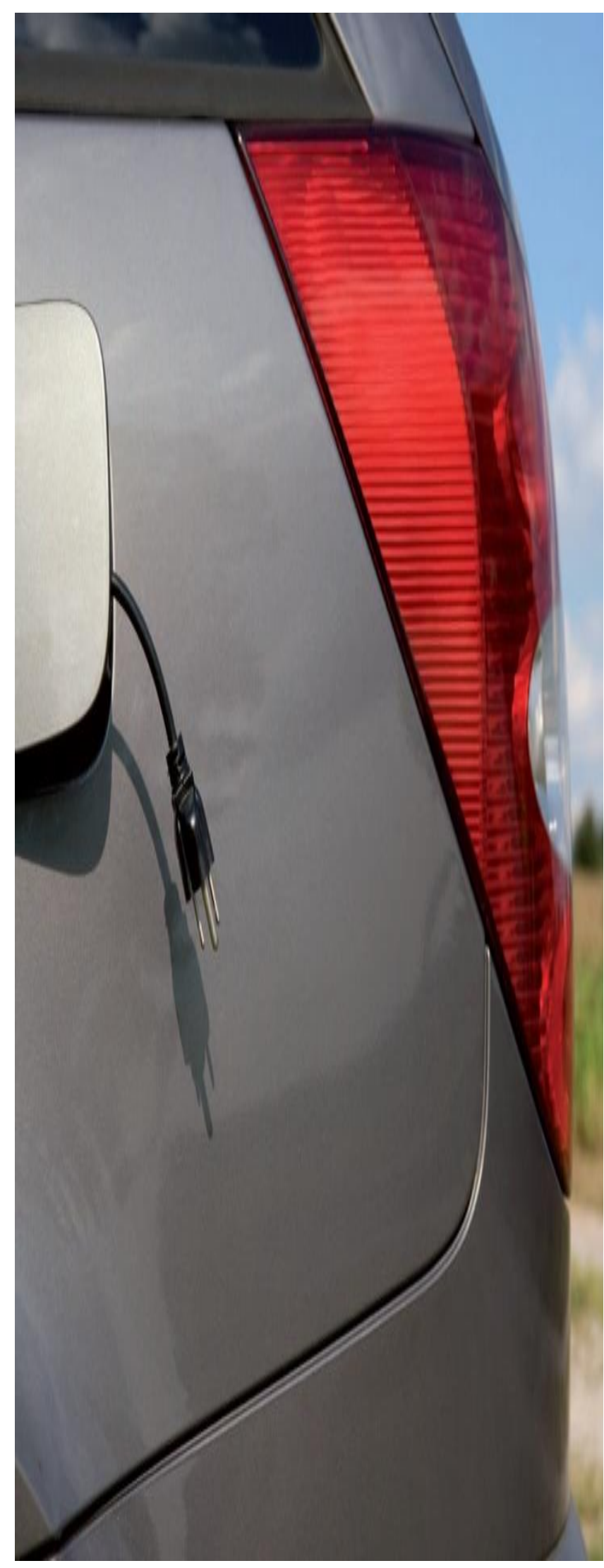




\begin{tabular}{|c|c|}
\hline LCA & Life Cycle Assessment \\
\hline LDV & Light Duty Vehicle \\
\hline LNG & Liquefied Natural Gas \\
\hline LPG & $\begin{array}{l}\text { Liquid Petroleum Gas (mainly butane and } \\
\text { including lubricants \& greases) }\end{array}$ \\
\hline LTA & Land Transport Authority \\
\hline MCIL & Ministry of Commerce, Industry and Labour \\
\hline MDG & Millennium Development Goals \\
\hline MNRE & $\begin{array}{l}\text { Ministry of Natural Resources and } \\
\text { Environment }\end{array}$ \\
\hline MNRE-RED & $\begin{array}{l}\text { Ministry of Natural Resources and } \\
\text { Environment, Renewable Energy Division }\end{array}$ \\
\hline MOF & Ministry of Finance \\
\hline MOR & Ministry of Revenue \\
\hline MWCSD & $\begin{array}{l}\text { Ministry of Women, Community and } \\
\text { Social Development }\end{array}$ \\
\hline MWTI & $\begin{array}{l}\text { Ministry of Works, Transport and } \\
\text { Infrastructure }\end{array}$ \\
\hline NECC & National Energy Coordinating Committee \\
\hline NEP & National Energy Policy \\
\hline NGHGAS & National GHG Abatement Strategy \\
\hline ODA & Overseas Development Assistance \\
\hline O\&M & Operation and Maintenance \\
\hline OECD & $\begin{array}{l}\text { Organisation for Economic Co-operation } \\
\text { and Development }\end{array}$ \\
\hline PAR & Participatory Action Research \\
\hline PEMM & Pacific Energy Ministers Meeting \\
\hline PIF & Pacific Island Forum \\
\hline PIGGAREP & $\begin{array}{l}\text { Pacific Islands Greenhouse Gas Abatement } \\
\text { through Renewable Energy Project }\end{array}$ \\
\hline PIEP & Pacific Islands Energy Policy \\
\hline PPA & Power Purchase Agreement \\
\hline PHBEV & Plug-in Hybrid Electric Vehicle \\
\hline
\end{tabular}




$\begin{array}{ll}\text { PPM } & \text { Parts per million } \\ \text { PPS } & \text { Petroleum Products Supply Limited } \\ \text { PV } & \text { Photo Voltaics } \\ \text { RE } & \text { Renewable Energy } \\ \text { RET } & \text { Renewable Energy Technologies } \\ \text { SDS } & \text { Strategy for the Development of Samoa } \\ \text { SIDS } & \text { Small Island Developing States } \\ \text { SPC } & \text { Secretariat of the Pacific Community } \\ \text { SROS } & \text { Scientific Research Organisation of Samoa } \\ \text { STEC } & \text { Samoa Trust Estate Corporation } \\ \text { S } & \text { Sene; 100 Sene equal 1 Tala } \\ \text { SUV } & \text { Sport Utility Vehicle } \\ \text { UNDP } & \text { United Nations Development Program } \\ \text { ULP } & \text { Unleaded Petrol } \\ \text { UNFCCC } & \text { United Nations Framework Convention } \\ & \text { on Climate Change } \\ \text { WST } & \text { Western Samoan Tala } \\ & \text { (1NZ\$ - 1.82 T\$ at 2 Aug 2013) }\end{array}$




\section{Chapter One: Introduction}

\subsection{Genesis of the Research Project}

I can clearly remember the summer holidays in 2008 when New Zealand, like the rest of the world, was reminded at the petrol pumps that crude oil price had hit a record of US \$ 145 per barrel. The cost of travel had shot up and sent inflationary ripples through the economy in the form of hasty surcharges on goods which were exposed to transport. It was a painful reminder just how dependent we had become on the ready and cheap availability of petrol, kerosene and diesel. Although oil price shocks have regularly occurred in the past and resulted from physical and political disruption of oil supply, this oil price spike was primarily caused by the strong demand of a booming world economy in the face of stagnating world oil production (Hamilton, 2009). Some of the sense of urgency about large fuel price hikes has since dissipated as the global economy is still lingering in the demand depressing Global Financial Crisis (GFC) but it would be fair to assume that the travelling public has not entirely forgotten what an important part of everyday life car travel and associated fuel cost has become.

Fuel consumption or to be more precise, $\mathrm{CO}_{2}$ as the main waste product of burning fossil fuels, has remained in the news for another reason as the link between $\mathrm{CO}_{2}$ emissions and dangerous global temperature increases has become established and credible (IPCC, 2014; Potsdam Institute for Climate Change Impact Research and Climate Analysis, 2012; World Economic Forum, 2013). These wellrecognised and existential threats to global ecosystems by the global warming phenomenon and the glacial progress in addressing these threats, however, point to a paradox of human origin. On one hand rational inquiry, a skill set so important for the modernist development project, is used to identify and certify the existential, adverse effects of global warming but on the other hand irrationality reigns supreme when it comes to use effective measures to correct the exponential trajectory of global temperature increases (Daly \& Farley, 2011). This irrationality may well be embedded in our modernist conceptions itself with its focus on universalism, 
progress and economic essentialism in the form of the neo-classic economic paradigm (McKinnon, 2008).

Accordingly, the International Panel on Climate Change (IPCC) found that despite a growing number of climate change mitigation policies greenhouse gas emissions (GHGs) kept on growing with the largest increases per year in the decade from 2000 to 2010. The transport sector is an important contributor of GHG emissions which in 2010 amounted for 14 per cent of global emissions (IPCC, 2014 p 5-7).

The urgency of transport reform aiming at GHG emission reductions has been taken on board by global institutions and covers the involvement of the government sector, NGOs, the manufacturing industry and civil society. The International Energy Agency (IEA) in the main has taken on responsibility in coordinating some of these reform efforts and has opted for the Electric Vehicle Initiative (EVI) as its main platform to reduce vehicle emissions. The result has been an increased focus on research over and on top of ongoing commercial automotive research, more effective coordination of government assistance in the research effort and provision of additional infrastructure for alternative transport forms and the involvement of civil society at local and regional level.

Samoa, a small, isolated and independent island nation in the Pacific, is already exposed to adverse climate change effects largely not of its making (Government of Samoa, 2008a). It also has opted to join the international economy with the ambition to better the material standard of living of its citizens of which the transport sector is an important part. Accordingly, its transport sector has followed a similar evolutionary path compared to metropolitan countries. However, unlike metropolitan countries, Samoa has developed a high degree of fuel dependence with 23 per cent of its 2011 GDP devoted to fuel imports which is not sustainable in the long run (Government of Samoa, 2011c).

The Samoan government has recognised its various exposures to climate change and globalisation and has worked towards shouldering some responsibilities 
in GHG mitigation while at the same time aiming to reduce its fuel import dependence. Legislation, strategies and projects are in place to actively pursue energy efficiency improvements in its energy and transport sector.

Electro-mobility is considered a promising option to mitigate adverse climate change effects. Apart from the potential suitability of electro-mobility for Samoa's transport sector, there are a range of hurdles which the introduction of such an innovation needs to overcome. Samoa's low GDP per capita and structural balance of payments deficit reflect the nation's small and underdeveloped economy which will make the broad introduction of alternative transport slow and probably limited to elite income sections of Samoa's society.

Samoa's transport sector reform may benefit from a different analytical approach concentrating on technical or social alternatives which may be better suited for Samoa's unique culture and socio-economic arrangements. Postdevelopment thinking may help to uncover alternative ways of improving material and social conditions and in the process reveal postdevelopment specific methodologies to undertake that development (Gibson-Graham, 2005; McKinnon, 2008).

\subsection{Central Research Question}

The overall goal of this research is to identify what role alternative transport modes could play in the reduction of Samoa's national transport cost and GHGs. This aim was achieved by examining information from each of the eight secondary research questions. The study concluded with the preparation of the eCar pilot project cabinet submission which was approved by the Samoan National Energy Coordinating Committee (NECC) on 27 January 2014. The objectives are discussed below and involved separate methods of data collection and analysis and are summarised as follows:

Objective 1: To establish the current state of knowledge on alternative transport and global transport stakeholder views on alternative transport. 
Method: A literature review of current transport technology, implementation experience and how it could be applied to Samoa's Energy Sector Plan.

Objective 2: To apply alternative transport concepts to the Samoan transport sector. Method: Literature findings are applied to the Samoan transport sector and local primary transport data are collected, prepared and analysed.

Objective 3: To identify stakeholders in the transport arena, their specific role and interests.

Method: Scoping conversations with government and private sector stakeholders using institutional networks and a snowballing approach.

Objective 4: To conduct participative information workshops with identified stakeholders to provide information about electro-mobility and jointly to develop electro-mobility possibilities in the Samoan context. Actively seek feedback to further refine transport possibilities.

Method: Participative workshop format.

Objective 5: To obtain more feedback from workshop participants and other interested parties.

Method: Semi-structured interviews, informal conversations, journal entries.

Objective 6: To compile feedback, new findings and develop proposals in a second participative workshop. Jointly incorporate feedback, commentary and new findings into existing transport possibilities. Actively seek feedback.

Method: Participative workshop format.

Objective 7: To propose eCar pilot project to workshop participants and jointly develop and agree on overall project objective. Actively seek feedback.

Method: Participative workshop format.

Objective 8: To prepare an eCar pilot project cabinet proposal for submission to the executive National Energy Coordination Committee 
Method: Research and publication.

\subsection{Overview of Thesis Structure}

Chapter Two introduces the Samoan transport and energy world. Aspects of Fa'a Samoa will be introduced which has some bearing on contemporary everyday life of Samoans. This will include the country's tussle with influences of globalisation and its coping mechanisms to afford the integration in the international economy, through the reliance on remittances and overseas development assistance (ODA). It will suggest that car use is seen an important expression of modernity. The transport and energy sectors will be presented as the country's dominant fossil fuel users and have attracted government attention to increase energy use efficiency and where and if possible replacement with alternative sources of energy.

Chapter Three reviews literature regarding future energy use scenarios and current knowledge about technical innovations required to achieve global $\mathrm{CO}_{2}$ emissions reductions to limit global temperature increase to two degrees Celsius. We will go into quite some technical detail to appreciate the paradigmatically opposed ideological views of authoritative transport reviews ranging from the modernist, neo-classic economic thinking of the car manufacturing sector to the more (recently) reformed neo-structuralist programs of the International Energy Agency (IEA). The Renewable Energy Network (REN21) survey will give us an upto-date impression of global stakeholder support for renewable energy and adoption trends. We will also take a closer look at the state of research in electro mobility to enable us to get an appreciation of likely future price trends, footprint comparisons of different transport modes and infrastructure requirements.

With this background information at hand we will focus on ongoing battery powered electric vehicle (BEVs) pilot trials in the Pacific. I will also discuss Samoa's national energy policies (NEPs) and a biodiesel project as it is considered an important option to increase the use of renewables in the energy sector as the integration of the transport and energy sectors will play an important role in the 
future. The chapter will conclude with the discovery of a retrofit BEV movement which has grown to some prominence in many metropolitan countries.

Chapter Four concentrates on contemporary postdevelopment theory as the chosen conceptual framework for my study. Contemporary postdevelopment thinking will be reviewed and will highlight its contribution to the development discourse in the field. I will argue that postdevelopment theory offers methodologies to utilise technology, in this case electro-mobility, to be incorporated in Samoan expressions of modernity. I will propose that the selection methodology for 'outside' information needs close attention if researcher bias and lack of buy-in is to be minimised and at the same time local communities are given access to the best tools for developing their form of modernity.

Chapter Five examines my research methodology. I will expand on experiences with participative development from the literature and formulate my own differentiated research approach aiming at providing balanced outside information about potential solutions to Samoa's fuel dependency. I will describe how my participatory action research (PAR) approach has allowed me to inform, respond to new information requests, assist in facilitating free information exchange and learn as much as possible from stakeholders about factors influencing the Samoan transport sector. I will also describe my positionality in my role as the action researcher.

Qualitative research methods which cover information dissemination and collection activities will be selected. The learning trajectory of the participatory workshop series will be followed as a workshop member. The use of semi-structured interviews, informal conversations and participant observation will also be introduced. The research methodology thus will accurately reflect transport stakeholder views as part of my attempt to leave the initiative for the identification of transport sector possibilities with stakeholders.

Chapter Six documents my research findings. A summary of relevant key findings from the literature review to be followed by Samoan operating cost estimates of 
battery powered electric vehicles, biodiesel powered vehicles and conventional vehicles is presented. The second section will document the summarised outcomes of the participative workshops. The third section will contain a presentation of the eCar pilot project proposal which resulted from earlier workshop feedback. Workshop participants will develop the project objective of the eCar pilot project proposal, prepared by the action researcher and submitted to cabinet.

Chapter Seven discusses the research findings and follows the path of my participatory action research and the literature review is put in the local context. The mutual learning experience of the workshops will be documented and electromobility is pointed out as a promising option for transport reform and how local conceptions and the use of the postdevelopment lens may create a genuine Samoan version of mobility. I will highlight that in order to make the benefits of the technology accessible to a broad section of Samoan society, the technology needs to be deconstructed and rebuild within the constraints of local affordability and cultural needs. 


\section{Chapter Two: The Transport and Energy Sector in Samoa}

This chapter sets the scene for research into the potential alternatives to conventional transport practices in the Pacific region. The study mainly concentrates on Samoa but similar forms of fuel dependency can be found in other Pacific Island Countries (PICs) with the exception of Papua New Guinea. The investigation looks at Samoa's cultural and political institutions to gain a thorough understanding of the cultural influences impacting on modern Samoan life. I analyse the regional political economy of the transport sector and draw conclusions about the drivers of fuel dependency and what could be done to reduce it.

Current Samoan transport policy has taken on board the challenges of fuel dependency and the obligation of greenhouse gas (GHG) emission mitigation and I will use government policies as a guide in my analysis of electro-mobility options. Although electro-mobility is anticipated at some point in the future, current government policy has overlooked current rapid developments in electric vehicle technology and associated attempts by International Non-Government Organisations (INGOs) to use BEVs in their efforts to reduce GHG emissions. This study picks up on the potential of electro-mobility to contribute to a reduction in Samoa's fuel dependency and develops a program to inform Samoan transport stakeholders about the current state of BEV innovation. However, first I give an overview of Samoa's cultural and social institutions and how they may impact on transport stakeholder perceptions of electro-mobility.

\subsection{Samoa's Cultural and Political Institutions}

\subsubsection{Fa'a Samoa: Samoa's way of dealing with outsiders}

When the Dutchman Roggeven visited Samoa in 1722, he found a highly developed, quasi aristocratic and hierarchical society of Polynesians which considered their islands as 'Sa' (sacred) moa (centre) and the centre of their identity (Davidson, 1967). These underlying traits of Samoan society have remained fundamentally intact. Samoan villages are still the sources of political power based 
on fa'amatai, the system of a titled position of authority presiding over the aiga (extended family) and over the village via the matai fono. The institution of the fa'amatai has the authority and obligation to protect the autonomy of the aiga and extend its influence by employing the aiga's physical and human resources to that end. Aiga members derive rights of abode, social identity, protection and access to agricultural land from the matai (Macpherson, 1999; Macpherson \& Macpherson, 2011).

The spread of Christianity throughout Samoa and its contemporary, strong influence on the cultural and political life of Samoa was in no small part possible due to the affinity and benefits the Christian faith had for Samoa's elites (Davidson, 1967). Fa'amatai adapted the Samoan concept of reciprocity to spirituality by promoting the adoption of the Christian faith with a view to have access to European technology and wealth. The thinking was that supporting the religious faith of the outsiders, material wealth would be in time reciprocated (Muliaina, 2006). One of the pervasive ways was the ability of the matai to select a Christian denomination for his extended family. The matai fono could select a denomination for the whole village. In time, the fa'amatai institution led to the combination of political with spiritual power by the co-option of matai into missionary work.

The Christian faith has continued to play an important part in contemporary Samoan culture and increasingly also its economy. When Samoa became an independent country in 1962, its political leadership chose as its guiding constitutional principle fa'avae I le Atua Samoa, 'Samoa is founded on God' to declare to the world the close relationship between fa'a Samoa ${ }^{1}$ and the Christian faith. The integration of Samoa in the international market economy, however, has introduced the cash economy to church obligations (fa'alavelave) such as weddings, funerals, and title bestowals.

Likewise, the competitive church practice of folafola (announcing the amount of gifts and the giver after a tithe collection), taulaga (annual monetary collections),

\footnotetext{
${ }^{1}$ Fa'a Samoa, translated as the 'Samoan Way' describes the socio-cultural and political way of life of Samoans.

${ }^{2}$ There are differences between MFat and GoS statistics.
} 
weekly donations, tithes and offerings in order to finance the village priests outgoings, church buildings etc. has become a significant portion of household cash expenditure. The 2002 HIES report estimates that on average 44.7 million Tala were spend on cultural and 5.3 million Tala on church obligations which in the past were met by non-monetary means (Government of Samoa, 2008; So'o, Va'a, \& Lafotanoa, 2006). According to Thornton et al (2010) church obligations have had a particularly severe financial impact on poor households (Davidson, 1967; Macpherson \& Macpherson, 2011; Thornton, Kerslake, \& Binns, 2010).

\subsubsection{Contemporary and Independent Samoa}

"Changes in technology and in population must in the long run be accompanied by changes in value systems'

(Hau'ofa, 1985)

In 2010 Samoa with a land area of $2820 \mathrm{~km}^{2}$ was home to 180,741 Samoans who mainly lived on Upolu (76 per cent) and the remainder on Savai'i and some seven small islands. In 2013 Samoa achieved a per capita GDP of US \$ 3,160 which is composed of small contributions of 10 per cent from the primary sector, 22 per cent from the secondary sector and a relatively large 68 per cent from the tertiary sector (Asian Development Bank, 2013). A Human Development Index (2011) of 0.688 puts Samoa at $99^{\text {th }}$ rank out of 187 countries (Government of Samoa, 2010a). North-west Upolu and Apia have evolved as the commercial, political and administrative centre of the Nation.

Hau'ofa's remark above is illustrated by a drive from Faleolo airport to Apia through the 'North-West commercial corridor'. Traditional villages, freehold housing, commercial buildings and an assembly of all important church denominations freely mix and show the hybridised and peri-urban character of this district. Apia with a population of 40,000 is clearly the epicentre of Samoa's experience with globalised trade and culture. A survey of the city scape quickly shows the town's transitional character with its large administration buildings exhibiting the architectural style of its donors rather than of Samoa's rich cultural heritage. Apia's physically merged 
villages are currently evolving into city sectors and suburbs but are governed by fa'a matai. Commercial buildings often are located on aiga land, expressing aiga ambitions but not necessarily a comprehensive city planning approach. Official and unofficial food markets are interspersed with supermarkets offering consumer products for the participants of the cash economy. Can fa'a Samoa assimilate these new expressions of modernity as successfully as it did in the past?

\subsubsection{Samoa's Tussle with Globalisation}

There are other signs that Samoa's entry in the international political economy is having an impact on fa'a Samoa. For the Government of Samoa (GoS) the transition towards an internationally integrated market economy so far has produced socio-economic changes which are consistent with experiences in other comparable transition countries (Wade, 2002). Government finances are characterised by structural imbalances such as chronic balance of payments deficits, significant loan management obligations, higher wealth inequality and poverty on one hand and a higher material living standard for a sector of Samoan society, better education and health services. (Government of Samoa, 2010b, 2010c; The World Bank, 2011).

Nevertheless, the Government of Samoa has been able to manage the modernisation project reasonably well by judging its performance towards Millennium Development Goals (MDGs) and more general social indices. According to the second MDG progress report Samoa is generally on track to achieve its MDGs by 2015 with some concerns remaining about basic needs poverty reduction, education targets for boys and girls, women empowerment, HIV prevention and reproductive health targets (Government of Samoa, 2010c). The UN resident MDG project coordinator identified good collaboration of the GoS and development partners to address shortcomings and gaps in MDG achievements. The collaboration also showed good progress of working towards full implementation of Paris Declaration principles (Government of Samoa, 2010c; OECD, 2005/2008; Poku \& Whitman, 2011; Wood et al., 2011). 
There are, however, increasing signs based on evidence from the 2002 and 2008 Household, Income and Expenditure Surveys (HIES) that the process of integration in the international market economy is entrenching inequality and poverty in parts of Samoa's society. Rural Samoa and low decile household income urban settlements, in particular, are finding it relatively more difficult to earn sufficient cash income to meet basic living expenses and meet cultural and religious obligations (Macpherson \& Macpherson, 2011; So'o et al., 2006; Thornton et al., 2010; Tuilaepa, 2006). The relatively small and urban based, formal employment sector cannot provide enough employment which is leading to rising unemployment and also increases in absolute and relative poverty as well as nationwide poverty of opportunity (So'o et al., 2006).

In 2010 basic needs poverty affected 20.1 per cent of households with a marked increase in rural household poverty in Upolu and Savai'i during the last census period from 2002 to 2008 . The peri-urban settlements of the greater NorthWest Upolu region have also been affected with basic needs poverty of 19.4 per cent of households (Government of Samoa, 2010). These changes in the distribution of household income are also reflected in changes of Samoa's national Gini coefficient. The coefficient increase from 0.43 in 2002 to 0.47 in 2008 is considered a significant increase of inequality (Government of Samoa, 2010).

\subsubsection{Samoa's MIRAB Economy}

As Samoa is heavily reliant on development assistance and remittance transfers, it is prudent to gain some insight into the structure and stability of these income streams. Samoa is considered a 'classic' MIRAB economy with a wellestablished reliance on external cash transfers from expat remittances and development assistance (Geoff Bertram, 1999). Remittance transfers between 2000 and 2012 averaged 23.6 per cent of GDP. Development assistance and concessionary lending contributed 37 per cent of the 2010/2011 budget (in New Zealand Ministry for Foreign Affairs and Trade, 2013; Ulu, 2013 p 67) $)^{2}$. Remittance income from family members often is the only form of cash income for rural

\footnotetext{
${ }^{2}$ There are differences between MFat and GoS statistics.
} 
communities and is used for everyday family household expenses, major household items such as white ware and cars but, most importantly, it also contributes to foreign currency reserves.

Bertram (2004) argued that the Polynesian remittances diaspora is a complementary phenomenon and will lead to some convergence with their neighbouring metropolitan economies as the exchange of labour for employment and educational opportunities serves both parties (G. Bertram, 2004). Although this proposition gained currency amongst some academic scholars as a pragmatic response to regional development, other scholars are more ambivalent about Bertram's convergence theory and pointed to complexities beyond the narrow economic paradigm (Fingleton, 2008; Hughes, 2003; Kerslake, 2007; Rosser, 2008; Storey, Bulloch, \& Overton, 2005).

Certainly, Pacific scholars have provided a wider cultural context to the malaga (cycles of extensive travels and returns) and convergence argument by suggesting that the dominant Western narrative is too simplistic in describing the activities of the Pacific Rim diaspora as individualist/communitarian, village/metropolitan or core-periphery dichotomies. This narrative does not take notice of indigenous knowledge, pre-European history or contemporary evolution of the malaga within modern metropolitan countries (Gegeo, 1998, 2001; GibsonGraham, 2005; Hau'ofa, 1985, 1994; Lilomaiava-Doktor, 2009).

Moreover, some newer insights are being gained on evolving migration patterns as the Polynesian malaga has proven to be not temporary and produced the second and third Pacifika generation now resident in their host countries. There is also some evidence to suggest that a degree of 'remittance fatigue' is developing as the lingering GFC leads to declining employment prospects in host countries and second and third migrant generations do not feel the same responsibility towards their Samoan roots as the initial malaga generation did (G. Bertram, 2004, 2006; I. G. Bertram \& Watters, 1986; Fraenkel, 2006; Lilomaiava-Doktor, 2009; Poirine, 2006; Thornton et al., 2010). 
Thus, these recent developments may exhibit a different trajectory as originally described by Bertram and others who have described remittance cash transfers as a complimentary, pragmatic but also culturally appropriate phenomenon resulting from the Polynesian malaga. The fact that the malaga has produced permanent Pacifica populations in metropolitan countries with fading family bonds with their island aigas and the dynamics of continued labour unit withdrawal from the island subsistence economies has affected the traditional and the cash economies of the PICs. Some of the pragmatic synergism of the MIRAB model may now show some distinct disadvantages for contemporary island economies and cultures.

Samoa's other major source of income, Overseas Development Assistance (ODA), is also showing signs of volatility and potentially a decrease. In the 2010/2011 financial year ODA made up 37 per cent of Samoa's Gross National Income (GNI) in (OECD, 2013). Between 2008 and 2011 net ODA increased from US\$ 40 million to US\$147million (2010) to fall again significantly to US\$101 million in 2011. The global trend of increasing volatility in aid disbursements and the current decline in aid commitments by donor countries may well affect Samoa in the future and it already requires the GoS to spend considerable administrative effort to manage aid volatility. Moreover, it is the cause of much frustration by recipient country agencies involved in the implementation of Paris Declaration and Millennium Development Goals (MDG) related projects.

In conclusion, Samoa's progressive integration in the world economy has produced challenges for government finances in the form of structural balance of payments deficits as consumer goods imports hugely outpace exports. Whereas this pattern is a well-known phenomenon for developing countries, in Samoa's case these imbalances are made worse by lack of opportunities to reduce these imbalances due to Samoa's isolation and economy of scale constraints and, maybe even more importantly, the tensions created by the demand creation of a cash economy which largely has no cultural foundations.

The Government's ability to maintain its fiscal commitments are being threatened by several external factors, most notably the lingering GFC affecting the 
global business climate but also the drop in remittance income from overseas Samoans and volatile ODA also affected by the GFC. All in all a picture is painted of a Samoa which is undergoing significant cultural and economic changes caused by its integration in the world economy.

Of particular concern are the effects of long-term unsustainable balance of payment deficits on Samoa's sovereignty, fossil fuel dependency and socioeconomic stresses as the monetisation of the Samoan economy lurches ahead without creating sufficient employment in the cash economy. As we will see in chapters 2.3 and 3 , the transport sector is an important part of the imported modern economy. In the following some cultural aspects of car ownership are outlined.

\subsection{Socio-economic Aspects of Car ownership}

With import liberalisation Samoa's car fleet has grown considerably, however, in the face of constrained household disposable income. Re-prioritised household expenditure towards car ownership is driven by practical considerations but also by perceived benefits arising from increased status and 'being a member of modern society'. Car ownership, however, has also placed stresses on household budgets as capital and on-going maintenance cost competes with more basic household requirements (healthy food, healthy housing etc.) (Government of Samoa, $2010 \mathrm{p}$ 40).

Apart from financial impacts on household budgets, car maintenance is a culturally acquired technical skill and awareness which the majority of Samoan car owners still have to acquire. A consequence of this lack of skill and awareness are badly maintained or abandoned cars (Taulealo, 2013 pers. comm.). As I will discuss in chapter 6.2.8., badly maintained cars not only cause higher direct operation cost but also indirect environmental externality cost.

The vehicle fleet consists of surprisingly modern cars with a traffic density resulting in twice daily rush hour traffic jams on the important arterial roads into Apia. The modern car fleet is made up of sedans, trucks, utilities, colourful and locally 
made buses and new four-wheel drive utilities. As will be discussed in detail below, the transport sector has become an important participant of Samoa's economy. In more ways than one the fast pace of modernisation has placed strains on the infrastructure requirements of Samoa.

\subsection{Some Macroeconomic Statistics Relating to the Energy Sector}

The relative isolation of Pacific Island Countries (PICs) has given rise to a heavy reliance on refined fossil fuels for electricity generation, lighting and transport needs. This state of affairs is especially relevant in the smaller PICs where fuel imports constitute a significant proportion of economic activity as measured by GDP (ADB, 2007). During the last decade petroleum prices have risen faster than general import prices and more importantly their share of GDP has also grown as shown in table 2.3.1. In the Pacific region only PNG has domestic resources of oil. The remaining PICs rely entirely on fuel imports for their transport fleet (Jayaraman \& Evan, 2011; Mohanty, 2012; Pacific Islands Forum Secretariat, 2006; Singh, 2012).

Access to affordable forms of energy have become vital for the development aspirations and poverty alleviation in the PICs. Several commentators, however, point out that with energy standardisation based on fossil fuels, the PICs have also become highly vulnerable to oil price rises and particularly price volatility (Davies \& Sugden, 2010; Levantis, 2008). A primary reason for this vulnerability is the highly fossil fuel intensive nature of the island economies. Unlike metropolitan economies with large tertiary sectors which tend to be relatively low users of fossil fuels compared to the primary and secondary sectors, PIC economies are more primary sector focused in their fossil fuel energy use. Due to the high presence of petroleum products in the electricity and transport sector, petroleum price rises tend to filter quickly through to consumers (Davies \& Sugden, 2010; Levantis, 2008 p 7). 
Table 2.3.1: Petroleum Imports as a percentage of Total Imports and GDP by selected PICs

\begin{tabular}{|c|c|c|c|c|c|c|}
\hline Country & 2001 & 2002 & 2003 & 2004 & 2005 & 2006 \\
\hline \multicolumn{7}{|l|}{$\mathrm{Fiji}$} \\
\hline $\begin{array}{l}\text { per cent of } \\
\text { Total Imports }\end{array}$ & 21.9 & 22.1 & 20.3 & 23.5 & 28.8 & 32.7 \\
\hline GDP & 13.4 & 12.5 & 12.5 & 14.7 & 18.5 & 21.9 \\
\hline \multicolumn{7}{|l|}{ Samoa } \\
\hline $\begin{array}{l}\text { Total Imports } \\
\text { per cent of }\end{array}$ & 12.5 & 13 & 13.5 & 14.3 & 15.4 & 15.8 \\
\hline GDP & 7.1 & 6.6 & 6.4 & 7.9 & 8.7 & 9.7 \\
\hline $\begin{array}{l}\text { Solomon } \\
\text { Islands } \\
\text { per cent of }\end{array}$ & & & & & & \\
\hline $\begin{array}{l}\text { Total Imports } \\
\text { per cent of }\end{array}$ & 21.3 & 21 & 21 & 37.8 & 42.5 & 39.5 \\
\hline GDP & 5.3 & 4.9 & 4.9 & 8.5 & 13.9 & 15.5 \\
\hline \multicolumn{7}{|l|}{ Tonga } \\
\hline $\begin{array}{l}\text { Total Imports } \\
\text { per cent of }\end{array}$ & 15.8 & 13.2 & 19.2 & 19.8 & 23.1 & NA \\
\hline GDP & 8.5 & 7.9 & 10.4 & 10.5 & 12.8 & NA \\
\hline \multicolumn{7}{|l|}{$\begin{array}{l}\text { Vanuatu } \\
\text { per cent of }\end{array}$} \\
\hline $\begin{array}{l}\text { Total Imports } \\
\text { per cent of }\end{array}$ & 14.7 & 11.8 & 14.7 & 13.3 & 11.4 & 11.9 \\
\hline GDP & 5.4 & 4.5 & 5.4 & 5.1 & 4.6 & NA \\
\hline
\end{tabular}

Source: $A D B$ (2007) Key Indicators of Developing Asian and Pacific Countries. Manila.

In response to the large oil price spike in 2008 several regional studies have again concentrated on the nexus between petroleum price inflation and economic growth. Jayaraman et al (2011) found that in the short run oil prices affect economic growth but the negative effects of oil price inflation can be modified by macroeconomic policy to reduce the stresses to society caused by inflation. In the long-run, however, petroleum price inflation requires a different policy response as social programs aimed at buffering the negative effects of fuel price increases need to be financed by government revenue which itself is coming under increasing strain from fuel import inflation. Jayaraman and Evan and others suggest that the most immediate path of action to reduce fossil fuel dependence is developing energy use efficiency programs and a move away from fossil fuel intensive modes of production (Davies \& Sugden, 2010; Jayaraman \& Evan, 2011). 
The reduction of fossil fuel dependence is currently a high priority for PICs and regional governments have moved to initiate energy efficiency programs in the electricity and housing sectors. It remains to be seen to what an extent fuel use efficiency programs can counteract the effects of fuel price inflation and the region's fuel dependence. As Jayaraman, Levantis and others point out, the PICs' high sensitivity to fuel price inflation is a structural economic disadvantage resulting from the region's geographic and economic isolation as well as a different development trajectory.

\subsection{Samoa's Transport and Energy Sector}

In the following Samoa's current energy supply arrangements and planned projects in the renewable energy field are discussed. As much as is possible Samoa's fossil fuel dependency, particularly in the transport sector is quantified. Electro-mobility also requires an understanding of the electricity generation sector as the operation of EVs relies on an increased integration of sources of primary energy.

\subsubsection{Background}

Samoa's fossil fuel imports are mainly consumed in the transport and electricity sectors. In 2011 the transport sector used approximately 63 per cent of total petroleum imports (56.7 million litres) to operate vehicles and domestic shipping fleets. Electricity generation utilised approximately 23 per cent with the remainder, 13 per cent, being used by the commercial, agriculture, forestry and residential sectors (Government of Samoa, 2011a). Over the recent past fuel imports have been increasing from 62 million litres in 1999 to 89.9 million litres in 2011. A graphical break up of petroleum users is shown in figure 2.4.1. 
Figure 2.4.1: $\quad$ Total Petroleum consumption by Sector, 2011.

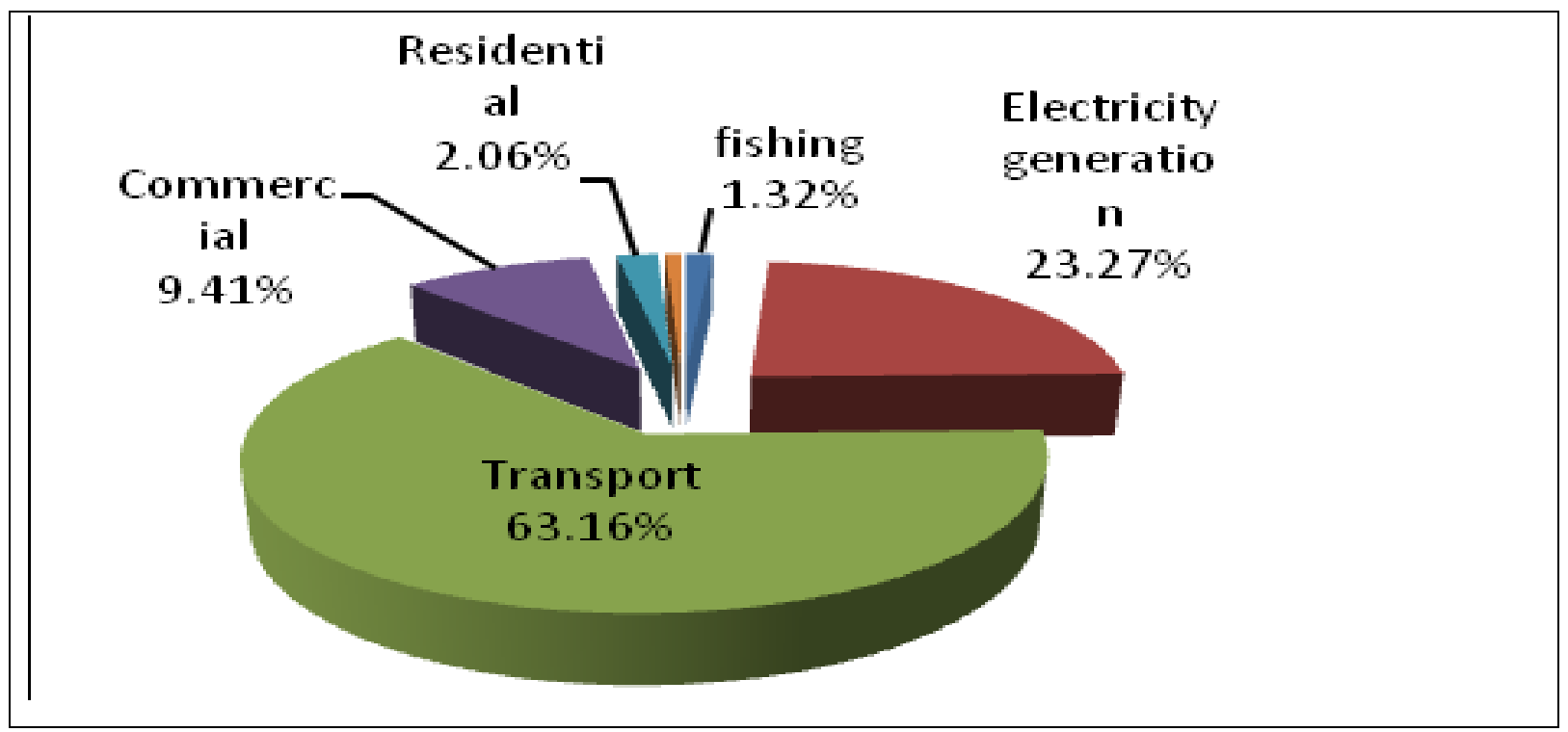

Source: GoS (2011) Samoa Energy Review 2011

Dramatic petroleum price inflation was experienced in the late 2000s.

Between 2010 and 2011 prices for petrol (ULP) and diesel (ADO) rose to \$WST 2.81 and \$WST 2.85 respectively, which reflects an increase from 2010 of 16 per cent and 17 per cent respectively. These increases affected the transport sector as primary energy users and the Electricity Power Corporation (EPC) as generator and distributor of secondary energy. A price trend for imported petroleum products for the last decade is shown in table 2.4.1.

Table 2.4.1: Fuel Price Inflation 1999-2012

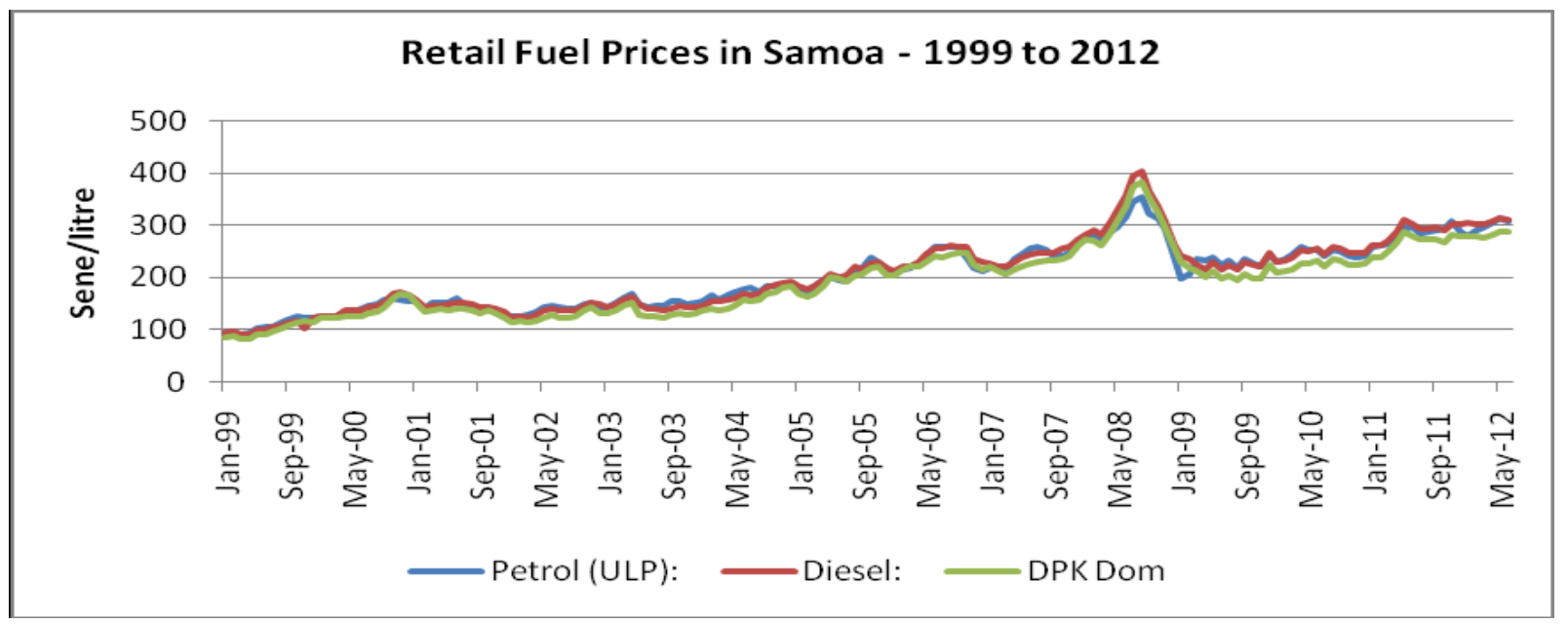

Source: GoS (2011). Samoa Energy Review 2011. 
There are also indications that price increases and volatility in 2010 and 2011 and the lingering GFC have led to some decrease in primary fuel and electricity consumption. Fuel consumption in road transport decreased by 1.72 per cent (Government of Samoa, 2011a p 22). Similarly, gross electricity generation recorded a decrease of 1.5 per cent to 109.5 GWh reflecting increases in industrial and commercial consumption due to cyclone damage and a larger decrease in the residential sector possibly responding to economic uncertainties (Government of Samoa, 2011a p 18). The decreases are not large, however, and may well be identified as statistical noise in later fuel consumption data sets.

Electricity generation cost is subjected to the vagaries of diesel price fluctuations as can be seen in Table 2.4.2. The oil price spike of $2007 / 8$ dramatically affected generation costs to climb from a low of 43 sene ${ }^{3}$ per kWh in 2005 to a high of 93 sene per kWh in 2008. In 2011 it declined to 67 sene per kWh reflecting a lower global fuel demand caused by the GFC.

Table 2.4.2: Electricity Cost variation, 2005-2011.

\begin{tabular}{|lccc|}
\hline Month & $\begin{array}{c}\text { EPC diesel cost } \\
\text { (sene per litre excl. } \\
\text { VAGST) }\end{array}$ & $\begin{array}{c}\text { Fuel efficiency } \\
\text { rate (kWh per } \\
\text { litre) }\end{array}$ & $\begin{array}{c}\text { EPC diesel cost to } \\
\text { generate electricity } \\
\text { (sene per kWh excl. } \\
\text { VAGST) }\end{array}$ \\
\hline $\begin{array}{l}\text { Low -June 05 } \\
\text { High - August }\end{array}$ & 165 & 3.8 & 43 \\
08 & 355 & 3.8 & 93 \\
Average 2008 & 277 & 3.8 & 73 \\
Average 2009 & 178 & 3.8 & 46 \\
Average 2010 & 198 & 3.8 & 52 \\
November & 254 & 3.8 & 67 \\
2011' & & & \\
\hline
\end{tabular}

Source: EPC Annual Reports2009/10 and 2010/11.

Electricity tariffs trailed these oil price pressures, albeit in much modified form, and throughout 2011 rose from 79 sene/kWh to 86 sene/kWh for residential consumers and from 93 sene $\mathrm{kW} / \mathrm{h}$ to 102 sene/kWh for commercial customers. The mechanism used is the monthly fuel surcharge reflecting diesel price volatility (Government of Samoa, 2011a p 18).

\footnotetext{
${ }^{3}$ I West Samoan Tala and its decimal fraction the Sene were 0.549 NZ\$ on the 2 August 2013.
} 


\subsubsection{Relevant Policy governing the Transport and Energy Sector}

The Strategy for the Development of Samoa (SDS) 2012 - 2016 articulates Samoa's development vision of an 'Improved Quality of Life for All'. This ambition is built on the implementation of prioritised development strategies. In order to ensure policy fit and avoid policy overlap, any policy needs to demonstrate relevance to the SDS priority areas and key outcomes ${ }^{4}$.

With respect to the transport and energy sectors, the Samoa Energy Sector Plan (SESP) 2012 - 2016 picks up the SDS's infrastructure priority area and in turn provides a number of strategies. The most relevant strategies for this discussion are:

- Promotion and increase of RE investment and generation; and

- Promotion of energy efficiency practices in all sectors, particularly the transport sector.

Key strategies envision a regulation of energy efficiency specifications of imported cars with performance indicators stipulating a 10 per cent reduction of average engine size and an average six month reduction of average age of imported cars. Baseline data are not available but will be provided and revised tariffs will be successfully implemented by 2014/15 (Government of Samoa, 2010c app2). The recent accession to the WTO, however, has seen a modification of this policy.

\section{Samoa's second National Communication under the United Nations} Framework Convention on Climate Change (UNFCCC) identified the transport and electricity generation sector as the largest contributor to $\mathrm{CO}_{2}$ emissions (see table 2.4.3.). The National GHG Abatement Strategy 2008-2018 (NGHGAS) responded to this challenge and formulated energy efficiency strategies for the transport and energy sector (Government of Samoa, 2008a). The SESP in turn follows up on the energy efficiency requirements and stipulates a measurable outcome in the form of a

\footnotetext{
${ }^{4}$ Important key national outcomes for the energy strategy are the Infrastructure Sector (outcome 10: Efficient, Safe and Sustainable Transport Systems and Networks; outcome 12: Sustainable Energy Supply) and Environmental Sector ( outcome 13: Environment Sustainability; outcome 14: Climate and Disaster Resilience)
} 
reduction of fossil fuel imports by 10 per cent by 2016 and a simultaneous 10 per cent increase of renewable forms of energy (Government of Samoa, 2011c).

Table 2.4.3: Ranked top six sources of GHG emissions.

\begin{tabular}{|c|c|c|c|}
\hline Rank & Source & $\begin{array}{l}\text { Emissions (GHG } \\
\left.\mathrm{CO}_{2}-\mathrm{e}\right)\end{array}$ & $\begin{array}{l}\text { total emissions, per } \\
\text { cent }\end{array}$ \\
\hline 1 & Road Transport & 95.11 & 27 \\
\hline 2 & Livestock Farming & 88.36 & 25 \\
\hline 4 & $\begin{array}{l}\mathrm{N}_{2} \mathrm{O} \text { from Agricultural } \\
\text { Soils }\end{array}$ & 47.01 & 13 \\
\hline 3 & Electricity Generation & 44.21 & 13 \\
\hline 5 & $\begin{array}{l}\text { Other Energy } \\
\text { Consumption }\end{array}$ & 34.14 & 10 \\
\hline 6 & $\begin{array}{l}\text { Wastewater } \\
\text { Total }\end{array}$ & $\begin{array}{c}25.44 \\
\mathbf{3 3 4 . 2 7}\end{array}$ & $\begin{array}{c}7 \\
95\end{array}$ \\
\hline
\end{tabular}

Source: GoS (2007). Samoa's Second National Communication to the United Nations Framework Convention on Climate Change

Both policies flag the potential benefits of battery powered electrical vehicles (BEVs) to reduce GHG emissions and the replacement of fossil fuels with biofuels wherever feasible (Government of Samoa, 2008a p 4-8). The suggestion of a potential role of BEV's in Samoa's transport sector was the result of a sighting of some literature as part of the SESP production by the Ministry of Finance's Energy Policy Coordination and Management Division in 2010 ( Foliaki 2013, pers.comm). That effort was mainly concerned with a general overview of the potential application of electro mobility at some point in the future and did not aim at a detailed exploration of the state of electro mobility nor did it attempt an analysis of potential applicability in Samoa. Nor was any attempt made to suggest a timeline for any application of electro mobility.

As will be discussed in chapter Three, the last two intervening years have seen the commercialisation of BEVs and significant improvements of battery technology which was considered a significant obstacle for the development of electro mobility (King, 2007). Progressive commercialisation of BEVs also saw the reduction of new BEV prices. There is now also increasing confidence by a wide range of global transport sector stakeholders that electro mobility based on BEVs 
and fuel cell technology will in all likelihood be part of a global decarbonising effort of the transport sector (King, 2007, 2008; Martinot, 2013b).

These new developments have largely been overlooked by Samoan government institutions and the private sector. However, given the open-ended SESP recommendation on the desirability of electric vehicles, the commercialisation of electro mobility has the potential to give a new impetus to Samoan transport policy.

\subsubsection{Energy Security}

With the vital importance of petroleum based fuels in Samoa's economic development, the Government of Samoa has initiated a number of programs aimed at reducing fuel supply disruption, fuel retail prices and reducing fossil fuel use while steadily introducing renewable energy resources in the primary energy supply.

The GoS has opted to intervene in the setting of retail fuel prices and has contracted the management of fuel supply the private Petroleum Product Supplies Ltd (PPS). The Government has however retained the authority to set petrol, diesel and kerosene prices on a monthly basis built on a price formula including distribution cost and retail margins. PPS is responsible for a Government mandated security of supply equivalent of ten days of national fuel consumption. A current initiative is to increase the national security of fuel supply (Government of Samoa, 2011a).

The Government tendering system has given Samoa relatively low fuel prices compared with the Pacific region including Australia and New Zealand. As figure 2.4.2 shows lower retail prices are achieved by low importer margins, lower government excises and levies and GST. 
Figure 2.4.2.: $\quad$ Comparison of Retail Fuel prices, WST\$, 2011.

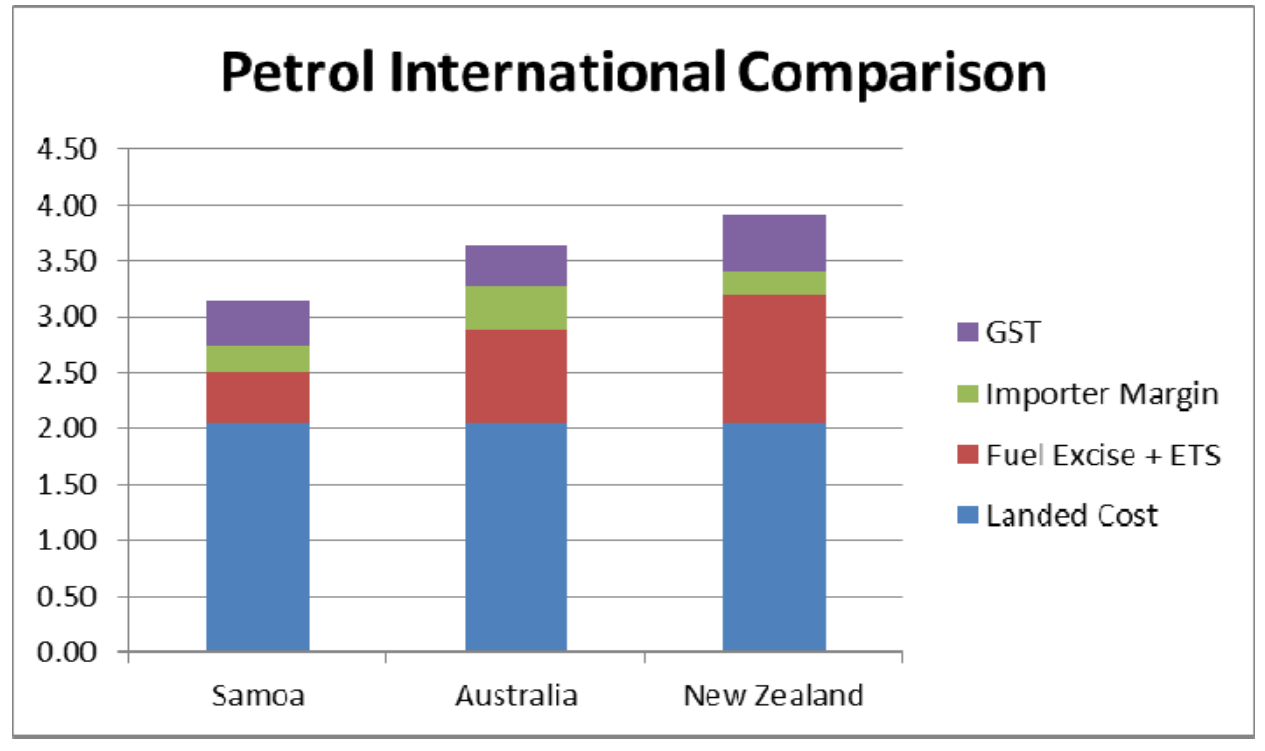

Source: MOF (2011) Energy Sector Plan 2012 to 2016.

The second approach to improve energy security is the commitment by the energy sector to employ energy efficiency measures and gradually replace fossil-fuel use with renewable forms of energy. In the energy sector the efficiency drive has led to the commissioning of more fuel efficient diesel generators with the aim to increase the current $3.80 \mathrm{kWh} / \mathrm{litre}$ of diesel to $4.55 \mathrm{kWh} / \mathrm{litre}$ of diesel.

Figure 2.4.3 depicts the current research effort into renewable forms of energy, their current cost structure, albeit often based on experimental cost estimates, and most importantly, excluding externality cost. The marginal cost of 68 sene/KWh to operate the upgraded Upolu power plant was used as the opportunity cost cut-off for assessing the financial viability of renewable energy modes. Only biogas gasification (sene 50/KWh) and one hydro scheme (sene 50/KWH) are below the cut-off. Distributed wind generation (sene $72 / \mathrm{KWh}$ ) and photovoltaic electricity (sene $81 / \mathrm{KWh}$ ) are close enough to the cut-off to become viable options as soon as ongoing reductions in capital cost (CapEx) and operations and maintenance (O\&M) of these alternative technologies meet the increasing marginal cost affected by diesel import inflation. 
Figure 2.4.3: Total Generation Cost, sene/kWh after electricity generation upgrade.

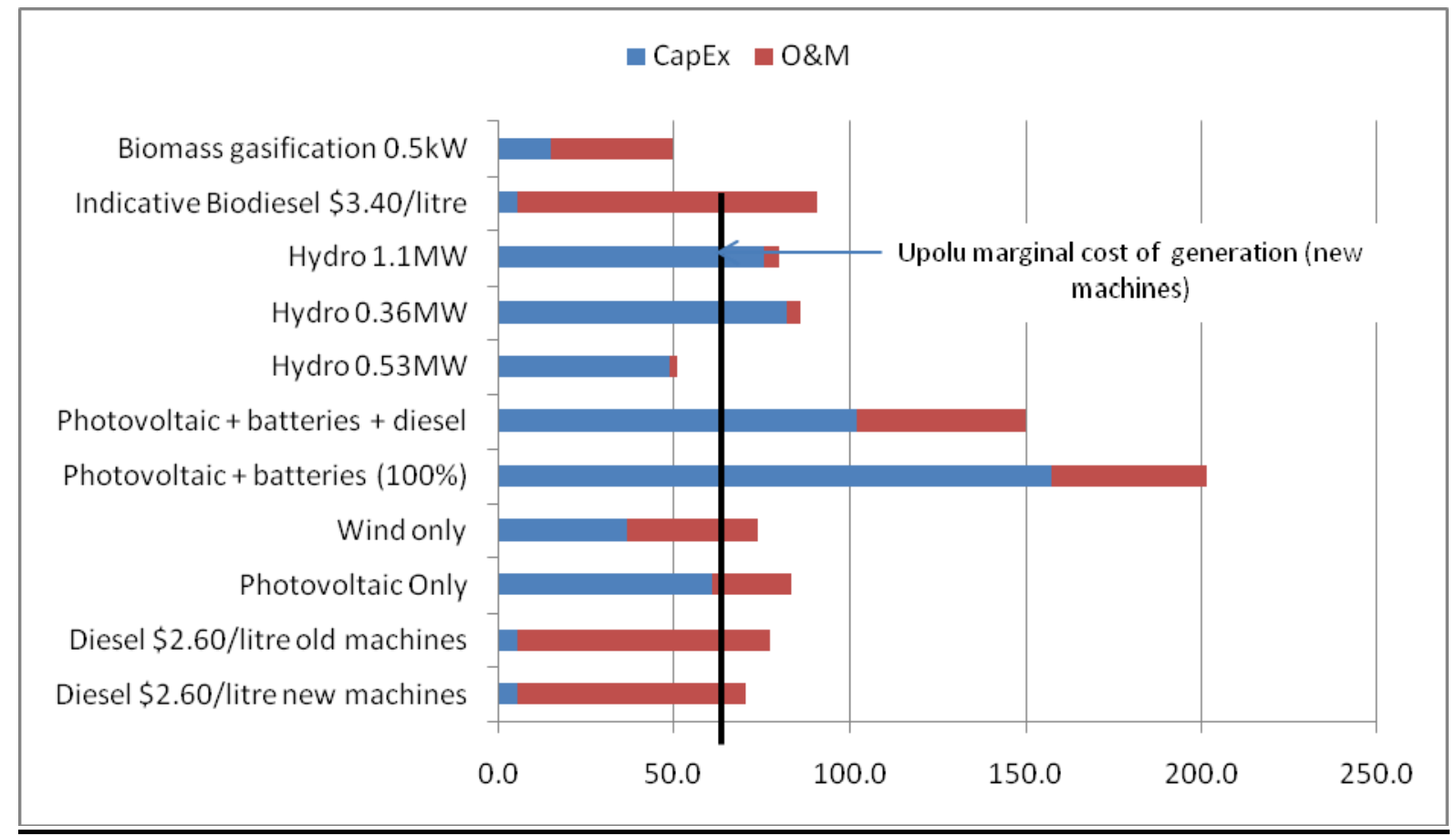

Source: MOF (2011) Energy Sector Plan 2012 to 2016.

Accordingly, the GoS is developing several electricity generation proposals including biomass gasification and distributed photo voltaics (PV) to meet Upolu's increasing electricity requirements but also to commence the energy substitution process with renewable forms of energy. It should be noted that diesel electricity generation provides base load electricity which will limit displacement by bio gasification and $\mathrm{PV}$ to around 20 per cent of total generation until more renewable sources for base load generation such as some marine options can be implemented.

\subsubsection{Samoan Renewable Energy Targets}

The renewables sector is governed by the Strategy for the Development of Samoa 2012 to 2016 in general terms and more specifically by the Samoa Energy Sector Plan 2012 to 2016 (SESP) (Government of Samoa, 2011c, 2012a). The strategy's overall energy sector objective is 'to reduce the growth rate in the volume of imported fossil fuels by 10 per cent by 2016'. Its high level indicators specifically stipulate an 'increase in the supply of renewable energy services by 10 per cent by 2016 '. So, the aims are clearly set out. 
In 2011, estimates of total energy consumption were approximately 113.1 kilotonnes of oil equivalent. Of total energy consumption, 78.04 kilo-tonnes of oil equivalent (69 per cent) was utilised by petroleum products and the remainder was supplied by renewables, including 32.35 kilo-tonnes of oil equivalent ( 28.6 per cent) biomass, 2.71 kilo-tonnes of oil equivalent (2.4 per cent) hydropower, biofuel and other minor renewables like solar PV. Hence, by basing the stipulated 10 per cent renewable increase on the 2011 baseline of a 31 per cent renewables contribution, the energy sector needs to achieve 34.1 per cent renewables at the expense of petroleum products. In quantitative terms, the 2016 energy consumption would need to be made up of 74.53 kilo-tonnes of oil equivalents of petroleum products and 38.57 kilo-tonnes of oil equivalents of renewables (Government of Samoa, 2011a). How realistic is such a policy setting?

The drive towards increasing shares of renewable energy has seen repeated checks and even reversals as economic orthodoxy has favoured fossil fuel imports. Figure 2.4.4 shows the gradual increase of fossil fuel imports at the expense of the use of biomass, the main pillar of the renewables component. Biomass in the form of fuel wood is mainly used for residential purposes such as cooking. The drop may mainly be caused by the replacement of biomass with LNG or electricity which in turn is achieved by increases in LNG and diesel imports. This gradual transition may well be explained by concepts of modernity and convenience. Short of a major policy intervention or a major economic downturn this development is likely to continue. 
Figure 2.4.4: Fuel use changes by type.

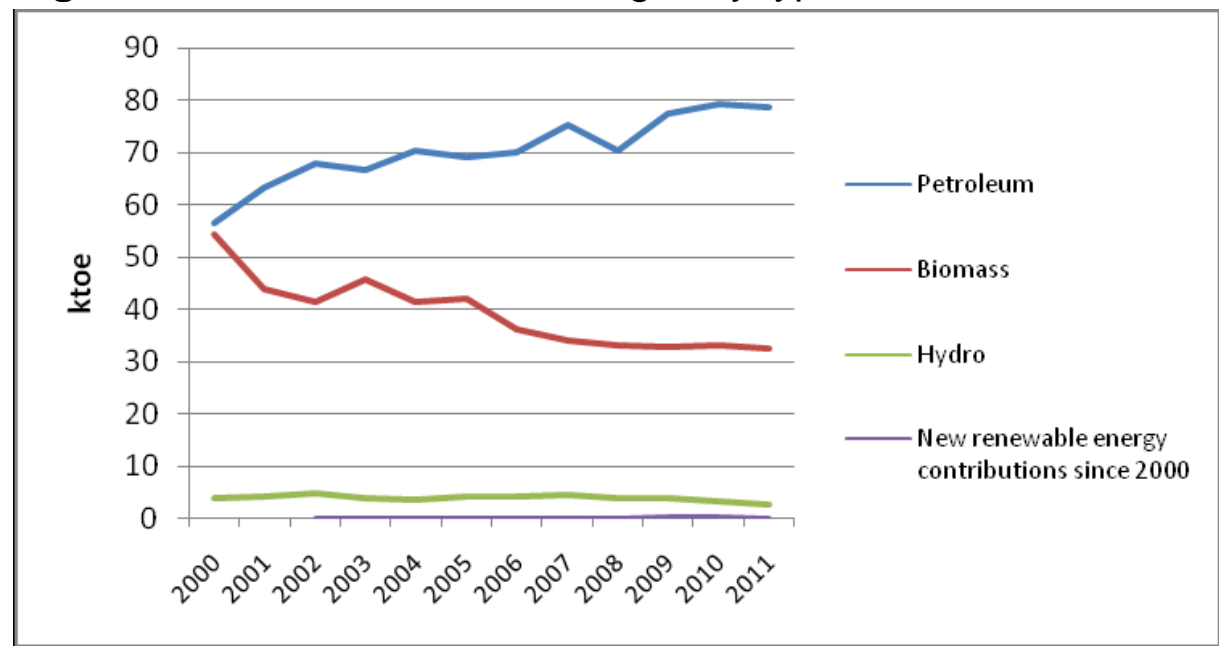

Similarly, but for different reasons, hydro-electricity generation has been subjected to a small but gradual decrease in electricity production mainly due to climatic volatility with relative drought diminishing hydro storage. Consequently, renewables targets may now only be achieved by significant energy efficiency measures and 'new' renewables contributions like bio-gasification, solar PV and biodiesel. However, at this stage several larger scale renewable projects like the much publicised, private sector Solar Samoa have failed to obtain necessary investor backing to install its planned grid-connected solar PV 4MW facility by 2013. A similar fate was suffered by the private sector Biogen 3 with its planned $4 \mathrm{MW}$ bio gasification project (Tuiafiso, 2013 pers. comm.)

At the time of conducting this research, only a relatively small installation of grid connected, $400 \mathrm{~kW}$ Solar PV by the State-owned enterprise EPC can be confirmed on top of the already and equally small $13.5 \mathrm{~kW}$ solar PV mini grid managed by EPC and the Scientific Research Organisation of Samoa (SROS) (Tuiafiso, 2013 pers. comm.). To conclude, the 'new' renewables contribution since 2000 has only been approximately 0.08 per cent and the achievement of a 10 per cent renewables increase by 2016 would have to be considered ambitious. Even if the Solar Samoa and Biogen 3 will eventually come on stream and assuming a similar electricity production as the existing 'Apolima' installation, only approximately 5.2 per cent of production capacity could be reached. 


\subsubsection{The Current Situation in the Transport Sector}

The transport sector is considered to be economically important in itself as well as an important link in the social and economic life in Samoa. The transport sector's economic importance is underlined by the predominant position petroleum imports have in Samoa's imports. In 2011, petroleum imports constituted 11.5 per cent of Samoa's GDP and 22.7 per cent of its imports (Samoa Bureau of Statistics, 2012). Accordingly, these imports constitute a significant drain on Samoa's foreign exchange reserves and also divert crucial resources from other government responsibilities.

Car registrations have grown significantly during the last 10 years with a surprising large component of new and large vehicles on the road as is depicted in photograph 2.1.

Photograph 2.1: $\quad$ Modern cars in central Apia.

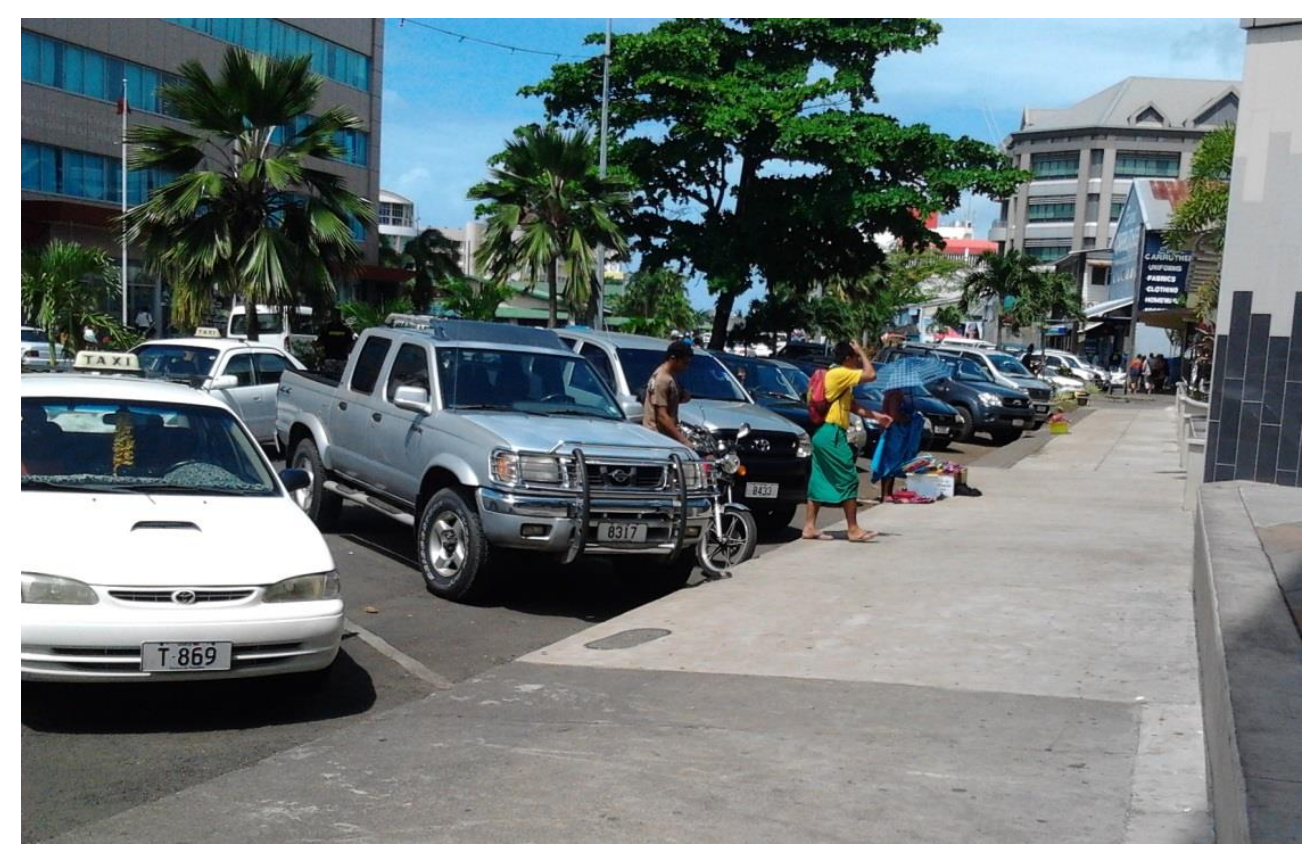

Some of this increase may be attributed to the change to left-hand drive traffic which was specifically promoted by Prime Minister Tuilaepa Sailele Malielegaoi to facilitate the importation of cheap second-hand and general imports from Japan. The 
driving side switch had created strong opposition amongst the general Samoan public and can also be considered an alignment policy with Samoa's metropolitan patrons (Chapman, 2009).

Samoa's late accession to the WTO and the adoption of stringent WTO admission conditions (Samoa had opted to join late) created a flurry of legislation aimed at harmonising existing legislative commitments with WTO's neoliberal policy prescriptions. More specifically, the SESP's energy efficiency strategy clashed with WTO policy requirements of improved market access of previously banned vehicles older than 12 years. In order to retain the integrity of the SESP energy efficiency strategy a nation-wide vehicle safety inspection system was created to remove noncomplying vehicles from public roads. While such a vehicle safety inspection system cannot be considered a bad policy prescription per se, it is debatable however, if a similar but cheaper outcome could not have been achieved by maintaining the ban on 12 year old cars. Moreover, there is some anecdotal evidence to suggest that the car inspection system is widely abused resulting in continued presence of noncomplying cars on Samoan roads (Anonymous, 2013).

Figure 2.4.5: $\quad$ Samoan vehicle registrations by type

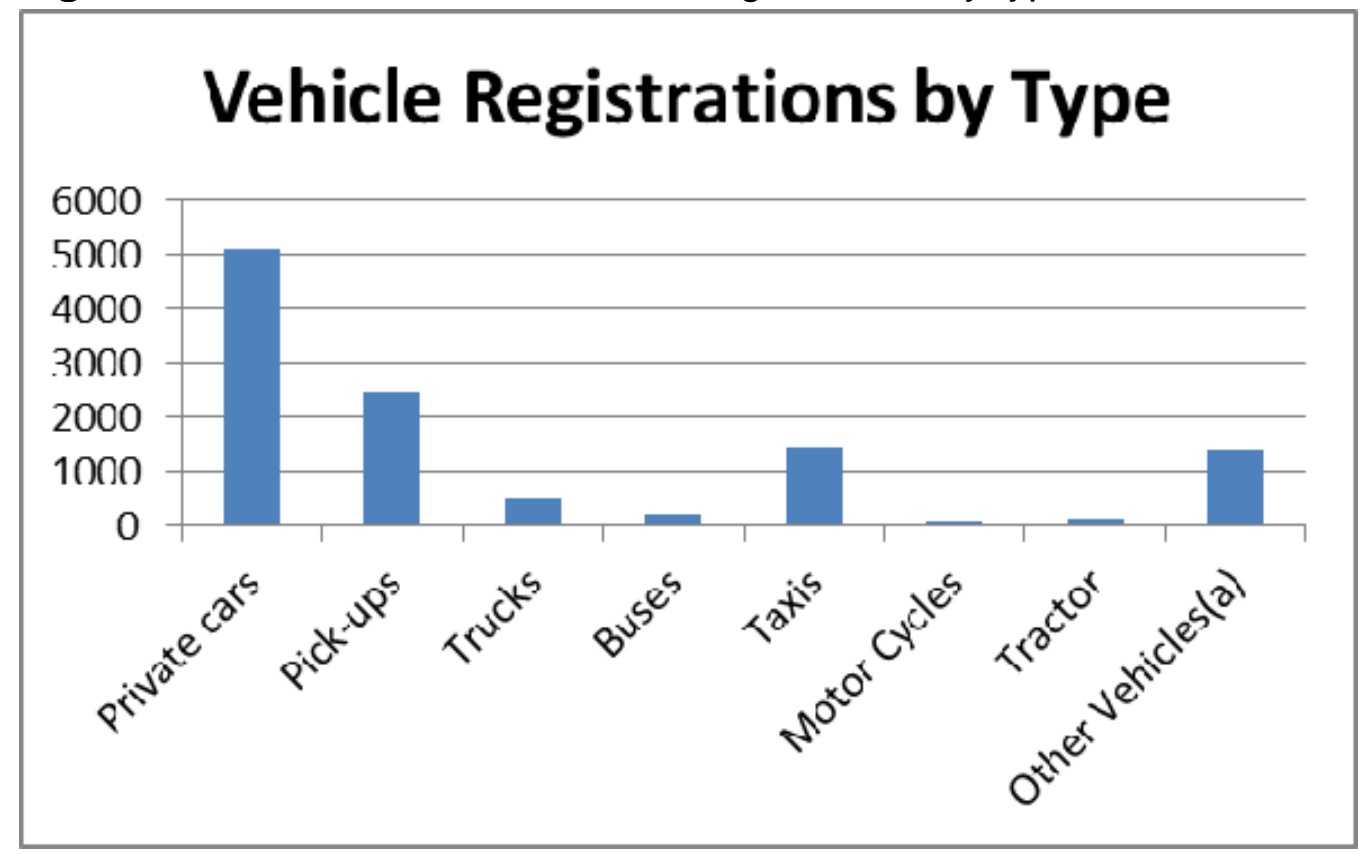

Source: (Government of Samoa, 2011c p 29) 
Registration data indicate a total vehicle fleet of around 18,000 vehicles. However, there is some doubt about this figure and it needs to be confirmed. Principally, the vehicle fleet is dominated by sedans of various sizes and engine configurations. Sport utility vehicles (SUVs) are also part of this category. Pick-up truck utilities are the second most dominant grouping and are used for commercial and passenger transport. The status vehicle is more a recent phenomenon and is generally a late model utility truck or SUV. In rural Samoa the status car is driven by the elite which include church members, matais and commercially connected village members.

Taxis are the third largest vehicle category and are utilised more as a hybrid version of a public transport mode to carry patrons and their cargo within town and around the island. According to taxi drivers and an appraisal of the number of taxis there appears to be an oversupply of vehicles in Apia.

Samoa's colourful buses are hard to ignore as traffic participants as they are the main form of public transport in Samoa. The industry is private and bus routes and frequency are licensed by government on a public needs basis. The buses service destinations across the islands and are built locally on truck chassis. Buses operate on a relaxed timetable and pick up and drop off passengers and cargo along a route. Fares are inexpensive and buses are usually overloaded at least during certain times of the day, pointing towards capacity issues (Photograph 2.2). 
Photograph 2.2: Public Transport at Apia's Bus Station.

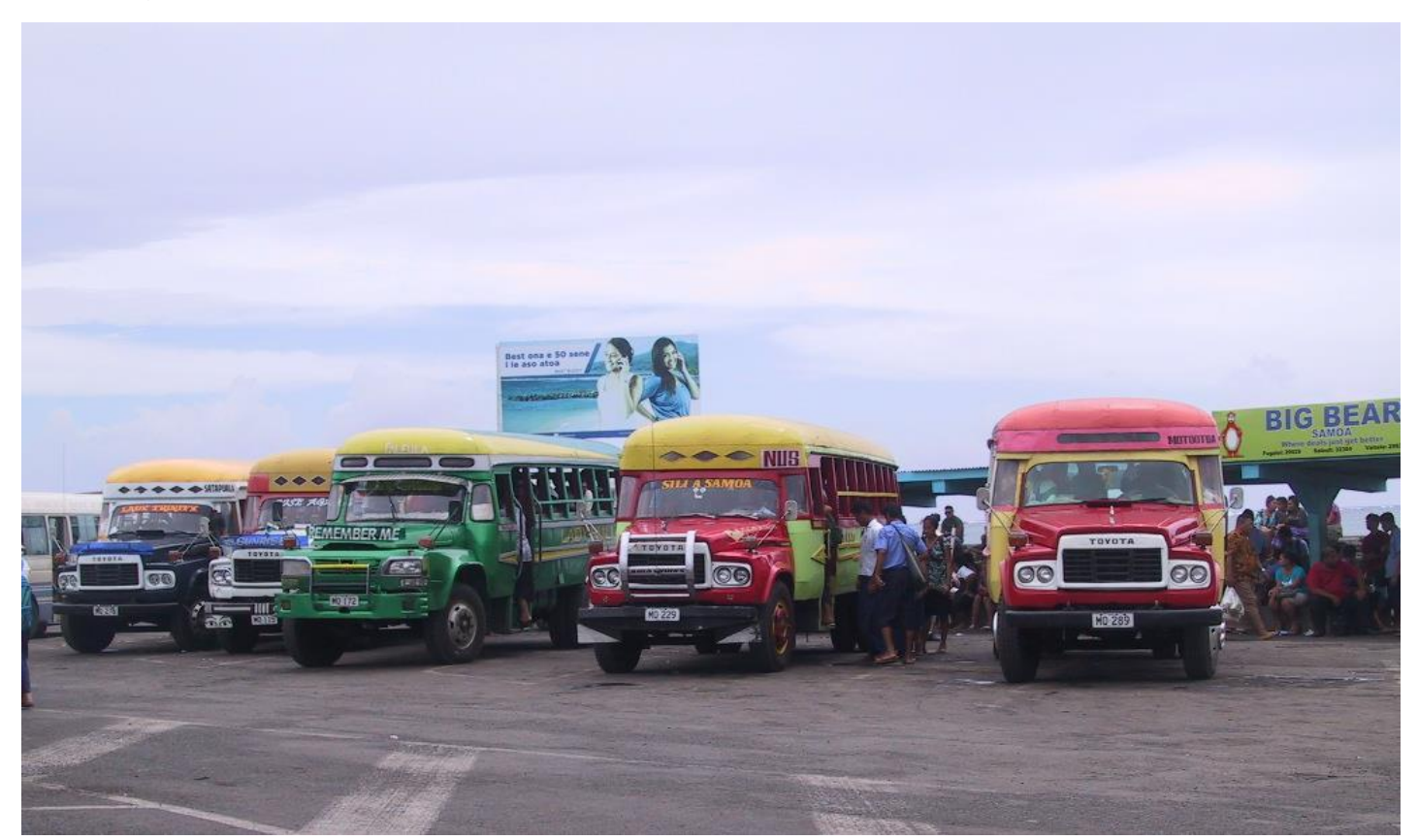

\section{$2.5 \quad$ Conclusion}

This chapter has covered a wide area from Samoa's cultural and political institutions which will have an influence how technical innovation may be adopted to Samoa's current socio-economic predicament. An important conclusion is that the hybridised character of Samoan society in the early 2000s has become reliant on imported consumer goods, in particular vehicles for private and public use. Recent social indicators like the 2008 Household, Income and Expenditure Survey, however, point to a decline in the ability to afford many consumer goods as employment opportunities are receding, particularly for lower income households in rural Samoa and North-West Upolu. On a nationwide basis the same dynamics are revealed by the structural balance of payments deficits and the prominent role fuel imports play vis-à-vis static or even declining export earnings.

The Samoan Government is acutely aware of this predicament and has started implementing energy substitution programs to increase the renewable energy sector with variable success. There are, however, no new initiatives capable of having significant impact on reducing fuel imports apart from an ongoing biodiesel 
trial aimed at substituting some diesel imports at some point in the future. Thus, there is an urgent need to find an alternative transport mode mainly capable of substituting fuel imports but also as a means to maintain access to transport for a wide section of the Samoan public. 


\section{Chapter Three: Developments in Electric Mobility and Relevance for Samoa}

\subsection{Overview}

The purpose of this chapter is to develop an understanding of the economic importance of the global transport sector, its impact on climate change and how recent developments in climate change mitigation may affect automotive innovation. The Stern Review and the ensuing robust debate about his advocacy for total emission reductions of 25 per cent by 2050 are used to highlight the often ignored but important underlying economic and ethical assumptions of the debate. The Stern review and ongoing assessment reports by the IPCC, the World Bank and IMF provide the rationale for the identification of alternative transport modes.

An appraisal of the 'big scenario' studies such as the King Review, the IEA's Electric Vehicle Initiative $(E V I)$ and others introduces transport sector initiatives ranging from policy recommendations and promotion of improved driving practices to low carbon transport initiatives. In particular, I focus on the IEA's global Electric Vehicle Initiative which uses the Stern Review's rationale of the 2 degree Celsius warming limit as the initiative's objective to reduce $\mathrm{CO} 2$ emissions by replacing combustion engine vehicles with 20 million BEVs globally by 2020. The EVI is based on the appreciation that the transport sector requires substantial government and other stakeholder support due to a global market failure to internalise climate change externality costs.

This study from now on concentrates on learning from global experiences in the use of BEVs, BEV infrastructure requirements, life cycle assessment (LCA) of promising transport technologies and socio-political drivers of innovation. Real-world projects and experiences emanating from peer-reviewed literature are discussed with a view to potential applicability to the Samoan transport sector.

Accordingly, this chapter concentrates on awareness, knowledge about BEVs and the legal and political arrangements governing alternative transport forms and most importantly the energy infrastructure supporting the conventional transport 
sector and potential BEVs. The experiences of several island states' with alternative transport projects involving electro-mobility are also covered.

The literature review finishes with the unexpected and 'below the research radar' discovery of a retrofit BEV industry which has existed in metropolitan countries for a number of years. The existence of a retrofit BEV conversion movement raises some questions about its potential contribution to electro-mobility in Samoa. In the light of the discussion below the applicability of postdevelopment thought for the evolution of a grassroots movement to address Samoa's transport problems it also creates some possibilities.

\subsection{Economic and Environmental Context of the Transport Sector}

The international research effort into sustainable transport options is mainly motivated by economic drivers such as fossil fuel price inflation and volatility and increasingly the adverse environmental effects of conventional transport. Globally the transport sector is a large and increasing user of fossil fuels, particularly as emerging and developing countries build their economies. In OECD countries road transport energy grew 1.9 per cent and in non-OECD countries 3.3 per cent from 1990 to 2006. In 2006, OECD countries used more than 60 per cent of petroleum products in the transport sector whereas non-OECD countries used about 50 per cent (IEA, 2009). Increased mobility has been instrumental in growing economic prosperity for a wide cross section of society, improved quality of life for billions of people across the globe and has become an industry in itself. There is no doubt in the minds of these authors that road transport will remain a vital component of global economic life and will grow further (IEA, 2013 ; King, 2007, 2008; McKinsey \&Co., 2009; UK Department of Transport, 2008).

Apart from economic benefits, the transport sector has also adversely impacted on the environment. Commonly accepted projections of a global business as usual scenario (BAU) point to a doubling of $\mathrm{CO}_{2}$ emissions by the transport sector by 2050 (IPCC, 2014 p 24; King, 2007). Thus, a policy challenge exists as to whether these projected $\mathrm{CO}_{2}$ increases from the transport sector are tolerable within 
the current sustainability paradigm and to what extent damages need to be mitigated.

The Stern Review in 2007 was the first comprehensive attempt to understand the economic implications of climate change. The review itself was commissioned by the British government and its author, Sir Nicolas Stern, is a well-respected economist with positions as chief economist at the World Bank, a permanent second secretary position of HM Treasury and the head of the UK Government Economic Service (Ackerman, 2007; Nicholas Stern, 2007).

The review argued that scientific evidence of climate change was now overwhelming, climate change was posing a serious risk to human habitation on the planet and that an urgent global response was required. If no mitigating action on climate change was taken, a business as usual (BAU) approach would commit the world community to a temperature increase of more than two degrees Celsius by the end of the century. In economic terms global GDP would be negatively affected at least by five per cent each year, now and forever. If wider risks and externality costs were included in the assessment, costs could rise to 20 per cent or more depending on regions and development status of the country. On the other hand if mitigating action were to be commenced soon cost could be limited to one per cent of global GDP each year, now and forever (Nicholas Stern, 2007).

The review introduced an un-orthodox view (from the perspective of the dominant neo-classic economic paradigm) of the use of low net present value discount rates ${ }^{5}$ for the cost-benefit analysis (CBA) for climate change mitigation and the use of uncertainty as a concept in the context of climate change. By using a low discount rate of 1.4 per cent in a cost-benefit analysis of climate change mitigation, Stern made an ethical choice to value future generations' right to enjoy limited

\footnotetext{
${ }^{5}$ Discount rates are used in cost-benefit analysis to calculate the cost of future monetary transactions in present monetary terms. An underlying assumption in dominant neo-classic economic thinking is that future wealth is markedly larger than at present. Consequently, it is more rational not to save for present consumption as future wealth is larger. Hence, present value is discounted.
} 
resources at the same rate as present generations ${ }^{6}$. In the ensuing debate Nordhaus (2007) provided the orthodox economic view of 'pure time preference' by using higher market interest rates as (net present value) discount rates to reflect a 'text book' world of perfect markets and perfect rationality. By doing so he introduced a bias in favour of present generation consumption as he argued that futurity and uncertainty of climate change adverse effects will be tackled by technological remedies not yet known but available at some time in the future (Nordhaus, 2007).

Arrow (2007) accepted the validity of higher net present value discount rates but arrived at the conclusion that even with high 'pure time preference' discount rates (as high as 8.5 per cent) mitigation benefits outweigh expected market and nonmarket bad effects (Arrow, 2007). Weitzman (2009) also took issue with Stern's low discount rate and argued for a higher initial discount rate rapidly declining into the future. He, however, determined 'that Stern may be right for the wrong reasons' and proposes uncertainty and the inability of markets to learn early enough the management of extreme and low probability events as sufficient reason to start mitigation early. Therefore Weitzman argues insurance against worst-case catastrophes is required in the form of precaution (Weitzman, 2009 p 724).

Thus Weitzman and Arrow disagreed about technical aspects of Stern's methodology of analysis but sustained his main arguments in support of intergenerational equity and the importance of considering the effects of uncertainty in cost-benefit analysis of climate change mitigation costs.

Subsequent assessment reports by the International Panel on Climate Change (IPCC) (particularly assessment reports AR4 and AR5) confirmed that climate change is taking place now, is of anthropogenic origin and its extent is already causing adverse effects for many generations to come (IPCC, 2013, 2014). In 2012 DARA' $^{7}$ published the 'Second Climate Vulnerability Monitor' and found that

\footnotetext{
${ }^{6}$ For a detailed discussion of discount rates refer to Ackerman, F. (2007). Debating Climate Economics: The Stern Review vs. Its Critics. In G. D. a. E. Institute (Ed.). Medford MA: Tufts University; Daly, H. E., \& Farley, J. (2011). Ecological Economics Principles and Applications (2 ed.). Washington: Island Press.

${ }^{7}$ Fundacion DARA is an independent organisation committed to improving aid effectiveness for vulnerable populations suffering from climate change, disasters and conflicts. The INGO is respected by UN agencies and the World Bank Group.
} 
in 2010 climate change had caused economic losses of one per cent of global GDP (DARA \& Climate Vulnerable Forum, 2012). The findings of the Second Climate Vulnerability Monitor confirmed the Stern review's 2007 conclusions.

The urgency of addressing climate change trajectories is now also appreciated by Bretton Woods Institutions like the World Bank and the IMF who have published widely on the merits of avoiding temperature increases beyond 2 degrees Celsius (Potsdam Institute for Climate Change Impact Research and Climate Analysis, 2012). The World Economic Forum's Global Risks 2013 edition has also allocated the failure to adapt to climate change and increasing $\mathrm{CO}_{2}$ emissions a high likelihood and impact (World Economic Forum, 2013 p 5).

As we will see in following analyses of climate change mitigation studies, Stern's advocacy for a greenhouse gas stabilisation target of $550 \mathrm{ppm}^{8}$ requires total emission reductions of 25 per cent by 2050 relative to 2000 . The transport sector features prominently as a major emitter of $\mathrm{CO}_{2}$ and accordingly would also need to contribute significantly to any future emissions reductions.

\subsection{The Big Scenario Studies}

\subsubsection{The King Review}

The King Review (2007) followed Stern's recommendations and argued that in order to achieve Stern's reduction targets, significant decarbonisation of the global car fleet would have to take place with suggested reductions in the developed world of around 90 per cent per kilometre emissions by 2050 (King, 2007). In the shortterm a refocus on increasing vehicle energy use efficiency is thought to be able to reduce vehicle per kilometre emissions by 30 per cent within five to ten years. Short term options include already existing fuel use promotions such as the use of more fuel-efficient vehicles based on labelled fuel economy and $\mathrm{CO}_{2}$ emissions, improved driving practices and vehicle maintenance and increased use of lower carbon

\footnotetext{
${ }^{8}$ Parts per million, $\mathrm{CO}_{2}$ equivalent greenhouse gases in the world's environment.
} 
transport alternatives like walking, cycling and encouraging public to start car clubs and share cars where appropriate.

Several authors, however, have found that the driving public generally did not favour long-term fuel savings over other perceived short-term benefits such as engine size, comfort and fashion appeal. Moreover, there is also a contradiction between the driving public's perceived support for the environment and actual driving behaviour (King, 2007). Hence, public education and promotion of fuel use efficiency practices has limitations and may well need to be accompanied by regulation and incentivisation.

In the long-term, post 2030, the review sees decarbonisation of the transport sector as the only possibility to achieve an 80-90 per cent reduction of emissions, prescribed by the maximum 2 degree permissible warming limitation. At this stage only battery driven and fuel-cell driven vehicles are seen as capable of delivering such large scale emission reductions provided those vehicles are powered by zero or near zero carbon electricity (King, 2008).

These long-term goals also set the scene for 'back-staging' mid-term strategies. The review believes car emissions can be reduced by 50 per cent as current hybrid car and battery technology is increasingly being commercialised and current cost barriers are overcome. Apart from these technical hurdles, there is a call for a national and international policy framework enabling and even pushing for vehicle energy use efficiency and acceleration in the commercialisation of noncarbon fuel technology. This approach is motivated mainly by the failure of previous voluntary government-private sector agreements. In particular, a successful policy framework requires:

- Legislation prescribing vehicle emissions and anticipating future reductions to enable industry planning;

- Demand side legislation to encourage consumers to choose best model in class and if appropriate to downsize in engine size. This can be achieved by 
making information about fuel use and emissions compulsory and mandatory to be exhibited on new and second-hand vehicles;

- Incentivisation of lower emission vehicles;

- Public body procurement programs are prescribed to be low emission vehicles;

- Increased public expenditure on low carbon R\& D including low carbon vehicles. A limited number of long-term research 'milestones' are connected to $R \& D$ priorities to encourage research focus.

\subsubsection{The International Energy Agency 2 Degree Celsius Scenario}

The IEA adopted the findings of IPCC, the Stern and King Reviews and is working towards a collaborative response to climate change mitigation/adaptation involving industry, government and civil society. Its working objective is the achievement of the 2 Degree Scenario (2DS) as follows:

“The $2^{\circ} \mathrm{C}$ Scenario (2DS) describes an energy system consistent with an emissions trajectory that recent climate science research indicates would give an 80 per cent chance of limiting average global temperature increase to $2^{\circ} \mathrm{C}$. It sets the target of cutting energy-related CO2 emissions by more than half in 2050 (compared with 2009) and ensuring that they continue to fall thereafter. Importantly, the 2DS acknowledges that transforming the energy sector is vital, but not the sole solution: the goal can only be achieved provided that $\mathrm{CO}_{2}$ and GHG emissions in non-energy sectors are also reduced. The 2DS is broadly consistent with the World Energy Outlook 450 Scenario through 2035 (IEA ETP, 2013 p 20)."

In order to be able to determine $\mathrm{CO}_{2}$ emissions reduction targets, the IEA prepared an energy consumption scenario for the global economy up to 2050 based on a BAU scenario of 6 degree Celsius warming and the 2DS scenario. The difference in $\mathrm{CO}_{2}$ emissions between the scenarios yielded the required energy 
savings by sector. The transport sector would be required to save 22 per cent of its projected $\mathrm{CO}_{2}$ growth up to 2050 to meet the 2DS emissions projections (IEA ETP, 2013 p 20).

In order to achieve these emission savings, the IEA via the Electric Vehicles Initiative $(\mathrm{EVI})^{9}$ signalled a goal of 20 million registered $\mathrm{BEV}$ passenger cars (BEV \& HBEV) (2 per cent of projected total car sales) by 2020 (IEA ETP, 2013 p 80; Steinhilber, Wells, \& Thankappan, 2013). So far BEV sales for 2011 and 2012 have matched 2DS consistent global sales data but from 2014 onwards projected manufacturing sales start to lag behind 2DS BEV sales requirements.

Figure 3.1: Government sales targets and BEV/PHBEV production/sales data

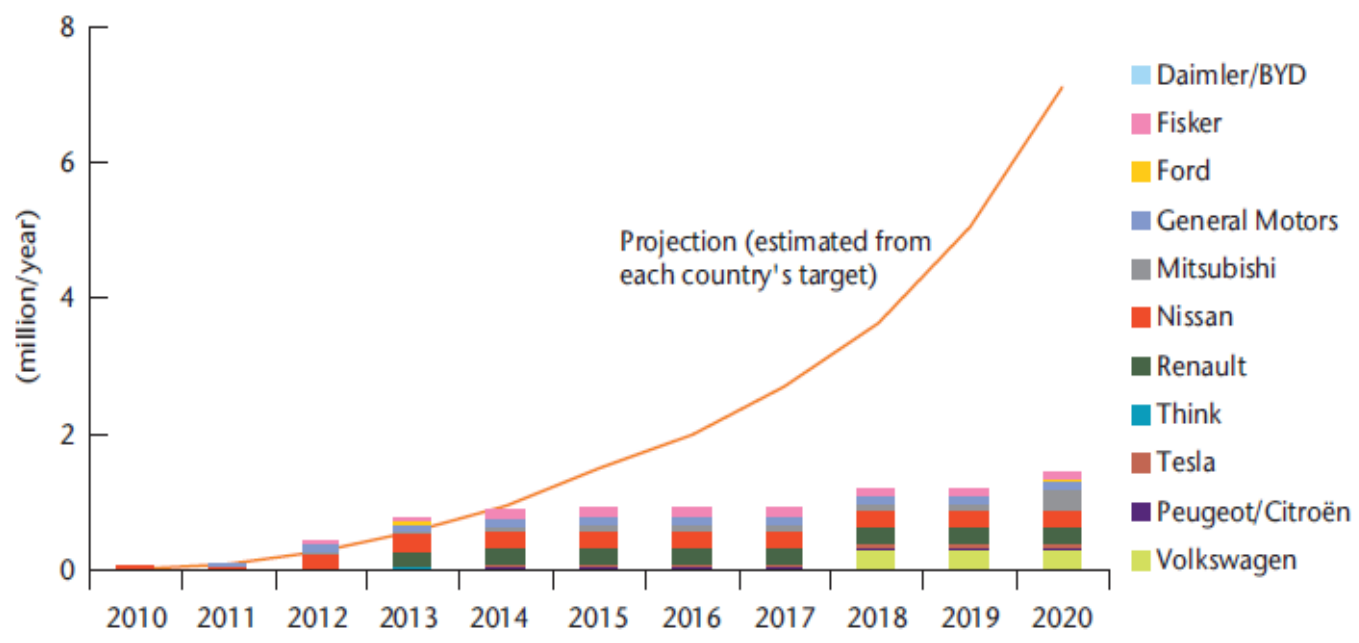

Source: (IEA, 2011 p 24)

As figure 3.1 shows, from 2014 onwards there is a projected and increasing disparity between car industry production targets and the 2DS consistent/EVI targeted $\mathrm{BEV}$ sales required to achieve $\mathrm{CO}_{2}$ emissions reductions. This increasing disparity signals a market failure caused by neglecting to include externality cost in the conventional transport sector. I will expand on the concept of externality costs in chapter 6.2.8.

\footnotetext{
${ }^{9}$ Electric Vehicle Initiate (EVI) is made up of membership of the world's major economies and BEV markets operating under the IEA umbrella.
} 
In principle, the $\mathrm{EVI}$ is an initiative designed to counteract this systemic market failure by implementing measures to make BEVs more cost competitive with conventional ICEV markets. This includes measures like purchase incentives, government car procurement policies specifying cars with a low emission profile aimed to bring down the price of BEVs and give BEV car manufacturers confidence in future market uptake. Support towards ongoing technology improvements may include R\&D support and industry/research industry grants and BEV specific infrastructure support. In particular in 2012, government, municipality and private support resulted in 46,000 slow and 1,900 fast recharging stations in EVI countries. Research grants and other support in conjunction with industry investment led to a 48 per cent reduction in battery cost from a 2008 price of US\$ 1000 to US\$ 485 on a $1 \mathrm{kwh} / \mathrm{h}$ basis in 2011 . Industry consensus suggests that at US $\$ 300 / \mathrm{kwh}$ cost parity with ICEVs can be achieved and would remove a major hurdle in BEV adoption (Contestabile, Offer, \& North, 2012).

In 2012, a breakthrough in charging technology for BEVs was achieved by the Volvo Car Corporation developed a three-phase, on board BEV battery charger which reduced re-charging times to 1.5 hours. There is also anecdotal evidence to suggest that Chinese and South Korean companies have developed an even faster recharge process. Several EVI member countries have incentivised BEV and PHBEV sales and public and private BEV fleet acquisitions to bring BEV prices down. Aggregate government sales targets for 2020 are seven million to nine million BEVs which is consistent with the 2DS goal of seven million BEVs (IEA, 2013 ; IEA ETP, 2013).

\subsubsection{The Renewable Energy Network Survey}

A recent survey of global transport and energy stakeholders (170 parties) by the Renewable Energy Network (REN21) shows that since the 2007 King review support for renewable energy in general and the non-fossil fuel powered transport sector is finding increasing support (Martinot, 2013b). The REN21 survey was able to document a massive growth in investment in renewables. In 2011 US $\$ 260$ billion was invested in renewables with projections for the coming decades up to 2050 
ranging from US\$ 300 billion to US \$ 1 trillion. The survey found that the main drivers for the unprecedented investment growth are supportive government policies, cost inflation of conventional energy, cost reductions in renewable technology and the general acceptance of future carbon constraints. Industry experts believe that these investment flows point to a 'mainstreaming' with more global investments now being directed to renewable energy instead of fossil fuels and nuclear energy with stakeholder confidence pointing towards continued investment activity (Martinot, 2013b).

The REN21 survey also found support for three distinct growth scenarios for the renewables sector ${ }^{10}$, depending on the particular preferences of different stakeholder groups. Energy sector interest groups believed that the renewables contribution to global energy supply up to 2050 would remain at around 20 per cent maintaining the current status quo (BP, 2012; ExxonMobil, 2012). Other low adoption scenarios such as the Kinsey report proposes an 'Optimised ICE Scenario' with reduced emissions and improved fuel efficiency maintaining a 99 per cent ICI market share in 2030 (McKinsey \&Co., 2009). A 'moderate' outlook sees a contribution of 30-45 per cent renewable electricity with the transport sector accommodating a modest but growing use of bio-fuels along with electric vehicles and plug-in hybrids (Martinot, 2013b; McKinsey \&Co., 2009). A 'high renewables' scenario projects a 50-95 per cent contribution of renewable electricity by 2050 . The transport sector would consist of large contributions of biofuel powered plug-in electric vehicles, electric passenger and freight vehicles (Greenpeace, 2012; IEA WEO, 2012; McKinsey \&Co., 2009). Interestingly, the "high renewables" scenario is promoted by the International Energy Agency (IEA) via the Electric Vehicle Initiative (EVI).

A common threat was that the growth of renewables in the energy sector was not a technological or even an economic issue. Sufficient technology in all renewable sectors does already exist and their long-term economics behaviour was reasonably

\footnotetext{
${ }^{10}$ Energy scenarios are proposed by experts in the energy field and by vested interest parties. Scenarios presented by interviewees relied on 18 key variables from the political economy, energy market regulation, renewable energy cost projections over time, social issues, population growth and demographics etc. We should also note that scenario projections may be descriptive using forecasts based on current trends or normative using back casting from a predetermined endpoint. The REN21 study has used both scenario types with many (but not all) high renewables scenarios being based on back casting based on future carbon related constraints.
} 
clear and in several cases cost-competitive with conventional forms of energy in 2013 (Martinot, 2013b p 61). Transformational change was required at political and institutional levels as energy generation and its various uses became increasingly more intertwined. For example until recently transport fuels were exclusively supplied in the form of petroleum products and natural gas. With the advent of electric mobility and biofuels different energy supply chains and transport options are now available as well as a hybridisation of all energy forms.

A transformational change towards decarbonisation of the energy sector requires greater integration of electricity generation and the transport sector. One interviewee, quoted in the REN21 survey, formulated the integration process thus: "Electric utility companies will face some of the greatest challenges in technical and institutional restructuring that they have ever faced in the past 100 years." Another said: "Transportation systems will definitely become less homogeneous, with a multitude of fuel types and vehicle types, and with local solutions tailored to local conditions and geography. The days of 'one size fits all' transport are numbered." (Martinot, 2013b p 61).

Indeed, some integration of energy platforms has already been achieved, notably by countries with existing national energy policy targets. For example, Denmark targets a 100 per cent renewables contribution in electricity generation by 2030 and highly industrialised Germany is planning for 50 per cent by 2030 and 80 per cent by 2050 (Martinot, 2013a). Arguably even faster change on policy level and renewables initiatives is occurring at regional and municipality level where infrastructure and transport systems which incorporate renewables are demanded by local governments, community groups and residents (Martinot, 2013b p 11).

Thus, a picture emerges of a more or less coordinated concern about a costeffective response to well-founded environmental threats voiced by the Stern review and the IPCC. Exemplary for pragmatic responses are national initiatives like the 2008 King Review which explored the role the transport sector should play in reducing $\mathrm{CO}_{2}$ emissions. Some countries, notably Denmark, the United Kingdom, Germany and Spain have taken the lead in formulating progressive, national 
renewable energy goals. In the absence of internationally binding legal frameworks, international energy policy is formed on a commercial basis and by the forming of stakeholder alliances. Judging by the global survey results of the Renewable Energy Network21, the integration of renewable forms of energy in the energy sector is well on the way and supported by a wide assembly of stakeholders (Martinot, 2013b)

The IEA's Electrical Vehicle Initiate (EVI) can be seen as an attempt to bridge the gap between the mainstreamed concerns about climate change and a prevailing market failure to respond to these imminent threats (Nicholas Stern, 2007). The IEA's projected $\mathrm{CO}_{2}$ emission reductions in the transport sector have been translated in measurable performance indicators like cumulative 20 million BEV sales by 2020 . Flowing from that are tangible initiatives by central government, local government and the private sector to achieve these goals within a time frame.

Central and local government are now seen as important participants to achieve the IEA's 2DS goals over the next decade. Policy instruments available are carbon pricing and energy taxes, standards and mandates in the energy sector and direct public support for RD\&D in alternative transport modes.

\subsection{Current Status of BEV and PHBEV Technology}

The scholarly debate about alternative fuels and vehicle technology has waxed and waned since the 1970s and has produced a vast number of studies being devoted to evaluating technical, economic and environmental impacts of alternatively fuelled vehicles. Accordingly, emphasis was given to battery electric vehicles in the 1970s. Later on attention switched to hydrogen powered vehicles and lately biofuels and latterly again a renewed interest in electric vehicles has grabbed the attention of the research community.

The focus of the research effort has also shifted from the more economic considerations motivated by the 1970s' oil shocks to the environmental concerns of climate change which has spawned a range of comparative and time limited scenario studies. In this section information is drawn from diverse sources and includes the 
McKinsey/powertrain alliance report, various International Energy Agency (IEA) studies, the National Hydrogen Association (NHA), the Renewable Energy Network (REN21) survey, the General Motors/LBST and GM Well-to-Wheel Analysis of Energy Use and Greenhouse Gas Emissions and Criteria Pollutant Emissions and several technical reports from reputable NGO's.

Electric vehicles are promoted now by several national and international institutions as mid-long term options to achieve decarbonisation. In fact, a lot of the decarbonisation debate heavily relies on commercial and environmental viability of electric mobility. At this stage the general performance and utility of BEVs, in particular vehicle purchase price and driving range, is inferior to conventional ICEVs for their use in metropolitan, industrialised countries. The review identifies the componentry of electro-mobility holding back the commercialisation timeline envisioned by IEA and gives an update on the state of the research effort in these respective technologies.

\subsubsection{Battery Technology}

Lithium-ion battery technology for use in electric vehicles has (post 2010) largely replaced lead-acid batteries (Scrosati \& Garche, 2010). Battery research is now focusing on advanced materials with prospects to decrease battery weight and cost. The next generation of battery improvement is expected to reach commercial application around 2020. The cost of a standard lithium-ion battery is currently around US $\$ 800 / \mathrm{kwh}$ with a cost of US $\$ 21,000$ to power a medium sized BEV with a range of approximately $150 \mathrm{~km}$. By 2020 battery costs are expected to decrease to around US $\$ 10,000$ and to US $\$ 6,400$ by 2030 with expected driving range extensions. These developments could lead to battery cost reductions down to US \$ $300 \mathrm{Wh} / \mathrm{kg}$ which would represent cost parity with conventional transport systems. (Element Energy, 2012).

Life cycle assessment (LCA) data of the lithium battery production process are limited, contradictory and difficult to compare. Moreover, LCA data mainly cover $\mathrm{CO}_{2}$ aspects whereas additional impacts like ozone depletion, acidification, 
photochemical smog and water quality effects are rarely considered. A review on LCA data by Contestable et al (2012) determined a 6 tonne $\mathrm{CO}_{2}$ of battery related footprint per vehicle using mid points for results from the most relevant studies and assuming a $30 \mathrm{kWh}$ battery pack and a driving range of $160 \mathrm{~km}$ (Nissan Leaf) (Contestabile et al., 2012). For a vehicle service life of $150,000 \mathrm{~km}$ this would equate to $40 \mathrm{gCO}_{2} / \mathrm{km}$. As lithium ion battery technology has only recently been commercialised, studies suggest an improvement of resource use efficiency up to 3 tonnes per vehicle or $20 \mathrm{gCO}_{2} / \mathrm{km}$. Recycling is considered a realistic option to achieve price parity with operating cost of ICBEVs as well as reducing pollution (Contestabile et al., 2012; Dewulf et al., 2010). ${ }^{11}$

The IEA's 2DS BEV production projections stipulate that lithium world production would have to grow by 2900 per cent by 2050 relative to 2011 . According to UKERC, identified lithium resources are abundant and lithium prices will be mainly determined by battery recycling efficiency and battery parity price with ICEVs not lithium availability (Speirs, Gross, Gross, \& Houari, 2012).

\subsubsection{BEV Infrastructure Innovation}

In metropolitan countries the currently limited driving range of BEVs has become an obstacle for speedy adoption of electro-mobility and, moreover, has put a focus on the requirements and design of battery recharge infrastructure. The extensive experimentation with battery recharge options highlights the process of how best to integrate electro-mobility's novel requirements in existing electricity networks.

One school of thinking is that BEVs will be mainly purchased by a clientele which has access to private parking space and power supply. This argument poses some difficulty for EV owners living in multilevel apartment buildings without access to electricity at the parking space. Another view is that recharging happens mainly in public places which initially would require longer recharge times and would be a

\footnotetext{
${ }^{11} \mathrm{~A}$ relatively efficient petrol car with a fuel consumption of $8 \mathrm{I} / 100 \mathrm{~km}$ will produce approx. 28 tons of $\mathrm{CO}_{2}$ during its service life considering only the 'pump to tank' $\mathrm{CO}_{2}$ balance.
} 
distinct disadvantage to conventional fuel re-filling. Apart from the inconvenience, the longer recharge times would require a change of driving, commuting and work practices as well as additional infrastructure cost on top of the existing fuel distribution infrastructure (Negre, 2011). In several European cities the recharging time issue and the driving range issue is solved by the installation of battery swapping stations (The Royal Academy of Engineering, 2010). There is, however, agreement that the currently evolving BEV infrastructure is in a state of flux and will need some forms of standardisation. However, due to the near complete electrification cover of metropolitan countries, significantly lower operating cost of EVs and the standardised and integrated nature of electricity as a highly versatile form of energy, some novel and decentralised forms of battery recharge and mobility may evolve most likely at regional or local level (Electric Car Company, 2013a; Martinot, 2013b).

Apart from recharging infrastructure issues in metropolitan countries, large BEV fleets will change electricity supply and demand dynamics. There is agreement that only high penetration of BEVs and PHBEVs will have an impact on the low voltage (120V -240 V) electricity distribution system. The main concern would be thermal overload of urban or sub-urban networks but only if large scale recharging happens at peak electricity use times. Hence, there is interest in shifting recharging to off-peak times by 'smart metering' and variable electricity tariffs (Slater \& Dolman, 2009).

Moreover, in industrialised countries, off-peak electricity is more likely provided by sustainable sources of electricity like wind farms etc. Conversely, peaktime recharging will generally involve higher carbon electricity production. Slater and Dolman estimate that by 2030 grid electricity will have reduced its $\mathrm{CO}_{2}$ intensity down to $140 \mathrm{gCO}_{2} / \mathrm{kWh}$. Depending on the management of sustainable and carbon intensive forms of electricity production, BEV carbon intensity could range between $30-80 \mathrm{gCO}_{2} / \mathrm{km}$. By 2030 experts expect the carbon intensity of the conventional car fleet to reduce to $100 \mathrm{gCO}_{2} / \mathrm{km}$, hence reducing the advantage in carbon intensity enjoyed by BEVs. The decarbonisation of electricity generation and better utilisation 
of the electricity supply by more refined electricity demand management would also improve the economics of electricity utilities (Slater \& Dolman, 2009).

Although the intended location for the commercialisation of EVs is industrialised metropolitan countries and engineering and marketing effort has concentrated on these markets, there are developments and evolving technical EV specifications which may well be of relevance to Samoa. Most important are the current technical specifications of EVs with a driving range of approximately $150 \mathrm{~km}$. Although no drive cycle data are available for Samoa, the small size of the islands would enable nearly all travel activities to be undertaken on one daily battery charge. Additionally, low Samoan travel speeds are also well below EV top speed specifications. Lower travel speeds will favourably improve electricity use efficiency of EVs in line with the expected lower vehicle friction loss.

\subsubsection{Some Footprint Comparisons of ICEVs, FCVs, BEVs and PHBEVs}

A number of economic and environmental high profile studies are available for the comparison of BEVs, Fuel cell vehicles (FCVs), PHBEVs and ICEVs (Contestabile, Offer, Slater, \& Jaeger, 2011; Element Energy, 2011; IEA, 2009; IEA ETP, 2013; McKinsey \&Co., 2009; Offer, Howey, Contestabile, Clague, \& Brandon, 2010; Thomas, 2012). The studies have produced massive amounts of information. However, due to the presence of so many variables pointing towards medium and long-term possibilities, research results are difficult to compare. There is agreement, however, that all transport technologies, including conventional ICEVs have the potential to improve fuel use efficiency considerably. Improved ICEV technology will lead to increasing fuel use efficiency and associated $\mathrm{CO}_{2}$ emissions reductions in the short term and maybe even in the mid-term (IEA, 2009; King, 2007; Thomas, 2012). However in the mid-long term, the main effort of decarbonisation of the transport sector will have to be tackled with BEV, PHBEV and fuel cell vehicles (FCVs). In figure 3.2 GHG emissions by alternative transport forms are summarised.

Figure 3.2: Greenhouse gas emissions by various alternative transport forms. 


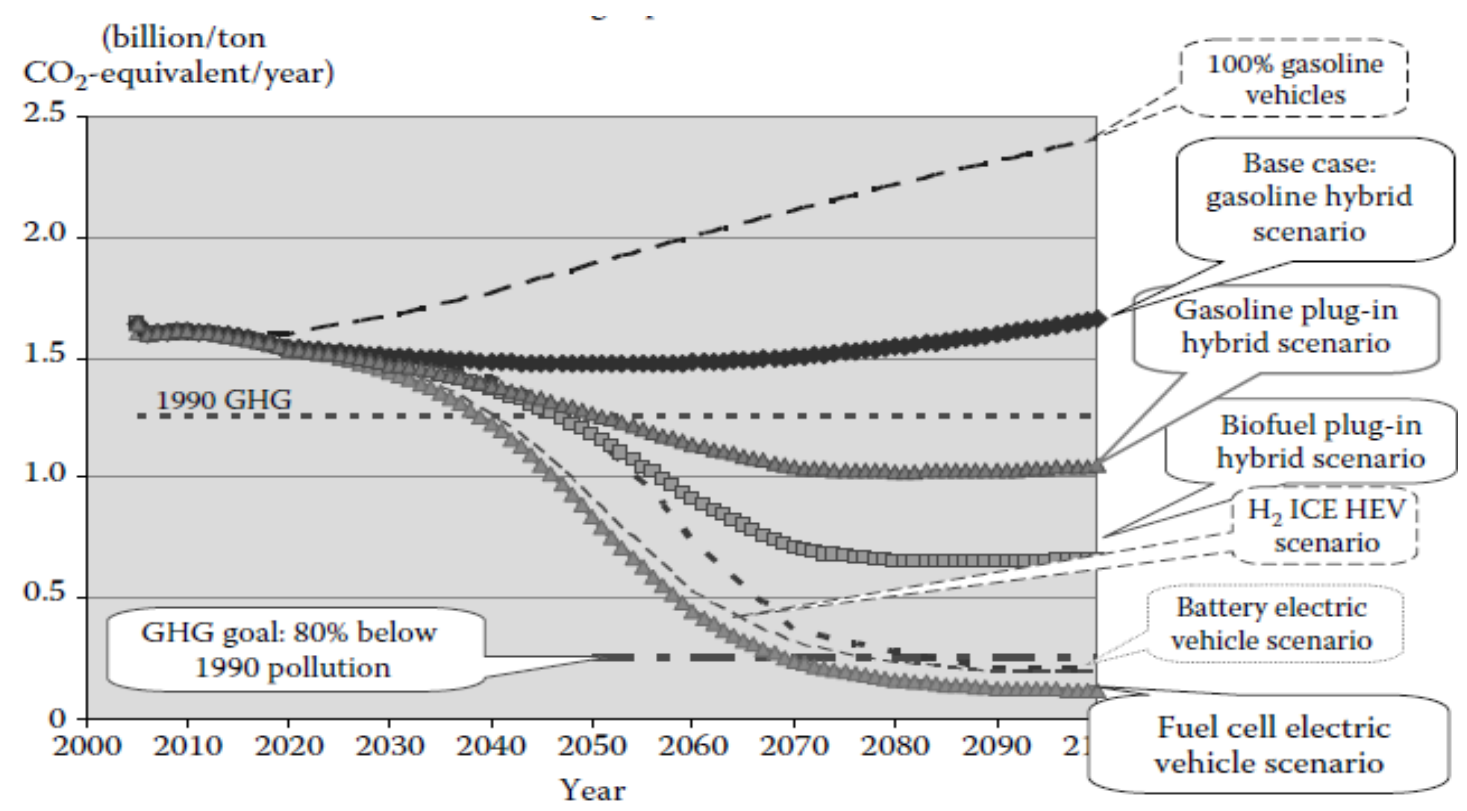

Source: Urban pollution projections over century for reference BAU scenario and various alternative transport fuels in USA. After Thomas, C.E. (2012) Clean Car Options for the Twenty-First Century.

According to Thomas (2012), $\mathrm{CO}_{2}$ emissions reductions sufficient to achieve the IEA's $2 \mathrm{DS}{ }^{12}$ may only be achieved by FCVs, BEVs and ICEs powered by hydrogen, provided the primary energy source utilises renewable forms of energy (Thomas, 2012).

A majority of studies, however not all, conclude that in the mid to long term low to no-carbon transport systems will feature differentiated car segments. Thus, BEVs and FCVs may be used in the small car segments and PHBEVs, powered by sustainable biofuels, will be used for larger car segments. The boundaries of these segments are largely defined by technology innovations in battery research and the sufficient availability of sustainably produced biofuels. Moreover, Contestabile (2011) and others claim that these scenario studies have largely excluded the impact of changing car user behaviour in the future. There may also be some resource constraints in the form of rare earth minerals like neodymium used for permanent magnets in the electric motor production (Speirs et al., 2012).

\footnotetext{
${ }^{12}$ The 2DS scenario conforms largely to Thomas' $80 \%$ below 1990 GHG emission threshold
} 


\subsection{The Role of Renewable Energy in the Pacific Island Countries}

\subsubsection{Political Arrangements in the Region}

Pacific Island Countries (PICS) have not been idle bystanders in the developing climate change crisis. The onset of global warming is arguably already affecting the PICs by higher frequency of storms, heat waves and general climate volatility. Like metropolitan countries, PICs have progressively been affected by energy costs and their regional dependence on petroleum products. Unlike metropolitan countries, however, the PICs have significantly fewer options to deal with rising cost and volatility of petroleum imports.

Regional fossil fuel dependence has exposed several shortcomings in the region's socio-economic institutions. Fuel price inflation and volatility has led to fuel imports occupying a large proportion of public expenditure thus diverting scarce foreign exchange reserves from other essential imports (Jayaraman \& Evan, 2011). Fossil fuel dependency is structural (isolation, economies of scale) and not easily and quickly replaced by alternative energy options (Xiaojiang \& Tapling, 1997); The institutional, technological capacity of the PICs is inadequate to promptly formulate and enact alternative energy policies (Singh, 2012; Xiaojiang \& Tapling, 1997; Zieroth, 2008). Technical and administrative requirements of modern institutions have led to cultural tensions, higher life style aspirations and a lack of expertise in managing complex technology (Jafar, 2000; Krumdieck \& Hamm, 2009; Lefale \& Lloyd, 1993; Lloyd \& Tukana, 1990); Aid delivery has left many PICs open to inappropriate structural adjustment programs of donor countries and institutions (Geoff Bertram, 1999; Wade, 2002). Thus, a picture is painted of a region struggling to adjust to fossil fuel price inflation, perhaps more so than other regions, but with limited options to respond and at the same time the transport sector has become vital for the region's economic and social development.

Regional institutions such as the Pacific Island Forum (PIF), Pacific Energy Ministers Meetings (PEMMs), the regional Secretariat of the Pacific Community (SPC), the South Pacific Regional and Environmental Program (SPREP) have responded to the evolving fuel dependence by developing National Energy Policies 
(NEPs) which on the national level involved drawing up plans to incorporate renewable energy technologies (RETs) (Singh 2012). This collaboration has evolved, with the financial support of the EU and other donor countries, into the 2002/4 Pacific Islands Energy Policy (PIEP) and (at least) eleven national energy policies (NEPs) which include Cook Islands, Federated States of Micronesia (FSM), Fiji, Kiribati, Marshall Islands, Nauru, Niue, Palau, PNG, Samoa ${ }^{13}$, Solomon Islands, Tonga, Tuvalu and Vanuatu (Zieroth 2008).

NEPs have assumed a certain intended, standardised, regional structure. In their respective countries, NEPs envisage relatively large electricity supply grids within urban areas and rural electrification via small-grid and stand-alone installations. Some island nations, as is the case with Samoa, have been able to achieve an electrification level of 98 per cent across Upolu, Savaii and Apolima Island (Government of Samoa, 2011c). The endowment with renewable energy resources across the PICs is highly variable which generally left the bigger and mountainous islands such as Fiji, PNG, Solomon Islands and to a degree Samoa with more options. The smaller islands are mainly limited to solar and wind energy (Singh 2012).

An analysis of NEPs, however, shows that RE policy is, at least at this stage, limited to electricity generation and demand management. There is a lack of emphasis on the use of renewable energy in the transport sector although Samoa's SESP 2012-16 envisages the use of biofuels as a transport fuel with limited application and electro mobility as a possible alternative at some point in the future (Government of Samoa, 2011c).

\subsubsection{Practical Experiences with Biodiesel}

Samoa's research into alternative transport fuels grew out of a range of EU, NGO and academic initiatives concerned with sustainable transport in Small Island Developing States (SIDS). Cloin (2005) reviewed the use of coconut oil and found

\footnotetext{
${ }^{13}$ Samoa's National Energy Policy 2007 but more particularly its implementation strategy, the SESP 20012-16 is discussed in chapter 1.
} 
that coconut oil additions, ethanol-methanol fuel mixes and biodiesel could be used as blends or total substitutes in conventional transport fuels (Cloin, 2005, 2007). The Scientific Research Organisation of Samoa (SROS) has been operating a biodiesel pilot trial since 2009 under its PIGGAREP program where a 10 per cent biodiesel mix made from coconuts has been trialled under commercial conditions. Technical results so far are positive both for car use and use in diesel generators at the Electricity Production Corporation (EPC). According to Fiame (2013) the biodiesel mix for use in cars could be increased considerably without marked loss of performance and deterioration of engines. In other studies direct blending of coconut oil with diesel has been found to be mechanically sound only up to 20 per cent of coconut oil content, although the experience of SROS with their biodiesel trial appears to contradict this. Biodiesel use may or may not require some engine modifications but would require an increased regional production of methanol, a feedstock of biodiesel production process (Cloin, 2005)

The main issues, however, are high production cost/price relative to current petroleum prices (Biodiesel WST \$3.4/l; Petrol WST \$2.98/I) and supply volatility of coconut stock. SROS is currently trialling a potentially cheaper production process (Fiame Leo 2013, pers. com). There are, however, financial, agronomic and technical problems to overcome and include major replanting of defunct plantations and significant investments into the mechanisation of copra processing as well as potential competition as a food source and high value export (Cloin, 2005).

Finally, according to Cloin (2007) the potential to use coconut oil as a transport fuel is limited to only around 30 per cent transport fuel demand in the Pacific region. This issue is supported by Dr.Fiame Leo in the Samoan context as he points to the dilapidated state of coconut plantations and the ongoing and presumably increasing risk of regular cyclone damage to plantations, either coconut or the more experimental Jatropha (Fiame Leo 2013, pers. com). 


\subsection{Small Island Nations' Experience with Electric Mobility}

Several island nations are currently hosting BEV pilot trials or have seen the recent introduction of BEVs. A common motivation shared between the islands is the desire to reduce high transport cost which in particular affects island states.

Secondary considerations are compliance with air pollution regulations and $\mathrm{CO}_{2}$ emissions reductions. The island state of Hawaii has seen a combination of BEV car user interest, government incentives and research grants promoting BEVs. Hawaiian BEV/ICEV fuel cost comparisons put an Nissan LEAF at an fuel operating cost of US $\$ 0.074 / \mathrm{km}$ and a comparable conventional Subaru Outback at US $\$ 0.11 / \mathrm{km}$.

Electricity charges are US $\$ 0.39 / \mathrm{kWh}$ and the comparable petrol price is US $\$ 1.25 / \mathrm{l}$ (Campbell, 2013). In Hawaii, a Nissan LEAF qualifies for a US $\$ 7,500$ tax credit. According to Campbell the retail prices of the cars are comparable (Nissan LEAF US\$24,320; Subaru Outback US 25,795) after BEV incentives are included. Recharging infrastructure development is evolving with car manufacturer support and retail businesses offering free recharging points near their businesses (Larson, 2012). According to the Hawaiian state energy report in June 2013, 15, 258 hybrid vehicles were registered. BEV registrations had experienced a 83 per cent increase to 1,551 units which brought the total of BEV/PHBEVs to 1.4 per cent of total car registrations (Sakamoto, 2012). Thus, a combination of incentives and the documented transport fuel savings have allowed BEVs to enter the transport fleet. On the bigger islands the travel distance and recharge opportunities keep on limiting faster expansion but it appears that private sector interests may fill this gap.

On the smaller island of Guam with a comparable population to Samoa, legislation is currently being introduced along the lines of the Hawaiian model. The legislation promotes a cash rebate of US $\$ 7,500$ for the purchase of a BEV. Battery recharge cost is pegged at US\$2.50 and amounts to an approximate transport cost saving of 48 per cent compared to the 2013 US $\$$ cost of $4.73 /$ gallon. 
A detailed case study of BEV performance under everyday road conditions was conducted in Malta in 2011. Compact sedans were tested under drive cycle ${ }^{14}$ conditions and showed that BEV use is economically viable for use on small islands and cities worldwide even with outdated lead acid battery technology. The main advantages were short daily travel distances and low travel speeds. Government incentives during the early stages of the pilot project have contributed to the success of the pilot project (Merz \& Abertax, 2011).

Camus (2012) took another approach in a study of an isolated island community in the Azores and balanced the off-grid, renewable electricity generation upgrade with the introduction of battery driven electric vehicles (BEVs). The energy balancing process involved matching the night excess of electricity generation of the geothermal power plant with the battery recharging requirements of an optimal number of electric vehicles (Camus \& Tiago, 2012). Other studies on the use of distributed energy and related grid-balancing requirements indicate that up to 20 per cent of distributed energy from wind or PV sources do not pose a problem for voltage management (Leia, 2013).

Thus, practical experiences have been gained by a number of pilot studies on small islands and a case can be made that under local conditions electro-mobility is economically and environmentally viable. In particular, small travel range, usually the low speeds required by the driving environment and high fuel prices set small island settings apart from more complex and demanding driving conditions in metropolitan countries.

\subsection{The Retrofit BEV Movement/Industry}

In recent years a BEV conversion movement has gained support mainly in metropolitan countries. The movement draws support from people who are attracted by the cheaper operating cost of BEVs and have an environmental awareness of the negative effects of car emissions. Other motivations are limited choice and high cost

\footnotetext{
${ }^{14}$ Drive cycle tests record fuel consumption and emissions on a distance or time dependent basis. Standards vary from country to country. Of importance is the EUDC (1990), EPA Federal Test and the Japanese JC08.
} 
of early BEV models and a lack of a second market for BEVs. The 'Retrofit Community' has a large presence on the internet where conversion parts, whole conversion kits and conversion manuals are available and advice is exchanged (DIY Electric Cars, 2013; Electric Car Company, 2013a; Shoebridge, 2009).

While historically an activist 'backyard garage' conversion movement, the do-it yourself movement has spread around the world and has spawned a commercial BEV conversion industry which is recognised by some state and national governments. Lately several US states ${ }^{15}$ have incentivised petrol/diesel-BEV conversions. In New Zealand and Australia legal BEV conversions attract a car registration rebate.

Probably due to the novelty and the amorphous character of this 'grass-roots movement', no scholarly study is yet available. Yet within the context of future and affordable transport needs of small and developing island nations, domestic BEV conversions of second hand cars are worth further investigation. Within the scope of this thesis, only some background information is provided.

In order to provide an alternative to commercially available BEVs, retrofit conversions need to be significantly cheaper and be within local, technical capacity to undertake car conversions. In the following, a cost sample is provided for a prospective conversion project in Samoa using Samoan drive cycle data. Cost estimates include conversion material, excluding labour cost of approximately US \$ 6,500- US $\$ 7,000$ (Electric Car Company, 2013b; Shoebridge, 2009). The value of the conversion car is assumed to be up to US $\$ 1500$. Battery cost is determined by the expected driving range and battery technology employed. For the purpose of this cost estimate a driving range of $60 \mathrm{~km}^{16}$ and lithium-ion batteries are assumed. At an electricity use of $0.18 \mathrm{kWh} / \mathrm{km}$, a battery pack with the capacity of $12 \mathrm{kWh}$ is required at a conservative cost estimate of US\$ $7200^{17}$. Hence, at a conversion cost of US $\$$ of 16,000 (excluding labour) this price compares favourably with the US\$32,000-

\footnotetext{
${ }^{15}$ Montana, Utah, Illinois, Georgia, Colorado incentivise conversions with income tax credits and rebates on conversion material.

${ }^{16}$ Preliminary drive cycle data from Samoa and other electro mobility island studies suggest that more than 85 per cent of daily travel requires return trips of less than $50 \mathrm{~km}$.

${ }^{17}$ Lithium battery price is current with further price declines likely
} 
US $\$ 40,000$ of new, mid-sized BEV models (Thoma, 2013). However, compared to cheap Samoan second hand imports the conversion price is at a significant premium.

According to information provided by the 'Retrofit community', only a low level of mechanical skills is required. However, within the context of available Samoan technical capacity, it is assumed that some training would be required to enable BEV conversions at the village community level.

Within the context of the IEA projections of a worldwide growth of 20 million BEVs by 2020, is there a place for 'retrofit' conversions? Apart from the price range of US $\$ 32,000$-US $\$ 40,000$ for a new BEV and slightly cheaper PHBEV, it is unlikely that a second hand BEV/PHBEV market will be established in the PICs within the next 10 years as the new BEV/PHBEV fleet is aging in metropolitan countries and progressively fill the second hand car market there.

BEV operating cost savings will most likely increase as fuel inflation affects the ICEV fleet relatively more and some highly likely internalisation of externality cost like a carbon tax will also increase fuel cost.

Photograph 3.1: Illustration of conversion process of a mid-sized sedan with a picture taken before a conversion and after.

Before: Mid-sized ICEV engine compartment

After: Converted BBEV
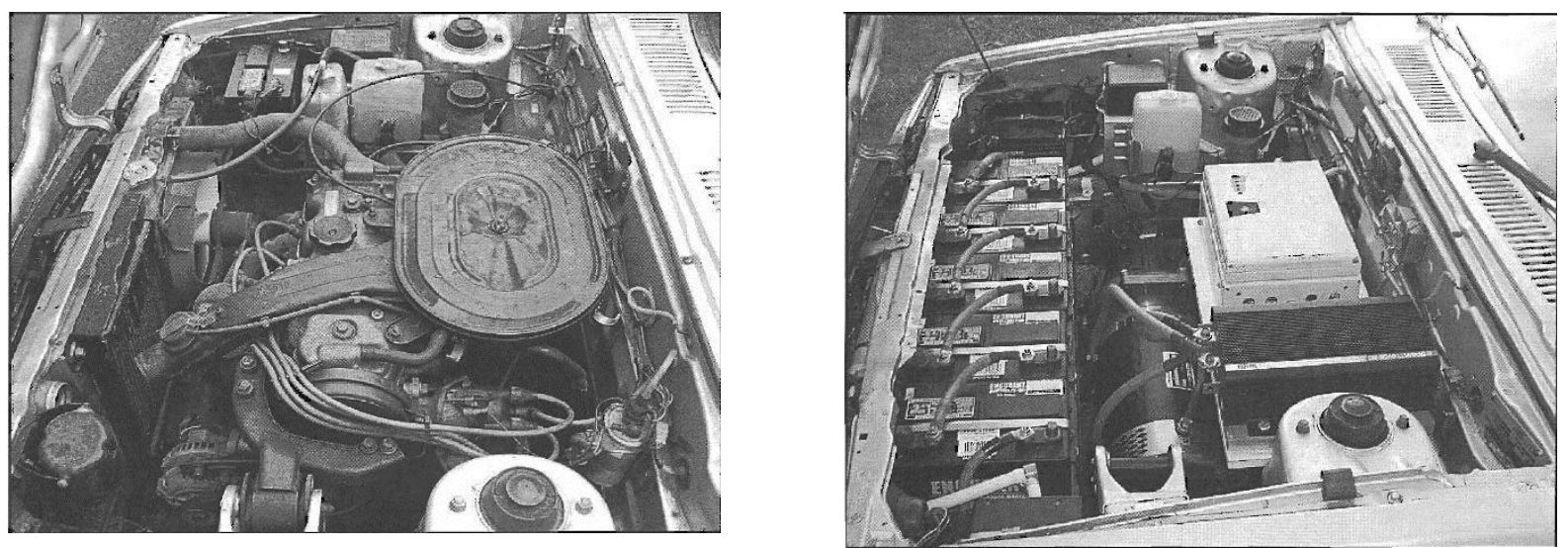
High level reviews on the causes of adverse climate change effects have convinced global transport stakeholders to reduce $\mathrm{CO}_{2}$ emissions from the transport sector. The depth of concern can be gauged by the substantial interdisciplinary research effort which is currently expended to identify alternative transport technology based on electro-mobility, fuel cells and technology hybrids on the grounds of their $\mathrm{CO}_{2}$ emissions profile. This certainty of some form of technology standardisation based on electric cars gives all technology user countries, including Samoa, some confidence that their policy efforts and investments in alternative transport infrastructure using these technology platforms will remain cost-effective.

PICs are already suffering adverse environmental effects from climate change and in the case of Samoa there is clear policy support to contribute to GHG emissions reductions. I discussed relevant legislation and strategies in chapter Two, which anticipates fossil fuel substitution by different alternative energy forms and highlighted provisions in several acts and strategies which anticipated the eventual introduction of electro-mobility. Thus, the international research effort into alternative transport and the EVI will give Samoan institutions involved in GHG emissions mitigation and alternative transport options confidence and access to otherwise unaffordable expertise.

We can also draw on experiences with electro-mobility from other small islands states. The experience in Hawaii, Guam and Malta points to successful introduction of BEVs and PHBEVs backed by Governments support schemes and the private sector. However, ultimately the unique driving conditions on small islands such as short travel distances and generally low travel speeds hand electro-mobility an eminent advantage over conventional transport.

Perhaps the most unexpected discovery of my technical literature review was the existence of an electric car retrofit movement which draws support from people with an environmental awareness and are attracted to cheaper operating cost of BEVS. Retrofitted BEVs are significantly cheaper than new BEVs but still markedly 
more expensive than cheap Samoan second hand cars and may be a pragmatic option provided some conditions can be met as outlined below.

Thus, a possible electro-mobility technology path leading towards a more sustainable transport sector has been identified which also meets the aspirations of current legislation. However, findings from chapter Two suggest that in Samoa only a small proportion of the travelling public would be able to afford the US\$32,000 -US\$ 40,000 investment to own a BEV. Given, BEV pricing will decline with increasing commercialisation but I would argue that prices would need to decline significantly and fast to allow widespread adoption leading to the desired policy outcome.

Moreover, car use has assumed status functions apart from its utilitarian uses. In order to be able to explore the suitability of electro-mobility which may well limit car size and in the case of retrofits involve ordinary mid-sized sedans, we need to identify other embedded functions and values of the car. Such a deconstruction would require an ontological and epistemological tool box, other than the ones used in the current modernist development project, to make all transport possibilities visible and potentially useful. Contemporary postdevelopment theory can offer such an analytical approach. In the following chapter I will explore the suitability of postdevelopment thinking for the exploration of transport possibilities. 


\section{Chapter Four: Postdevelopment}

The purpose of this chapter is the introduction of contemporary postdevelopment theory as the prism through which transport possibilities in Samoa are viewed. Contemporary postdevelopment theory is presented with the intention of drawing on its epistemology and using some of its methodology in field work. Accordingly, several projects with postdevelopment thinking in the field are reviewed, notably McKinnon's study on new theories of hegemony showing the development professional to take an activist position within the complex power play of government agencies (McKinnon, 2008). Gibson-Graham's path breaking study is introduced and the use of a discourse analysis to make visible a complex wealth of real and existing community assets not visible with the tools of the contemporary development discourse is highlighted (Gibson-Graham, 2005). In order to answer recurring criticism about postdevelopment theory's perceived illiteracy with regards to the use of technology, I introduce Bunker Roy's Barefoot College in India which uses a postdevelopment approach to train illiterate rural people in the production and maintenance of hand pumps and off-grid solar lighting and cooking technology (Roy, 2008).

An overview of the historic context of postdevelopment theory which caused such a stir in the 1990s is reviewed. The review suggested that a lot of the anxiety of its critics resulted not so much from some justified technical criticism about shortcomings of development projects or some defects here and there in postdevelopment thinking. The real reason was its extraparadigmatic position rejecting the modernist development project in its entirety.

Some of the most heated arguments, particularly those around environmental degradation and the questioning of the validity of the Eurocentric economic paradigm have since been answered to a large extent by authoritative studies of economic impacts on climate change (Nicholas Stern, 2007). Doubts about the stability of the orthodox economic paradigm have also increased since the advent of the Global Economic Crisis (Keen, 2011). And old contentions about the validity of the 
economic growth doctrine raised by Meadows et al in the 1970s have now been confirmed (Turner, 2008).

One of the real strengths of postdevelopment theory is its emancipatory character. Grass roots communities are encouraged to wisely create their version of modernity and also assume responsibility for that. Some of these traits have been emulated as participative development by the development profession with variable success as and are further discussed in chapter Four. Demand for the creation of own modernities and the hegemonic character of the modernist development project has been widely theorised on and for quite some time (Eisenstadt, 2000; Huang, 2009; Huntington, 1996; Polanyi, 1944; Tu, 2000).

Rather I argue that technology should be used if it can assist in the imagining of local expressions of modernity. A precondition to this endeavour is the ability of grass roots communities to sight the embedded content of somebody else's modernity and to separate it out if it does not assist in the creation of one's own. All the while there needs to be an awareness of the downstream environmental consequences, the externality cost of technology connecting the local to the global. The difference of approach between orthodox development and postdevelopment thinking in the case of electro-mobility is the attempt to deconstruct EV technology into its components and then reassemble it in a way which meets global environmental requirements as well as the financial capacity of local communities.

\subsection{Background on Postdevelopment Theory}

When postdevelopment theory burst on the scene in the 1990s, it did so with all the hallmarks of an activist movement rejecting the Eurocentric development discourse en toto. Wolfgang Sachs echoed this sentiment famously:

The idea of development stands like a ruin in the intellectual landscape. Delusion and disappointment, failures and crime have been the steady companions of development and they tell a common story: it did not work. Moreover, the historical conditions which catapulted the idea into prominence 
have vanished: development has become outdated (Wolfgang Sachs, $1993 p$ 3).

The theory's categorical 'no' to orthodox development discourse challenged development institutions which particularly since WWII had evolved via institutional reform waves and became a vital component of the developed North's industrial policy.

With the benefit of hindsight it is quite obvious that the coalescing of environmental problems growing from the regional to the global, worldwide expansion of the neoliberal agenda and debt crises, frequent failures of conventional development interventions and the foundering of the communist metanarrative in the 1980s provided sufficient ground for a critique of the contemporary socio-economic paradigm (Agostino Ascione, 2003; British Petroleum, 2012; Corbridge, 1990; Nugroho \& Lonsdale, 2010; Wolfgang Sachs, 2010; David Simon, 2003; Toye, 1987).

In the light of these recurring crises and developments, postdevelopment authors like Sachs $(1992,1999)$ documented global and environmental degradation, Nandy (1988) rejected the imposition of science as power, Constantino (1985) pointed to negative effects of cultural Westernisation and homogenisation. Rist (1997) saw economic development as the 'new religion of the West' and Kothari (1988) believed that development, particularly after the 'lost decade' of the 1980s, simply does not work. These authors are joined by Escobar (1995), Rahnema \& Bawtree (1997) and Esteva (1999) who came to the conclusion that the reductionist and dominant economic view of human existence and the resulting development paradigm itself is at fault and in need of replacement (Constantino, 1985; A. Escobar, 2012 [1995]; Esteva, 1999; Kothari, 1988; Nandy, 1988; Rahnema \& Bawtree, 2010; Rist, 1997).

Discourse analysis was used to show development as a deeply Eurocentric project, replete with its many unequal power relationships and its Enlightenment genealogy. A deconstruction of the languages of development showed implicitly value charged encounters of the development industry with its subjects (McKinnon, 
2008). As a result, postdevelopment authors removed themselves from the ongoing development debates concerned about market-based, state-based or communitybased interventions (McGregor, 2009; Potter, 2004). Their view of development 'normality' was of a discourse with political and economic motivations, even a materials-based religion of modernity (Brigg, 2002; Rist, 1997).

In the 1970s UN agencies themselves recognised UN policy failures which resulted in the declaration of the New International Economic Order (NIEO) ${ }^{18}$ aimed at reducing poverty and North-South wealth inequality. The reform efforts cumulated in the 'Lost Decade' of the 1980s. Statistical evidence confirmed that living conditions in several world regions, notably Latin America and Africa, were worsening (Agostino Ascione, 2003; D. Simon, 1999). Worse still, the Asian financial crisis of the 1990s showed up the failure of the latest neoliberal reform initiatives (particularly Structural Adjustment Programs) in Africa and Latin America (Wade, 2002). Postdevelopment theorists and critics from disciplines like post-structuralism, critical theory and ecological movements concluded then that currently practiced reform interventions did not work (Pieterse, 2000; Wolfgang Sachs, 2010; Shiva, 1988).

For authors like Sachs, Escobar, Esteva, Rahnema and Bawtree, Rist, Nandy and de Sousa Santos an assessment of development ambitions led to the simple conclusion that, apart from issues of location and equity, material wealth enjoyed by Western society is impossible to attain for the majority of the world's population, hence the need for a new paradigm. First, there is a strong demand that Western development essentialism should not be deployed to other regions as the organising principle of social life, particularly as an ideology with its intrinsic economic and political intentions. Second, development's synonymy with neoclassic political economy, its being an integral part of Western culture and discursive dominance make it impossible to reform. Boaventura de Sousa Santos (2004) eloquently visualises Eurocentric culture to only think and act in 'monocultures of knowledge, linear time, classification, universal and global and capitalist productivity' thus

\footnotetext{
${ }^{18}$ NIEO development policy was aimed at making technology accessible to all UN member countries to enable a catch-up in wealth and included self-sustaining economic development and participatory decision making between member countries.
} 
'absenting' any other form of knowledge and culture. Instead, alternative discourses of development are needed (de Sousa Santos, 2004).

Third, echoing post-structural thinking and Foucaultian discourse analysis of unequal power and knowledge relationships, a transformation of the 'political economy of truth' is required and development institution's expert knowledge needs to be enlarged to include social movements' 'knowledge and practices about alternatives' (A. Escobar, 2012 [1995]). Fourth, echoing Escobar and in particular Sachs, the neoclassical, consumer-led market economy is posing a serious global threat to the environment with economic institutions unable or unwilling to reform themselves.

\subsection{Critiques of Postdevelopment}

Critique and commentary to these fundamental objections to the development paradigm were early and robust (McGregor, 2009; Pieterse, 2000; David Simon, 2003; D. Simon, 2007; Ziai, 2004). The main point of controversy can be summarised as follows: development is presented as a monolithic construct and homogenising thrust towards modernisation ignoring its complexities, adaptabilities and its contradictions. The underdeveloped/developed binaries are valid points of discovery, discourse analysis can nevertheless lead to oversimplification and, moreover, has overlooked sectors of Third World societies' (not only elites) desire to develop. Lack of practical remedies to the development dilemma in the field restricts the critique to an academic discourse with limited effect. The ability and effectiveness of grassroots movements to solve its problems is romanticised and finally, some measurable progress in poverty alleviation has been made.

In particular, Pieterse argued that both Shiva (1988) and Sachs (2010) prefer an 'ivory tower' position by restricting their involvement to discourse analysis. Shiva problematises cultural poverty vis-à-vis real material poverty and Sachs distinguishes between subsistence economies' frugality and consumer led market economies of which both conclusions may only contribute to academic discourse. Pieterse goes on to argue that alternative development approaches à la Paulo 
Freire's 'conscientisation', human-scale development à la Max-Neef (1982) and Chambers (1983) participatory action research place great importance on agency of poor actors in development interventions (Chambers, 1983; Max-Neef, 1982).

Escobar (2012[1995]) and Yapa (2002) see some validity in these arguments but also maintain that the identification of development problems and the visualisation of solutions requires textual deconstruction in order to arrive at potential solutions (Yapa, 2002). In answer to Pieterse's claims of lack of practical solutions in the field, McGregor finds that postdevelopment practitioners are engaged in in-depth field work (McGregor, 2009). I will follow up several field projects later on.

Since the beginning of the 2000s the robust development epistemology debate has given way to more constructive dialogue and led to the mainstreaming of some, once radical alternatives (David Simon, 2003). Both sides to the argument have accepted that the development-postdevelopment binary was presented as a monolithic construct while ignoring the more subtle, progressive, retrograde and contradictory dynamics in the field. Most notably is the well documented self-interest of the development industry, often expensive and large scale 'white elephant' projects, 'misguided philanthropic and welfarist motives', the patronising of indigenous societies' intentions from the outside but also some romanticising and stereotyping of postdevelopment projects (A. Escobar, 2012 [1995]; Roder \& Parker, 2010).

Accordingly, Simon (2007) envisages an evolutionary and pragmatic continuation of development interventions while incorporating the perceived desires and necessities of the recipient communities into the project. This approach resembles contemporary, participatory development industry policy deliberations. Nevertheless, deficiencies of the stereotypical modernisation framework are recognised and could include a definition of sustainability and indeed a reformulation of the economic paradigm.

Escobar (2012[1995]) on the other hand, acknowledges development institutions' renewed interest in the reinterpretation of the Eurocentric and 
neoclassical political economy, its newly appreciated socio-cultural dimension and a potential reappraisal of modernity itself. However, he places importance in the critical examination of development via what he calls a 'new ethnography' to de-essentialise development (A. Escobar, 2012 [1995]; Mosse, 2008). Too great are his suspicions of normative economic essentialism remaining undetected during development interventions. With this qualification in place and some confidence in the critical reporting of development activities in the field, Escobar is confident to witness a transformation. Thus, channels of communication have been reopened with the acknowledgement of epistemological overlaps in development disciplines like alternative development but significant differences and suspicions remain (Rapley, 2006).

\subsection{Postdevelopment in the early 2000s}

The lingering GFC, more acute effects of climate change and the global drawdown of environmental services are providing a reminder of the predictions, commentary and conclusions by postdevelopment theorists that the neoclassical economic orthodoxy has failed in the economic sphere and is affecting the viability of global ecosystems (A. Escobar, 2012 [1995] p 199; Wolfgang Sachs, 2010 p 34).

On a governmental level, the Commission on Growth and Development and the United Kingdom Sustainable Development Commission acknowledged in their respective 2008 'Growth Report' and 2009 'Prosperity without Growth' publications what postdevelopment theorists and others had concluded in the 1990s, namely that the extension of the neoclassical economic orthodoxy across the globe would affect the global environment too much and markedly reduce economic growth gains achieved over the last 200 years (Growth Commission, 2008; Jackson, 2009).

The Commissions' conclusions have been built on the theoretical basis of Georgescu-Roegen (1971) and others' economic throughput model which describes economic activity within the constraints of the global environment's ability to provide resources and absorb pollution (Daly \& Farley, 2011). The laws of thermodynamics and in particular the law of preservation of mass, energy and entropy are able to 
show that environmental sink services cannot be re-integrated into the neo-classic economic circular flow model due to the relatively higher entropy of waste products. Most importantly, energy is not retrievable economically. If it were we would indeed be able to operate our economy like the 'fabled perpetual motion machine' (Daly \& Farley, 2011; Georgescu-Roegen, 1971). In reality, the energy deficit is made up from energy inputs from outside the circular flow model. In particular, GeorgescuRoegen (1971) outlines that if global energy requirements exceed the constant solar energy inflow, excess energy requirements have to be taken from the natural capital fund like coal, oil and gas. Equally, if high entropy waste flows exceed the regenerative capacity of global ecosystems then this process leads again to a degradation of natural capital.

The environmental implications of the draw-down of natural capital are corroborated by the World Wildlife Fund which found that the Earth's ecosystems, over the 30 years predating 1997, had declined by around 33 per cent whereas the World's ecological footprint had increased around 50 per cent over the same time period exceeding the biosphere's regeneration rate (World Wildlife Fund, 2000). Thus, ecosystem degradation represents the drawing down of natural capital which reduces environmental services in the present but also precludes some natural capital use options for future generations.

Similar conclusions are drawn by Turner who was able to confirm Meadows et al (1972) 'Limits to Growth' conclusions by substituting Meadow's modelled data sets with credible field data collected by UN agencies for the modelled time period by Meadows (Meadows, Meadows, Randers, \& Behrens_III, 1972). Turner found, in line with Meadow's conclusions, that the current economic growth trajectory cannot be maintained beyond the mid- $21^{\text {st }}$ century as resource constraints become too great and the global pollution absorption capacity dwindles (Turner, 2008).

Similarly, climate change science has made tremendous advances and confirmed its anthropogenic causes. The Stern Report (2007) is considered an authoritative treatise of the economics of climate change and concluded that climate change is the 'greatest and widest ranging market failure the world has ever seen' (N. Stern, 2007). Stern's findings were later supported by the IPPC's 2007 and 2013 
assessment reports (AR4\&5) which also found that climate change was progressing faster than expected (IPCC, 2007, 2013). In another indication of the ongoing adverse financial effects caused by climate change, the global insurance and reinsurance industry reports incidences of 'unprecedented climate events' and is recording a gradual increase in climate related insurance pay-outs (Jackson 2009).

In conclusion, the post-World War II period which has provided such a focus to postdevelopment theorists in the 1990s has continued to provide evidence of the pervasive manifestations of Westerncentric modernity. In the intervening years the paradigm has truly gone global and pervaded the international political economy and the global environment (Daly \& Farley, 2011; Wade, 2009a). The activist position of postdevelopment was subjected to critical commentary by the development academe which benefited the entire discipline's epistemological approach as well as the evolution of a participatory culture in the field being cognisant of the local both with respect to culture, location and increasingly local and global environment (Potsdam Institute for Climate Change Impact Research and Climate Analysis, 2012; Roder \& Parker, 2010; Wolfgang Sachs, 2010; Sanderson, 2004; David Simon, 2003; World Wildlife Fund, 2000). However, in the light of the unresolved and interrelated global crises, the fundamental question still remains if the current paradigm is able to be reformed sufficiently to avoid irreparable damage to global environments. Nevertheless, the crises have already added to the urgencies of financially overstretched development and government institutions. This vacuum may well need to be filled by locally organised forms of community action.

\subsection{Postdevelopment in the Field}

During the early 2000s a new generation of development practitioners took postdevelopment into the field ready to build on its Foucaultian theoretical base and experiment with different meanings of development. The objective was not to give up on development and find ways back to a romanticised life before 'development'. Instead, research was informed by designs beyond modernity and coexistence with other forms of modernity. Moreover, environmental and economic crises had been 
eroding the credibility of the Eurocentric modernity paradigm for a considerable time now. Escobar puts this view of the world thus:

Modernity can no longer be treated as the Great Singularity, the giant attractor towards which all tendencies ineluctably gravitate, the path to be trodden by all trajectories leading to an inevitable steady state. Rather, "modernity and its exteriorities"... should be treated as a true multiplicity, where trajectories are multiple and can lead to multiple states (Arturo Escobar, 2004).

This view is also shared by other development practitioners like Matthews who points to African experiences of postdevelopment modernity and Indian imaginations of local modernities (Matthews, 2004). In her field work in Thailand, McKinnon (2008) showed that postdevelopment's reliance on Foucaultian concepts of power and governmentality was proving of limited use in the field (McKinnon, 2008; Rose, 1999). McKinnon used her ethnographic study of hill tribes in North Thailand to show that indeed governmentality can explain the development process of state power relations at peripheral locations and cultures. In order to describe, however, advocacy roles of stakeholders, both local and from the outside, she draws on Laclau and Mouffe's (1985) theories on 'malleable hegemonic formation' in recognition of any subject's influence on contestable meanings of hegemony. In her study she was then able to view development agents (GTZ development professionals and Thai bureaucrats) not only as conduits of Western development norms and governmental hegemonic intentions but also as advocacy professionals with altruistic values, concepts of empowerment and universalistic, human rights based approaches. There is now a theoretical framework to see how development professionals and their objects may modify the meaning and action of development (Laclau \& Mouffe, 1985; McKinnon, 2008).

The collaboration of a local community with outsiders under a postdevelopment framework is further explored by Gibson-Graham's path breaking study of community economies in the Philippines (Gibson-Graham, 2005). A valuable contribution to the postdevelopment debate was the use of discourse 
analysis to enable the Jagna ${ }^{19}$ community to see that apart from a lack of assets (its identification usually encouraged by conventional development discourse), a wealth of real and existing assets could also be found as part of local infrastructure, local institutions and amongst its people. Similarly, by not limiting the investigation to the framework of capitalist production, a complex economy surfaces with different forms of labour compensation ${ }^{20}$, forms of markets ${ }^{21}$ and use of capital and leads to a richer socio-economic network not unlike that postulated by de Sousa Santos' 'sociology of emergences' (Roller \& Waveman, 2001). Moreover, community imagination of its future revealed a rich 'meshwork' of traditional forms of economic transactions of which reductionist capitalist forms were only a small part (Gibson-Graham, 2005).

A characteristic of Jagna's Community Partnering Project is the building of its community economy on traditional and modern, economic 'meshworks' and making use of international experiences in community development like the Mondragon Cooperative Corporation in Spain. In a further evolution of concepts of community development within postdevelopment thinking some remittances from overseas contract workers (OCWs) are invested in community development projects capable of generating surpluses to be reinvested in further job creation instead of the more conventional subsidies for extended family consumption and private savings.

The Barefoot College, founded by Sanjit Bunker Roy in Rajasthan, India, in 1974 provides another example of a grassroots institution using a postdevelopment approach to improve rural livelihoods by building on traditional knowledge of village communities and utilising villagers' desires for greater self-reliance to integrate appropriate technology in the continuing learning process. The Barefoot College's philosophy is based on Gandhian principles such as equality throughout the colleges, austerity in the form of a living wage based basic needs for the entire staff and collective decision-making. In a major departure from the dominant educational dogma of measuring educational success by literacy and academic paper

\footnotetext{
19 Jagna is a regional municipality on the island of Bohol, Philippines

${ }^{20}$ Includes self-employment, cooperative, indentured, reciprocal labour, in kind, work for welfare (Gibson-Graham 2005)

${ }^{21}$ Includes sale of public goods, ethical 'fair-trade markets, local training systems, alternative currencies, underground markets, co-op exchanges, barter, informal market, alternative credit and non-market exchanges like household flows, gift giving, indigenous exchange, state allocations, gleaning, theft and poaching (Gibson-Graham 2005).
} 
qualifications, the Barefoot College's firm belief is in the promotion and further development of local knowledge, creativity, practical wisdom and survival skills of the rural poor (Roy, 2008). These principles have evolved into a range of training programs for illiterate rural people, particularly older rural women, in the production and maintenance of hand pumps and 'off-grid' solar lighting and cooking systems as part of the college's training and night class program.

The Barefoot College approach to rural development involves the hands-on training of mainly illiterate trainees from villages in India and increasingly also from Africa, South America and Asia. With respect to the college's rural electrification program, the process involves the selection of trainee "Barefoot Solar Engineers" (BSE) by the village to be electrified. A training contract involves a firm financial undertaking by the village to support a six month training period of 'their' trainee, solar electrification hardware and ongoing repair and maintenance. Monthly contributions are paid in a trust account for the continuing village electrification and maintenance. The direct link between the Barefoot College's hands-on training, the supply of hardware and the returning BSE for the water supply/electrification project ensure the project is entirely managed on a village grassroots level without the assistance of outside aid agencies and governments. The training of illiterate and semiliterate villagers as successful 'barefoot' village teachers, engineers, architects, hand pump mechanics and accountants has repeatedly demonstrated that urban or overseas 'experts' are rarely required to achieve a more desirable self-sufficiency and sustainability at the village level.

Moreover, the enduring success in the use of solar voltaics in remote village electrification has also demonstrated that the selective use of advanced technology may be used within a traditional, local and regional cultural context. Rural village development can be de-linked from formal literacy requirements and Eurocentric dogma as the mainly illiterate rural BSEs go about their self-funded and selfdetermined village electrification (Roy, 2008).

The barefoot rural development approach has since spread throughout developing regions in Africa, Latin America and Asia. Up to 2008, trained BSEs have 
electrified approximately 550 schools, 13,000 households in more than 600 villages around the globe with a total installed capacity of 646 kilowatts. This capacity is not large in absolute terms. However, what it demonstrates is that the electrification needs of rural households in developing countries are significantly lower than perceived minimum Western electricity demand. Electricity demand in rural households may well increase over time but this growth will be achieved within the sustainability perspectives of austerity, equality and self-determined local learning and problem solving.

The barefoot approach, in line with postdevelopment thinking, draws a connection from the local to the global by including sustainability principles in rural development projects. Since 1989 up to 2008, rural electrification in India alone has reduced carbon emissions by 122,400 tons, mainly by substituting kerosene lamps with solar voltaics (Roy, 2008).

None of these practices in themselves can be considered historically unique or radical in terms of local ethnography and social or economic organisation. To be sure, some innovative approaches like comprehensive asset mapping have found their way into contemporary development practice under terms like 'Appreciative Inquiry' and 'Social Capital Assessment' and thus have built on Paulo Freire's 'conscientisation', Max-Neef's human-scale development and Chambers' participatory action research (Chambers, 1994; Max-Neef, 1982; Mikkelsen, 2005).

Put together under the umbrella of sovereign community imagination and implementation, however, a picture emerges of communities around the world 'daring' to create and experiment with own forms of governance inside and outside of the framework of Eurocentric modernity and in doing so assuming considerable risks /hopes in putting these various projects into practice.

\subsection{Conclusion}

Postdevelopment theory in 2014 has evolved considerably from its radical 'no' to development position in the 1990s. The changes, however, have mainly occurred in the field (McGregor, 2009). Various economic and environmental crises, 
anticipated during the 1990s and in particular the Stern review on the economics of climate change, have also gained postdevelopment theory some credibility (Potsdam Institute for Climate Change Impact Research and Climate Analysis, 2012; Nicholas Stern, 2007; Turner, 2008; World Economic Forum, 2013).

Contemporary postdevelopment critique can be summed up as 1) a demand to cease Western cultural and economic hegemony and to accept different interpretations of modernity; 2) a stop to the domination of Westerncentric expert knowledge and accept alternative knowledge and practices from regional social movements; 3) a recognition of the global nature of environmental threats, its predominant origin in Western type development and work towards sustainable work practice and a reformulation of the economic paradigm.

Grassroots movements with explicit or implicit postdevelopment principles have been described by McKinnon, Gibson-Graham and Roy as communities which try to utilise aspects of their traditional belief systems to develop their own modernity as they 'need to come to terms' with globalisation around them. This process often involves contestation of hegemony and/or formulation of new relationships with government, professional agents, academe and the outside world in general. The example of the Jagna community in the Philippines experimenting with a wider 'meshwork' of traditional and contemporary economic activities shows that community development can be achieved with reduced dependency on the export commodity paradigm at the very least if not a rebuilding of wider community resilience to external shocks (Gibson-Graham, 2005).

The Barefoot College movement in India has built its programs on traditional Gandhian principles as it is developing its 'extraparadigmatic' education and extension programs to improve the livelihoods of the rural poor around the world. It also has demonstrated that the use of modern solar voltaic technology can be consistent with transforming lifestyles and assist with the economic and social emancipation of the rural poor (Roy, 2008). 
Accordingly, contemporary postdevelopment thinking can provide some guidance in how local communities may make use of innovations from somewhere else in ways which ensure communities are able to actualise own expressions of modernisation while maintaining socio-economic cohesion. However, while postdevelopment advocates concentrated on the 'big picture' by pointing out shortcomings of orthodox development thinking and showed successful implementations of postdevelopment thinking in the field, there is still scant experience with methodological approaches in dealing with the selection process of innovations to be promoted by and for grass-roots movements.

Certainly this lack of reliable knowledge and experience is not surprising as the postdevelopment movement is still working to give practical meaning to its extraparadigmatic conceptions of development. Nevertheless, within the context of this study some effort needs to be employed to develop a selection methodology for appropriate transport modes which are based on sustainability and Samoan socioeconomic criteria. Failure to gain an understanding may lead to well documented lack of buy-in, showcase the personal preferences of the innovating agent (agency), assist in the introduction of well marketed green wash products and last and not least, prolong economic and cultural dependencies on the North. 


\section{Chapter 5: Research Methodology}

\subsection{Introduction}

This chapter introduces my research methodology which is guided by postdevelopment thinking with its particular views on Westerncentric power relationships with the developing South and how local knowledge and reinterpretations of modernity may help reducing Samoa's fuel dependency. My chosen conceptual framework required a differentiated research approach involving conventional literature review techniques, qualitative research and participative action research methodology inviting Samoan transport stakeholders to assess these outside innovations for local use and participate in creating own reform. Transport stakeholders may seek and promote a modification of the current transport mode as well as incorporate components of outside technical innovation in a modified transport mode as a result of participatory learning and reflecting over potential solutions of Samoa's fuel dependency.

I adopted a participatory action research approach to be an active partner in the problem solution process. I wanted to be able to provide information, respond to new information requests, assist in facilitating free information exchange and learn as much as possible from stakeholders about factors influencing the Samoan transport sector. In various ways my research constituted an aid intervention even if only the provision of information was concerned. Accordingly, I review literature about participatory development. The chapter concludes with my perceptions of the positionality of the action researcher immersed in MNRE-RED's working environment and in the participative workshop series.

\subsection{The Origins of the Participatory Development Paradigm}

The lost decade of the 1980s provided a renewed motivation to analyse the causes of protracted development failures. Noteworthy contributions to the ongoing development debate are the promotion of bottom-up participatory concepts involving communities in need and on an ontological basis, postdevelopment theory. Indeed, 
postdevelopment theory may well be considered a product of the era of frustration with development and owes a large part of its field methodology to the participatory paradigm (Chambers, 1983, 2005; A. Escobar, 2012 [1995]; Freire, 1970; Rist, 1997; Wolfgang Sachs, 1993).

For sure, from an ethical and democratic perspective, it would be difficult to deny the participation of villagers and rural dwellers in the planning of their future. However, Chambers (1994) found that outside agencies used participation just as a cosmetic label to make a project look contemporary. The pretence of participation was also used to access free labour, however, with no planning input from the project's beneficiaries. And, as originally intended by many advocates, participation was also used as an empowering process by leaving the analysis, planning and implementation of its destiny to local communities (Chambers, 1994; A. Escobar, 2012 [1995]; Scott-Villiers, 2004).

Pretty's (1995) 'Typology of Participation' expands on the participation continuum and developed seven steps of participation commencing with the lowest level of passive participation where people do not actively participate in project planning and only partake in aspects of its execution. The decision on type and the timing of the project is made by an outside institution. On the other end of the participation continuum Pretty (1995) describes interactive participation and selfmobilisation. People participate with external agents in project design and execution. The learning processes tend to utilise a wide range of information sources which leads to local decision making and ownership of the project. And finally, selfmobilisation indicates project initiation and execution without any involvement of external institutions (Pretty, 1995).

Apart from Pretty's and Chamber's theoretical and practical observations of the meanings of the participation paradigm, several scholars found further limitations of the participation concept. Cooke and Kothari (2001) established that participatory facilitators were able to manipulate otherwise legitimate decision making processes and even benefactor group dynamics are likely to reflect the influence of powerful community hierarchies (Cooke \& Kothari, 2001). 
Whereas for some sectors of society outcomes of participatory planning and implementation may yield desirable benefits over time, for poor people participation must yield tangible results soon as their discretionary time and energy are limited and compete with essential daily activities. Brett (2003) argues that the risks of failure weigh proportionally harder on poor families regardless of the empowering and democratic benefits of participation (Brett, 2003).

The portrayal of communities as socially homogeneous entities without much consideration of gender differences, ethnicity and rural/urban divides at the household and community level needs to be considered as an idealised portrayal of reality. Participatory techniques such as participative learning and reflecting may improve decision making processes and empowerment but in themselves are no guarantee that elites may not over proportionally benefit from aid interventions at the expense of poorer sectors of society (Mosse, 1994; Scheyvens \& Storey, 2003).

As we discussed in chapter 4.4, postdevelopment's concern with the local and its advocacy of strong participation in planning and decision making processes at the grass-roots level can be limited by political influence at the national and international level. An example in the Samoan context is the change of legislation in the transport sector as a result of Samoa's accession to the World Trade Organisation enabling near unrestricted vehicle imports while also causing higher administration cost and unsustainable consumption pressures.

Thus, there is experience with participatory development concepts to show that their application may have systemic shortcomings in the field. Causes of the deviation from bottom-up participation are to be found in the socio-cultural make-up of benefiting communities as well as in the implicit and explicit motivations of intervening agencies. Moreover, there are also overarching influences such as the currently prevailing neo-classic economic paradigm which impacts on power relations within local communities as well as the project objectives of intervening institutions (W. Sachs, 1998). Thus, in order to be able to benefit from the everyday 
life enhancing advantages of participatory development, I also needed to be aware of the well documented problems of participatory development.

\subsection{Participating in MNRE's Search for Alternative Transport Modes}

My research environment in the Ministry of Natural Resources and Environment (MNRE) differed markedly from the above described grass-roots beneficiary groups. Indeed, my respondent group consisted of public servants of various ministries with responsibilities in the formulation and implementation of transport and energy policy, private sector stakeholders with commercial interests (mainly tourism and car rental companies) in transport and research institutions. I expected their contribution to come from feedback on socio-economic applicability of alternative transport modes. Moreover, I provided technical information to retrofit passenger cars in case the respondent group felt such a technology modification might benefit Samoa's transport sector.

In order to optimise my study objectives within the existing research environment, I needed to identify the 'methodological space' of my study within participatory development and participatory action research. Pretty's (1995) 'Typology of Participation' was used to place my research methodology involving participative workshops, participant observation and semi-structured interviews at the 'Interactive Participation' continuum. Participating stakeholders are involved in the analysis of information supplied by all study participants. For my part, I am learning from stakeholder input and participating workshop members are learning from the information exchange and are able to reflect on possible improvements to the transport sector.

Accordingly, my specific research objectives are located in the above methodological space and allowed me to structure my research effort. As per chapter 1 , objectives 1 and 2 can be considered as the action researcher's research contribution to Samoa's alternative transport project. An extensive literature review established the current state of knowledge on alternative transport possibilities and what relevance could be established for Samoa. The conclusions are applied to 
Samoa's transport sector and local data are collected and analysed. The next step required the identification of stakeholders in the transport sector (objective3).

The holding of workshops on the 27 September 2013 and the 13 November 2013 marks the interactive phase of the action research. Workshops participants learn from provided information, learn from each other's comments, provide public and anonymous feedback and reflect on transport possibilities (objectives 4\&5). In parallel, semi-structured and qualitative interviews are conducted with transport stakeholders. Information gained from participant observation and informal conversations were captured in a journal. Feedback and findings were compiled and disseminated and additional follow up data was requested during the second workshop (objective 6). The eCar pilot proposal was presented and workshop participants jointly developed and agreed on an overall project objective (objective 7). The eCar pilot project cabinet proposal was prepared for submission to the executive National Energy Coordination Committee (objective 8).

Mutual exchange of information and ongoing feedback by many transport stakeholders resulted in many iterative loops to follow up on new findings. The result was a complex and non-linear inquiry process aimed at identifying a potential alternative transport mode which increasingly pointed towards a role for electromobility in Samoa's transport sector. In figure 5.1 the dynamics of the information exchange are illustrated. 
Figure 5.1: Action research stages and iterations

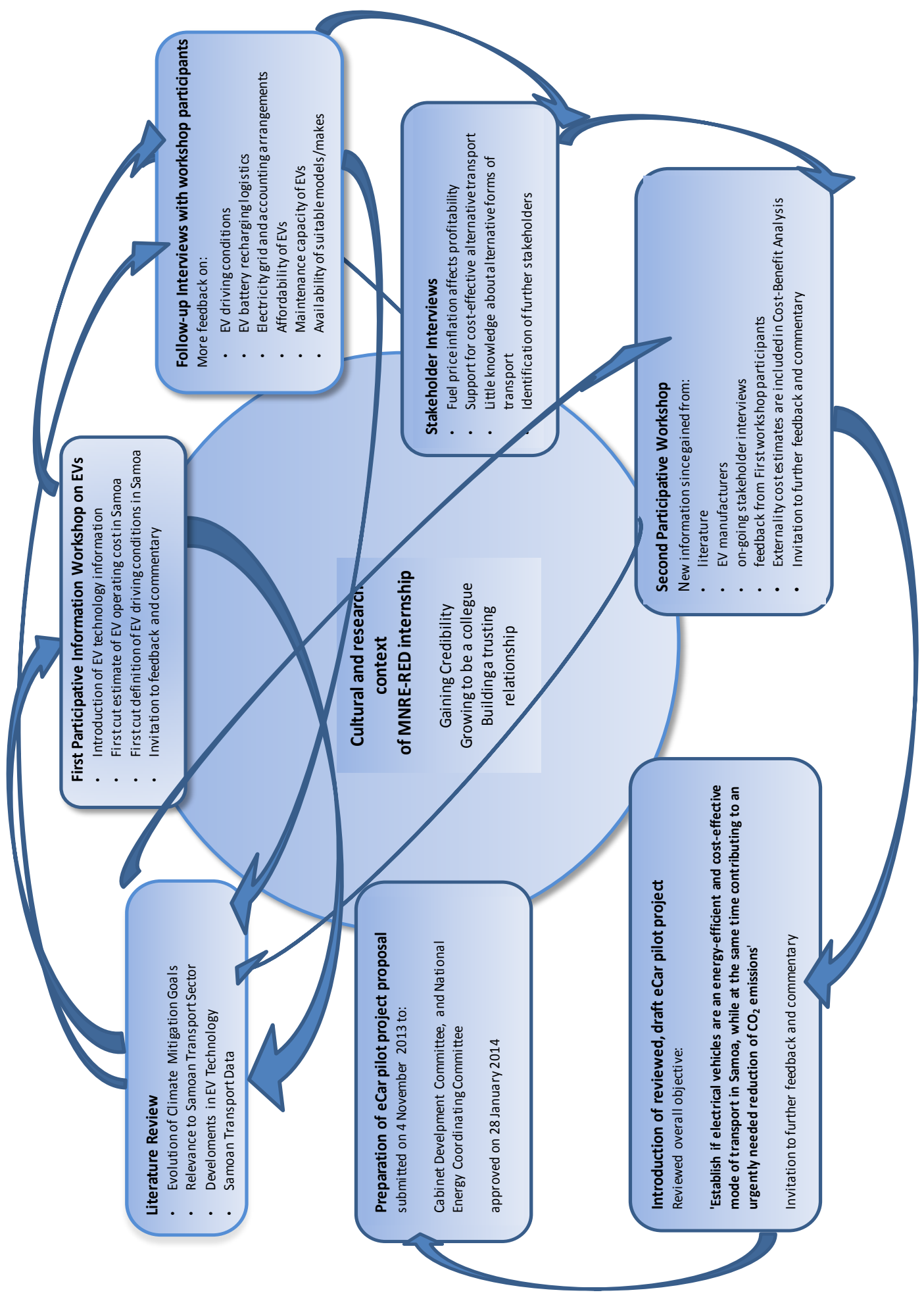




\title{
5.4. Participatory Action Research at MNRI
}

Participatory action research (PAR) occupies a methodological domain which sees the researcher subjectively involved in a project with emancipatory character benefiting individuals or communities. Reason and Bradbury (2008) have described the process as follows:

\begin{abstract}
"action research is a participatory process concerned with developing practical knowing in the pursuit of worthwhile human purposes. It seeks to bring together action and reflection, theory and practice, in participation with others, in the pursuit of practical solutions to issues of pressing concern to people, and more generally the flourishing of individual persons and their communities" (Reason \& Bradbury, 2008).
\end{abstract}

There is a need to put PAR methodologies into the context of my study at MNRE. Following from the above definition of PAR aiming at practical and emancipatory community/individual development based on participatory learning and reflection, my research methodology utilises only some of the core strengths PAR, namely participative learning and reflection over information initially provided by a development professional. After the first workshop mutual learning and reflecting had created a genuinely different and unpredictable learning direction, a direction which could not be defined as an outcome by me. This open trajectory sets my participatory action research apart from other activist projects aimed at achieving predetermined and emancipatory research endpoints.

I needed to be cautious about claiming a largely independent learning trajectory for Samoa's policy community and private sector stakeholders. As action researcher I have technically and linguistically influenced the learning trajectory by providing highly technical information about electro-mobility and international political economy. I may have provided information to be transformed into local knowledge so it can be constructively and creatively applied to the Samoan transport problem. But I 
have nevertheless provided information with inherent cultural biases (Cooke \& Kothari, 2001; Mosse, 1994).

My subjective and emancipatory action research motivation was most prevalent when introducing the concept of externality cost to the transport sector. In a clear case of limited local knowledge but even more limited awareness, the policy community was initially unable to contribute to a solution, mainly as the problem was perceived as a simplistic economy-environment dichotomy. Only when I was able to make transparent the already existing (but not yet quantifiable) health cost and tangible cost to the immediate environment, was the policy community able to contribute to the analysis of the externality cost issue. There is, however, a long road to transfer my externality cost estimates into an effective policy as such a programme requires new skills, knowledge and potentially new institutional arrangements (Mosse, 1994).

\section{5. $\quad$ Applying Postdevelopment Thinking to the Problem of Fuel Dependency}

Postdevelopment's epistemological and ontological position regarding the modernist development project has been strengthened with the recognition of shortcomings of the neoclassic economic paradigm and its downstream effects on climate change (Daly \& Farley, 2011; Keen, 2011; Wolfgang Sachs, 2010). As discussed in chapter Four, postdevelopment thinking has evolved from its earlier 'no' to development and provided productive theoretical analysis of the development discourse as well as practical experience in the field.

Of particular relevance for my study is McKinnon's theorising on how development professionals may contribute positively within complex everyday power dynamics and thus offer a productive but different take on the development discourse (McKinnon, 2008 p 289). McKinnon draws on Laclau's and Mouffe's (1985) explorations of hegemony which is conceptualised as a fluid and shifting claim to power and social influence by actors in society (including development professionals) unlike concepts of power which become stationary and normative 
within governing institutions (Laclau, 2000; Laclau \& Mouffe, 1985; McKinnon, 2008). This theorised new relationship of development professionals allows the visualisation and communication of values other than those sanctioned by governmentality norms, in my case ethical concepts of poverty alleviation and environmental stewardship (Rose, 1999).

The participatory workshop series is a good example of effective PAR as the activity involves mutual learning, reflecting and creating innovation with my role being confined to providing information and facilitating learning. However, as discussed above by Chambers, Perry and McKinnon, participation strategies may have imbedded values, in my case I may well convey and transfer values of modernity exemplified by a contemporary electric vehicle. Moreover, I was providing heterodox economic views in the shape of a cost-benefit analysis based on internalised externality cost. This approach brings us to a finding of my literature review, namely how to deal with the invariable selection process of societal and technical innovation by a development professional.

The approach I took was to report relevant technical innovation with a broad scope ensuring wide coverage of research activity. In the case of electric vehicle innovation, I reviewed the research and commercial aspects of electro-mobility but I also included alternative expressions of electro-mobility like second-hand car retrofits. When it came to reporting normative information such as climate change data and $\mathrm{CO}_{2}$ emission reduction initiatives, I reported the range of normative recommendations and predictions to workshop participants to allow incorporation of outside knowledge into the Samoan transport stakeholder reality.

The eCar pilot project proposal marks the endpoint of the PAR workshop series and illustrates well how participating transport stakeholders envisioned the implementation of a promising alternative transport mode (see appendix 9.3). If we compare other electric-mobility introductions in island nations (chapter 3.6), we note that the eCar pilot project took a structured and cautious approach aiming at establishing viability of the technology and ensuring that eCar maintenance and service capacity is acquired. A further conditionality provided for second-hand car 
retrofits once eCar maintenance capacity is achieved and community support is assured. Thus, PAR methodology enabled workshop participants to develop a considered plan to reduce Samoa's fossil fuel dependency, reduce $\mathrm{CO}_{2}$ emissions of the transport sector and conserve foreign currency reserves. In doing so, it considered technical innovation, or in the long-term, maybe only car retrofit components as a genuine Samoan response to a regain some sovereignty.

\subsection{Ethics Issues}

The Victoria University's Human Ethics Committee granted approval for this research on the $21 / 8 / 2013$. For the interview segment, each respondent was given an information sheet explaining the nature of the research and was encouraged to sign a consent form to indicate willingness to participate in the research project. With three exceptions, all respondents agreed to be interviewed and to be audio recorded. The respondents who did not wish to formally sign the consent form were nevertheless willing to be interviewed but with the proviso of strict confidentiality.

\subsection{Positionality of the Researcher}

My internship with MNRE-RED carried an outsider status as a palangi working within a Samoan institution. My presence as a palangi was by no means exceptional as at the time of my internship several palangi were working at various ministries. Nevertheless, for my respondents and colleagues being palangi carried a status of affluence or at least material comfort almost regardless of my self-funded situation as a postgraduate student undertaking field work towards a Master's thesis.

The issue of undertaking some free work for MNRE-RED was initially regarded with scepticism by many respondents, acquaintances and colleagues as work in the elite public service was seen as a very desirable career goal. I could often perceive the unspoken question like 'what is he really getting out of this?' Even as I tried to explain that my academic work required this field work component as part of my career. In fact, this line of thought culminated by the insinuation by my 
ministerial boss that I may be working as a spy for the New Zealand government. Clearly, my position as a palangi outsider contained several stereo-typical assumptions on the part of my hosts which I could not instantly correct by making of personal statements. However, on the other hand my age, being 58 years old, would also have given me a different standing compared to a conventional age of a master's student.

Apart from perceptions about my intentions, status, relevance for Samoa's everyday life and Samoa's policy community, my outsider's value systems and subjectivities also played a role in my interactions with Samoa. I was aware that my personal background as a migrant to New Zealand with a multilingual background, academic training in anthropology, political science and ecological economics would have given me a differentiated set of lenses in making sense of my Samoan existence and my interactions with Samoan counterparts. Life experiences, my cosmopolitan outlook and involvement in our organically certified family farm have sharpened my senses of the challenges innovation in the field of sustainability may create within a rural community as well as local government. My positionality is thus shaped by my personal subjectivities as well as perceptions of my hosts.

My ongoing interdisciplinary studies in development studies have afforded me the luxury to specifically prepare for the socio-economic challenges posed by the process of promoting innovation in the Samoan transport sector. In conjunction with previous experience and ongoing exposure to the complex processes coming into play with changing society values, this constellation somewhat helped to compensate for the limited time I could dedicate to field work in Apia as is often the case (Murray \& Overton, 2003; Scheyvens \& Storey, 2003). Moreover, I was also able to extend the duration of my stay up to four months, which in more ways than one enabled me to establish my credibility and allowed mutual learning experiences to take place in a reasonably unconstrained time frame.

The issue of the equitable sharing of the benefits of research is considered a crucial issue in the relationship between the 'outsider' agency and the receiving country. And again, in more ways than one, I was reminded of potential inequality of 
benefits by colleagues and my in-line boss during my stay when the intention and scope of my action research project became clear. Previous experiences with master's students undertaking field work within Samoan government ministries had often led to frustrations as that work was perceived with little if any benefit to Samoa. When it became clear that the nature of my research was of an applied nature and designed to be of benefit in the near future, my standing within MNRE changed dramatically and I was implicitly seen as what Mullings (1999) termed a temporary insider (Mullings, 1999). Clear Evidence of the evolved loyalties in the Ministry work place was the degree of protection I was now given in the daily wrangle of "office politics" and inclusion in the free information stream circulating around the office, quite apart from the never-ending arrival of anonymous lunch parcels and fruit to help stave off imminent starvation of the 'spindly' palangi.

My chosen methodology of participatory action research allowed me to be immersed in the learning process as a provider of information as well as the receiver of opinions and information. These iterative loops of learning, reflecting and feeding back new findings were very satisfying, particularly as techniques like participant observation and informal conversations allowed immersion in the Samoan customary conversation etiquette. I found that with only rare exceptions that the use of English as a second language on my part and the part of respondents did not detract from having a discussion, casually exchanging ideas and at times 'not talking about anything in particular while circling around the issues nevertheless' (Vaioleti, 2006).

With my declared subjectivity in the participatory information exchange I felt I also came closer to canvassing a wider group of local stakeholder opinions apart from the narrower MNRE policy community. With the ever widening circle of interviews and conversations and my commitment to relay these opinions and statements amongst our 'participative alternative transport community' I felt that consultation and actual effect on the formulation and design of the eCar pilot project reached considerably beyond the MNRE and MOF policy community. As Scheyvens (2003) noted development research is often challenged by involving local opinion in the policy formulation process. I felt repeatedly that following the 'snowballing trail' towards new interviewees in my new role as temporary insider I started to build a 
sound kaleidoscope of positions and opinions about alternative transport (Scheyvens \& Storey, 2003).

One of the reasons of my arrival in Apia, an introduction by a friend to my direct line manager, gave me some credibility but in reality I needed to gain my own trustworthiness in order to be taken seriously by my professional peers in MNRE. Moreover, my central interest in postdevelopment theory and how participatory grassroots development may evolve within developing global environmental values place crucial importance on effective communication between the action researcher and the participating policy community and ultimately the village community. 


\section{Chapter Six:}

\section{Discovering Samoa's BEV Possibilities}

\subsection{Overview}

In this chapter research findings of my action research are presented in three sections. The first section draws from the literature review and informs about recent technical developments in electric mobility and puts BEV innovations in the international context of various economic and climate change reviews. REN21's global transport stakeholder survey provides information on stakeholder intentions in the renewable energy field. The International Energy Agency's recent experiences with the Electric Vehicle Initiative (EVI) are introduced to show an emissions reduction path for the transport sector with direct applicability to Samoa. The desktop study concludes with Samoan estimates of operating and capital cost of BEVs, $\mathrm{CO}_{2}$ emissions and emissions savings estimates compared to other transport modes and savings effects on currency reserves.

The second section marks the commencement of my participatory action research. As a team member of the MNRE's Renewable Energy Division I had worked hard to become a temporary insider with some credibility in my field. The first step of my action research process aimed at informing stakeholders taking part in the first workshop about latest developments in electro-mobility. Feedback and commentary was invited throughout this phase and led to mutual and repeated informing, learning and reflecting on new information at hand. The feedback and learning cycle involved formal and informal interviews and conversations, a second participatory follow-up workshop on electro mobility in Samoa and as part of the workshop, a final round of feedback from workshop participants and stakeholders (Vaioleti, 2006). The iterative learning process gradually led to a realisation that the incorporation of BEVs in Samoa's transport fleet may be a viable proposition. The learning process cumulated in the joint preparation of the overall objectives of the eCar pilot project.

The third section commences with the preparation of the MNRE 'eCar Pilot Project' cabinet submission based on the learning outcome of the last workshop. An integral part of the justification requirement of the proposal was a cost-benefit 
analysis, largely based on operation and capital cost. As part of my own subjective action research commitment I introduced the externality cost concept and used Samoan cost estimates for the transport sector.

Thus, the purpose of this chapter is the pulling together the various strands of my research towards their goal of establishing a pilot project for BEVs on Samoan roads. In doing so, I also wanted to demonstrate the powers of participatory action research in informing and learning from transport stakeholders and contributing to the improvement of Samoa's transport sector.

\subsection{Literature Review Findings}

The literature review in chapter Three provided detailed information about recent developments in the field of electro-mobility. Some of this data proved important as background information for the planning of the action research phase, other information can be considered as instrumental findings with direct technical application for the eCar pilot project.

The importance of the climate change phenomenon regarding the transport sector was an important finding of the review. The science used is largely based on modelled and predictive data which is then used o project likely climate change outcomes. The nature of these data and the involved assumptions required an in depth review of the normative debate about the validity of climate change predictions and resulting advocacy for a ceiling of 2 degree Celsius warming by 2100 . Thus, this data type is influenced by the predictive limits of science and actor normativity but nevertheless is the best available baseline data for transport policy formulation. It forms the basis for the justification of the eCar pilot project.

The EVI and the King Review use back casting methodology based on the Stern Review and IPCC climate modelling data to limit global temperature increase to a 2 degree Celsius limit by 2100. The use of electric cars with EV production targets, coordinated under IEA's Electric Vehicle Initiative (EVI), is a crucial strategy to achieve the transport sector's share of $\mathrm{CO}_{2}$ emission reductions. The IEA's role in 
the initiative is the coordination of member governments to realise a long-term 80-90 per cent decarbonisation of the transport sector beyond 2030 (IEA, 2011; IEA ETP, 2013; King, 2007; Martinot, 2013b). The EVI provides assurance that electro-mobility has been chosen by global transport stakeholders as a practical response to meet decarbonisation objectives and gives confidence in the continued commercialisation EV technology.

The REN21 survey of global transport stakeholders provides more insight in the activities of the renewables sector. Confidence in the renewables sector is supported by investment in the sector and offers projections up to 2050 ranging from US $\$ 300$ billion to US \$ 1 trillion. Electro-mobility scenarios range from a low EV uptake of one per cent of the global vehicle fleet to a "high growth" scenario of ten per cent market share of Light Duty Vehicles (LDVs). The higher adoption scenarios find support by a wide cross section of stakeholders and coincide with IEA's electric vehicle initiative. In figure 6.1 literature findings which were instrumental for the action research phase are summarised according to topics.

\subsubsection{Relevance of Literature Findings for Samoan Legislation}

Analysis of the 'Samoa National Greenhouse Gas Abatement Strategy 20082018' showed an alignment with international attempts to reduce $\mathrm{CO}_{2}$ emissions. Legislation in the transport sector, in particular the 'Samoa Energy Sector Plan 2012 - 2016', draws a clear connection between the sector's considerable emissions contribution as a proportion of the Nation's total emissions profile and responsibilities towards climate change mitigation. The eventual introduction of alternative modes of transport including BEVs is anticipated but knowledge and awareness of recent technical developments is limited.

Thus, literature review results suggest that global electro-mobility research and wide institutional support for electro-mobility has paved the way for the commercialisation of BEVs with ambitious BEV sales targets of 20 million registered vehicles by 2020. Relevant Samoan policy anticipated the eventual introduction of 
BEVs but Samoa's policy community was not aware of recent technical developments in electro-mobility.

Figure 6.1: Summary of literature review findings instrumental for action research phase.
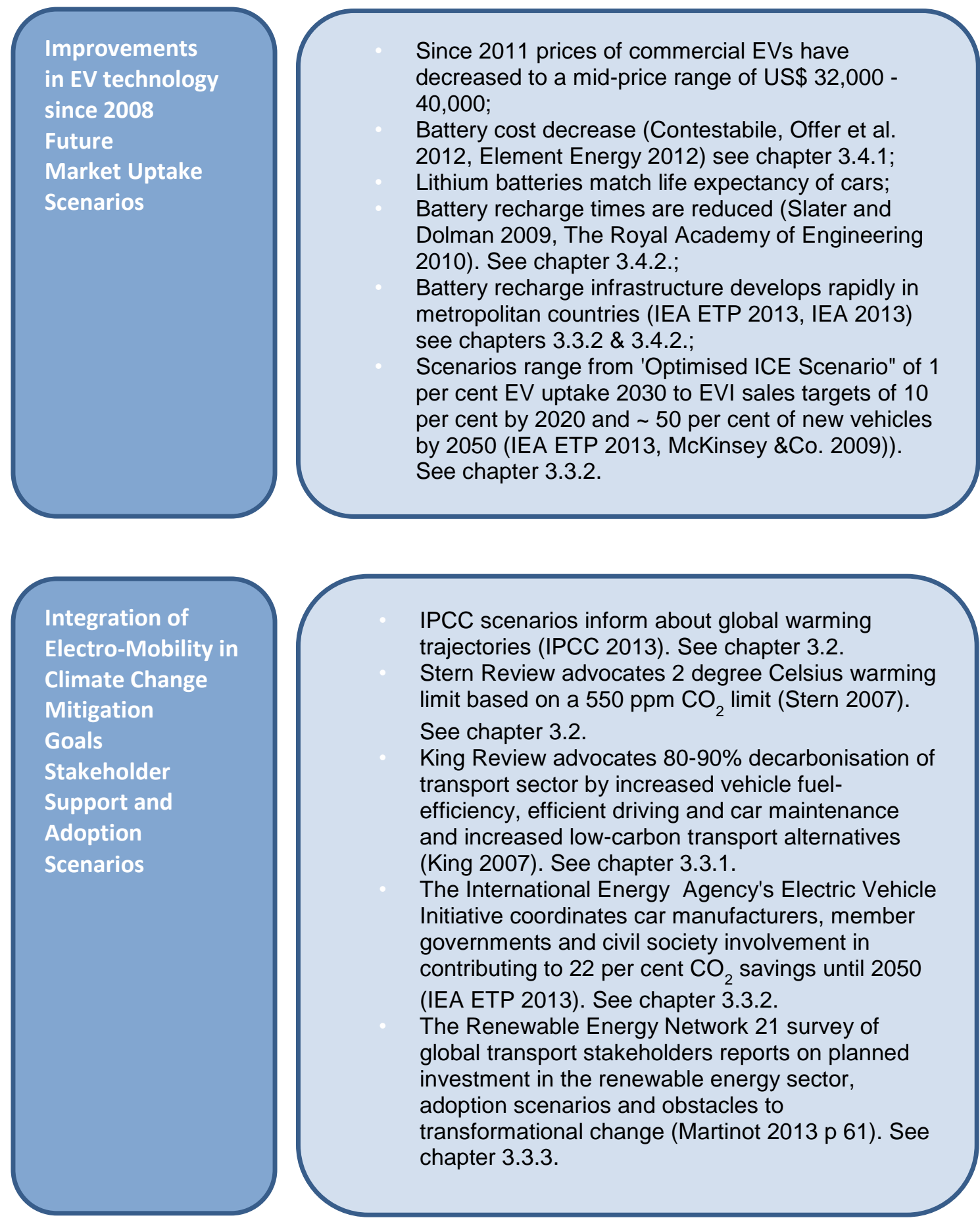


\subsubsection{Samoan Transport Data}

As we have seen in the previous chapters, a wealth of technical information for a range of electro-mobility applications is available from the international literature. In addition, the literature review revealed considerable data and experience in the use of BEVs in small island environments. However, in order to allow a detailed cost comparison between different transport modes under Samoan driving conditions, we needed to collect local transport data.

Fuels cost for three car types powered by electricity, petrol and diesel and biodiesel were modelled. Car types included a small compact car, a mid-sized sedan and a utility pick-up truck. Energy consumption data from electrical vehicles were taken from BEV manufacturers and are expressed as units of $\mathrm{kWh} / \mathrm{km}$ to allow easy comparison with conventional fuel use. Fuel use data for biodiesel blends were also not available and estimates were based on the literature assuming a slightly higher consumption than conventional diesel vehicles due to a seven per cent lower energy density of biodiesel (Alternative Fuel Centre, 2013). However, as the current biodiesel trial conducted by SPREP uses only a 10 per cent biodiesel/diesel blend, the energy density differences are not significant.

Fuel comparison data are presented on the basis of distance travelled in kilometres per 1 WST (Western Samoan Tala) by different fuel types. Table 6.1 shows that fuel use of the compact BEV was 48 per cent lower (on a travelled km basis) than a comparable petrol fuelled compact sedan. Less fuel savings were achieved by the mid-sized BEV (30.88 per cent) and the BEV utility (15.69 per cent). The two biodiesel blends ( 10 per cent and 50 per cent) had moderately higher fuel consumption than comparable conventional vehicles and a significantly higher fuel use (37 per cent @ 10 per cent biofuel blend and 40 per cent @ 50 per cent blend) compared to BEVs.

Fuel use efficiency differentials between petrol, electric power and biodiesel blends compare well with existing international data and are in the main based on the well-established energy conversion efficiency of the electric motor design ( $~ 46$ 
per cent primary energy conversion) and the relatively inefficient energy conversion capacity of the internal combustion engine ( 15 per cent- 18 per cent primary energy conversion) (California Energy Commission, 2014).

In addition, some energy conversion efficiency is gained from operating large electricity generator sets at optimum operating conditions. Samoan energy sector data show a 30 per cent diesel fuel-electricity conversion efficiency (Government of Samoa, 2011c, p. p.9).

In order to demonstrate the different resource use characteristics of a nominal 1000 vehicle fleet consisting of mid-sized sedans was modelled with regard to effects on fuel cost to the travelling public, resulting GHG emissions and effects on foreign currency reserves per year (See table 6.2). The modelled BEV fleet showed the most economic fuel economy with a transport cost to the travelling public of WST 1.42 million, followed by biodiesel blends (WST 3.2-3.3 million) and CVs (WST 3.72 million). The BEV fuel efficiency advantage was translated in significant reductions of GHG emissions with BEVs emitting 1206 tons $\mathrm{CO}_{2}{ }^{22}$, followed by the 50 per cent biodiesel blend (1372 tons $\mathrm{CO}_{2}$ ), ten per cent biodiesel blend (2469 tons $\mathrm{CO}_{2}$ ) and $\mathrm{CVs}$ (2755 tons $\mathrm{CO}_{2}$ ). The same sequence was maintained with reserve currency savings effects with BEVs achieving the highest savings of WST 2.3 million, followed by 50 per cent biodiesel WST 1.737 million, ten per cent biodiesel 0.347 WST million compared to the 'business as usual' use of CVs.

\footnotetext{
${ }^{22}$ Emissions calculations are based on $0.14 \mathrm{kWh} / \mathrm{km}$ electricity use.
} 
Table 6.1: Fuel Cost Comparison - CV, BEV and BVD

\begin{tabular}{|c|c|c|c|c|c|}
\hline \multicolumn{4}{|c|}{ Distance travelled per $1 \$$ - Conventional Vehicles } & \multicolumn{2}{|l|}{ Net Savings \% } \\
\hline Small compact car, CV Petrol & $6.5 \mathrm{l} / 100 \mathrm{~km}$ & 4.82 & $\mathrm{~km}$ & Compact Car BEV-CV & $48.01 \%$ \\
\hline Mid-size Sedan, CV-Petrol & $8 \mathrm{l} / 100 \mathrm{~km}$ & 3.92 & $\mathrm{~km}$ & Mid-size Sedan BEV -CV & $30.88 \%$ \\
\hline Utility Pick-up Truck, CV-Diesel & $11 \mathrm{l} / 100 \mathrm{~km}$ & 2.87 & $\mathrm{~km}$ & Utility Pick-up Truck, BEV -CV & $15.69 \%$ \\
\hline \multicolumn{2}{|c|}{ Distance travelled per $1 \$$ - Biodiesel Vehicles, $10 \%$ Blend } & & & Biodiesel (10\%) & $\%$ \\
\hline Mid-size Sedan, BD & $8.5 \mathrm{l} / 100 \mathrm{~km}$ & 3.68 & $\mathrm{~km}$ & Mid-size Sedan CV- BD & $-6.35 \%$ \\
\hline Utility Pick-up Truck, BD & $11.5 \mathrm{l} / 100 \mathrm{~km}$ & 2.72 & $\mathrm{~km}$ & Utility Pick-up Truck CV-BD & $-5.30 \%$ \\
\hline \multicolumn{2}{|c|}{ Distance travelled per $1 \$-$ Biodiesel Vehicles, $50 \%$ Blend } & & & Biodiesel (50\%) & \\
\hline Mid-size Sedan, BD & $8.5 \mathrm{l} / 100 \mathrm{~km}$ & 3.59 & $\mathrm{~km}$ & Mid-size Sedan CV- BD & $-9.25 \%$ \\
\hline Utility Pick-up Truck, BD & $11.5 \mathrm{l} / 100 \mathrm{~km}$ & 2.65 & $\mathrm{~km}$ & Utility Pick-up Truck CV-BD & $-8.17 \%$ \\
\hline \multicolumn{2}{|c|}{ Distance travelled per $1 \$$ - Electric Vehicles } & Base Tariff & & & \\
\hline Small compact car (eg Miev) & $0.11 \mathrm{kWh} / \mathrm{km}$ & 9.28 & $\mathrm{~km}$ & & \\
\hline Sedan (BYD taxi model) & $0.18 \mathrm{kWh} / \mathrm{km}$ & 5.67 & $\mathrm{~km}$ & & \\
\hline Utility Pick-up Truck,? Estimate & $0.3 \mathrm{kWh} / \mathrm{km}$ & 3.40 & $\mathrm{~km}$ & & \\
\hline \multicolumn{6}{|l|}{ Fuel Cost, Aug-13 } \\
\hline Diesel, ADO & $3.17 \$ / 1$ & & & & \\
\hline Petrol, ULP & $3.19 \$ / /$ & & & & \\
\hline Biodiesel Blend, $10 \%$ & $3.19 \$ / /$ & & & & \\
\hline Biodiesel Blend, $50 \%$ & $3.28 \$ / 1$ & & & & \\
\hline \multicolumn{6}{|l|}{ Biodiesel@ \$3.4/I indicative } \\
\hline \multicolumn{6}{|l|}{ Electricity Cost, Aug-13 } \\
\hline Base Tariff $<50 \mathrm{kWh}$ & $0.98 \$ / k W h$ & & & & \\
\hline Larger Consumers $>50 \mathrm{kWh}$ & $1.2 \$ / k W h$ & & & & \\
\hline
\end{tabular}

Table 6.2: Transport mode effects on annual transport cost, GHG emissions and foreign exchange savings by a 1000 vehicle fleet.

\begin{tabular}{|l|c|c|c|}
\hline \multicolumn{1}{|c|}{ Vehicle Types } & $\begin{array}{c}\text { Transport Cost to } \\
\text { Driving Public } \\
\text { WST Million }\end{array}$ & $\begin{array}{c}\text { GHG Emissions } \\
\text { tons } \mathbf{C O}_{\mathbf{2}}\end{array}$ & $\begin{array}{c}\text { Currency } \\
\text { Reserve Savings } \\
\text { \$ Million }\end{array}$ \\
\hline CV, @ \$3.19/I & 3.72 & 2755 & - \\
EV, \$3.17/I & 1.42 & 1206 & 2.3 \\
BD Blend & & & \\
@ \$ 3.19/I -3.28/I & & & $0.347-1.737$ \\
\hline $\mathbf{1 0 \% - 5 0 \%}$ & $3.2-3.3$ & $2469-1372$ & \\
\hline
\end{tabular}

GHG Emissions as per USEPA; Petrol: $2.359 \mathrm{~kg} \mathrm{CO} / /$; Diesel: $2.685 \mathrm{CO}_{2} / \mathrm{l}$ 
Thus, on the basis of fuel cost comparison, BEVs are significantly cheaper to operate on electricity generated by diesel than CVs on imported petroleum products. Biodiesel blends (up to 50 per cent) have only a minor savings effect to the driving public with blending percentages influencing savings only insignificantly. The high energy conversion efficiency of BEVs and the optimised electricity yield from large diesel generators also lead to the lowest $\mathrm{CO}_{2}$ emissions profile of all three transport modes. Here biodiesel blend percentages (ten per cent - 50 per cent) play a significant role in $\mathrm{CO}_{2}$ emission yields. A high proportion of biodiesel in the blend leads to comparable $\mathrm{CO}_{2}$ emissions with $\mathrm{BEV}$ propulsion (which is due to the cycling of carbon in the biological system).

Conversely, a low biodiesel percentage blend shows up with an emissions profile similar to the CV profile. We need to keep in mind, however, that security of supply of biodiesel is low due to aging coconut plantations, coconut price fluctuations, competing uses, unclear supply status of other oil producing plants, food security issues with coconut being a food staple and increasing risk of extreme weather events. There is also no consensus as to engineering requirements of diesel engines operating on high percentage biodiesel blends in the long-term.

The largest reserve currency savings of WST 2.3 million could be achieved by $\mathrm{BEV}$ s relative to $\mathrm{CV}$ petroleum import requirements. The biodiesel contribution depended on the blend percentage with high biodiesel sourced from native sources achieving WST 1.737 million savings and the ten per cent blend achieving WST 0.347 million.

\subsection{3. $\quad$ First Participatory Information Workshop}

The first workshop, held on 27 September 2013, was an important event in the participatory action research project time line and aimed at gaining a 'buy-in' into the topic of electro-mobility. Apart from the technical, climate change mitigation goals and Samoan policy aspects of the literature review component, the preparation phase involved establishing relationships with colleagues from the MNRE Renewable Energy Division, key contacts in MNRE, MOF, LTA, EPC and non- 
government stakeholders. This process took considerably more time than anticipated, as the Polynesian concept of public service proved to be subtly different to New Zealand conventions. A master's student internship was not necessarily seen as positive and in general the presence of a palangi researcher within the Samoan public service was also viewed with some suspicion as to the possibility of some 'spying' taking place on behalf of the New Zealand government.

In principle, my experience with the everyday activity of MNRE's Renewable Energy Division (MNRE-RED) was being one of a small staff of three employees having to cover a large area of duties in the fields of energy efficiency in the housing sector, renewable energy projects like biogas and biodiesel, non-motorised transport initiatives and other 'legacy' projects like land disposal of septic tank waste from households. These projects and responsibilities included tasks not normally associated with project management duties in a 'Western' type public service. Publicity responsibilities included the design and production of publicity material, interviews and presentations with all national media outlets. Traditional cultural responsibilities involved attending weddings, funerals of extended family members and their children's school functions. School children often spent some of their after school time at the office. The isolated location of Samoa also led to relatively high communication responsibilities in the forms of inter-island attendances of conferences and workshops and hosting visitors from other island nations. All in all a picture emerged of a latent routine task over-commitment in the light of hard to fathom social responsibilities to the extended family. Many public servants routinely spent some of their weekend time on catching up with tasks.

The process of gaining credibility may be gauged by the fact that the workshop date was changed eight times. There were several reasons for the postponements, not the least of which was the sheer work load of the government sector and the latent understaffing at least as it appeared in the MNRE-RED. Other reasons were the perception that environmental cost was subordinate to economic prerogatives in the light of severe economic pressures, even though the Samoan government had entered numerous treaties promoting environmental sustainability (GHG emissions etc.). The prioritisation of 'economics over environment' was 
supported by government employees and the general population. In addition, a partly valid image of electro mobility as being too expensive and therefore not suitable for Samoa's transport fleet had decreased interest in that option although its potential implementation is foreshadowed in the Samoa Energy Sector Plan 2012 - 2016. And the rapid and very recent technological advancements in electric mobility have received no attention by Samoan Government agencies although the ongoing commercialisation of BEVs and improvements in car battery capacity and resulting reductions in cost have significantly improved economic viability of electric mobility.

The success in holding the workshop on the 27 September 2013 can be considered as a clear break with previous lack of interest. Workshop attendance represented all government departments which have an interest in the transport sector, fuel supply and government financial viability ${ }^{23}$. As discussed previously, the workshop theme was one of information about electric mobility and its potential relevance for reducing Samoa's fuel import dependence and GHG emissions reduction obligations. The presentation also pointed to international trends identifying a change from former reliance on standardised fossil fuel imports to a switch to more domestic transport energy supplies and infrastructure. A perceptible increase in interest by way of questions and comments was noted when local electric mobility data showed clear qualitative and strategic advantages over conventional transport forms under Samoan driving conditions. This applied in particular to median estimated travel distances per day (40 km/day/car), the small size of the islands and low travel speeds (rural speed limit of $56 \mathrm{~km} / \mathrm{h}$ ) all of which were significantly below the minimum performance specifications of commercially available BEVs.

Other favourable infrastructure conditions included a high degree of electrification coverage ( 98 per cent of islands) potentially enabling decentralised plug-in recharge of BEVs and the ability of the electricity grid to integrate 20-30 per cent distributed energy into the existing electricity base load. The audience was also aware that Samoan government policy stipulates that any future growth in energy generation will need to be met by renewable energy expansion. Review findings that

\footnotetext{
${ }^{23}$ Workshop participants: Leasi Vainalepa Galuvao, CEO - LTA; Tologata Tile Leia, CEO - EPC; Taulealea L Malua, CEO MNRE; Sala Sagato Tuiafiso, ACEO/RED MNRE; Sione Foliaki, ACEO/Energy MOF; Tamaseu Leo Bartley, Manager RUM LTA; Isikuki Punivalu Director for IPA (Isikuki Punivalu and Associates)
} 
the cost of self-consumption PV installations for BEV battery recharge may already be commercially viable in sunnier parts of the globe also raised comment by the participants.

Reflection on the workshop outcome and informal 'chats' with colleagues, nevertheless confirmed that Samoan cultural etiquette does not encourage public criticism which is considered impolite, particularly if criticism may be construed as embarrassing to an individual. For those reasons a follow-up series of interviews with willing workshop participants was conducted, primarily to ensure that information dissemination was successful and if necessary explained more thoroughly but also to allow the possibility for a more free and frank voicing of opinion.

\subsubsection{Follow-up Interviews with Workshop Participants}

The offer of a follow-up interview was accepted by Leasi Vainalepa Galuvao (CEO - LTA),Tologata Tile Leia (CEO - EPC) and Sala Sagato Tuiafiso (ACEO/ MNRE-RED). A summary of feedback and comments is presented in the following. Mr Galuvao of the Land Transport Authority was mainly interested in finding out which car segment was deemed to be the best suited for initial introduction should the eCar pilot trial be approved by government. He also suggested that the Samoan wet season and high humidity might be a handicap for trouble-free operation of BEVs. He also felt that new BEVs are too expensive for a large proportion of the traveling public. Moreover, he was not too sure about the servicing and maintenance capacity of Samoa's service sector.

Mr Leia, CEO-EPC, was mainly interested in a thorough explanation of the cost assumptions for BEV battery recharging and recharge logistics. He also confirmed that EPC electricity demand planning has no provisions for increased electricity use from BEVs. There are no provisions for feed-in tariffs for surplus electricity produced by distributed electricity generation. He was also not supportive of the installation of two recharge PV units for BEVs for research purposes, mainly on the grounds that current grid design and accounting arrangements make no 
provision for distributed feed-in electricity and under current policy such a development would reduce profitability of the state-owned EPC. In general, however, the potentially increased demand of electricity was welcomed for the same reasons, particularly as the presented BEV cost calculations revealed a higher energy conversion by the EPC electricity generator sets compared to direct ICE combustion thus showing consistency with government policies on resource use efficiency.

Mr Sala Sagato Tuiafiso, ACEO of MNRE-RED, obviously had some biases as my in-line manager responsible for the eCar pilot study but nevertheless his participatory comments and reflections are thought to be valuable for the further evolution of the project. Moreover some commentary was useful for triangulation of information. Mr Tuiafiso reiterated concerns about the capital cost of BEVs, mainly as an obstacle towards the introduction of BEVs to a large segment of the travelling public. He also picked up on the car as status symbol and in particular the expensive four-wheel drive utility trucks (WST \$105,000) and suggested that the testing of a BEV utility truck would help a prospective BEV introduction program. Following from other workshop participant comments about BEV affordability by larger community sections, he proposed to explore further the possibility of secondhand car conversions once some technical capacity in BEV car maintenance has been acquired via the eCar pilot.

As part of MNRE-RED's involvement in renewable energy research he is also acutely aware of the need for policy review to allow the integration of distributed, renewable energy generation in the national energy grid. He believes the eCar pilot project could provide the opportunity to learn how to operate PV recharge stations both from a technical and policy point of view. One hurdle to overcome is the review of existing electricity charging policy.

Thus, the workshop participants provided helpful and practical feedback and in general there was support for an eCar pilot proposal aiming at 'proof of concept' and identifying obstacles towards a potential larger scale implementation. A number of comments arose during the workshop and from one-to-one follow up interviews, which can be summarised as follows: 
- Surprise that electricity generated by diesel can provide a more efficient form of transport energy than direct use of diesel or petrol;

- Surprise at the commercial availability of BEVs and their driving range;

- Concerns about the impact of the Samoan climate (wet season, humidity) on the reliability and usefulness of BEVs;

- Concerns about affordability of compact and mid-sized BEVs in Samoa;

- Concerns about maintenance capacity of the Samoan service sector;

- Concerns about the effects of a large BEV fleet on the electricity grid balancing requirements;

- Concerns about the effects of PV self-consumption units used for BEV recharging and effects on EPC profitability;

- Concerns about the current EPC electricity charging setup;

- Concerns about limited range of affordable BEV models, particularly utility trucks.

This feedback was incorporated into ongoing research and learning and proved very effective in the more detailed planning of the eCar pilot project.

\subsubsection{Summary of Findings from Semi-structured Stakeholder Interviews}

Apart from the iterative information, feedback and learning workshop approach, a series of semi-structured interviews were held with private sector stakeholders including rental car companies, entrepreneurs, businesses, aid community and tourist resorts.

The main interest of the interviews was to find out if current fuel prices affected their business performance or household and if there was an interest in utilising BEVs if proven advantageous. A question also tried to identify, by ranking, importance of economic, environmental and marketing considerations in their 
business approach. The interviewee also had the option of free commentary at the end of the interview. Interview questions are listed in appendix 9.1.1.

There was a general agreement from all respondents that fuel expenses had 1) increased in the past two years and 2) that cost increases had affected profitability or as in the case of NGOs resulted in passing on increased fuel cost to granting bodies. In particular, tourism businesses had felt the increase in fuel cost as tourists were either picked up at Faleolo Airport for their destination and/or driven around the islands as part of their service. Rental companies responded with the same concerns.

All respondents had only rudimentary knowledge about alternative forms of transport. If there was some knowledge it extended only to the ongoing SPREPmanaged biodiesel trial. There was, however, no knowledge about the economic details of the trial, only the broad idea of the purpose of the trial to reduce dependence on fuel imports, which all respondents supported. One respondent (a rental car company) mentioned hybrid cars as a future possibility, none were aware of the commercial availability of BEVs in metropolitan countries.

However, all respondents would consider the use of alternative forms of transport if it was available and not surprisingly, if it was cheaper. With the exception of the NGO who was able to pass on increases in fuel cost to donor agencies, economic and marketing considerations were very important for all respondents.

The snowballing approach in identifying respondents produced two 'alternative transport entrepreneurs' who were either planning to introduce five to seven years old first generation hybrid sedans and/or were intending to modify vehicles. The above interview format was not appropriate for the interests of these respondents and an unstructured, explorative interview approach was adopted. $\mathrm{Mr}$ Speedy of the Auckland firm Wongchiu International Ltd is an expatriate Samoan who has been involved in the conversion of conventional cars in New Zealand since 1995. He confirmed that electric car conversions using lead-acid batteries were not satisfactory due to the resulting very limited driving range, low power output/weight 
ratio of the batteries, relatively short battery life expectancy and high battery cost. Mr Speedy is now promoting hydrogen as a transport fuel supplement and converts CVs to hybrid cars using hydrogen from on-board production. He claims around 20 per cent fuel savings, greater supply of power and less pollution but is hesitant to explain either the conversion process or the principles involved.

Another entrepreneur is promoting the importation of first generation five to seven year old second-hand hybrid sedans such as the Toyota Prius and the conversion to a plug-in hybrid with a $60 \mathrm{~km}$ driving range. Both entrepreneurs aim to be able to offer a hybrid transport mode with significantly lower operating cost and believe their products reduce transport cost, emissions and dependence on fuel imports.

Thus, the information gained from interview respondents was quite uniform with very limited variation of responses to interview questions. There was general agreement that fuel cost had indeed increased and that fuel price inflation has affected their business cost. The only exception was an NGO who was able to pass on increased fuel cost to the donor agencies. There was also little differentiation of the offered motivations for using alternative modes of transport. Again, all respondents (with exception of the NGO) agreed that the possibility of lower operating cost, reduction of greenhouse gases and a market advantage would make the eCar trial worthwhile judging by the advantages potentially to be gained. More independence from imports was considered reasonably important to very important.

There was little awareness of either alternative forms of transport or means of increasing fuel use efficiency. Some respondents had heard about the ongoing SPREP biodiesel trial through the local press. None of the respondents knew that the biodiesel operating cost would be more expensive than current fuel prices although some reduction in $\mathrm{CO}_{2}$ emissions and some foreign exchange savings would be achieved (see table 6.2). This lack of information is most likely due to the technical nature of the information and the not yet available research findings and conclusions of the continuing SPREP research project. 
All respondents, and in particular tourism operators, were prepared to be involved in testing a BEV. The main reason was the possibility of transport cost reductions but the opportunity to show green credentials was also attractive.

\subsubsection{Second Participatory Workshop and Presentation of Draft eCar Pilot Project}

The second workshop was held on the 6 November 2013 and was designed with the feedback from the previous workshop and interviews in mind. Attendance grew significantly from the first workshop as a result of the information effect of the ongoing interviews but also because of the by now topical nature of the research project as it was perceived within the circles of the private sector and government stakeholders. Interestingly, the workshop did not suffer from any postponements which may be explained by the increase in interest in the topic of alternative transport modes. Workshop participants from the following institutions attended: Seimaleula Sinapati (LTA), Richard Heather (MOR), Sione Foliaki (MOF),Tu'u'u leti (PSC), Natasha Kolose (STEC), Tologata Tile (EPC), Robert Bartley (MWTI), Ken Wong (SROS), Anne Rasmussen (GEF), Samuelu Enari Auelua, Christine Hoponoa, Bellarose Fetuao (MCIL), Sala Sagato, Anne TrBEVor, Lillian Penaia (MNRE).

The workshop built on new information since gained from the literature, BEV manufacturers and interview feedback from stakeholders. Findings from the ongoing interviews with stakeholders as well as one-to-one interviews with attendants from the first workshop were also included. The workshop PowerPoint presentation is attached in appendix 9.2. A draft BEV pilot project proposal was then introduced for general discussion and further feedback.

New information from international literature and BEV manufacturers is summarised as follows:

- Cost of BEVs has decreased now to around US $\$ 35,000$ for a compact sedan;

- BEV battery cost has continued to reduce and for new BEVs battery life expectancy are guaranteed for the life of the car; 
- Battery recharge times are getting shorter with a network of recharge stations being established in metropolitan centres.

Comments and concerns from stakeholder interviews are summarised as follows:

- Lack of BEV maintenance capacity;

- Unclear legal status of BEVs on Samoan roads;

- Need to determine suitability of BEV sizes for Samoan family's travelling requirements;

- Suitability for Samoa's rural road network, particularly during the wet season;

- Current EPC charging schedules not suitable for 'feed-in tariffs', (e.g. only consumption is charged but not line maintenance);

- Knowledge gaps on BEV re-charging and feed-in PV self-consumption units as it relates to daily grid-balancing;

- Feed-in tariffs may affect EPC profitability and may need to be considered at policy level;

- Considerable cost differential between new BEVs and new CVs;

- No second hand market for BEVs yet;

- Affordability of BEVs;

\subsubsection{The Draft eCar Pilot Project Proposal}

A reviewed draft of the eCar Pilot Project was introduced during the second workshop presentation. The overall project objective was modified on the basis of further stakeholder input to read as follows:

"Establish if electrical vehicles are an energy-efficient and costeffective mode of transport in Samoa, while at the same time contributing to an urgently needed reduction of $\mathrm{CO}_{2}$ emissions"

There was support for a set of subordinate objectives as follows:

- Determine if BEVs are suitable for Samoan driving conditions

- Determine transport cost of BEVs 
- Determine operational and maintenance requirements of BEVs

- Determine local BEV servicing capacity requirements.

The eCar pilot project fleet was designed to represent the widest possible everyday use options of the current conventional vehicle fleet. The BEV fleet consists of: two-three compact sedans, two-four mid-sized sedans, one minibus and five eScooters. At this stage no BEV version of a utility vehicle is available. A total of three recharge stations with a daytime capacity to recharge $2 \times 16 \mathrm{kWh} B E V$ batteries in five hours were proposed to be installed at a high visibility government car park (TATTE Building), the Faleolo International Airport and an as yet unspecified location.

The composition of the BEV fleet and the location of the recharge stations was largely determined by stakeholder requests. For example, the inclusion of the minibus and the number of mid-size sedans took into account the requirements of tourist operators and rental car companies as well as government agencies. The location of a recharge station at Faleolo International Airport was largely requested by tourism and rental car companies as their tourist pick-up and drop-off services commence and end at the airport. The discussion about the third recharge station location is still ongoing. Government department requirements were largely determined by public relations prerogatives and demands for promotion and education in the application of BEV in everyday use.

There is considerable interest in the collection of operational data from the BEV fleet. However, private and government sectors have different interests in data types. For example, private sector interest is mostly focused on obtaining operating cost under Samoan driving conditions and the logistical requirements of battery recharging. The government agencies' interest is concentrated on policy implications of BEV use (what car type, cost, drive cycle data and maintenance capacity requirements etc.).

Additional information is required for BEV car servicing and capacity building. A robust servicing training package and a spare part supply agreement are 
negotiated with the suppliers of BEVs. The agreement may involve the creation of a specific training program for prospective BEV servicing mechanics, jointly managed by the agents of the BEV suppliers and the implementing Samoan government agency.

In order to guarantee orderly and professional use of the BEV test fleet and ensure the quality of collected data, selection criteria for test drivers and clear data collection instructions are required. In order to ensure the involvement of a wider group of private and government stakeholders and to ensure no sector monopolises BEV usage, BEVs will be rotated between stakeholder groups for specified times according to a 'test driver contract'. The agreed upon data collection requirements from the test fleet are as follows:

- Daily drive cycle data, BEV and CV: e.g. travel type, odometer readings, breakdowns, servicing history, comments;

- Daily recharge data, BEV: e.g. overnight plug-in times, daytime recharge times, breakdowns, comments;

- Fuel use data of CVs: (e.g. distance travelled (km) and fuel used (I));

- Monthly data compilation, BEV\&CV: e.g. drive cycle and recharge data.

In addition, data is required regarding capacity building and EV infrastructures to test car manufacturers' training programs are effective for car servicing, operation and maintenance training. Similarly, capacity training in PV recharge units' operational and maintenance schedules needs to be monitored.

\subsubsection{Cost Benefit Considerations}

There was general support by workshop participants that the potential introduction of BEVs is governed by the overall aim to achieve the:

'Greatest public good for the greatest number of Samoa's citizens while also taking into account intergenerational justice' 
During the workshop presentation the different cost profiles of BEVs and CVs were used to illustrate everyday financial trade-offs between the different transport modes and to explore likely externality cost, associated with transport. The costbenefit examples considered here are limited to direct economic cost of BEVs and CVs and externality cost estimates wherever possible.

As discussed, modelled fuel cost of BEVs were considerably cheaper than fuel cost of CVs mainly because of significant differences in energy conversion efficiencies of the electric motor and large diesel generators. The increased efficiency led to lower operating cost, reduced $\mathrm{CO}_{2}$ emissions and saving of foreign currency reserves. On the other hand however, capital cost of BEVs is presently higher than CVs although purchase prices for BEVs have declined significantly over the last few years. In this analysis a price differential between BEVs and CVs of US $\$ 10,000$ is used. Thus, savings from BEV operations may be used to offset their higher capital cost.

Various pay-back scenarios however highlighted just how complex such a nominally simple trade-off calculation may become. The simplest although unrealistic scenario is illustrated in figure 6.1 where the assumption of constant fuel savings leads to an amortisation of the more expensive BEV capital investment within 13 years. It needs to be appreciated, however, that any future projections of fuel savings and thus costs and benefits to society may be subject to a range of global and local economic interferences which may affect fuel prices. These include but are not limited to:

- possible 'major systemic financial failure' (World Economic Forum, 2013);

- even higher likelihood of continuing fiscal imbalances for many world economies (World Economic Forum, 2013);

- exchange rate fluctuations affecting fuel import cost;

- possible establishment of a carbon management regime (carbon tax, carbon trading) with implication for transport cost;

- changes in EPC electricity charging schedules. 
In addition, a substantial development effort into renewable energy, BEV and biofuel car design is currently taking place and may reduce the price differentials between $\mathrm{CV}$ and BEV prices and renewable energy cost as evidenced in the last two years (Martinot, 2013b). These interferences and developments will all impact on investment pay-back analysis for future transport policy reviews.

It would seem more realistic to allow for some degree of inflationary impact on the pay-back time of the more expensive BEV capital investment. In order to illustrate an inflation impact, a conservative five per cent annual fuel price inflation is assumed to affect the travelling public throughout the study period and is compared to constant fuel savings by BEV users at 2014 prices. A net three per cent saving on annual fuel expenses for BEV users consists of a two per cent inflationary impact on electricity charge out rates whereas the full five per cent fuel price inflation affects $\mathrm{CV}$ users. The differential estimate between two per cent electricity charges and five per cent fuel price inflation arises because of the relatively more efficient energy conversion of the industrial EPC electricity generator sets as compared to the internal combustion engine of vehicles. This leads to a net and cumulative increase in fuel savings by the BEV user who is then able to pay back his/her BEV investment in 7.5 years instead of the 13 years pay-back period for constant inflation and savings at 2014 prices. Regardless of the accuracy of the assumed inflation rate, differential fuel inflation will reduce the pay-back time of the BEV capital investment. 
Figure 6.2: Pay-back times for BEV capital investment based on two inflation scenarios, (US \$).

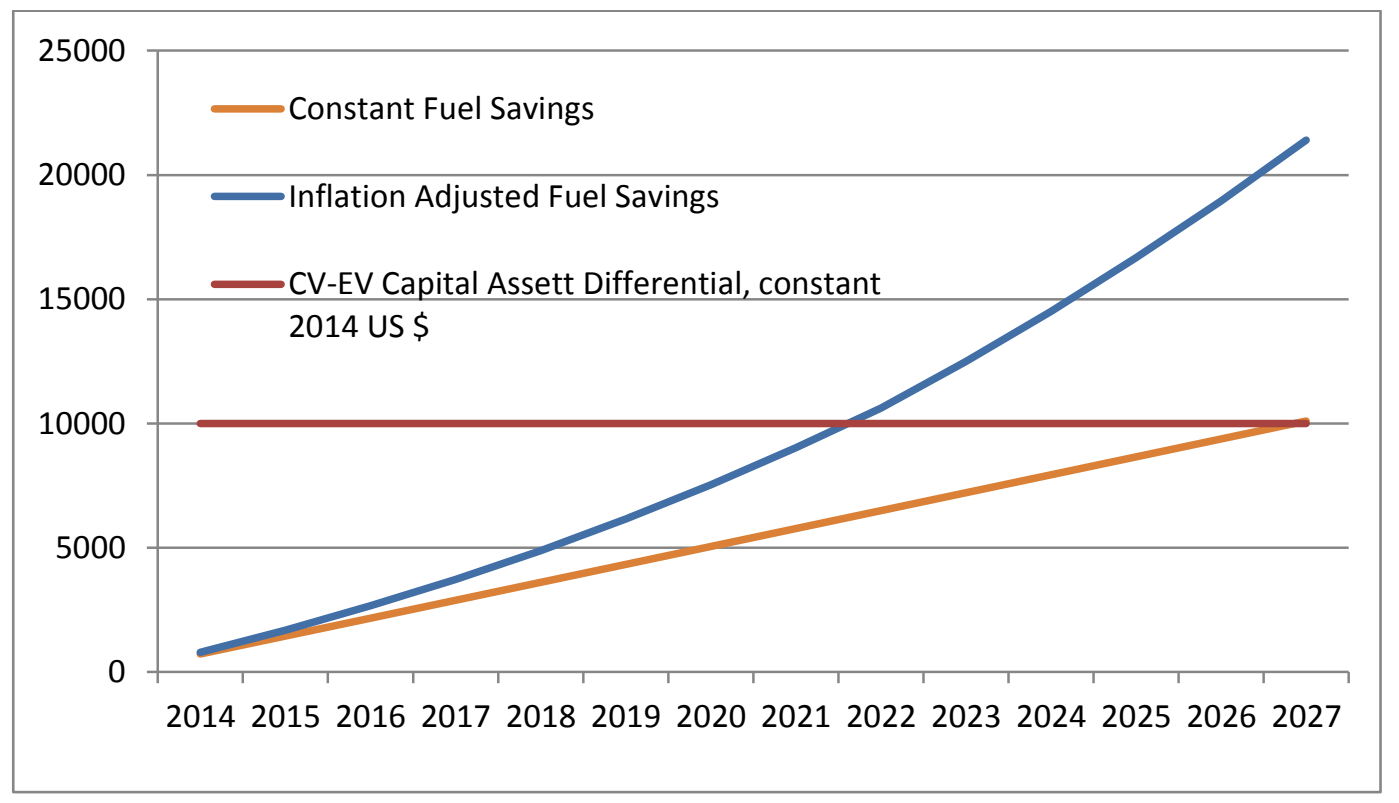

The addition of externality cost makes trade-off calculations even more complex, particularly as accurate data are difficult to obtain and are not available in Samoa. However, we can assume that in relative terms negative externality cost is created by the travelling public and thus may be added to vehicle operating cost. In principle there is agreement that negative externality cost may be allocated within the following segments (Victoria Transport Policy Institute, 2013):

- Environmental damages - environmental damages from processing and bulk transport, but also oil/fuel spills and emissions by transport fleet and urban storm water runoff ${ }^{24}$.

- Health risks - injuries and illnesses resulting from traffic activity but also from air pollution caused by the transport fleet and electricity generation. An example is a significant air pollution plume caused by the 'Apia rush hour';

- Depletion of non-renewable resources - depriving future generations of resources with associated net present value implications;

\footnotetext{
${ }^{24}$ There is anecdotal evidence to suggest that considerable amounts of fuel, oil and presumably heavy metals like zinc and copper are draining into Apia lagoon.
} 
- Financial subsidies - various financial subsidies to resource production industries affecting the price of imported fuel;

- Macro-economic impacts of importing fuels draws scarce financial resources away from other productive activities

- Security risks - not all that relevant in Samoa but still instrumental in influencing global price of oil;

Literature on fuel externality cost is immense and contradictory. Estimates of the 'well to fuel tank' negative externality cost range from around US $\$ 0.8 /$ litre to \$4/itre (Anair \& Mahmassani, 2012; Victoria Transport Policy Institute, 2013). Clearly, at such additional cost current economic activity would have to undergo fundamental and, in the short term, unacceptable changes.

Accordingly, examples of some externality cost estimates incurred in Samoa by BEVs and CVs are as follows:

1) Direct operating cost. BEVs are 15 per cent to 48 per cent more efficient than CVs depending on car type leading to reduced fuel imports and lower operating cost. There is anecdotal evidence to suggest that BEV car maintenance is significantly cheaper than $\mathrm{CV}$ maintenance. However, maintenance data need to be confirmed in the Samoan context. There may be higher insurance cost for BEVs.

2) Health cost: International studies suggest a significant adverse health effect by ICE exhaust fumes, particularly in urban locations. An example of average air pollution cost per metric ton of pollutant gases from the USA is: VOCs US\$ 7,510; CO US $\$ 1,677 ; \mathrm{NO}_{x}$ US $\$ 13,297$; PM-10 US\$ 36,835; PM-2.5 US\$ 118,552; $\mathrm{SO}_{2}$ US $\$ 21,873$ (Thomas, 2012 p. 798). The health costs caused by traffic fumes to the Samoan public and health system are assumed to be significant in the mid-term.

3) Environmental cost: Examples are GHG emissions and urban storm water runoff, heavy metal accumulation, oil compounds leaching into the coastal environment and entering the food chain. Modelled GHG emissions from EVs 
are 57 per cent lower than CVs. In 2030 lifecycle GHG emissions for CVs are estimated to be less than $100 \mathrm{~g} / \mathrm{km}$ and as low as $50 \mathrm{~g} / \mathrm{km}$ for BEVs (Contestabile et al., $2012 \mathrm{p}$ 13). BEVs remain with a relatively smaller footprint.

Although Samoan externality cost data are not available at present, we can allocate externality cost in relative terms. Accordingly, we can consider fuel cost savings from operating BEVs as disposable income available for other purposes including repayment of the capital investment towards the BEV as per figure 6.1. The as yet undefined but nevertheless incurred negative externality cost, particularly in the health and environment sector, then needs to be proportionally allocated to CVs and BEVs (BEVs still discharge some lubricants and other pollutants in the environment). It is however safe to assume a relatively higher negative externality cost allocation to CVs due to ongoing higher fuel consumption, higher lubricant use. As discussed in chapters 3.4.1. and 3.4.3. total lifecycle emissions incurred by CVs are higher than for BEVs, although definitive data depend on a range of assumptions including carbon intensity of electricity generation and the CV fleet and capacity of BEV battery packs (Contestabile et al., 2012 p 13; Slater \& Dolman, 2009 p 61). For the purpose of this study, build-in externality cost arising from car manufacturing is excluded and will be addressed at a later stage.

In figure 6.3. relative and cumulative savings are expressed as the vertical difference in US $\$$ between the three different savings variables, inflation adjusted and constant and externality cost estimate. Pay-back times of the BEV investment are illustrated by the crossing of the different savings variables with the CV-BEV differential US $\$ 10,000$ investment line. For example, using the same assumptions as in table 6.1 (mid-size sedan, $40 \mathrm{~km}$ daily drive cycle) and the example data in figure 6.3, BEV use has saved US $\$ 5047$ in inflation unadjusted fuel cost after six years of operation and under that scenario would require a total of 13.5 years to amortise the BEV investment. By making some additional fuel inflation assumptions BEV use is able to save an additional US $\$ 2485$ for a total of US $\$ 7532$ in six years. The BEV investment is paid back in a little over seven years. If we internalise the externality cost estimate in the form of relative savings of US $\$ 2268$ achieved by the 
BEV (relative to the CV), we are able to achieve a pay-back time of six years of our BEV investment and have saved a total of US $\$$ of 9800 over that period.

If we also consider that the capital cost premium of BEVs compared to CVs is likely to decrease in line with ongoing savings trends observed during current BEV commercialisation then we are safe to assume that the pay-back times will decline further.

Figure 6.3: Illustrated pay-back times for BEV capital investment including internalised externality cost (US \$).

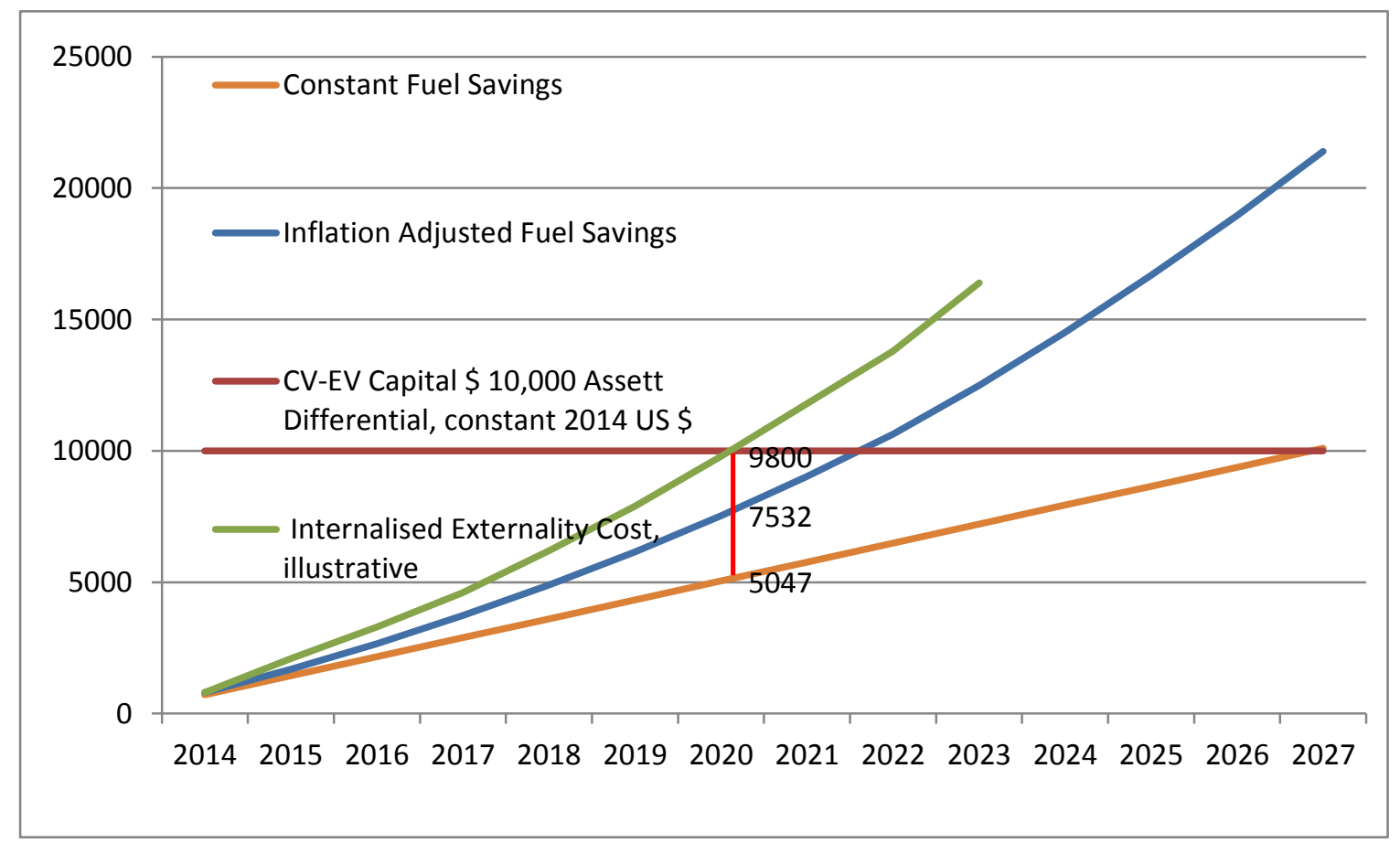




\subsection{Preparation of Samoan Government Cabinet Submission}

A logical conclusion of the workshop series and my action research cycle was the preparation of the eCar pilot project cabinet submission for consideration by the Cabinet Development Committee and the executive National Energy Efficiency Coordinating Committee (NECC). The eCar pilot project proposal formalised the detailed project design which resulted from the second participatory workshop. The workshop pilot project objective was adopted as follows:

"Establish if electrical vehicles are an energy efficient and costeffective mode of transport in Samoa while at the same time contributing to an urgently needed reduction of $\mathrm{CO}_{2}$ emissions".

Subordinate objectives were also adopted as follows:

- Determine if BEVs are suitable for Samoan driving conditions

- Determine transport cost of BEVs

- Determine operational and maintenance requirements of BEVs

- Determine local BEV servicing capacity requirements

As team member of MNRE-RED, I was given authority to draft the proposal and initiate a final round of consultations with MOF, the executing agency, and the EPC and LTA, the other two implementing agencies apart from MNRE. It is debateable if my position as intern should have given me the authority to draft the proposal but I had achieved the confidence of the ACEO as part of my evolution from intern to temporary insider. A direct and significant advantage was the 'buy-in' I had already achieved from all these agencies, who were active participants in the workshop series. The draft was vetted by all assistant chief executive officers of the participating agencies, submitted on the 4 November 2013 and approved on the 27 January 2014. At the time of writing this thesis, the Ministry of Finance as the executing agency has undertaken to source funding for the BEV hardware from the 
Japanese Government and other project funding from donor agencies. A complete version of the eCar pilot project submission is presented in appendix 9.3.

In conclusion, the research result section has presented a wide range of findings which marked the different stations of my action research. Literature review findings about technical developments in electro-mobility, the evolution of climate change mitigation goals and global stakeholder perceptions about viability of electro-mobility formed the 'outside' information I thought as action researcher applicable to the Samoan transport sector. In order to make these outsider findings relevant I needed to apply them to the everyday transport situation in Samoa. This attempt is presented in the form of comparative fuel use data and the modelling of a nominal $\mathrm{BEV}, \mathrm{CV}$ and $\mathrm{BDV}$ fleet producing respective transport cost to the travelling public, $\mathrm{CO}_{2}$ emissions and effects on currency reserves necessary for international trade.

The first participatory workshop marks the beginning of my wider interactions with Samoan transport stakeholders and my attempt to enter constructive communication and resulting iterative learning, exchanging of information and reflecting as a group with a common interest in the improvement of the transport sector. As it became apparent that electro-mobility may have a place in Samoa's transport sector, interaction grew greatly and took on its own momentum. Information flowed freely and the action researcher could start defining the shape of the eCar pilot project. All the while participant feedback from informal conversations, semi-structured interviews and newly found contacts completed the transport picture and the potential place of BEVs within it.

The second participatory workshop was designed to act as clearing house and dissipation platform for all new information gained since the earlier workshop. Increased attendance reflected a 'buy-in' into the electric-mobility investigation and cumulated in the formulation of objectives for the eCar pilot project by workshop participants. I received further support to prepare the 'eCar pilot project for submission to Cabinet and the NECC. 
The study has covered a wide range of the rapidly evolving EV technology. It also took some time to elaborate on the justifying arguments for making electromobility a major contributor to global $\mathrm{CO}_{2}$ emissions reductions. Apart from uncertainties regarding technical viability, access to electro-mobility will be seriously restricted for the large majority of the Samoan travelling public. I analyse this problem with a postdevelopment perspective and propose some unorthodox solutions which are not visible within our current development paradigm. In this endeavour my action research approach has helped me greatly to see and hear, what Samoa's perceptions of modernity in the transport sector may mean. 


\section{Chapter Seven: Discussion}

\section{1. $\quad$ Outline}

In the previous chapter I presented the results of my action research project informing Samoan transport stakeholders about global transport innovation. The workshop participants and the action researcher jointly learned how this information could be applied to the local transport sector. Global information needed to be specific about the 'big picture' motivations of the international research effort, namely climate change, and its implicit relevance to Samoa. Two participatory workshops were held and aimed at mutual learning, reflecting on outsider and temporary insider information and confirming relevance. The common learning experience cumulated in the preparation of the eCar pilot project proposal. In this chapter, I discuss my findings from a postdevelopment perspective and show how Samoa's transport sector could be made more resilient to external economic shocks and at the same time contribute to global climate change mitigation.

\section{2. $\quad$ Research Project Summary}

Before I discuss in detail my research finding from chapter Six, I precede a summary of various findings of my investigation. The literature review needs to be considered as a basis of my 'outside' research as it served me well in sketching out the shape of alternative transport options. The review very soon pointed to electromobility which is experiencing a lot of research attention and is in the early stages of commercialisation. Car manufacturers are increasing the production of BEVs and a number of governments and institutions promote electro-mobility in metropolitan countries. We learned that technical innovation is progressing rapidly, mainly in the field of battery capacity, cost and recharge technology and the cost of EVs has begun to decline.

We also learned that BEV innovation is largely underpinned by institutions who are very concerned about the adverse effects of $\mathrm{CO}_{2}$ emissions from the 
transport sector on climate change. According to the REN21 survey there is widespread support by global transport stakeholders which is also reflected in a wide range of government support at national and regional level. The EVI initiative best illustrates how various forms of collaboration between government agencies, INGOs and civil society may alleviate a global market failure to efficiently respond to climate change. Moreover, the EVI initiative has given confidence in further development of a nascent BEV market and seen early BEV/PHBEV commercialisation targets met up to 2014 (see figure 3.1).

Widespread adoption in metropolitan countries, however, is still facing considerable hurdles as electro-mobility has still some limitations in comparison to CVs, the main ones being driving range, battery cost and battery life expectancy. We need to keep in mind, however, that these BEV specifications and limitations pertain to the driving conditions of larger metropolitan countries and greater convenience and performance expectations of highly developed consumer societies.

Accordingly it comes as no surprise that the Samoa Energy Strategy 20122016 has been anticipating the advent of more efficient transport technology in the conventional belief that appropriate and relevant transport innovation will be disseminated in time and become available to the Samoan travelling public. After all these policy assumptions are based on a rather monolithic innovation process consistent with the Eurocentric worldview. In reality, however, we discover that the economic trajectory of Samoa with its chronic and structural balance of payments deficits and low GDP per capita (US \$3,160 in 2011) will only ever allow a limited penetration of BEVs as per the EVI initiative. In other words the Eurocentric version of sustainable transport is not working for Samoa if we accept conventional definitions of utility as the aim to achieve the 'greatest public good for the greatest number of Samoa's citizens'. But could we necessarily conclude that electro-mobility is inappropriate for Samoa's ambitions to develop a sustainable transport sector? Only if Samoa adopts the unique commercial BEV specifications designed for the metropolitan North from far away. 
In order to make progress in the identification of sustainable transport practices, a deconstruction of some notions of modernity was necessary to identify values and priorities for the Samoan travelling public. Aspects of this emancipation process may include giving different meanings to expressions of modernity and be aware of the tensions created by the worldview dichotomies of the Pacific Way and Western modernity. These dichotomies may include communal/individual, consensual/confrontational, cooperative/competitive, reciprocal/profit oriented, Christian/secular perspectives and, most confusingly, ongoing hybridisation of these worldviews. Some of these worldview manifestations and their further evolution into extraparadigmatic space may well be more suited to overcome the adverse effects of fuel dependency than what the current modernist development project can offer.

Given, the current experience of car use in Samoa does not show much awareness of environmental issues nor rationality in the use of a limited and expensive (fuel) resource. The current status quo in the transport sector may well lead to a continuation of the myopic pervasiveness of Eurocentric consumer society.

Nevertheless, a postdevelopment-inspired approach does provide a tangible and practical rationale to address fossil-fuel dependence by using a participatory problem solving method to enable participants to identify the more complex forces behind fuel dependence. Moreover it can point to considerable savings in vehicle operating costs. And it connects the global with the local with the introduction of the transport externality cost concept to illustrate the full impact of conventional transport on the environment and society in general. Postdevelopment thinking may even encourage further transport policy review by promoting electro-mobility in the form of a more complete 'resource user pays system' placed on fossil-fuel powered cars.

As discussed previously, none of these employed methodologies can claim exclusive postdevelopment parentage and indeed they are employed within other conceptual frameworks. However, I would argue that with postdevelopment theory's interest in extraparadigmatic space, in particular now expanded by the GFC and the political economy of climate change, these methodologies have the potential to create Samoa's own version of modernity in the transport sector. 
We will follow this line of thinking towards the possibility of retrofit BEV conversions to illustrate contemporary postdevelopment thinking in offering new possibilities of tackling fossil-fuel dependence. However, before we do so, I place this study in the context of Samoa's various policies governing the transport sector as my internship with MNRE-RED obliged me to accommodate my study within existing legislation. As we learned in chapter 2.4.2., the SESP 2012-2016 does provide ample space to accommodate alternative forms of transport and does in fact anticipate its eventual introduction.

\subsection{Transport Policy and Electro-mobility}

The use of electricity as transport energy will require a lot more integration of legislation governing the transport and energy sectors as potential BEV adoption would add vehicles as significant electricity users. There are already good examples of policy integration in the form of Samoa's 'Strategy for the Development of Samoa (SDS) 2012-2016' which is designed as an overarching piece of planning legislation which gives direction to other sectors. The SDS clearly recognises the cross-cutting nature of sustainable transport and tries to encourage its development within its defined National priority areas. Accordingly, the transport sector visions are found in the infrastructure priority area, namely as outcome 10 'Efficient, Safe and Sustainable Transport Systems and Networks. Sustainable transport systems are interconnected with other priority areas in the environment sector as key outcome 14 , namely 'environmental sustainability' and again in the infrastructure sector as outcome 12 specifying sustainable energy supplies (Government of Samoa, 2011c). For specific guidance we need to go to the Samoa Energy Sector Plan (SESP) 20122016 where the overarching objectives and high level indicators for sustainable transport are outlined. The overall sector objective is:

'To reduce the growth rate in the volume of imported fossil fuels by 10per cent by 2016'(Government of Samoa, 2011c p 18)

The successful outcome of this policy is expected to be achieved by an 'efficient, sustainable, safe and cost effective energy use in the transport sector'. 
Moreover, the SESP anticipates the eventual availability of BEVs under section 5.6. (Government of Samoa, 2011c p 27). The introduction of BEVs is intended to help achieve the above objectives. In particular, it observes that capital cost of BEVs is already declining and it sees a complementary fit with other existing policy objectives promoting future growth in electricity generation with 'growth in the renewables' sector. Thus, there is an excellent policy fit with my BEV feasibility study as was anticipated in chapter One.

Comparative fuel use results presented in table 6.1 of chapter Six show fuel efficiency advantages of all different BEV vehicle types and moreover provide tangible data supporting the qualitative assumptions on the eventual introduction of BEVs made in the SESP. Given, these data are also partly based on assumptions and are not collected from drive cycle data which are unfortunately not available in Samoa. However, this attempt is the first time Electric Power Corporation (EPC) electricity cost (August 2013) are used in conjunction with BEV manufacturers' electricity use specifications to determine energy consumption. The fact that Samoan drive cycle data are necessary for any fuel use efficiency evaluation but are not available at this stage needs to be considered as a finding of this study. The usefulness of Samoan drive cycle data for any future transport policy review found support from participating transport stakeholders.

The partial confirmation of superior energy use efficiency by BEVs under Samoan driving conditions has also provided a starting date for more concrete planning towards electro-mobility should the Samoan government choose to do so. And as I will discuss later on in theoretical deliberations about some practical implications of postdevelopment theory, the ability to pull forward the advent of electro-mobility was achieved not by waiting for Eurocentric innovation to arrive at Samoa's shores but by using a postdevelopment lens trained at seeking to identify a potential alternative transport mode suitable for Samoan conditions.

In table 6.2 the effects of a modelled 1000 vehicle fleet of CVs, BDVs and $\mathrm{BEVs}$ on annual fuel use, $\mathrm{CO}_{2}$ emissions and Samoan currency reserves data are 
presented. Apart from the expected energy efficiency difference, a surprising discovery was the relatively small amount of fuel savings of the biodiesel transport mode compared to the petrol powered sedan. However, on closer analysis the small savings are consistent with the high purchase price of biodiesel at this stage. The data set provoked commentary from workshop participants as the transport policy community had higher hopes in the cost effectiveness of biodiesel as a locally produced alternative fuel.

Significantly lower $\mathrm{CO}_{2}$ emissions from BEVs and BDVs can also be seen as a cross-cutting benefit for Samoa's GHG abatement effort. As alluded to in chapter 2.4.2., the National Greenhouse Gas Abatement Strategy 2008-2018 has acknowledged that emissions from the transport sector contributed the largest proportion of 27 per cent of National GHG emissions (Government of Samoa, 2008b). These developments are picked up in objective 1 of the National Greenhouse Gas Abatement Strategy to aim at 'reduced GHG emissions from the land transport sector'. Expected outcomes are increased energy efficiency in motorised land transport. In order to achieve increased efficiencies, strategies explicitly mention the introduction of electric vehicles to increase fossil fuel use efficiency (Government of Samoa, 2008a p 4). The results of the fuel cost comparison add further evidence to the fuel use efficiency strategy.

$\mathrm{BEV}$ adoption is generally promoted in line with the use of renewable forms of energy as life cycle assessment literature finds a strong correlation between energy source and BEV vehicle footprint (Slater \& Dolman, 2009; Thomas, 2012). Accordingly, the footprint effect of a BEV powered by electricity generated by a coal fired power station is larger than electricity generated from renewable electricity sources. The same argument does apply to footprint impacts of electricity generated by diesel. There are however, some special circumstances in the Samoan situation which need to be considered.

Firstly, there is the somewhat counter-intuitive fact that BEVs powered by diesel generated electricity are more efficient than direct consumption of fuel in ICEs. Electric motor design in cars is up to three times more efficient than ICEs. In 
addition, large scale diesel generators are up to 85 per cent more efficient than ordinary ICEs. Put together, these efficiency gains more than enough to compensate for losses in energy conversion and the electricity grid.

Secondly, in small island economies diesel generators often provide the only affordable form of base load electricity generation due to economies of scale. Forms of renewable energy will progressively be used to substitute a percentage (up to 30 per cent) of base load generation capacity but until the arrival of reliable, renewable energy technology to replace the entire base load generation requirement, diesel generators will be part of the electricity generation mix. Thus, there is an inferior foot print of BEVs operating on diesel generated electricity compared to renewable electricity generation, however, compared in relative terms against CV performance, BEVs perform significantly better.

Thirdly, BEVs may eventually be recharged by self-consumption PV installations giving BEV technology more flexibility and potential cost savings in vehicle operation than $C V$ vehicles. In the early stages of $P V$ innovation, the price to pay for cost savings and flexibility is the acquisition of some technical knowledge in this field and the recognition that BEV recharge infrastructure requires a maintenance commitment. Thus, overall electro-mobility is relatively more energy efficient compared to the conventional traffic mode but it requires some flexibility and preparedness to learn how to operate BEVs and its distributed power supply. The gradual integration of renewable forms of energy will directly benefit electro-mobility.

The eCar pilot project may bring to light another desirable aspect which may favour a more independent development for Samoa. Should the eCar pilot project data confirm Samoan drive cycle statistics and energy uptake estimates, an unusual turn of events emerges where technical innovation emanates from the industrial North where electro-mobility currently struggles to meet the high expectations of metropolitan consumer societies. In isolated Pacific Islands, however, the current technical specifications of electro-mobility already meet the requirements of the islands' transport sector and could make the transformation towards sustainable forms of transport easier and faster. What makes the potential 'leapfrog' from 
transport energy dependency ahead of the North conceivable is the possibility to reassemble the crucial components of electro-mobility, both culturally and technically, within Samoa's capabilities. Again, postdevelopment thinking can assist by providing different views on conceptions of modernities, viability of current economic dogma and the role of local communities and grass roots movements in creating authentic modernities within a global sustainability. What an unexpected twist of the accustomed hegemonic discourse of the North-South technology gradient.

\subsection{Participatory Action Research}

The itinerary of my participative action research is more difficult to analyse and best visualised by the complex loops of iterative follow-ups and new information discoveries along the way of my participative workshop series (see figure 5.1). I will, however, propose three stages in my action research program commencing with time required to gain credibility with my colleagues at the MNRE-RED, the participative workshop phase working with transport stakeholders towards a shared goal and making outside information relevant, the preparation of the eCar pilot proposal which showed project 'buy-in' and my full immersion in the everyday 'politics' of MNRE-RED.

Credibility, reliability and loyalty of the researcher in relation to the employer and colleagues needed to be demonstrated over a certain time span. This process may well be considered a reasonable sequence of events in any professional organisation, however, it became obvious after a period of time that the reputation of research interns and in particular master's students was one of obligation with considerable responsibilities and little tangible benefits. From the point of view of MNRE officials master's candidates tended to undertake some form of policy analysis, do desktop research and interviews with little if any benefit to the host organisation. Repeated comments were that in Samoa the indigenisation of the policy analysis capability of the public service is advanced and rarely in need of outside support. This stands in stark contrast to high needs in applied field research and project support. In other words, master's thesis research activity needs to be redirected towards applied research from the point of view of Samoan public service 
officials. There could also be some other motivations behind this sentiment but within the scope of this research project these opinions are taken at face value. During subsequent interviews and conversations some of these opinions could be triangulated with findings in the field and verified.

From the perspective of this action research project, the main task was now to establish credibility for the electric mobility study by pointing out the direct and applied nature of my research objectives and the potential benefits to be gained by the driving public by reducing car operating cost and to the Samoan government by meeting treaty obligations and reducing expenditure of reserve currency. It was not hard to demonstrate that my activities were not focused on policy analysis, accounting practices and moreover, the project was self-funded which was met with some surprise by my colleagues. The success of the first participatory workshop on 27 August 2013 can be considered the beginning of the 'collegial phase' of my action research where the researcher became the temporary insider of the MNRE-RED and the beginning of the iterative learning, feedback and reflection process which led to the proposal of the 'Draft eCar Project'.

Nevertheless a considerable period of time needed to be spent to communicate the purpose of my hands-on research project in the face of a somewhat polite resistance of having to waste some time on research mainly benefiting the student. As my credibility increased beyond the narrower circles of my immediate colleagues, there still was some anxiety at senior MNRE management level that some of my interests could be directed at 'spying' at MNRE activities on behalf of the New Zealand government. Such a point of view may be symptomatic of tensions in the larger donor-recipient relationship with New Zealand and real or perceived anxieties which have arisen from those tensions.

Some effort was required to make the large amount of 'outside' data relevant to everyday experiences in Samoa. The process of information becoming relevant can clearly be observed by the early delays in holding the first workshop. The workshop was delayed for eight times. Even during the workshop, attention grew instantly once fuel cost savings of BEVs became apparent and participants could 
make the connection between outside information and local requirements. Thus, only when the contents and results of my first section, namely literature review of technical developments, evolving new values in the transport sector as a result of climate change, fuel price inflation and emerging global transport stakeholder support for electro-mobility became accessible, participants started to imagine relevance for the local situation and think creatively about prospective solutions.

With increasing credibility of my position within the MNRE-RED I found it easier to follow up on interview leads, identify further lack of information and gradually 'chisel' the shape of the eCar project in response to the expected and unexpected learning from respondents. Many informal conversations revealed lack of baseline information in the transport sector I assumed to be available as I expected to find a resemblance of a 'Western' type institutional infrastructure. Lack of drive cycle data and fuel consumption of conventional cars are such an example.

A further examination of the economics-environment dichotomy also showed that Samoan informant perceptions were too simplistic with the assumption that economic activity is vital whereas environmental qualities, while desirable, may have to wait until basic economic needs are met. Informants (not only in Samoa) were unaware of the tangible and transport related negative externality costs to the national economy. During these conversations the discussion invariably turned to practical ways to reduce this cost while maintaining economic activity just showing what a powerful tool participatory action research can be in 'learning on the job' for all involved parties.

For example, the presence of air pollution during the Apia rush hour was well known. However, the cost to public health were unknown due to lack of local data, which however may exist in Apia hospital records ready to be uplifted by a person with an interest in public health effects from the transport sector. There may be some awareness of a connection between public health and the transport sector but certainly there has not been any attempt to use externality cost of the transport sector to guide transport policy and/or promote alternative transport modes. 
I opted to present externality cost as part of a rudimentary cost-benefit analysis of the BEV versus $C V$ transport mode. By trading off various direct and indirect costs and benefits of BEVs and CVs, I could calculate the payback periods of the currently higher capital expense of the BEV under various inflation scenarios as well as an indicative negative externality cost scenario. By allowing negative externality cost to be added to the operating cost of conventional vehicles, the Samoan policy community and the travelling public can make more informed decisions about the real cost of operating a CV to the whole Samoan community and environment.

The fact that Samoan negative externality cost data are not available may be seen as a deficiency in the tool box of public policy or a nice technicality not affordable in a developing country. However, on the other hand the process of collecting transport externality data and various conversations with my colleagues about ways to find some of these missing data would have given more substance and local relevance to the concept of negative externality cost than reading a scientific paper about the topic. In fact, I still receive feedback from my colleagues about the benefits of putting some 'figures towards externality cost' which was a foreign concept to many.

Conversations and curiosities often involved the 'nuts and bolts' of the eCar pilot project and even more its follow-up stage phase, the village-based retrofitting of second hand vehicles. Literature and conversations with respondents suggested that a certain degree of affinity on the part of BEV technology users needed to exist for some moderately demanding tasks to maintain and service vehicles on an ongoing basis. In fact, according to Dr Leti Taulealo of the Samoan Public Service Commission this assumption may be fraught with some difficulty. Dr Leti Taulealo pointed to a culturally-acquired affinity with servicing complex technology which was acquired in metropolitan innovator countries over a long period of time but is not necessarily available in technology receiving countries of the South.

Indeed, experience with recently introduced PV technology in the PICs seems to support that point where failure to integrate technology into the local context has 
led to breakdowns and failure (Lefale \& Lloyd, 1993; Lloyd \& Tukana, 1990). Ungaro has found similar adoption problems when evaluating existing PV installations in PICs and proposes that more emphasis is placed on end-user participation and education (Ungaro, 2012).

Although I understood the maintenance issue on a theoretical level, I found this local information very reassuring and it is reflected in a capacity training component in the eCar pilot project. Although the stage Two segment of BEV introduction is not directly a part of this research project, the expected BEV maintenance skills outcomes are also hoped to be leveraged to allow more skills being transferred to the village based retrofit conversion of second hand cars.

The successful workshop on 6 November 2013 and support for the drafting of the eCar pilot project cabinet submission marked the transition into the stakeholder buy-in of the project. The eCar now needed support on the political level as well and on several occasions stakeholders and former workshop participants came to the 'defence' of the eCar project.

\subsection{Reflections on my Postdevelopment Approach}

After reporting on tangible results of my research and how these findings may be helpful within Samoa's transport policy and reflecting on my participatory action research experiences with my colleagues and respondents this final section reflects on implications this research may have on contemporary postdevelopment thinking.

Fuel comparison results (tables 6.1 and 6.2) have shown that even with diesel generated electricity BEVs are less expensive to operate than CVs, emit significantly less $\mathrm{CO}_{2}$ and have a positive effect on Samoa's foreign currency reserves. Any further technical issues arising from BEV use in Samoa's driving environment will be identified by the eCar pilot project and give the Samoan government some certainty about the usefulness of electro-mobility in tackling fuel dependence. And yet, electromobility as envisaged and promoted by Eurocentric transport stereotypes will remain unaffordable for a large proportion of Samoa's travelling public. This constellation is 
unlikely to change even if economies of scale in BEV production will lead to significant cost reductions. Given Samoa's economic trajectory and GDP per capita, the required cost declines may well be beyond metropolitan BEV manufacturer's ability to economise.

I would like to propose that we use postdevelopment thinking to deconstruct the notion of electro-mobility and concentrate on those components which may be useful to Samoa's transport sector. On closer analysis of electro-mobility we note that it can mean the ownership of an expensive BEV, inexpensive eScooter, membership of a BEV car sharing club or ownership of a retrofitted second hand BEV. Thus, there are several options to economise on transport operating cost but judging by the composition of Samoa's car fleet and the frequent occurrence of expensive cars with many features not useful on these small islands, the car is also used as a status symbol as in metropolitan countries. However, whereas expensive status cars blend in more readily in the affluent environment of metropolitan countries, in Samoa the tensions created by the car as a symbol for local status are far greater as it uses modernity symbolism from far away and contrasts it with a lot lower levels of material affluence.

Postdevelopment thinking may be useful in the deconstruction of connotations and projections of a fashionable and modern BEV as it is able to counterbalance overseas modernity appeal with local values and reinterpretations of modernity. A pertinent example is Samoa's colourful buses. Technology underneath the bonnet is from overseas, the superstructure is genuinely Samoan. 
Photograph 7.1: Projection and re-interpretation of transport technology
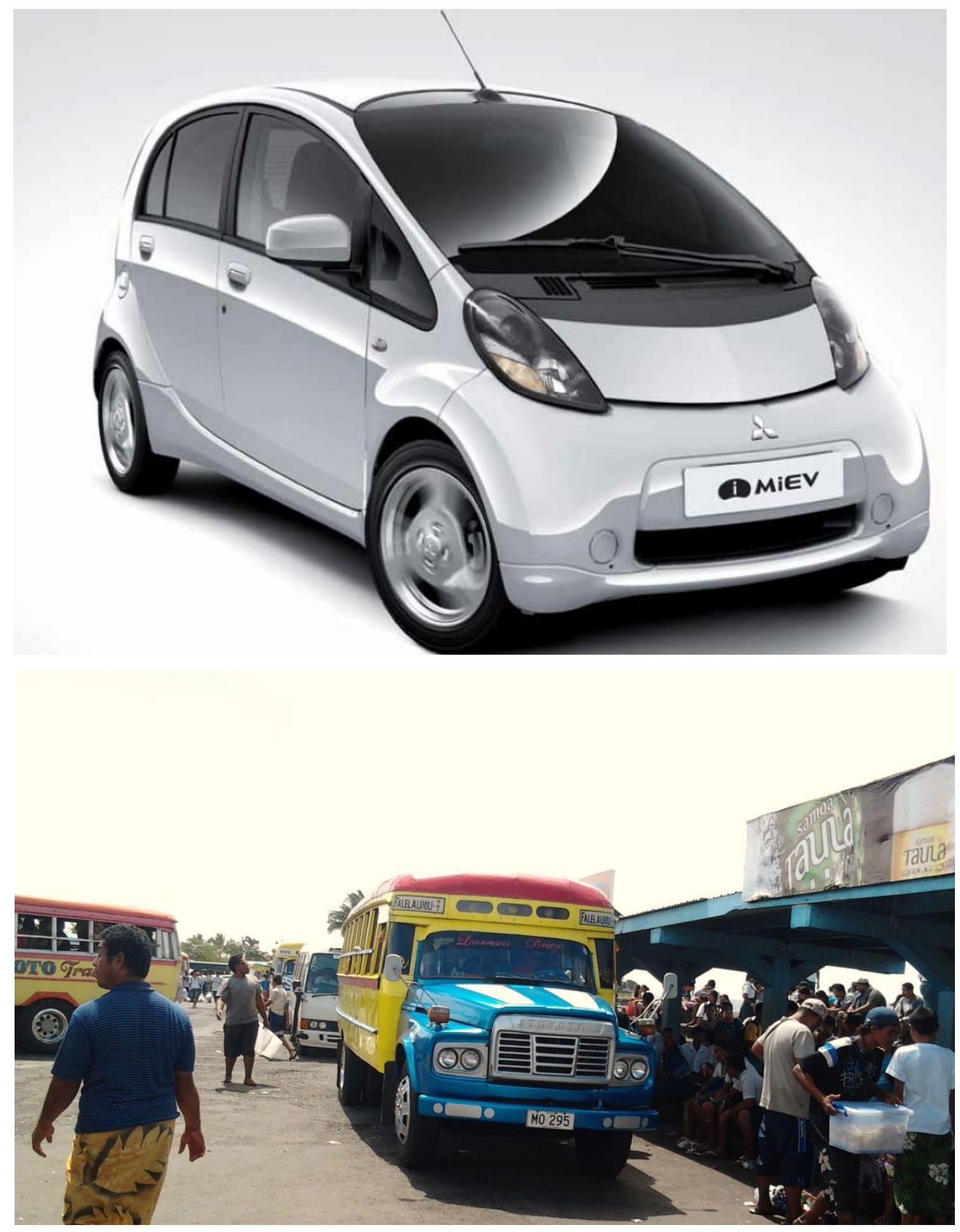

This observation leads us to the recognition that technical innovation still largely radiates along a technology gradient from the centre in the North to the periphery in the South. Consequently, transport technology arrives in Samoa largely 
value added and packaged as an unaffordable consumer good but the opportunity exists to literally deconstruct the 'BEV package' and select components useful for Samoa's transport problem. Such a deconstruction process has already been successfully undertaken by Bunker Roy's Barefoot College movement and resulted in the grassroots electrification program of villages around the developing world (Roy, 2008).

Indeed, the learning trajectory of the eCar pilot project is pointing towards a pragmatic solution of Samoa's transport problem by deconstructing electro-mobility and applying useful components to everyday transport problems. Methodologies employed in the design of the eCar pilot proposal show a high degree of Samoan transport stakeholder involvement which has given the project its Samoan flavour. Tourist industry stakeholders wanted a battery recharge station at Faleolo airport, LTA transport stakeholders wanted to test eScooters with their traffic inspectors and several other stakeholders felt that the availability of an 'eUtility' may help the BEV adoption process with status conscious Samoans. All the while workshop participants never lost sight of the need to build up BEV servicing capacity to be used in phase Two by taking these BEV servicing skills to the villages and converting second hand cars according to village community requirements.

The postdevelopment lens has similarly helped to sharpen the awareness of outside impacts as continuing financial instabilities are predicted by global institutions like the World Bank and the World Economic Forum (IEA, 2009; IEA WEO, 2012; Potsdam Institute for Climate Change Impact Research and Climate Analysis, 2012; UK Department of Transport, 2008; Wade, 2009a; World Economic Forum, 2013). These developments may well lead to a reduction of institutional support capacity at international, national and local level as financial resources become relatively more limited and local responses to climatic and financial calamities require site-specific and timely responses.

The participatory action research methodology has also attempted to solve a quandary within applied postdevelopment thinking, namely how to increase the likelihood that grassroots based decisions are 'wise' within the interconnected and 
cosmopolitan nature of our modern world. Indeed this study shows the quandary clearly as local wisdom and decisions also rely on reliable sources of information from the outside.

Accordingly, the study has tried to reduce actor biases and subjectivities by placing the justification for transport reform within the emerging consensus of international stakeholders, INGOs and government-funded reviews on the matter. While this methodology can still be seen as deficient and inaccurate in various aspects, the absence of cosmopolitan institutions with legal powers to enforce global commons values nevertheless leaves the local and participative initiative at a distinct advantage as long as accurate information channels can be accessed.

Thus, a retreat to the local to regain a sense of self-determination carries with it a set of collective and global responsibilities in the face of threats such as climate change and other global market failures. However, as the experience of postdevelopment grassroots movements like Bunker Roy's village education and electrification program and Jagna City's hybridised experimentation with traditional non-cash and modern cash based economic activities has shown, there are ways to combine the desire for increased local self-determination and self-sufficiency with making use of appropriate and modern technology without ceding much if any village sovereignty while still remaining connected to global developments (Gibson-Graham, 2005; Roy, 2008). The process of selecting modern technology for local application should include a critical appraisal of the merits of technology in the global environmental context and then undergo scrutiny for local relevance. 


\section{References}

Ackerman, F. (2007). Debating Climate Economics: The Stern Review vs. Its Critics. In Global

Development and Environment Institute (Ed.). Medford MA: Tufts University.

ADB. (2007). Key Indicators of Developing Asian and Pacific Countries. Manila: Asian Development Bank.

Agostino Ascione, A. (2003). An Exploration Of The Theory And Practice Of Post Development As An Alternative To Development. (PhD), Universtiy of South Africa.

Alternative Fuel Centre. (2013). Fuel Type Comparison: Alternative Fuel Data Centre.

Anair, D., \& Mahmassani, A. (2012). State of Charge: Electric Vehicles' Global Warming Emissions and Fuel Savings across the United States. Cambridge USA: Union of Concerned Scientists

Anonymous (2013). [Car Inspection compliance].

Arrow, K. (2007). Climate Change: Challenge to policy. Economists Voice, June, 1-5.

Asian Development Bank. (2013). Basic 2013 Statistics. In Economics and Research Department (Ed.). Manila: Asian Development Bank.

Bertram, G. (1999). The Mirab Model twelve years on. Contemporary Pacific, 11(1), 105-138.

Bertram, G. (2004). On the convergence of small island economies with their metropolitan patrons. World Development, 32(2), 343-364.

Bertram, G. (2006). Introduction: The MIRAB model in the twenty-first century. Asia Pacific Viewpoint, 47(1), 1-13.

Bertram, I. G., \& Watters, R. (1986). The MIRAB process: Earlier analyses in context. Pacific Viewpoint, 27(1), 47-59.

BP. (2012). BP Energy Outlook 2030. London: British Petroleum.

Brett, E. (2003). Participation and accountability in development management. Journal of Development Studies, 40(2), 1-29.

Brigg, M. (2002). Post-development, Foucault and the colonisation metaphor. Third World Quarterly, 23, 421-436.

British Petroleum. (2012). BP Statistical Review of World Energy: British Petroleum.

California Energy Commission. (2014). Transportation. Retrieved 23 January, 2014, from http://www.energy.ca.gov/transportation/

Campbell, S. (2013, 18 July). What's the Cost to Own and Operate EVs on Maui?, Maui Weekly. Retrieved from www.mauiweekly.com/page/content.detail/id/511503/What-s-the-Cost-toOwn-and-Operate-EVs-on-Maui-.html?nav=5065\#sthash.JdS2jMw0.dpuf

Camus, C., \& Tiago, F. (2012). The electric vehicles as a means to reduce $\mathrm{CO} 2$ emissions and energy costs in isolated regions. The Sao Miguel (Azores) case study. Energy Policy, 43, 153-165.

Chambers, R. (1983). Rural Development: Putting the Last First. London: Longman.

Chambers, R. (1994). Participatory rural appraisal (PRA): Challenges, potentials and paradigm. World Development, 22(10), 1437-1454. doi: 10.1016/0305-750x(94)90030-2

Chambers, R. (2005). Ideas for Development. London: Earthscan.

Chapman, P. (2009). Samoa prepares to drive on the left The Telegraph. Wellington.

Cloin, J. (2005). Biofuels in the Pacific: Coconut oil as a biofuel in Pacific islands. Refocus, 6(4), 45-48. doi: 10.1016/s1471-0846(05)70431-5

Cloin, J. (2007). Coconut oil as a fuel in the Pacific Islands. Natural Resources Forum 31, 119-127.

Constantino, R. (1985). Synthetic Culture and Development. Quezon City Philippines. Manila: Foundation for Nationalist Studies.

Contestabile, M., Offer, G. J., \& North, R. (2012). Electric Vehicles: A Synthesis of the Current Literature with a Focus on Economic and Environmental Viability (pp. 17): LCAworks.

Contestabile, M., Offer, G. J., Slater, S., \& Jaeger, F. (2011). Battery electric vehicles, hydrogen fuel cells and biofuels. Which will be the winner? London: Imperial College Centre for Energy Policy and Technology. 
Cooke, B., \& Kothari, U. (2001). The Case for Participation as Tyranny. In B. Cooke \& Kothari.U. (Eds.), Participation: the new tyranny (pp. 1-15). London: Zead Books.

Corbridge, S. (1990). Post-Marxism and development studies: Beyond the impasse. World Development, 18(5), 623-639. doi: 10.1016/0305-750x(90)90014-o

Daly, H. E., \& Farley, J. (2011). Ecolocical Economics Principles and Applications (2 ed.). Washington: Island Press.

DARA, \& Climate Vulnerable Forum. (2012). Climate Vulnerability Monitor: A Guide to the Cold Calculus of a Hot Planet ( 2 ed.). Madrid: DARA.

Davidson, J. (1967). Samoa mo Samoa: the emergence of the independent state of Western Samoa Retrieved from http://hdl.handle.net/2027/heb.03584.0001.001

Davies, M., \& Sugden, C. (2010). Macroeconomic Impacts of Energy Prices in the Pacific: Pacific Financial Technical Assistance Centre.

de Sousa Santos, B. (2004). The WSF: Toward a counter-hegemonic globalisation. In A. A. J. Sen, A. Escobar \& P. Waterman (Ed.), World Social Forum: Challenging Empires (pp. 235-245). New Delhi: The Viveka Foundation.

Dewulf, J., Van der Vorst, G., Dentruck, K., Van Langenhove, H., Ghyoot, W., Tytgat, J., \& Vandeputte, K. (2010). Recycling rechargeable lithium ion batteries: Critical analysis of natural resource savings. Resources Conservation and Recycling, 54(4), 229-234.

DIY Electric Cars. (2013). DIY Electric Car Forums. Retrieved 10 Dec, 2013, from http://www.diyelectriccar.com/forums/

Eisenstadt, S. N. (2000). Multiple modernities. Daedalus, 129.

Electric Car Company. (2013a). Electric Car Conversion Kits. Retrieved 11-Dec, 2013, from http://www.electriccarinternational.com/kits.php

Electric Car Company. (2013b). Electric Car Conversion Kits. Retrieved 19/12/2013, 2013, from http://www.electriccarinternational.com/kits.php

Element Energy. (2011). Influences on the Low Carbon Car Market from 2020-2030. Cambridge: Low Carbon Vehicle Partnership.

Element Energy. (2012). Cost and performance of EV batteries. Cambridge: The Committee on Climate Change.

Escobar, A. (2004). Beyond the Third World: Imperial globality, global coloniality and antiglobalization social movements Third World Quarterly, 25(1), 207-230.

Escobar, A. (2012 [1995]). Encountering Development. Princeton: Princeton University Press.

Esteva, G. (1999). Development. In W. Sachs (Ed.), The Development Dictionary: A Guide to Knowledge as Power. London: Zed Books.

ExxonMobil. (2012). The Outlook for Energy: A View to 2040. Irving, Texas: Exxon Mobil.

Fingleton, J. (2008). Pacific land tenures: New ideas for reform. Rome: FAO.

Fraenkel, J. (2006). Beyond MIRAB: Do aid and remittances crowd out export growth in Pacific microeconomies? Asia Pacific Viewpoint, 47(1), 15-30.

Freire, P. (1970). Pedagogy of the Oppressed. New York: Seabury Press.

Gegeo, W. (1998). Indigenous knowledge and empowerment: Rural development examined from within. The Contemporary Pacific, 10(2), 289-315.

Gegeo, W. (2001). Cultural rupture and indigeneity: The challenge of (re)visioning "Place" in the Pacific. The Contemporary Pacific, 13(2).

Georgescu-Roegen, N. (1971). The Entropy Law and the Economic Process. Cambridge, MA: Harvard University Press.

Gibson-Graham, J. K. (2005). Surplus possibilities: Postdevelopment and community economies. Singapore Journal of Tropical Geography, 26(1), 4-26.

Government of Samoa. (2008). Household Income and Expenditure Survey (S. B. o. Statistics, Trans.). Apia: Samoa Bureau of Statistics.

Government of Samoa. (2008a). National Greenhouse Gas Abatement Strategy 2008-2018. Apia: Ministry of Natural Resources \& Environment. 
Government of Samoa. (2008b). Samoa Second National Communication To The United Nations Framework Convention On Climate Change. Apia: Ministry of Natural Resources and Environment.

Government of Samoa. (2010). A report of the Estimation of Basic Needs Poverty Lines, and the Incidence and Characteristics of Hardship \& Poverty Apia: Samoa Bureau of Statistics and UNDP Pacific Centre.

Government of Samoa. (2010a). Development Cooperation Policy. Apia: Ministry of Finance.

Government of Samoa. (2010b). Evaluation of Paris Declaration on Aid Effectiveness and the Accra Agenda for Action In M. o. Finance (Ed.). Apia: Ministry of Finance.

Government of Samoa. (2010c). Millenium Development Goals: Second Progress Report.

Government of Samoa. (2011a) Samoa Energy Review. Apia: Energy Policy Coordination and Management Division.

Government of Samoa. (2011c). Samoa Energy Sector Plan 2012 - 2016: Ministry of Finance.

Government of Samoa. (2012a). Strategy for the Development of Samoa 2012 - 2016. Apia: Ministry of Finance.

Greenpeace. (2012). Energy [R]evolution: A Sustainable Future. Amsterdam: Greenpeace/European Renewable Energy Council (EREC)/Global Wind Energy Council (GWEC).

Growth Commission. (2008). Growth Report.

Hamilton, J. (2009). Causes and Consequences of the Oil Shock of 2007-08. San Diego: University of California.

Hau'ofa, E. (1985). The Future of Our Past In R. Kiste \& R.Heur (Eds.), The Pacific Islands in the Year 2000. Honululu: East West Center.

Hau'ofa, E. (1994). Our Sea of Islands. The Contemporary Pacific, 6(1), 147-161.

Huang, X. (2009). Politics in Pacific Asia. New York: Palgrave Macmillan.

Hughes, H. (2003). Aid has failed the Pacific. Issue Analysis 33. Sydney: Centre for Independent Studies.

Huntington, S. (1996). The West, Unique, Not Universal. Foreign Affairs, 75, 28-46.

IEA. (2009). Transport, Energy and CO2: Moving Toward Sustainability. Paris: International Energy Agency.

IEA. (2011). Technology roadmap: Electric and plug-in hybrid electric vehicles (pp. 52). Paris: International Energy Agency.

IEA. (2013 ). Global Energy Outlook: Understanding the Electric Vehicle Landscape to 2020. Paris: International Energy Agency.

IEA ETP. (2013). Tracking clean energy progress 2013. In I. E. Agency (Ed.). Paris: International Energy Agency.

IEA WEO. (2012). World Energy Outlook 2012. Paris: International Energy Agency

IPCC. (2007). Summary for policy makers Climate Change 2007: Impacts, adaptation and vulnerability. Contribution of the Working Group II to the Fourth Assessment Report of the Intergovernmental Panel on Climate Change. Cambridge UK: Cambridge University Press.

IPCC. (2013). Working Group I Contribution to the IPCC Fifth Assessment Report Climate Change 2013: The Physical Science Basis Summary for Policymakers. Geneva: IPCC.

IPCC. (2014). Summary for Policymakers IPCC WGIII AR5 (Vol. AR5). Geneva: The International Panel on Climate Change (IPCC).

Jackson, T. (2009). Prosperity without growth? The transition to a sustainable economy. London: Sustainable Development Commission.

Jafar, M. (2000). Renewable energy in the South Pacific-options and constraints. Renewable Energy, 19(1-2), 305-309. doi: 10.1016/s0960-1481(99)00045-2

Jayaraman, T., \& Evan, L. (2011). Oil Pprice and economic growth in small Pacific Island Countries. Modern Economy, 2, 153-162.

Keen, S. (2011). Debunking Economics: The Naked Emperor Dethroned? London: Zed Books. 
Kerslake, M. (2007). Malofua Structural Adjustment Programmes: The Case of Samoa. (PhD), Massey University, Auckland.

King, J. (2007). The King Review of low-carbon cars. Part 1: the potential for $\mathrm{CO}_{2}$ reduction. London: HM Treasury.

King, J. (2008). The King Review of low-carbon cars. Part II: recommendations for action. London: HM Treasury.

Kothari, R. (1988). Rethinking Development: In Search of Humane Alternatives. New Delhi: Ajanta.

Krumdieck, S., \& Hamm, A. (2009). Strategic analysis methodology for energy systems with remote island case study. Energy Policy, 37(9), 3301-3313. doi: 10.1016/j.enpol.2009.02.005

Laclau, E. (2000). Identity and hegemony: The role of universality in the constitution of political logics. In J. Butler, E. Laclau \& S. Zizek (Eds.), Contingency, hegemony, universality: Contemporary dialogues on the Left. London: Verso.

Laclau, E., \& Mouffe, C. (1985). Hegemony and socialist strategy. London: Verso.

Larson, M. (2012). Lessons Learned: The Early Adoption of Electric Vehicle Charging Stations from the Perspective of Oahu's Commercial Properties. Honululu: University of Hawaii Maui College.

Lefale, P. F., \& Lloyd, C. R. (1993). Photovoltaics for household energy use in Pacific Island nations (Fiji study). Renewable Energy, 3(2-3), 153-163. doi: 10.1016/0960-1481(93)90013-7

Leia, T. (2013). [Interview on suitability of EVs within Samoa's Electricty Generation Infrastructure].

Levantis, T. (2008). Oil price vulnerability in the Pacific. Pacific Economic Bulletin, 23(2), 214-225.

Lilomaiava-Doktor, S. (2009). Beyond "Migration": Samoan population movement (Malaga) and the geography of social space (Vä). The Contemporary Pacific, 21, 1-32.

Lloyd, C. R., \& Tukana, S. (1990). Photovoltaics as renewable energy resources on remote Pacific Islands. Solar and Wind Technology, 7(1), 3-7.

Macpherson, C. (1999). Changing contours of kinship: The impacts of social and economic development on kinship organization in The South Pacific. Pacific Studies, 22(2).

Macpherson, C., \& Macpherson, L. (2011). Churches and the economy of Samoa. The Contemporary Pacific, 23(2), 304-337.

Martinot, E. (2013a). Renewable electricity for New Zealand's future, The New Zealand Herald.

Martinot, E. (2013b). Renewables Global Futures Report. Paris: Renewable Energy Policy Network.

Matthews, S. (2004). Post-development theory and the question of alternatives: a view from Africa. Third World Quarterly, 25(2), 373-384.

Max-Neef, M. A. (1982). Experiences in Barefoot Economics. Stockholm: Dag Hammarskjold Foundation.

McGregor, A. (2009). New possibilities? Shifts in post-development theory and practice. Geography Compass, 3(5), 1688-1702.

McKinnon, K. (2008). Taking post-development theory to the field: Issues in development research, Northern Thailand. Asia Pacific Viewpoint, 49(3), 281-293.

McKinsey \&Co. (2009). Roads toward a low-carbon future: Reducing $\mathrm{CO} 2$ emissions from passenger vehicles in the global road transportation system (Vol. McKinsey \& Co.). New York.

Meadows, D. H., Meadows, D. L., Randers, J., \& Behrens_III, W. W. (1972). The limits to growth: A report for the Club of Rome's project on the predicament of mankind. New York: Universe Books.

Merz, K., \& Abertax, J. (2011). Case study pilot project: Performance of electric vehicles on small island and in small cities: Abertax Technologies.

Mikkelsen, B. (2005). Methods for Development Work and Research: A New Guiude for Practitioners. New Delhi: Sage Publications.

Mohanty, M. (2012). New renewable energy sources, green energy development and climate change: Implications to Pacific Island countries Management of Environmental Quality: An International Journal, 23( 3), 264 - 274. 
Mosse, D. (1994). Authority, gender and knowledge: Theoretical reflections on the practice of participatory rural appraisal. Development and Change, 25, 497-526.

Mosse, D. (2008). International policy, development expertise, and anthropology. Focaal-European Journal of Anthropology, 52, 119-126.

Muliaina, T. (2006). The role of the church in development in Samoa. Just Change. Retrieved 24-06, 2013, from http://www.globalfocus.org.nz/uploaded/documents/Just Change 6.pdf

Mullings, B. (1999). Insider or outsider, both or neither: some dilemmas if interviewing in a crosscultural setting. Geoforum, 30, 337-350.

Murray, W. E., \& Overton, J. (2003). Designing Development Research. In R. Scheyvens \& D. Storey (Eds.), Development Field Work. A Practical Guide (pp. 17-32). London: Sage Publications Ltd.

Nandy, A. (1988). Science, Hegemony and Violence: A Requiem for Modernity. New Dehli: Oxford University Press.

Negre, L. (2011). Green Book on publicly accessible charging infrastructures for "low - carbon" vehicles. Paris: Government of France.

New Zealand Ministry for Foreign Affairs and Trade. (2013). New Zealand Aid Programme, Samoa. Retrieved 4-07, 2013, from http://www.aid.govt.nz/where-we-work/pacific/samoa

Nordhaus, W. (2007). A Review of the Stern Review on the economics of climate change. Journal of Economic Literature, XLV, 686-702.

Nugroho, D., \& Lonsdale, M. (2010). Evaluation of OLPC programs globally: a literature review: Australian Council for Educational Research.

OECD. (2005/2008). Paris Declaration and Accra Agenda for Action. 2013, from http://www.oecd.org/dac/effectiveness/parisdeclarationandaccraagendaforaction.htm

OECD. (2013). Aid Statistics, Recipient Aid at a glance. Retrieved 18/06, 2013, from http://www.oecd.org/countries/samoa/

Offer, G. J., Howey, D., Contestabile, M., Clague, R., \& Brandon, N. P. (2010). Comparative analysis of battery electric, hydrogen fuel cell and hybrid vehicles in a future sustainable road transport system. Energy Policy, 38(1), 24-29. doi: http://dx.doi.org/10.1016/i.enpol.2009.08.040

Pacific Islands Forum Secretariat. (2006). Pacific Plan for Strenghtening Regional Cooperation and Integration.

Pieterse, J. N. (2000). After Post-Development. Third World Quarterly, 21(2), 175-191.

Poirine, B. (2006). Remittances sent by a growing altruistic diaspora: How do they grow over time? Asia Pacific Viewpoint, 47(1), 93-108.

Poku, N., \& Whitman, J. (2011). The Millennium Development Goals: challenges, prospects and opportunities. Third World Quarterly, 32(1), 3-8.

Polanyi, K. (1944). The Great Transformation: The Political and Economic Origins of Our Time. Boston: Beacon Press.

Potsdam Institute for Climate Change Impact Research and Climate Analysis. (2012). Turn down the heat: Why a $4 \mathrm{C}$ warmer world must be avoided. Washington: World Bank.

Potter, R. B., Binns, T., Elliot,J. and Smith, D.,. (2004). Geographies of Development (2 ed.). Harlow: Prentice Hall.

Pretty, J. (1995). The many interpretations of development. Focus, 16, 4-5.

Rahnema, M., \& Bawtree, V. (2010). Participation. In W. Sachs (Ed.), The Post-Develpment Dictionary ( 2 ed.). London: Zed Books.

Rapley, J. (2006). State capacity and development in a post-modern age. Progress in Development Studies, 6(2), 167-172.

Reason, P., \& Bradbury, H. (2008). The Sage Handbook of Action Research: Sage Research Methods.

Rist, G. (1997). History of Development. From Western Origins to Global Faith. London: Zed Books.

Roder, T., \& Parker, T. (2010). Volunteers Report - Samoa OLPC deployments visit. Retrieved 12/04, 2013

Roller, L., \& Waveman. (2001). Telecommunications infrastructure and economic development: a simultaneous approach. American Economic Review, 91(4), 909-923. 
Rose, N. (1999). Powers of freedom: reframing political thought. Cambridge: Cambridge University Press.

Rosser, A. (2008). Introduction: neoliberalism and its discontents in Australian Aid Policy. Australian Journal of International Affairs, 62(3), 315318.

Roy, B. (2008). Empowering the Rural Poor to Develop Themselves: The Barefoot Approach. Innovations, 67-93.

Sachs, W. (1993). The Development Dictionary London: Zed Books Ltd.

Sachs, W. (1998). The Need for the Home Perspective. In M. Rahnema \& V. Bawtree (Eds.), The PostDevelopment Reader (pp. 290-300). London: Zed Books.

Sachs, W. (2010). Environment. In W. Sachs (Ed.), The Development Dictionary: A Guide to Knowledge as Power (2 ed.). London: Zed Books.

Sakamoto, C. (2012). Driving EVs Forward: A Case Study of the Market Introduction and Deployment of the EV in Hawaii (E. D. a. T. Department of Business, Trans.). In University of Hawaii Maui College (Ed.). Honolulu: Hawaii State Energy Office,.

Samoa Bureau of Statistics. (2012). Gross Domestic Product, December 2012 Quarter. Apia: Samoa Bureau of Statistics.

Sanderson, E. a. K., Sara. (2004). Progress in participatory development: opening up the possibility of knowledge through progressive participation

* Progress in Development Studies, 4(2), 114-126.

Scheyvens, R., \& Storey, D. (2003). Development Fieldwork: A Practical Guide (1 ed.). London: Sage Publications Ltd.

Scott-Villiers, P. (2004). Personal Change and Responsible Well-Being In R. Groves \& L. Hinton (Eds.), Inclusive Aid Changing Power and Relationships in International Development (pp. 199-209). London: Earthscan.

Scrosati, B., \& Garche, J. (2010). Lithium batteries: Status, prospects and future. Journal of Power Sources, 195(9), 2419-2430.

Shiva, V. (1988). Staying Alive: Women, Ecology and Development. London: Zed Books.

Shoebridge, G. (2009). Electric Conversion Made Easy. Retrieved from www.evsecrets.com.

Simon, D. (1999). Development revisited. In D. Simon \& A. Narman (Eds.), Development as Theory and Practice (pp. 17-54). Harlow: Addison Wesley Longman.

Simon, D. (2003). Dilemmas of development and the environment in a globalizing world: theory, policy and praxis. Progress in Development Studies, 3(1), 5-41.

Simon, D. (2007). Beyond antidevelopment: Discourses, convergences, practices. Singapore Journal of Tropical Geography, 28, 205-218.

Singh, A. (2012). Renewable energy in the Pacific Island countries: resources, policies and issues. Management of Environmental Quality: An International Journal, 23(3), 254 - 263.

Slater, S., \& Dolman, M. (2009). Strategies for the uptake of electric vehicles and associated infrastructure implications. Cambridge: The Committee on Climate Change

So'o, A., Va'a, U., \& Lafotanoa, T. (2006). Sãmoa National Human Development Report: Sustainable Livelihoods in a Changing Sãmoa. In A. So'o, U. Va'a \& T. Lafotanoa (Eds.). Apia: The Centre for Sãmoan Studies, National University of Sãmoa.

Speirs, J., Gross, B., Gross, R., \& Houari, Y. (2012). Energy Material Availability: Handbook. London: UK Energy Research Centre.

Steinhilber, S., Wells, P., \& Thankappan, S. (2013). Socio-technical inertia: Understanding the barriers to electric vehicles. Energy Policy, 60, 531-539.

Stern, N. (2007). The economics of climate change: The Stern Review. Cambridge UK: Cambridge University Press.

Stern, N. (2007). Stern Review: The Economics of Climate Change. London: HM Treasury.

Storey, D., Bulloch, H., \& Overton, J. (2005). The poverty consensus: some limitations of the 'popular agenda'. Progress in Development Studies, 5(1), 30-44.

Taulealo, T. (2013). [Interview]. 
The Royal Academy of Engineering. (2010). Electric vehicles: charged with potential. London: The Royal Academy of Engineering.

The World Bank. (2011). World Development Indicators. Retrieved 27-6, 2013, from http://databank.worldbank.org/data/views/variableSelection/selectvariables.aspx?source= world-development-indicators

Thoma, K. (2013). Project Proposal: Electric (eCar) Pilot Trial. Apia: Ministry of Natural Resources and the Environment.

Thomas, C. E. (2012). Clean car options for the twenty-first century. In N. Muradov \& N. Veziroglu (Eds.), Carbon-Neutral Fuels and Energy Carriers. London New York: CRC Press.

Thornton, A., Kerslake, M., \& Binns, T. (2010). Alienation and obligation: Religion and social change in Samoa. Asia Pacific Viewpoint, 51(1), 1-16.

Toye, J. (1987). Dilemmas of development; the counterrevolution in development theory and policy. Oxford: Blackwell.

Tu, W. (2000). Implications of the rise of 'Confucian' East Asia. Daedalus, 129, 195-219.

Tuiafiso, S. (2013, 13/09). [Interview].

Tuilaepa, F. (2006). A participatory model of rural poverty in samoa. (PhD), Lincoln University.

Turner, G. M. (2008). A comparison of the limits to growth with 30 years of reality. Global Environmental Change 18,397-411.

UK Department of Transport. (2008). Government Response to the King Review of Low-carbon Cars. London: Department of Transport.

Ulu, A. (2013). Pule: Development policy sovereignty in Samoa. (Masters in Development Studies), Victoria University of Wellington, Wellington.

Ungaro, J. (2012). Solar Photovoltaics In Pacific Island Nations: An Analysis of Rural Household Electrification Strategies in The RMI and Vanuatu. (Master of Environmental Studies), Victoria University of Wellington, Wellington.

Vaioleti, T. (2006). Talanoa research methodology: A developing position on pacific research. Waikato Journal of Education, 12, 21-34.

Victoria Transport Policy Institute. (2013). Transportation Cost and Benefit Analysis II - Resource Consumption External Costs: Victoria Transport Policy Institute.

Wade, R. (2002). Globalization, poverty And income distribution: Does the liberal argument hold? Working Paper Series 02-33.

Wade, R. (2009a). The global slump: deeper causes and harder lessons. Challenge, 52.

Weitzman, M. (2009). On modeling and interpreting the economics of catastrophic climate change. The Review of Economics and Statistics, XCI(1).

Wood, B., Betts, J., Gayfer, F., Kabell, D., Ngawira, N., \& al., e. (2011). The Evaluation of the Paris Declaration, Final Report. Copenhagen: Danish Institute for International Studies.

World Economic Forum. (2013). Global Risks. Geneva: World Economic Forum.

World Wildlife Fund, U. (2000). Living Planet Report 2000. Gland, Switzerland: WWF International

Xiaojiang, Y., \& Tapling, R. (1997). Policy perspectives: environmental management and renewable energy in the Pacific Islands. Journal of Environmental Management 51, 107-122.

Yapa, L. (2002). How the discipline of geography exacerbates poverty in the Third World. Futures, 34, 33-46.

Ziai, A. (2004). The ambivalence of post-development: between reactionary populism and radical democracy. Third World Quarterly, 25, 1045-1060.

Zieroth, G. (2008). PIEPSAP End of Project Report: Concepts, Results, Lessons Learnt and Outlook: Pacific Islands Energy Policy and Strategic Action Planning (PIEPSAP). 
Appendices 


\section{Appendix 1. Interview Documents}

\subsection{Interview Schedule}

\section{Stakeholder Interview Schedule}

Use Information Sheet for Introduction

Answer: Why do I talk to you? You may have a big fuel bill.

Target groups: Rental Car Companies, WIBDI, Resorts, Public Servants, Aid

\section{Community}

1 Do you know how much you spend on fuel for your business activities?

$2 \quad$ What sort of car types does your company use?

Compact sedan, sedan, utility, light truck, van, passenger van (how many seats?), truck, bus

3 How long have you been in this business/position?

4 Have increased fuel prices affected your business/operations and in what way?

$5 \quad$ Have you heard about alternative transport options? What do you think about them?

6 Would you consider using alternative transport if available and cheaper? If yes,

$7 \quad$ How would you rank the following considerations?

Economics

Greenhouse gases

Market advantage

More independence from Imports

Branding

On a scale from 1-5 -> not at all, a bit, reasonably, important, very important

One or more can be used

If No,

8 What would be your reason?

9 Interviewer finish: What came up for me during the interview is that you.....

10 Is there anything you would like to add or ask? 


\subsection{Consent Form - Consent to Participate in Research}

\section{CONSENT FORM -- CONSENT TO PARTICIPATE IN RESEARCH}

\section{Title of project:}

\section{Non-fossil fuel transport options for the Samoan transport sector}

I have read and understood the information sheet and I understand that I can request more information at any stage. I am aware that participation is purely voluntary and I can withdraw at any time, refuse to answer any questions, or retract any statements before the 15 November 2013 without disadvantage.

I give consent for this interview to be recorded for the purpose of producing an accurate representation of the interview. If no consent is given the interview will be documented by taking notes.

I give consent for audio recording: YES / NO

I would like to be identified using: (please circle one)

$\square \quad$ The name of an organisation (please identify)

A code name (please identify)

Other: (please identify)

I understand that the information I give will not be used for any purpose other than listed below and in the information sheet without my consent.

I would like to receive a final report of the findings in electronic form at the conclusion of the research.

Yes / No

The researcher can be reached under the following physical contact address for the duration of the research project in Samoa: Valentine's Motel, Fugalei St., Apia;

At all times the researcher can be reached under the following email address:

klaus56thoma@gmail.com

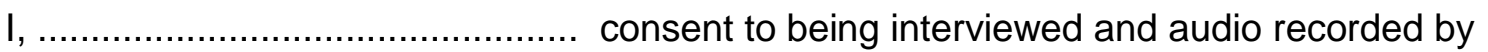

Klaus Thoma for the purposes of completing a Master's Thesis, producing one or more journal articles and presentations at conferences.

Signed

Date 


\subsection{Information Sheet}

Information Sheet for Research

Researcher: Klaus Thoma

I am a Masters student in Development Studies at Victoria University of Wellington and am preparing for my thesis research project. My research project will provide information about non-fossil fuel transport options and obstacles to their adoption in Samoa.

\section{Background}

Rising transport cost has affected the Pacific region severely, particularly since the "Peak Oil" phenomenon and the 2008 Global Financial Crisis. Although fossil fuel dependency has well been recognised by governments in the region, the problem is deeply rooted as the transport sector has become vital for the Pacific region's economic development and the recent elevation of the car as a status symbol to name a few. That economic efficiency is not necessarily the prime driver of everyday transport decisions can be gauged by the increasing sales of large engine cars despite fuel price rises. These developments have provided challenges for recently introduced sustainability principles in Samoan transport policy.

\section{Expected Results}

The study builds on on-going programs promoting the use of renewable energy and non-fossil fuel powered vehicles by several Government Ministries. The main focus of the study is the identification of technical, economic and social obstacles towards adoption of promising alternatives. It is hoped that the investigation will assist in the identification of non-fossil fuel transport options and provide background data for further refinement of the Samoa Energy Sector Plan 2012 - 2016.

\section{Interview Format}

Interviews will be conducted with a range of stakeholder groups, including Samoan Ministry of Natural Resources and Environment, commercial transport sector officials and technical experts in the renewable energy field. The interview is based on a semi-structured format and will be recorded if consent is given. Should the line of questioning progress in a way that makes you uncomfortable you can decline to answer any question(s). Participants who do not want to be recorded are also welcome.

\section{Confidentiality}

Your participation is completely voluntary and you can leave the interview at any time or retract statements made before 15 November 2013 without any disadvantage to yourself. All information is confidential and will only be seen by myself and my academic supervisor. Anonymity will be maintained by the use of a code name. Should there be an authorised recording of our conversation, the recordings will be stored at Victoria University in a password-protected computer for 5 years after the date of your signature. 


\section{Ethical approval}

This study has been reviewed and approved by the Ethics Committee of the Victoria University of Wellington in New Zealand.

\section{Data Use and Storage}

Data will be collected and stored in a way that it is only accessible by myself and my academic supervisor. Analysis of the interview data is based on anonymous information from the stakeholder groups and will be stored securely for a period of 5 years.

The completed thesis will be submitted for marking to the School of Geography, Environment and Earth Sciences and deposited at the University Library. It is intended that one or more articles will be submitted to scholarly journals and that the research may form the basis of conference presentations. You may receive a final report of my findings in electronic form if you wish.

If you have any questions or would like to receive further information about the project, please contact Prof John Overton at the School of Geography, Environment, and Earth Sciences, Victoria University, P O Box 600, Wellington, New Zealand.

john.overton@vuw.ac.nz 


\section{Appendix 2 Power Point Presentation of Second Participative Workshop}

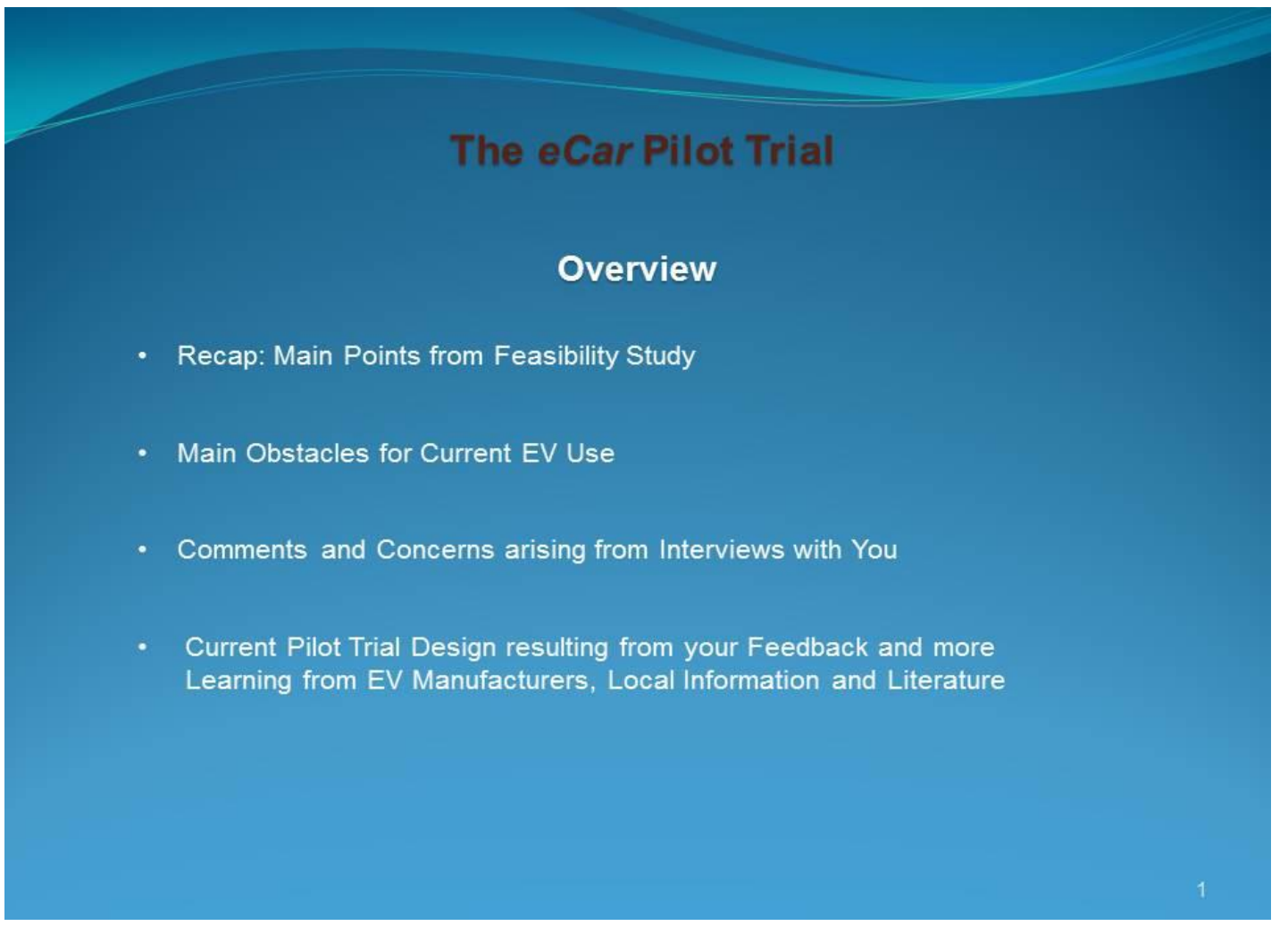

Is there a Role for EVs in Samoa's Transport Fleet in 2013?

\section{Recap:}

What are the Main Reasons for Conducting the eCar Pilot Trial ?

- EVs are $15 \%-48 \%$ cheaper to operate than $\mathrm{CVs}$, depending on car type @ $0.18 \mathrm{kWh} / \mathrm{km}$ performance $\rightarrow 0.17 \$ / \mathrm{km}$ for $E V$ @ 81/100 km performance $\rightarrow 0.26 \$ / \mathrm{km}$ for $\mathrm{CV}$

- Savings in Foreign Currency Reserves

- GHG Emission Reduction Commitments from the GHG Abatement Strategy

But also....

- Driving conditions (short distances, low travelling speeds) are ideal for EVs

- Taking Advantage of high electrification status in Samoa

- Centralised electricity grid allows for increase of renewable forms of energy

- The cost of self consumption PV installations for battery recharge may already be commercially viable 
Fuel Cost Comparison - CV, EV and Biodiesel Blend (BD)

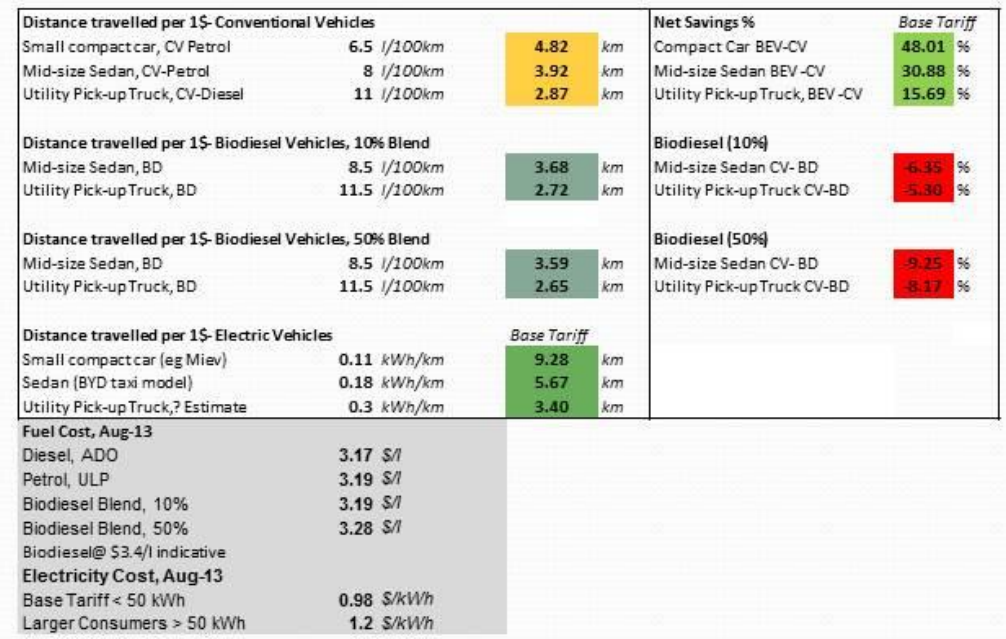

\section{Economic and GHG Considerations}

Cost and Emission Effects of a modelled 1000 Vehicle Fleet of EVs, BDs and CVs

\begin{tabular}{|l|c|c|c|}
\hline \multicolumn{1}{|c|}{ Vehicle Types } & $\begin{array}{c}\text { Transport Cost to } \\
\text { Driving Public } \\
\text { \$ Million }\end{array}$ & $\begin{array}{c}\text { Currency } \\
\text { GHG Emissions } \\
\text { tons } \mathrm{CO}_{2}\end{array}$ & $\begin{array}{c}\text { Reserve Savings } \\
\text { \$ Million }\end{array}$ \\
\hline CV, @ \$3.19/I & 3.72 & 2755 & - \\
EV, \$3.17/I & 1.42 & 1206 & 2.3 \\
BD Blend & & & \\
@ \$ 3.19/l -3.28/l & $3.2-3.3$ & $2469-1372$ & $0.347-1.737$ \\
\hline 10\%-50\% & & & \\
\hline GHG Emissions as per USEPA; Petrol: $2.359 \mathrm{~kg} \mathrm{CO}_{2} /$; Diesel: $2.685 \mathrm{CO}_{2} / \mathrm{l}$
\end{tabular}




\section{Environmental Considerations}

\section{Projected GHG US Emissions by Various Alternative Transport Fuels}

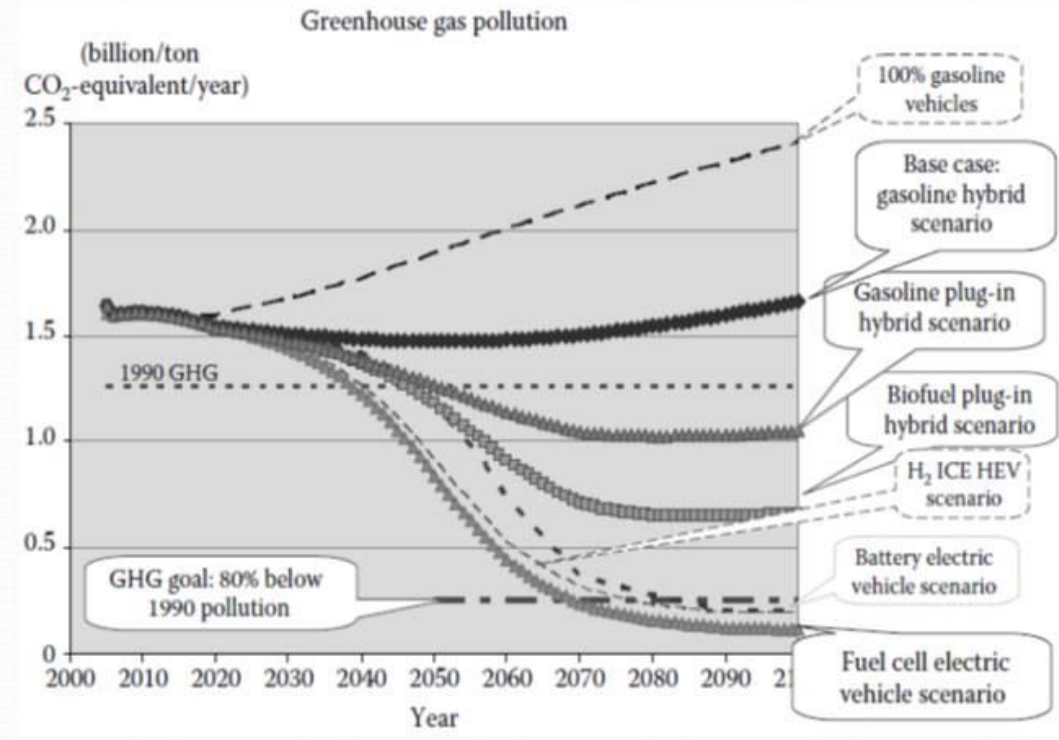

GHG projections over century for reference BAU scenario and various alternative transport fuels in USA. After Thomas, C.E. (2012) Clean Car Options for the Twenty-First Century.

\section{Public Health Considerations}

Projected US Urban Air Pollution Cost by Various Alternative Transport Fuels

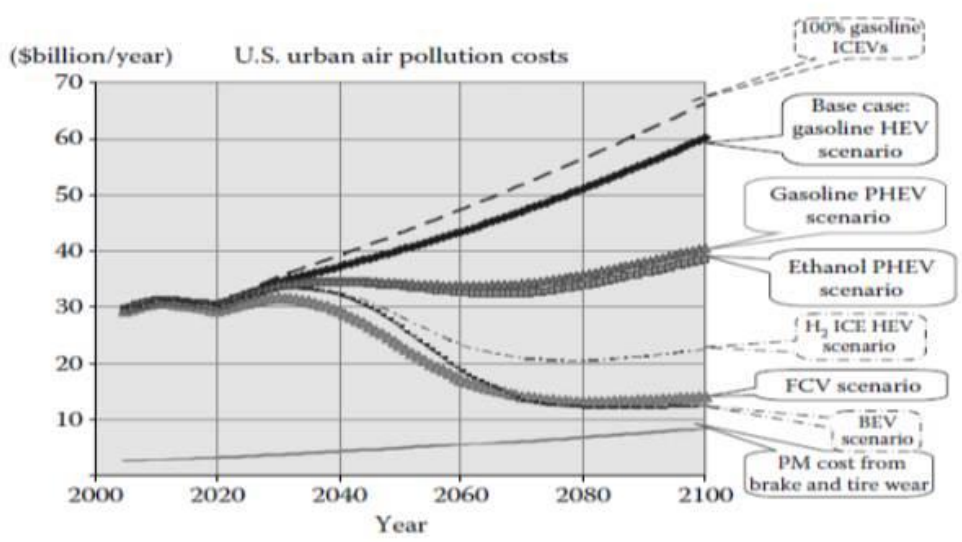

Urban pollution projections over century for reference BAU scenario and various alternative transport fuels in USA. After Thomas, C.E. (2012) Clean Car Options for the Twenty-First Century. 


\section{What are/were the Main Obstacles to EV Use?}

- Cost of EVs $\rightarrow$ Have decreased from the high US $\$ 80,000$ s to US $\$ 35,000$ for compact sedans in 2013

- Short Life of Batteries $\rightarrow$ Lithium ion batteries now have life expectancy of host car

- Long Battery Re-charge Times $\rightarrow$ Improvements with dual, fast and slow, charging times

- Short Driving Range of EVs under Metropolitan Driving Conditions $\rightarrow$ No concern in Samoa

- Unknown performance of EVs under Samoan Conditions, e.g. climate, infrastructure

- 'Big is better' status of cars $\rightarrow$ move towards electro mobility will take some time

\section{Summary of Your Comments and Concerns so far}

\footnotetext{
$\checkmark$ Maintenance Capacity of EVs

$\checkmark$ Legal Status of EVs on Samoan Roads

$\checkmark$ Suitability of EV Sizes for Samoan Family's Travelling Requirements

$\checkmark$ Suitability for Samoa's Rural Road Network, particularly during the Wet Season

$\checkmark$ Current EPC charging schedules not suitable for 'Feed-in Tariffs', e.g. only Consumption is charged NOT Line Maintenance

$\checkmark$ Knowledge Gaps on EV re-charging and feed-in PV Self-Consumption Units as it relates to daily Grid-Balancing

$\checkmark$ Feed-in Tariffs may affect EPC Profitability. May need to be considered at Policy Level

$\checkmark$ Considerable Cost Differential between new EV, new CV and more so $2^{\text {nd }}$ Hand Vehicles

$\checkmark$ Affordability of EVs
} 


\section{The eCar Pilot Project}

2. Draft and open for Your Input

Overall Objective

\section{"Establish if electrical vehicles are an energy-efficient and cost-effective mode of transport in Samoa}

while at the same time contributing to an urgentlyneeded reduction of $\mathrm{CO}_{2}$ emissions"

\section{Subordinate objectives}

- Determine if EVs are suitable for Samoan driving conditions

- Determine transport cost of EVs

- Determine operational and maintenance requirements of EVs

- Determine local EV servicing capacity requirements

\section{The eCar Pilot Project}

Hardware

\section{EV Fleet}

Option 1: A minimum EV fleet consists of:
- 2x Compact sedans
- 2x Mid-sized sedans
- $1 x$ Mini-bus (10-15 passengers)
- $5 x$ eScooters

Note: new vehicles are used for securing manufacturer maintenance and training support

Option 2: A more representative EV fleet consists of:
- 3x Compact sedans
- 4x Mid-sized sedans
- $1 \times$ Mini-bus (10-15 passengers)
- $5 x$ eScooters
- $2 x$ Utility vehicles (subject to commercial availability) 


\section{The eCar Pilot Project \\ Hardware}

\section{PV Re-Charge Stations}

\section{Design Specifications:}

- Daytime re-charge of $2 \times 16 \mathrm{kWh}$ batteries in 5 hours or less.

- PV units are connected to the electricity grid to allow re-charging during all weather conditions

- Surplus electricity is fed back into the grid.

\section{Locations:}

- High Visibility Government Car Park, e.g. TATTE Building

- Faleolo International Airport

- As yet unspecified location (any suggestions?)

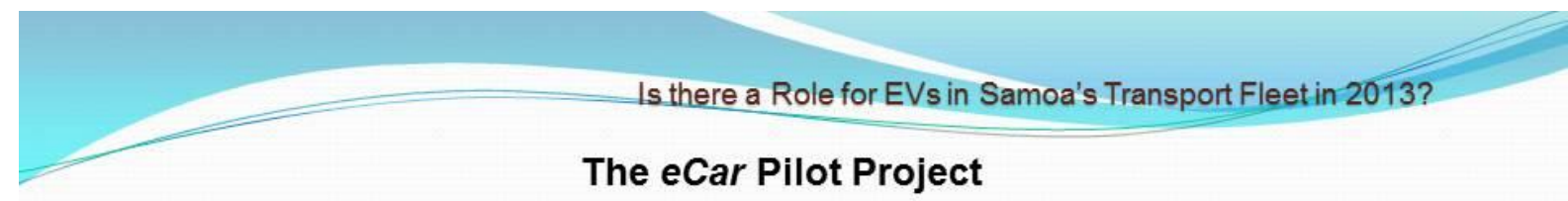

\section{Data/Information Collection by Test Fleet}

- Daily drive cycle data, EV\&CV: e.g. travel type, ODO meterreadings, breakdowns, servicing history, comments

- Daily re-charge data, EV: e.g. overnight plug-in times, daytime recharge times, breakdowns, comments

- Monthly data compilation, EV\&CV: e.g. drive cycle and re-charge data

\section{Operational Data Collection}

- Car servicing training according to manufacturer's training specifications

- Car operation and maintenance according to manufacturers specifications

- PV re-charge units service training according to manufacturers training specifications

- PV re-charge units operation and maintenance according to manufacturers specifications 


\title{
Some Cost Benefit Considerations
}

\author{
Aim: \\ 'Greatest public good for the greatest number of Samoa's citizens \\ while also taking into account intergenerational justice'
}

\section{But}

it is difficult to determine Total Cost and Benefits, particularly Externality Cost

\section{External Cost of transport activities can be found in the following segments:}

- Macro-economic impacts of importing fuels transfers wealth from consumers to oil producers

- Security risks - not all that relevant in Samoa but still instrumental in influencing global price of oil;

- Health risks - injuries and illnesses resulting from traffic activity but also from air pollution caused by the transport fleet and electricity generation. Point in case is a significant air pollution plume caused by the 'Apia rush hour'; US air pollution cost: VOCS US\$7,510; CO US\$ 1,677; NO $\mathrm{N}_{x}$ US $\$ 13,297 ;$ PM-10 US $\$ 36,835 ;$ PM-2.5 US $\$ 118,552 ; \mathrm{SO}_{2}$ US $\$ 21,873$ (Thomas 2012 P. 798).

- Environmental damages - environmental damages from processing and bulk transport, but also oil/fuel spills and emissions by transport fleet and urban storm water runoff. (There is anecdotal evidence of considerable amounts of fuel, oil and presumably heavy metals like zinc and copperdraining into Apia lagoon).

- Depletion of non-renewable resources - depriving future generations of resources with associated net present value implications;

- Financial subsidies - various financial subsidiesto resource production industries affecting the price of imported fuel (Victoria Transport Policy Institute 2013). 


\section{Financial Viability Considerations}

Pay-back times for EV capital investment based on two inflation scenarios, (US \$)

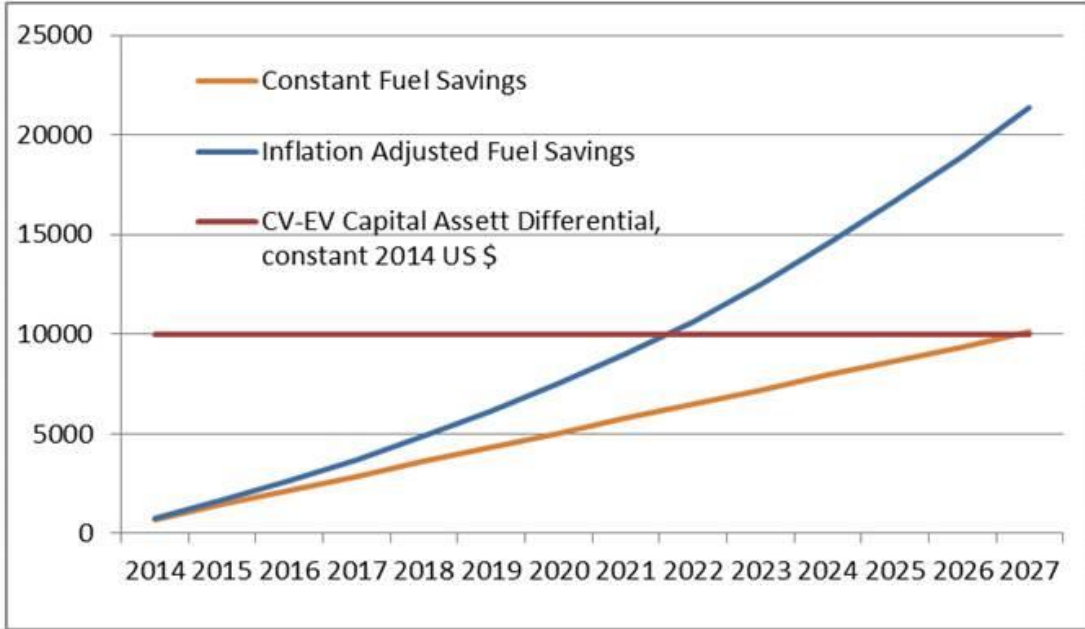

Illustrated pay-back times for EV capital investment including internalised externality cost (US \$)

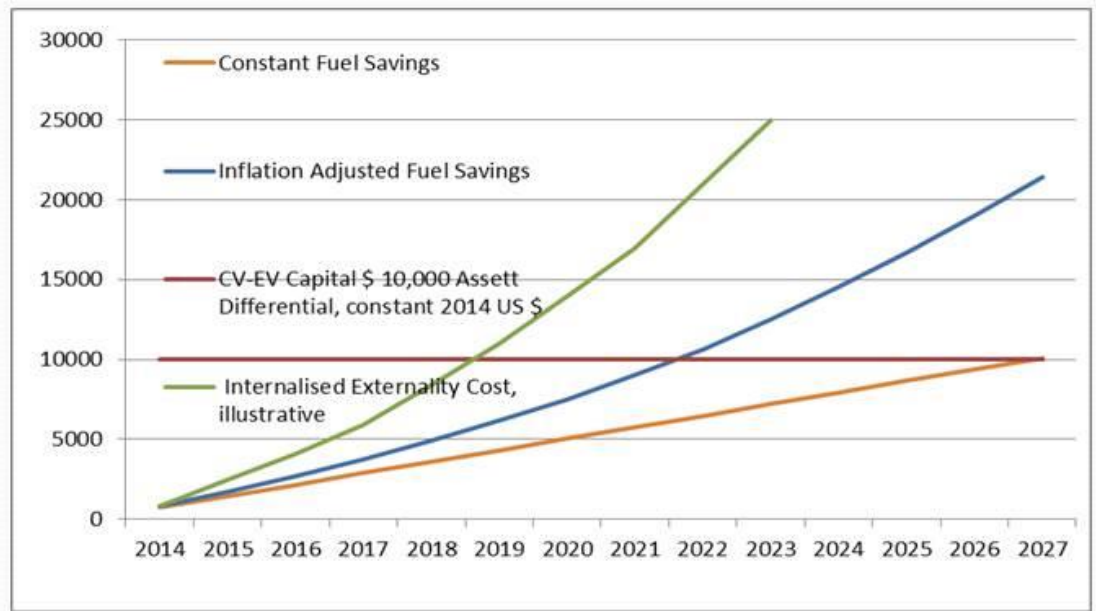

'Internalisation of Externality Cost' of conventional transport will lead to shorter pay-back period of EVs 


\section{Summary}

- The 'eCar Pilot Project' has evolved from a 'first cut' fuel use comparison between EVs, CVs, BDs using Samoan fuel cost;

- The Project is based on International research on non-fossil fuel transport options ranking EVs and Fuel Cell vehicles as the most likely future transport modes;

- We received and used your feedback in the design of the 'eCar Pilot Project';

- The Pilot Project takes a highly practical and mid-term view in identifying Advantages, Disadvantages and Infrastructure needs of the different EV types;

- The study uses commercially available and new vehicles to secure manufacturer maintenance and training support;

- The Public is informed about EV use by 'Field Days'.

\section{Conclusion}

- The 'eCar Pilot Project' will give valuable baseline data on drive cycles of EVs and CVs to be used for future transport policy reviews;

- Fuel cost savings will be confirmed by the use of scientific methodologies and under Samoan driving conditions;

- EV technology transfer and EV servicing capacity building will enable future O\&M of EVs;

- Servicing capacity will assist in the development of a 'retrofit' car conversion industry making use of Samoan $2^{\text {nd }}$ hand vehicles. 


\section{Where to from here ....}

EV drive data will enable informed planning decisions about:

- Re-charge station requirements, both location and distribution;

- Indicative demand for specific EV types

Technology transfer and capacity building will enable:

- Local servicing of PV recharge stations:

- Local servicing of EV test fleet;

- Creation of a local car retrofit industry, initially sedans, then utilities, buses if economically viable.

\section{Commercialisation of Electro Mobility}

Publish eCar pilot project research results

Convene a conference for commercial stakeholders aimed at uptake of EV technology

Promote and support Electro Mobility

'Retrofit' EV conversions are technically feasible and economically viable

Before...

A mid-sized sedan

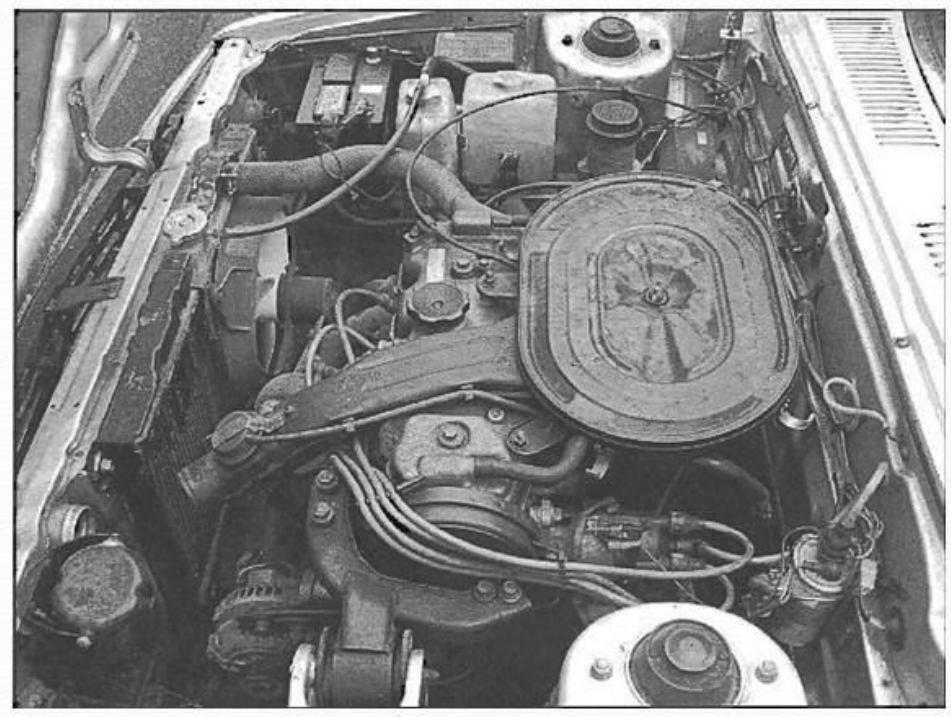


'Retrofit' EV conversions are technically feasible and economically viable

After.....

A tidy engine compartment, housing all engine parts.

The conversion requires only a moderate level of mechanical skills
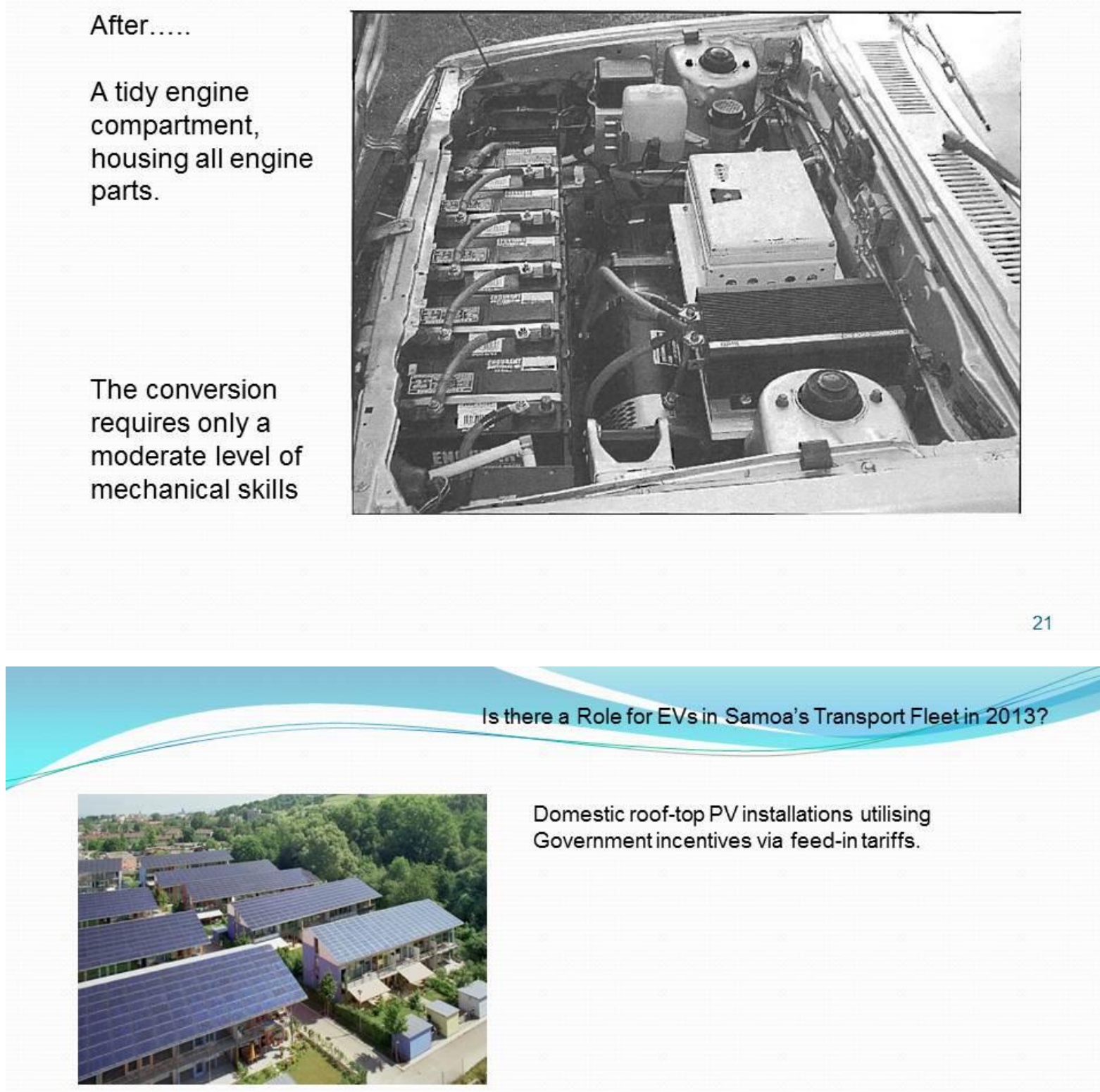

Europe's largest self consumption PV installation. Spread across two warehouses ( $11 \mathrm{ha}$ ), it comprises 33,000 solar panels and produces 8.1 megawatt for an estimated 1,800 European households. Saves 5,171 tonnes of $\mathrm{CO}_{2}$ annually.

This capacity would be enough to power nearly 4000 cars in Samoa.

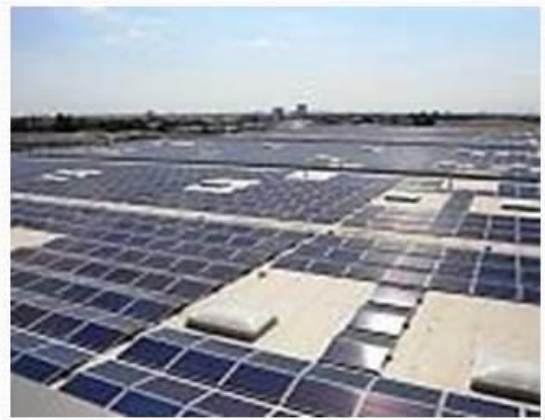




\title{
Appendix 3
}

\section{Project Proposal for Project: eCar Pilot Trial}

\author{
CDC Paper No \\ Project Proposal for Project: eCar Pilot Trial \\ Submitted by \\ Ministry of Natural Resources and Environment \\ for \\ Cabinet Development Committee
}

4 November 2013 
1. Sector:

Vehicle Land Transport Sector - Reduction of Greenhouse gas Emission

\section{Project Objective:}

The eCar pilot has the over-arching objective to:

"Establish if electrical vehicles are energy efficient and cost-effective mode of transport in Samoa while at the same time contributing to an urgently needed reduction of $\mathrm{CO}_{2}$ emissions".

\section{Subordinate objectives are as follows:}

Determine if BEVs are suitable for Samoan driving conditions

Determine transport cost of BEVs

Determine operational and maintenance requirements of BEVs

Determine local BEV servicing capacity requirements

\section{Executing Agency}

Ministry of Finance (MOF)

\section{Implementing Agencies}

Ministry of Natural Resources and Environment (MNRE), Electric Power Corporation (EPC), Lands Transport (LTA)

\section{Background}

In 2012 petroleum imports constituted 11.5per cent of Samoa's GDP and 22.7per cent of total imports of which approximately 54per cent of fuel imports are utilised in the transport sector. Although transport is considered a crucial part of Samoa's economic development and social fabric, the cost of petroleum imports does pose a significant drain on scarce foreign exchange reserves and on family budgets. The transport sector has evolved as an economic segment in its own right, however, there appears to be little contribution to the Nation's export productivity. 
Apart from the financial impact on Samoa's economy, the burning of fossil fuels is now also recognised to be a significant contributor to climate change. To that effect, the Government of Samoa has committed to an active role in the reduction of Green House Gases (GHG) and has introduced the National Greenhouse Gas Abatement Strategy 2008-2018 to minimise GHG emissions while also increasing energy use efficiency across all sectors.

Indeed, the economic and environmental impact of fossil fuel combustion in the transport sector has been recognised by policy communities around the world and several high powered reviews, notably the King Review and the Stern Review, concluded that a swift reduction of $\mathrm{CO}_{2}$ emissions is absolutely necessary and decarbonisation of the transport/energy sector by 2050 is indeed feasible (King, 2007; Nicholas Stern, 2007). A survey of global stakeholders in the energy sector by the Renewable Energy Network (REN21) also confirmed that renewable forms of energy have stakeholder support. Renewable energy is now considered an important part of the energy mix in the transport sector with biofuels, electric and plugin hybrid vehicles increasingly replacing conventional cars (Martinot, 2013b).

\subsection{Electric CAR Pilot Project Description}

In August-September 2013, the MNRE's Renewable Energy Division conducted a preliminary investigation of comparative fuel cost for an Electrical Vehicle (BEV), biofuel powered and a conventional vehicle. The research was assisted by $\mathrm{Mr}$ Thoma who has an academic background in applied environmental and socio-economic sciences. The investigation found that BEVs could be operated with large fuel cost savings compared to a 10per cent biofuel blend and a petrol/diesel powered vehicle. The $\mathrm{BEV}$ was also shown to lead to the largest reduction in $\mathrm{CO}_{2}$ emissions and savings in foreign currency reserves (tables 1 and 2). Other highlights of this preliminary investigation were the lack of baseline data of vehicle fuel use efficiency to enable accurate comparison of vehicle types and lack of Levellised cost of Samoan produced biodiesel leaving only indicative pricing of biodiesel. 
Table 1: Fuel Cost Comparisons, BEV, CV, BD

Fuel Cost Comparision - Conventional Car (CV) Battery Driven Electrical Car (BEV) and Biodiesel Blend (BD)

\begin{tabular}{|c|c|c|c|c|c|}
\hline \multicolumn{2}{|c|}{ Distance travelled per $1 \$$ - Conventional Vehicles } & & \multirow[b]{2}{*}{$\mathrm{km}$} & \multirow{2}{*}{$\begin{array}{l}\text { Net Savings \% } \\
\text { Compact Car BEV-CV }\end{array}$} & Base Tariff \\
\hline Small compact car, CV Petrol & $6.5 \mathrm{l} / 100 \mathrm{~km}$ & 4.82 & & & $48.01 \%$ \\
\hline Mid-size Sedan, CV-Petrol & $8 \mathrm{l} / 100 \mathrm{~km}$ & 3.92 & $\mathrm{~km}$ & Mid-size Sedan BEV -CV & $30.88 \%$ \\
\hline Utility Pick-up Truck, CV-Diesel & $11 \mathrm{l} / 100 \mathrm{~km}$ & 2.87 & $\mathrm{~km}$ & Utility Pick-up Truck, BEV -CV & $15.69 \%$ \\
\hline \multicolumn{2}{|c|}{ Distance travelled per $1 \$-$ Biodiesel Vehicles, $10 \%$ Blend } & & & Biodiesel (10\%) & \\
\hline Mid-size Sedan, BD & $8.5 \mathrm{l} / 100 \mathrm{~km}$ & 3.68 & $\mathrm{~km}$ & Mid-size Sedan CV- BD & $-6.35 \%$ \\
\hline Utility Pick-up Truck, BD & $11.5 \mathrm{l} / 100 \mathrm{~km}$ & 2.72 & $\mathrm{~km}$ & Utility Pick-up Truck CV-BD & $-5.30 \%$ \\
\hline \multicolumn{2}{|c|}{ Distance travelled per $1 \$$ - Biodiesel Vehicles, $50 \%$ Blend } & & & Biodiesel (50\%) & \\
\hline Mid-size Sedan, BD & $8.5 \mathrm{l} / 100 \mathrm{~km}$ & 3.59 & $\mathrm{~km}$ & Mid-size Sedan CV-BD & $-9.25 \%$ \\
\hline Utility Pick-up Truck, BD & $11.5 \mathrm{l} / 100 \mathrm{~km}$ & 2.65 & $\mathrm{~km}$ & Utility Pick-up Truck CV-BD & $-8.17 \%$ \\
\hline \multicolumn{2}{|c|}{ Distance travelled per $1 \$$ - Electric Vehicles } & Base Tariff & & & \\
\hline Small compact car (eg Miev) & $0.11 \mathrm{kWh} / \mathrm{km}$ & 9.28 & $\mathrm{~km}$ & & \\
\hline Sedan (BYD taxi model) & $0.18 \mathrm{kWh} / \mathrm{km}$ & 5.67 & km & & \\
\hline Utility Pick-up Truck,? Estimate & $0.3 \mathrm{kWh} / \mathrm{km}$ & 3.40 & $\mathrm{~km}$ & & \\
\hline \multicolumn{6}{|l|}{ Fuel Cost, Aug-13 } \\
\hline Diesel, ADO & $3.17 \$ / /$ & & & & \\
\hline Petrol, ULP & $3.19 \$ / l$ & & & & \\
\hline Biodiesel Blend, $10 \%$ & $3.19 \$ / l$ & & & & \\
\hline Biodiesel Blend, 50\% & $3.28 \$ / /$ & & & & \\
\hline \multicolumn{6}{|l|}{ Biodiesel@ \$3.4/I indicative } \\
\hline \multicolumn{6}{|l|}{ Electricity Cost, Aug-13 } \\
\hline Base Tariff $<50 \mathrm{kWh}$ & $0.98 \$ / k W h$ & & & & \\
\hline Larger Consumers > $50 \mathrm{kWh}$ & $1.2 \$ / k W h$ & & & & \\
\hline
\end{tabular}

Source: MNRE-RED, 2013

Table 2: Annual Effects of Transport Modes, 1000 Vehicle Fleet

\begin{tabular}{|lccc|}
\hline \multicolumn{1}{|c}{ Vehicle Types } & $\begin{array}{c}\text { Fuel Cost to } \\
\text { Driving Public } \\
\text { \$ Million }\end{array}$ & $\begin{array}{c}\text { GHG Emissions } \\
\text { (Burning Diesel) } \\
\text { tons } \mathbf{C O}_{2}\end{array}$ & $\begin{array}{c}\text { Currency Reserve } \\
\text { Savings } \\
\text { \$ Million }\end{array}$ \\
\hline CV, @ \$3.19/I & 3.72 & 2755 & - \\
BEV, @ \$3.17/I & 1.42 & 1206 & 2.3 \\
BD Blend & & & \\
@ \$ 3.19/I -3.28/l & & & $0.347-1.737$ \\
10per cent-50per cent & $3.2-3.3$ & $2469-1372$ & \\
\hline
\end{tabular}

GHG Emissions as per USEPA; Petrol: $2.359 \mathrm{~kg} \mathrm{CO}{ }_{2} / \mathrm{l}$; Diesel: $2.685 \mathrm{CO}_{2} / \mathrm{l}$

Source: MNRE-RED, 2013

Moreover, a cursory assessment of Samoan driving conditions showed that short travel distances, low travel speeds and the small size of the islands makes the current specifications of 
commercial BEVs Even more suitable for Samoan conditions than their contemporary use in metropolitan countries. Thus, there is sufficient Evidence to justify a closer investigation of the potential benefits of BEVs in Samoa.

The eCar pilot proposal aims at testing several BEV types for suitability and fuel use efficiency under Samoan traffic conditions, mainly around Apia. While the vehicles are being tested, ongoing service and maintenance requirements will also lead to the build-up of maintenance expertise and servicing capacity for BEVs.

The pilot project is expected to yield reliable and local information about fuel use efficiency, travel cycle data and suitability of BEV technology under Samoan conditions. The pilot trial will also produce transport sector wide drive cycle data and fuel use of the conventional vehicle fleet. This data would be very useful for prospective energy efficiency analysis of the existing transport fleet.

The use of electricity as a transport fuel requires a new planning approach towards present electricity generation practices and how regular battery re-charging may be integrated in base load management of the electricity grid. The pilot trial aims at assessing and gaining practical experience with two modes of battery recharge, namely battery plug-in in the electricity grid overnight and the use of three grid-connected, self-consumption PV installations for battery recharge during daytime when cars are parked between commuting times. This aspect of the trial will lead to gaining practical experience with recharging logistics for BEV users and field data for grid load balancing issues by EPC.

\subsection{Relevance to Existing Legislation, Sectoral Policies and Strategies}

The eCar pilot project objectives support the key outcomes of the SDS's, namely:

- Outcome 10: Efficient, Safe and Sustainable Transport System and Networks

- Outcome 12: Sustainable Energy Supply

- Outcome 14: Climate and Disaster Resilience

There are a range of policies and strategies subordinate to the SDS which have a policy relevance to the objectives of the pilot project, namely the overall sector objective of the SESP 2012-16:

- To reduce the growth rate in the volume of imported fossil fuels by 10per cent by 2016 
To be enabled by the following strategies, inter alia;

- 1.7 Promote the use of indigenous energy resources and renewable energy technologies

- 1.11 Promote energy efficiency in each of the three sub-sectors

The Greenhouse Gas Abatement Strategy 2008 - 2018 specifically developed emissions reductions objectives in the transport and electricity sectors which are relevant to the eCar pilot trial. These are:

Objective 1: $\quad$ Reduced GHG emissions from the land transport sector Strategies, inter alia:

- Focus on vehicle engines with efficient fuel consumption

- Introduce vehicles using fuel other than fossil fuel, e.g. electric cars

Objective 7: $\quad$ Reduced GHG emissions through new sources of renewable energy Strategies, inter alia:

- Encourage research and development in solar energy

- Promote collaboration between local and overseas development partners

- Facilitate the transfer of appropriate technology

- Promote the implementation of relevant CDM projects

\section{Outputs and Benefits}

The pilot trial's main measurable output will be the establishment of energy use data of different BEV types and operation and maintenance and service capacity requirements under Samoan conditions. Moreover, the study of BEV battery recharge practices via plug-in and/or selfconsumption PV stations will also be of great interest for BEV users and EPC.

Findings from testing the BEV fleet will confirm savings in fuel cost and corresponding reductions in $\mathrm{CO}_{2}$ emissions and foreign currency savings. (See tables 1 and 2). Fuel use efficiency data are going to be used primarily as 'proof of concept' data and may then be extrapolated with confidence to larger prospective vehicle fleets to be used in future energy and transport policy reviews.

The eCar pilot project objectives are guided towards national efforts to improve resource use efficiency incrementally in line with the introduction of BEVs. 
The eCar pilot will also aim at the identification of O\&M and human resource capacity requirements for operating BEVs. As such there will be an employment growth prospect, initially on a very small scale but should 'proof of concept' be successful, employment will be created to service the BEV fleet. Although it is beyond the scope of this proposal, there exists a real possibility to retrofit suitable, conventional cars for use as BEVs, once some expertise has been gained from BEV servicing. It would also not be too farfetched to investigate kit set assembly of some vehicle types for Samoan use or Even for a limited re-export to other PICs at some point in the future. Of essence would be a rapid build-up of servicing capacity.

Early in its implementation phase, selection criteria for BEV car types will be developed. This process will involve close liaison with prospective car manufacturing companies and identification of O\&M requirements. Capacity training, spare part supply, warranties and technology transfer options will be part of any Eventual purchasing agreement.

\section{Inputs}

The eCar pilot project does not require any land or buildings apart from three small sites housing the installation of a carport-type structure for the self-consumption PV stations, located on a high visibility site on two Government building car parks (or equivalent) and at Faleolo International Airport. The test vehicles will generally be housed at the facilities of the test driver and 'use responsibilities' and 'data logging obligations' for the BEV vehicle will be defined by a "test use contract". Storage space for some BEV vehicles, however, may be required from time to time. Some use access for promotional purposes for the implementing agencies and other Ministries will be part of the contract. The proposed BEV test fleet will consist of the following vehicle types in two configurations, namely:

1) Option 1: A minimum BEV fleet consisting of Compact sedan (2), mid-sized sedan (2), mini-bus (10-15 passengers) (1), eScooter (5). And

2) Option 2: A more representative BEV fleet consisting of:

Compact sedan (3), mid-sized sedan (4), mini-bus (10-15 passengers) (1),

eScooter (5) , and Utility vehicle (2) 
As of October 2013, a market for compact BEVs is Evolving with prices ranging from US\$ 32,000 to $\$ 40,000$. Some Chinese manufacturers are offering BEVs Even at substantially lower prices but information on quality, reliability and export servicing capacity is not available at this stage. This is a significant drop from anecdotal prices for 'early' BEV models selling for US $\$ 70,000$ to US\$ 120,000 . The Korean car maker HYNDAl is producing hybrids and BEVs of their TUSCON model but this model may not be available for export at the moment. The Korean company Kia, however, may release an export model soon underlining the highly dynamic competition for market share in this market. There is also an emerging market for utility vehicles including eVans, mini eBuses and large buses with BYD moving towards being a major exporter of eBuses.

At this stage, vehicles will be selected from market sales leaders (Renault-Nissan Alliance) and other large international manufacturers like Fiat, BYD, Ford and Mitsubishi. Accordingly, model options suitable for closer analysis include the Fiat 500e (US\$36,274), the Ford Focus (US\$39,995), the BYD e6 (US\$ 35,000), the Mitsubishi MieV (US\$ 45,971) and the Nissan Leaf (US \$ 34,570). The mini eVan, mini-eBus segment includes the Peugeot eMonarch (12 seats) (US\$ 94,990) and the Renault Kangoo Maxi Crew Van (US\$37,155).

Escooter models are offered at a wide range, however, quality and serviceability issues are not easy to ascertain. Some testing by consumer organisations has shown the German designed and China manufactured E-Max to be a cost competitive, quality model. Further analysis needs to be undertaken, but for the purpose of this preliminary assessment, the E-Max is included in the model mix at an estimated cost of US $\$ 2200$ per unit.

Should utility vehicles become commercially available during the duration of the eCar pilot project, two utility vehicles will be included in the test fleet. Similarly, should demand for test vehicles increase during the project, numbers may easily be increased subject to funding.

Three stand-alone recharge Photovoltaic (PV) units are proposed to be installed on Government building car parks and Faleolo International Airport. The technical specifications will allow for a daytime recharge cycle for two vehicles during working hours. A collaborative initiative with EPC is required to enable surplus electricity to be fed in the grid. At this stage, EPC has no provision for standard feed-in tariff schedules for distributed electricity production. Any electricity 
feed-in would require a permit by EPC and the Office of the Regulator, to be followed up by a Purchase Price Agreement (PPA) with EPC. The availability of the pilot trial's PV recharge stations may be useful to test some metering equipment and feed-in tariff policy.

\section{Revenues and Costs}

The pilot trial's main objective is the quantification of energy savings which could be achieved by a BEV transport fleet. Table 1 has outlined expected savings to be achieved by lower operating cost. It needs to be appreciated, however, that any future projections of fuel savings may be subject to a range of interferences which may include but are not limited to:

- possible 'major systemic financial failure' (World Economic Forum, 2013);

- Even higher likelihood of continuing fiscal imbalances for many world economies (World Economic Forum, 2013);

- exchange rate fluctuations affecting fuel import cost;

- possible establishment of a carbon management regime (carbon tax, carbon trading) with implication for transport cost;

- changes in EPC electricity charging schedules.

In addition, a massive development effort into renewable energy, BEV and Biofuel car design is currently taking place and will in all likelihood reduce the price differentials between $\mathrm{CV}$ and $\mathrm{BEV}$ prices and renewable energy cost as Evidenced in the last 2 years (Martinot, 2013b). These developments will all impact on investment pay-back analysis for future transport policy reviews.

In figure 1 , the effect of two inflation scenarios on the pay-back time of the more expensive BEV capital investment is illustrated. In this analysis a conservative 5 per cent annual fuel price inflation is assumed to affect the travelling public throughout the study period and is compared to constant fuel savings by BEV users at 2014 prices. A net 3per cent saving on annual fuel expenses for BEV users consists of a 2 per cent inflationary impact on electricity charge out rates whereas the 5 per cent fuel price inflation affects CV users. The 
differential estimate between 2 per cent electricity charges and 5 per cent fuel price inflation arises because of the relatively more efficient energy conversion of the industrial EPC electricity generator sets as compared to the internal combustion engine. This leads to a net and cumulative increase in fuel savings by the BEV user who is then able to pay back his/her BEV investment in 7.5 years instead of the 13 years pay-back period for constant inflation and savings at 2014 prices.

Figure 1: Pay-back times for BEV capital investment based on two inflation scenarios, (US \$).

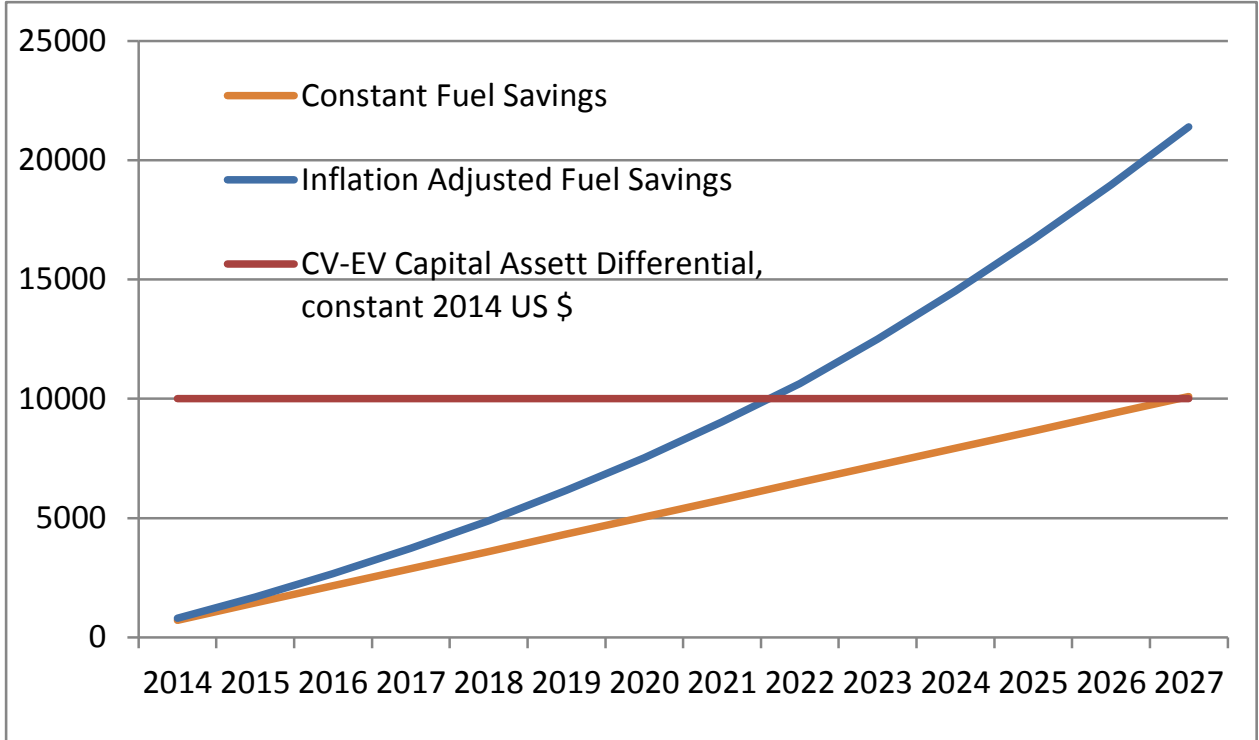

\section{Cost-Benefit Analysis}

The pilot project's approach to a cost-benefit analysis is one of aiming at the 'greatest public good for the greatest number of Samoa's citizens', while also taking into account intergenerational justice and efficiency of intergenerational, economic transfers beyond Samoa's national borders. There are some problems of computation, particularly when calculating externality cost of fuel use within the Samoan context.

There is general agreement externality cost may be allocated within the following segments like:

- Macro-economic impacts of importing fuels which go beyond direct fiscal effects

- Security risks - not all that relevant in Samoa but still instrumental in influencing global price of oil; 
- Health risks - injuries and illnesses resulting from traffic activity but also from air pollution caused by the transport fleet and electricity generation. Point in case is a significant air pollution plume caused by the 'Apia rush hour';

- Environmental damages - environmental damages from processing and bulk transport, but also oil/fuel spills and emissions by transport fleet and urban storm water runoff. (There is anecdotal Evidence of considerable amounts of fuel, oil and presumably heavy metals like zinc and copper draining into Apia lagoon).

- Depletion of non-renewable resources - depriving future generations of resources with associated net present value implications;

- Financial subsidies - various financial subsidies to resource production industries affecting the price of imported fuel (Victoria Transport Policy Institute, 2013).

There is a lack of Samoan externality data available for inclusion in a CBA. The approach taken here is using overseas data and deriving estimates relevant to BEV-CV comparisons where appropriate.

The international policy community is increasingly taking a Life Cycle Assessment (LCA) approach to project planning and justification. Nicholas Stern, the author of the UK Treasury commissioned 'Stern Review' famously stated: "Climate change is the biggest ever global market failure" (Nicholas Stern, 2007). And by that he meant that a large proportion of climate change activities and substances have not been incorporated in cost calculations by participants in the global economy. Literature on fuel externality cost is immense and contradictory. Estimates of the 'well to fuel tank' live cycle assessment (LCA) cost of fuel range from around US $\$ 1 /$ litre to $\$ 9 /$ litre. Clearly, at such prices current economic activity would have to undergo fundamental and, in the short term, unacceptable changes. It is however felt appropriate that an appreciation of the implicit and massive discount of externality cost of current fuel prices is gained in order to make informed mid-long term policy decisions ${ }^{25}$. The process of 'internalising externality cost' has already commenced particularly in global climate change initiatives.

Accordingly, the total cost of BEV and $\mathrm{CV}$ transport can be obtained by determining:

4) Direct operating cost. BEV fuel cost per $100 \mathrm{~km}$ : WT\$ 10.78. CV fuel cost: WT\$20.73. Based on the cost assumptions in table 1, a 1000 car BEV fleet is projected to save WT\$2,301,858

\footnotetext{
${ }^{25}$ The internalisation of fuel externality cost is currently analysed by the Swiss government and is spearheaded by the world famous Zurich ETH University.
} 
in fuel imports annually compared to a CV car fleet. The 1000 car Biodiesel (BD, 10per cent) fleet is projected to save WT\$347,480 in fuel imports annually. There is anecdotal Evidence to suggest that BEV car maintenance is significantly cheaper than CV maintenance, however, maintenance data need to be confirmed in the Samoan context. There may be higher insurance cost for BEVs and engine warranty issues for BD vehicles with higher biodiesel percentages in the fuel mix.

5) Capital cost: With still establishing market prices for BEVs, the approach taken here is assuming a US\$10,000 premium of BEV prices over comparable new CVs. Payback calculations are based on this price differential.

6) Health cost: International studies suggest a significant adverse health effect by ICE exhaust fumes, particularly in urban locations. An example of average air pollution cost per metric ton of pollutant gases from the USA is: VOCs US\$ 7,510; CO US\$1,677; NO US\$13,297; PM10 US\$ 36,835; PM-2.5 US\$ 118,552; SO US\$21,873 (Thomas, 2012 p. 798). The health costs caused by traffic fumes to the Samoan public and health system are assumed to be significant in the mid-term.

7) Environmental cost: Examples are GHG emissions and urban storm water runoff, heavy metal accumulation, oil compounds leaching into the coastal environment and entering the food chain.

In principle, direct and tangible benefits from the BEV pilot trial can be gained by confirming transport fuel savings in the order of 15 per cent- 48per cent depending on vehicle type (utility pick-up trucks, mid-size sedans and compact sedans). Assuming constant 2014 fuel prices, fuel savings will amortise the additional US\$10,000 investment in a BEV in 13 years (using compact sedan data). Assuming a net inflationary impact of 3 per cent on transport fuel prices, the payback period is 7.5 years (Figure 1 ).

Due to lack of baseline pollution and pollution cost data (e.g. air/storm water pollution), there is as yet incalculable externality cost from conventional traffic activity which needs to be offset against the additional BEV investment of US\$10,000. A smaller price differential between $\mathrm{CV}$ and BEV capital investment will also lead to significantly shorter pay-back periods of the BEV capital investment. It is proposed to separate externality cost benefits from BEV use into:

- a more immediate and tangible cost benefit derived from savings in public health cost to Samoan society; 
- some policy obligations incurred from GHG abatement strategy 2008-2018 objectives (Introduce vehicles using fuel other than fossil fuel, e.g. electric cars), and

- less tangible environmental cost savings as yet fully to be determined but nevertheless existing.

In table 2, the as yet incalculable effects of environmental externality cost are illustrated.

Table 2: Illustrated Pay-back times for BEV capital investment including internalised externality cost (US \$).

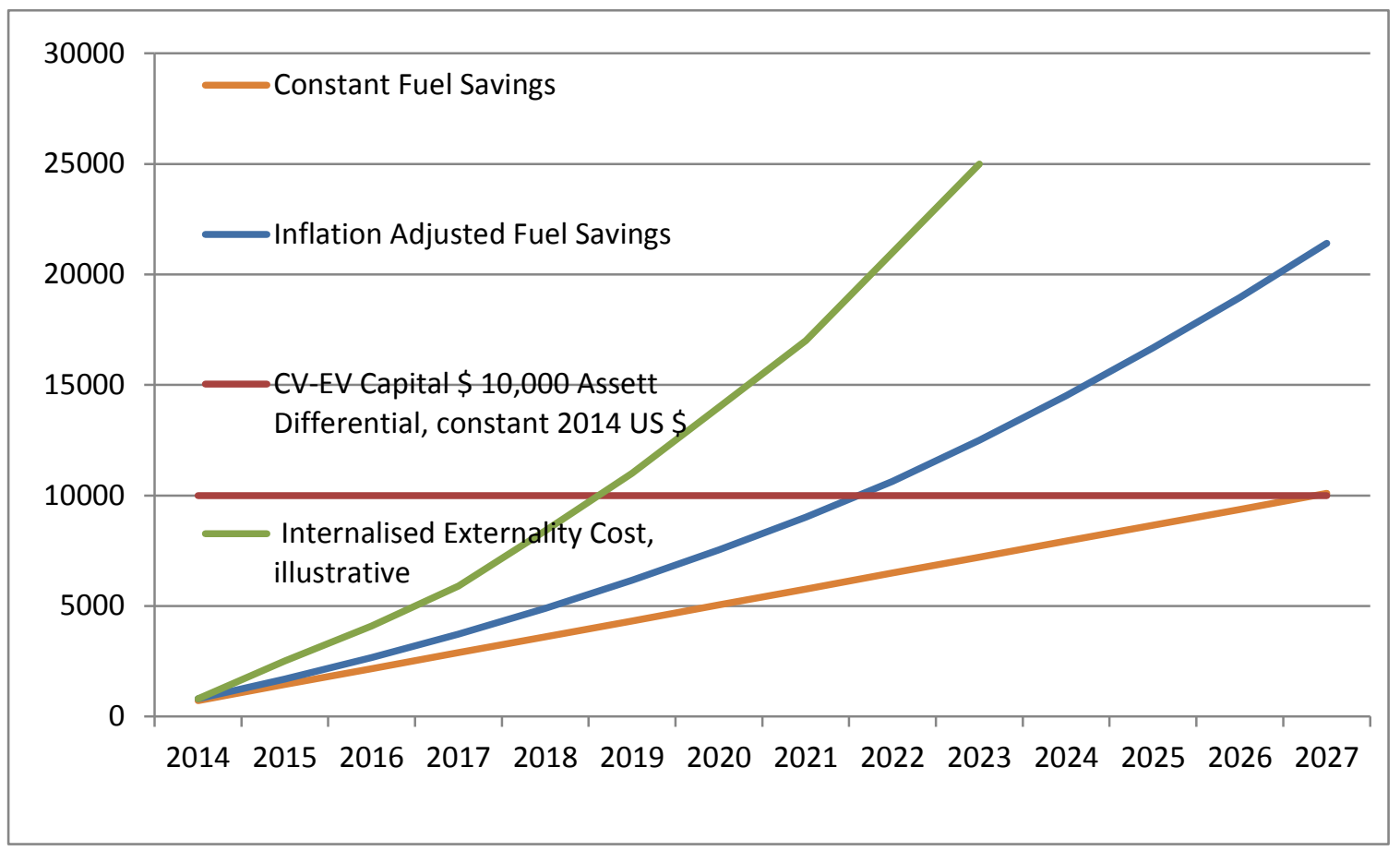

Principally, by including externality cost, the pay-back times for BEVs would be reduced.

\section{Project Implementation}

A list of activities and tasks required to implement the eCar pilot project is presented with the assumption of a project start after the 2014 Christmas holiday break. The project is designed to be implemented in 4 phases.

10.1 Phase 1: (Completed by September 2013)

Phase 1 activities build on international trends in non-fossil fuel transport and in particular on the findings of the UK Treasury commissioned King review and the REN21 2013 survey results of 
global energy stakeholders. A 'first cut' comparison of Samoan priced transport fuels, including biodiesel fuels, electricity and conventional fuels showed significantly higher fuel use efficiency of the BEV. A consultation process with other Ministries was commenced to collect and create reliable transport fleet data like daily driving cycles and fuel use and fuel use efficiency of different conventional car types. Similarly, a survey of BEV types, availability, prospective manufacturers, cost, $O \& M$ and training requirements was initiated. Specifications for self-consumption recharge PV stations are being collected. Some of these activities have been completed but others are ongoing and will continue on in phase 2 and 3.

\subsection{Phase 2:}

\subsubsection{Project Development Approval(s)}

As early as practically feasible approval is sought for Cabinet submission and a 'project funding request' is prepared.

\subsubsection{Composition of BEV fleet}

MNRE continues consultations with LTA, EPC, and MoF to determine the most appropriate BEV type composition for the test fleet; e.g. compact sedan, sedan, utility, minibus, eScooters.

\subsubsection{Survey of Vehicle Availability}

A survey of relevant BEV types, availability, manufacturers, cost, O\&M requirements, and warranty and service arrangements is continued. A short list of BEV vehicles, suitable for the test fleet as per consultation, is produced.

\subsubsection{Recharge Facility Specification and Power Purchase Agreement (PPA) with EPC.}

Following on from BEV vehicle specifications and in particular, recharge specs, suppliers for appropriate equipment are sourced. Cost, warranty and service arrangements are obtained. At this stage, it is intended to identify 3 recharge stations located at the TATTE building, another public site and Faleolo International Airport. A PPA will be negotiated between MNRE-RED and EPC on a surplus electricity feed in schedule.

\subsubsection{Legal Requirements for BEVs on Samoan Roads}

Confirmation of the legal status of BEVs is required before any purchasing orders are issued. This task will also involve availability of insurance and any other LTA requirements. 


\subsubsection{BEV Research Program}

Finalise data collection format for the BEV fleet

\subsubsection{Selection Criteria and 'test driver contract'}

Prepare selection criteria for test drivers, consider the merits of rotating sets of test drivers and draft a 'test driver contract' in conjunction with MNRE legal department.

\subsubsection{Appointment of Project Coordinator}

A project coordinator/manager is appointed to implement Phase 3 as shown by the RED organization chart below.

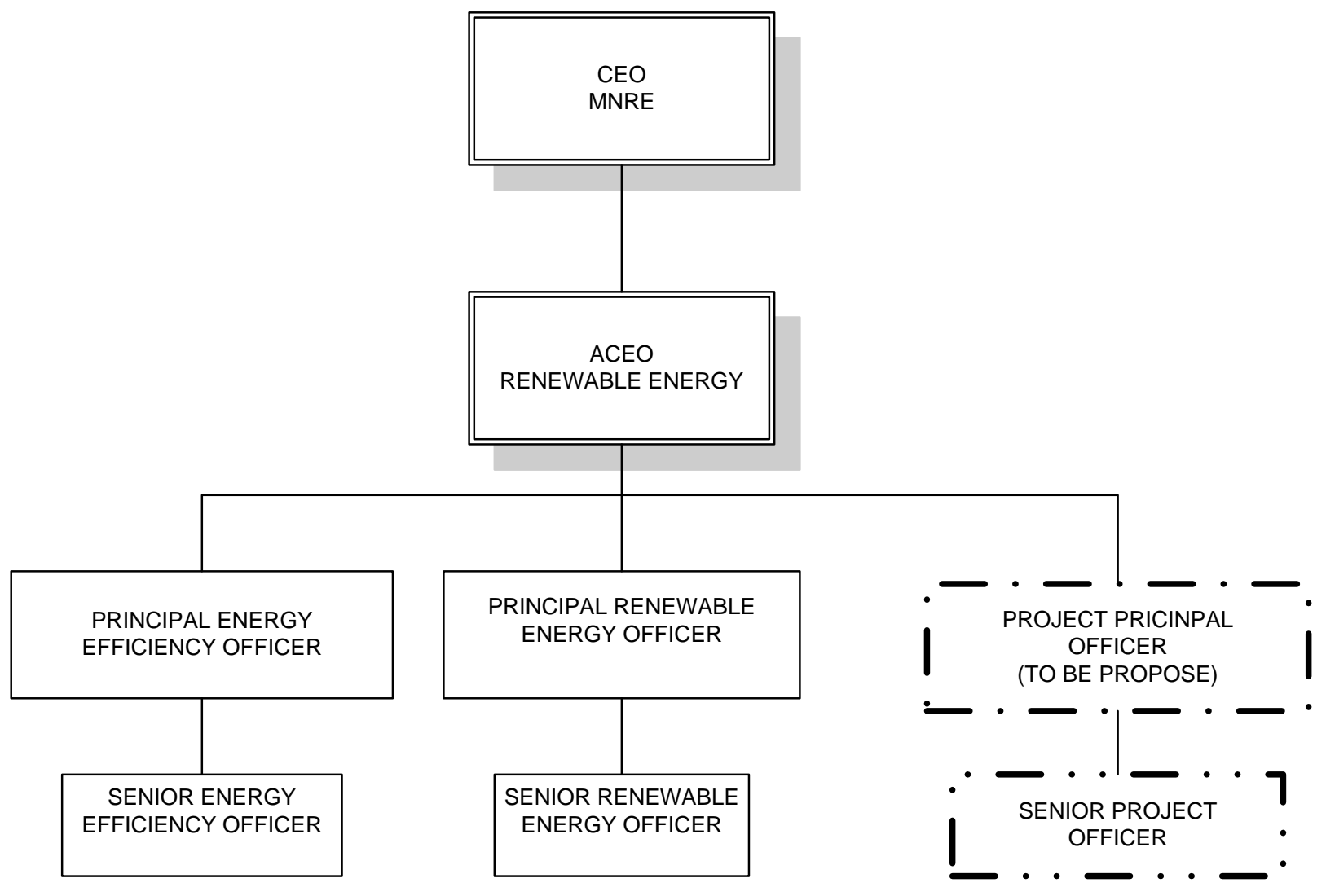




\section{Renewable Energy Division -Organization chart}

\subsection{Phase 3}

\subsubsection{Purchase of BEV Vehicles}

BEV types, numbers, warranty obligations, spare parts availability and servicing arrangements are finalised and purchase orders are issued.

\subsubsection{Self-consumption Battery Recharge Stations.}

Information is currently collected.

\subsubsection{Receipt of BEVs and PV units}

Units are received and checked for faults. PV units are installed and commissioned. The BEVs are tested against warranty conditions, serviced as required and also commissioned.

\subsubsection{Training in BEV Servicing}

Training Schedules for BEV servicing is commenced according to manufacturer's requirements and service contract.

\subsubsection{Testing schedule for self-consumption PV units}

After commissioning, the PV units are tested for daily power feed-in performance.

\subsubsection{Technical Support and after Purchase Service}

Warranty and maintenance service for BEV and PV unit commences. Spare part supply, maintenance support and delivery service commences.

\subsubsection{Test Driver Training}

First group of test drivers are selected and trained in BEV driving requirements, simple maintenance and data collection tasks.

\subsection{Phase 4}

\subsubsection{Road testing}

The BEV road testing programme is commenced

\subsubsection{Public Awareness Program}

The awareness program commences with an 'open day' demonstration of BEV technology, re-charging procedures and a tally of fuel and GHG emission savings. 


\subsubsection{Test data collection}

Driving and fuel data are collected, compiled in a database and summarised on a monthly basis.

\subsubsection{Capacity Training}

Regular training is conducted leading to full servicing proficiency

\section{Project Feasibility}

\subsection{Technical Feasibility}

The eCar pilot project is designed to take advantage of technology transfer by the importation of commercial, state of the art BEVs. A major objective and challenge of the project is the acquisition of servicing capacity for the BEV technology. As discussed above, technology transfer and implied capacity building will be a part of the vehicle purchasing process. The risks of failure are relatively low as:

1) Vehicles are sourced from companies with technology transfer capacity/experience; and

2) Pilot project vehicle numbers are very small and new with correspondingly low probability of failure.

\subsection{Market Feasibility}

The primary objective of the study is 'proof of concept' of BEV technology under Samoan conditions. Secondary objectives are the collection of economic and technical baseline data to be used for ultimate determination of economic/environmental BEV viability in Samoa and provide interdisciplinary/intergovernmental information for transport related government responsibilities.

\subsection{Management and Operating Organisation}

The primary implementing agency is MNRE-RED, who will be responsible for the line management of the principal and senior project officers.

\subsection{Environmental Impact}

Based on findings of the international literature, the environmental impact of BEVs is significantly lower than CVs (Thomas, 2012). 


\section{Project Sustainability}

\subsection{Policy Support}

The eCar pilot project is anchored in the overarching policy intent of the SDS but more specifically in the policy and objectives of the SESP 2012-2016 and the Greenhouse Gas Abatement Strategy 2008-2018 as discussed above.

\subsection{Environmental Aspects}

The literature on the subject supports a potentially smaller footprint of BEVs in comparison to CVs, albeit depending on the source of electricity and battery technology for energy storage.

\subsection{Socio-Cultural Aspects}

Similar to experience elsewhere, Samoa's driving culture is influenced to a considerable extent by car use as status symbols. The use of alternative means of transport on the other hand, is mainly motivated by economic and environmental considerations. Any future promotion of electric mobility will have to take into account status perceptions of BEVs and leading conventional vehicles.

The eCar pilot trial is considered an opportunity to promote the modern, cost-efficient features and environmental credentials of BEVs. To that effect, several open days will be held to introduce BEV technology in the 'flesh', demonstrate BEV re-charging procedures and highlight fuel and associated GHG emission savings of the ongoing pilot trial.

\subsection{Institutional and Management Capacity}

The eCar pilot project falls clearly within the institutional responsibilities of MNRE-RED which is involved in a range of renewable and energy efficiency projects at any one time. The LTA and EPC will be assisting with relevant logistics as may be required and will monitor performance of BBEVs under Samoan driving conditions

\section{Project Sustainability}

\section{Project Integration}


An informal integration has occurred between different players during proposal development and MNRE consulted relevant government partners and private sectors who are likely the future players when project is successful.

\section{Project Feasibility and Sustainability}

The long term sustainability of this project will build on the outcome of this electric vehicle trial and the Ministry of Natural Resources and Environment with approval of CDC shall include rolling over of Electric Vehicle as one of its National Appropriate Mitigation Action or low carbon development projects. Also there is a need for policy to encourage the use of electric vehicles in the near future if proven successful and economical.

\section{Technical Sustainability;}

All aspects of this proposal are technically feasible and strongly supported by the Land Transport Authority, Electric Power Corporation and Ministry of Finance are based on priorities set in the project proposal and have been discussed with stakeholders.

\section{Economical Sustainability}

Source of revenue will be from charge of electricity use for charging of electric vehicles and in the long term the EPC and LTA can finalise a plan for installation of charging stations. The Ministry of Commerce, Industry and Labour (MCIL) and Ministry of Inland Revenue have to consider reviewing of import duties for electric vehicles.

\section{Institutional Sustainability}

The project proposed the establishment of a programme to train EPC for monitoring of grid using smart system and private sectors personnel who are importing electric vehicles for maintenance of electric vehicles and as they will play a big role in this project. They will assist with specific project components through capacity enhancement through training, provision of some technical equipment, implementation oversight and technical backstopping.

\section{Consultations with other Relevant Line Departments/Agencies}

The MNRE Renewable Energy Division (RED) presented the initial results of socioeconomic benefit to relevant Ministries and included EPC and LTA. Building on the favourable outcome of the first consultation the MNRE-RED continue with interviewing of 
number of personnel in different capacity and professional both at the private and public sectors. The proposal was formulated based on the favourable feedback from various interviews and individual opinions about electric vehicles.

\section{Proposed Amount Requested}

The MNRE Renewable Energy Division (RED) presented the initial results of socioeconomic benefit to relevant Ministries and included EPC and LTA. Building on the favourable outcome of the first consultation the MNRE-RED continue with interviewing of number of personnel in different capacity and professional both at the private and public sectors. The proposal was formulated based on the favourable feedback from various interviews and individual opinions about electric vehicles.

\section{Project Executive Summary of Issues}

In August-September 2013, the MNRE's Renewable Energy. Conducted a preliminary investigation of comparative fuel cost for an Electrical Vehicle (BEV), biofuel powered and conventional vehicles The investigation was assisted by Mr Klaus Thoma who has an academic background in applied environmental and socio-economic sciences. The investigation found that BEVs could be operated with large fuel cost savings compared to a 10per cent biofuel blend and a petrol/diesel powered vehicle. The BEV was also shown to lead to the largest reduction in $\mathrm{CO}_{2}$ emissions and savings in foreign currency reserves

Moreover, a cursory assessment of Samoan driving conditions showed that short travel distances, low travel speeds and the small size of the islands makes some BEVs Even more suitable for Samoan conditions than their contemporary use in metropolitan countries. Thus, there is sufficient data to justify a closer investigation into the potential benefits of BEVs in Samoa.

The eCar pilot proposal aims at testing several BEV types for suitability and fuel use efficiency under Samoan traffic conditions, mainly around Apia. While the vehicles are being tested, ongoing service and maintenance requirements will also lead to the build-up of maintenance expertise and servicing capacity for BEVs. 
The pilot project is expected to yield information on fuel use efficiency, travel cycle data and suitability of BEV technology under Samoan conditions. The pilot trial will also produce transport sector wide drive cycle data and fuel use of the conventional vehicle fleet. This data will be very useful for prospective energy efficiency analysis of the existing transport fleet.

The use of electricity as a transport fuel requires a new planning approach towards present electricity generation practices and how regular battery re-charging may be integrated in base load management of the electricity grid. The pilot trial aims at assessing and gaining practical experience with two modes of battery recharge, namely battery plug-in in the electricity grid overnight and the use of two grid-connected, self-consumption PV installations for battery recharge during daytime when cars are parked between commuting times. This aspect of the trial will lead to gaining practical experience with recharging logistics for BEV users and field data for grid load balancing issues by EPC.

The international policy community is increasingly taking a Life Cycle Assessment (LCA) approach to project planning and justification. Nicholas Stern, the author of the UK Treasury commissioned 'Stern Review' famously stated: "Climate change is the biggest ever global market failure" (Nicholas Stern, 2007). And by that he meant that a large proportion of climate change activities and substances have not been incorporated in cost calculations by participants in the global economy. Literature on fuel externality cost is immense and contradictory. Estimates of the 'well to fuel tank' live cycle assessment (LCA) cost of fuel range from around US $\$ 1 /$ litre to $\$ 9 /$ litre. Clearly, at such prices current economic activity would have to undergo fundamental and, in the short term, unacceptable changes. It is however felt appropriate that an appreciation of the implicit and massive discount of externality cost of current fuel prices is gained in order to make informed mid-long term policy decisions ${ }^{26}$.

Accordingly, the total cost of Electric Vehicle (BEV) and Conventional Vehicle (CV) transport can be obtained by determining:

1) Direct operating cost. BEV fuel cost per 100km: WT\$ 10.78. CV fuel cost: WT\$20.73. Based on the cost assumptions in table 1, a 1000 car BEV fleet is projected to save WT\$2,301,858 in fuel imports annually compared to a CV car fleet. The 1000 car Biodiesel (BD, 10per cent) fleet is projected to save WT\$ $\mathbf{3 4 7 , 4 8 0}$ in fuel imports. There is anecdotal Evidence to suggest that

\footnotetext{
${ }^{26}$ The internalisation of fuel externality cost is currently analysed by the Swiss government and is spearheaded by the world famous Zurich ETH University.
} 
$\mathrm{BEV}$ car maintenance is significantly cheaper than CV maintenance, however, maintenance data need to be confirmed in the Samoan context. There may be higher insurance cost for BEVs and engine warranty issues for $\mathrm{BD}$ vehicles with higher biodiesel percentages in the fuel mix.

2) Capital cost: With still establishing market prices for BEVs, the approach taken here is assuming a US\$10,000 premium of BEV prices over comparable new CVs. Payback calculations are based on this price differential.

3) Health cost: International studies suggest a significant adverse health effect by ICE exhaust fumes, particularly in urban locations. An example of average air pollution cost per metric ton of pollutant gases from the USA is: VOCs US\$ 7,510; CO US\$ 1,677; NO US\$ 13,297; PM-10 US\$ 36,835; PM-2.5 US\$ 118,552; SO $\mathrm{S}_{2}$ US\$ 21,873 (Thomas, 2012 p. 798). The health costs caused by traffic fumes to the Samoan public and health system are assumed to be significant in the mid-term.

Environmental cost: Examples are GHG obligations and urban storm water runoff, heavy metal accumulation, oil compounds leaching into coastal environment and entering food chain.

In principle, direct and tangible benefits from the BEV pilot trial can be gained by transport fuel savings in the order of 15 per cent- 48per cent depending on vehicle type (utility pick-up trucks, mid-size sedans and compact sedans). Assuming constant 2014 fuel prices, fuel savings will amortise the additional US\$10,000 investment in a BEV in 13 years (using compact sedan data). Assuming a net inflationary impact of 3 per cent on transport fuel prices, the payback period is 7.5 years (Figure 1 ).

Due to lack of baseline pollution and pollution cost data (e.g. air/storm water pollution), there is as yet incalculable externality cost from conventional traffic activity which needs to be offset against the additional BEV investment of US\$10,000. A smaller price differential between CV and BEV capital investment will lead to significantly shorter pay-back periods of the BEV capital investment.

The success of the electric vehicle pilot trial will provide fundamental information for the government to develop a strategy to encourage importation of electric vehicles for reduction of GHG emission and most important is the collection of revenue earnings from 
charging of vehicles using solar panels from the EPC grid. EPC will be able to increase its revenue by charging for $\mathrm{BEV}$ recharging services.

The third phase of the proposal will concentrate on retrofitting of existing conventional vehicles once some confidence has been gained from collecting BEV pilot project baseline data

17. Signature of Head Executing Agency

Taulealesumai Tuifuisa'a Laavasa Malua

Chief Executive Officer

Ministry of Natural Resources and Environment

18. Date 


\section{1. eCar Pilot Project Implementation Budget}

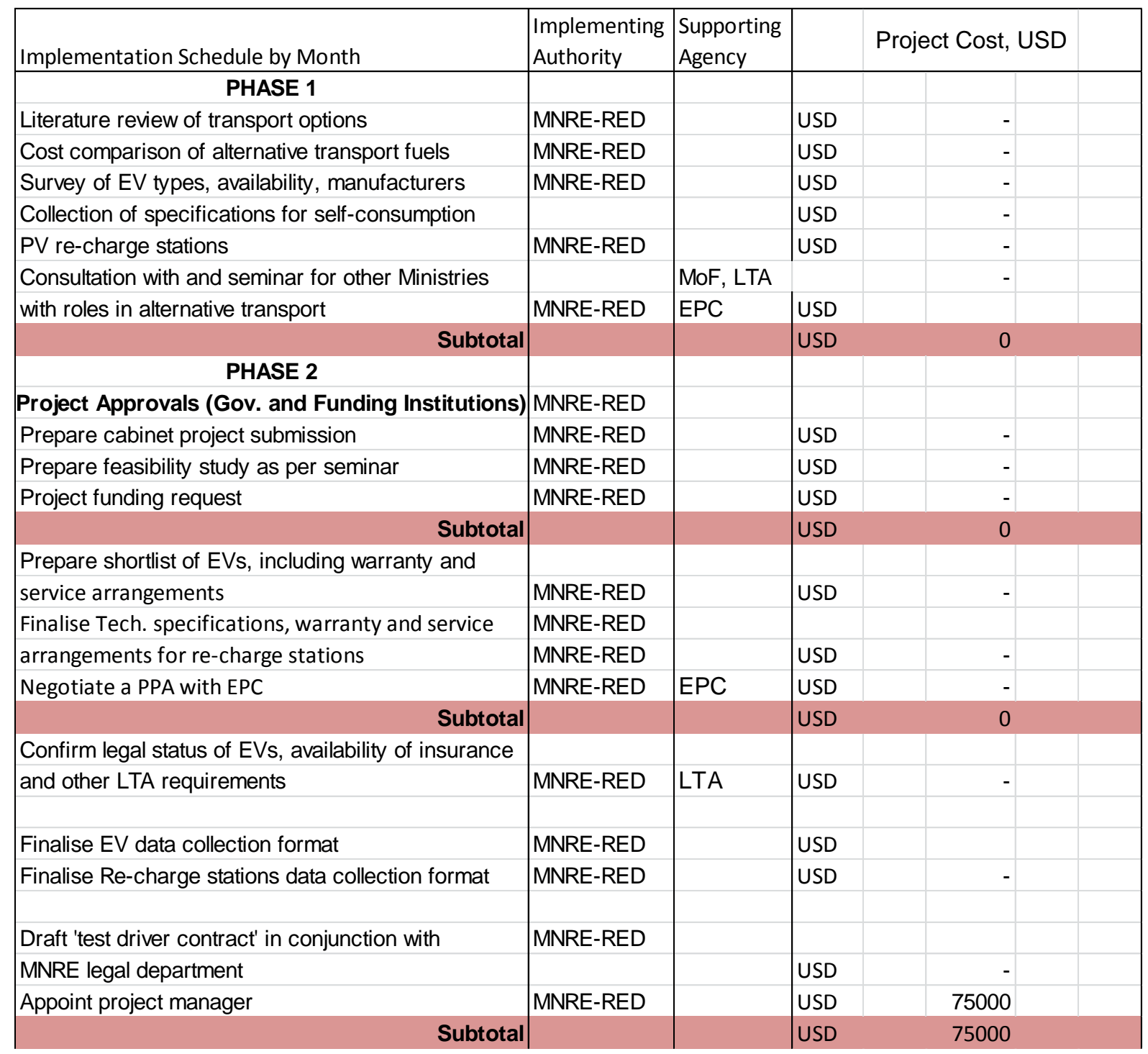




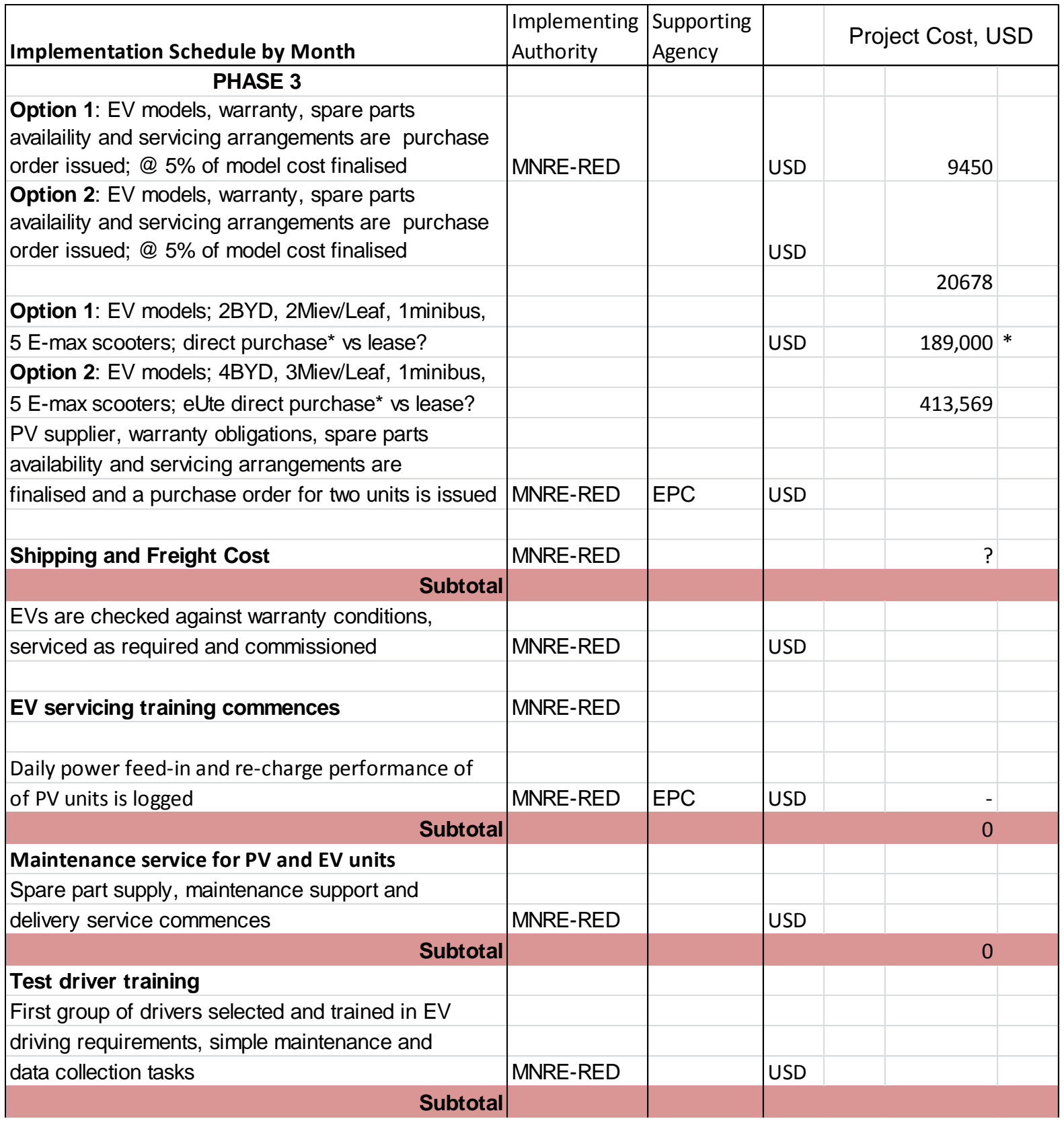




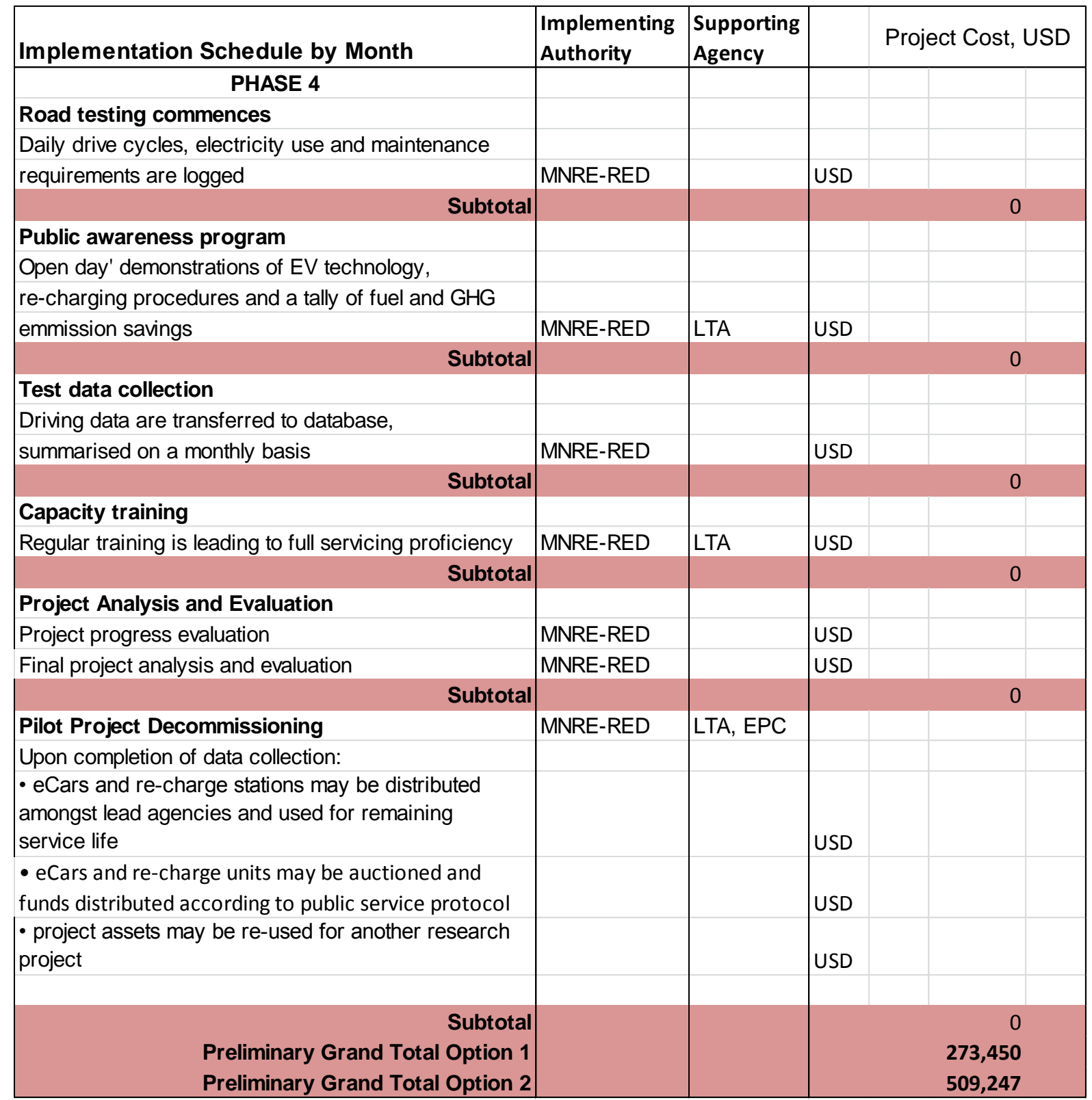




\section{2.}

Implementation Schedule by Month (relative to project

\section{commencement date)}

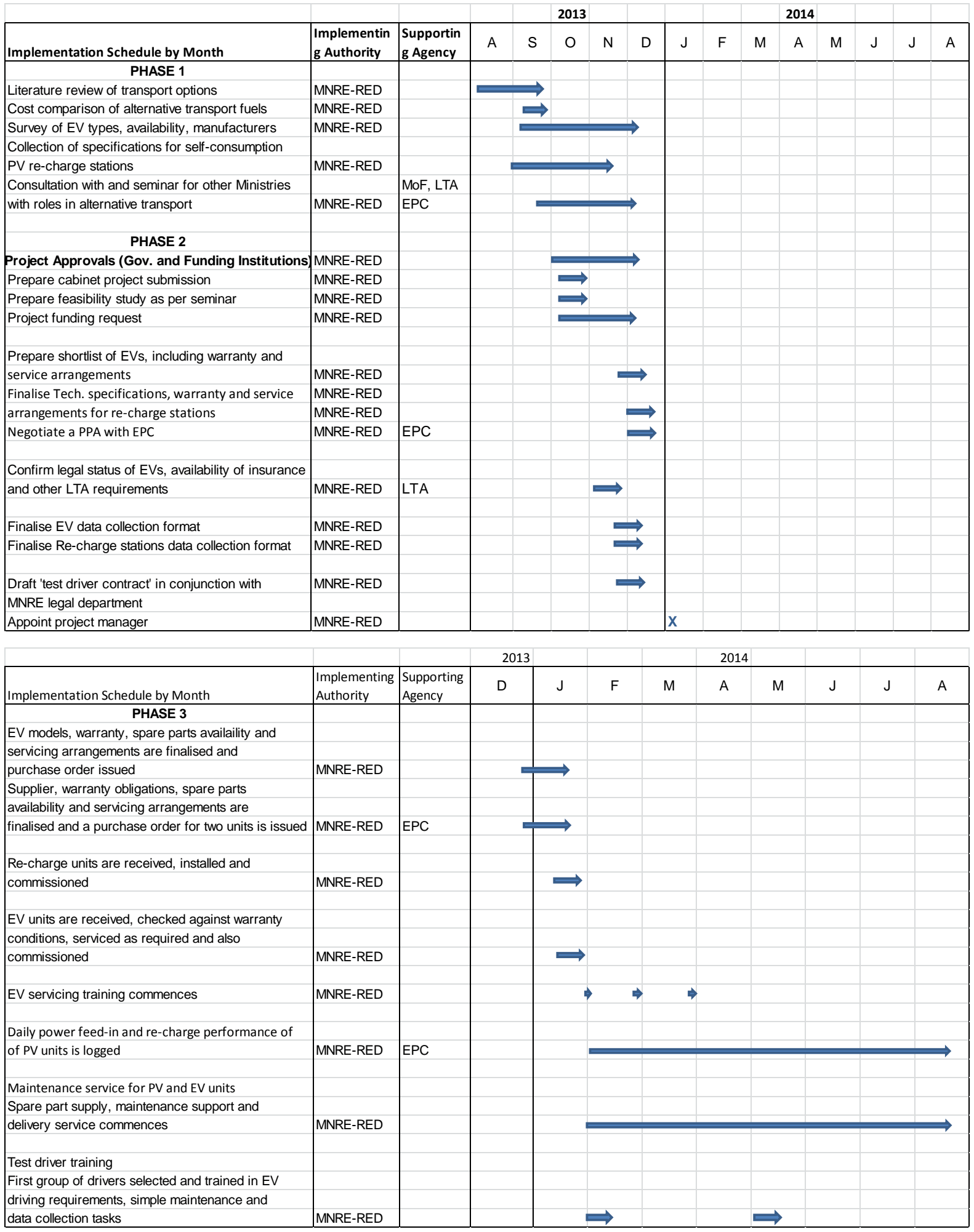




\begin{tabular}{|c|c|c|c|c|c|c|c|c|c|c|c|c|c|c|c|}
\hline & & & & & & & & 201 & & & & & & 2015 & \\
\hline Implementation Schedule by Month & Implementi & $\begin{array}{l}\text { Supportin } \\
\text { g Agency }\end{array}$ & $\mathbf{F}$ & M & A & $\mathbf{M}$ & $\mathbf{J}$ & $\mathbf{J}$ & A & $\mathbf{S}$ & $\mathbf{0}$ & $\mathbf{N}$ & D & $\mathbf{J}$ & $\mathrm{F}$ \\
\hline \multicolumn{16}{|l|}{ 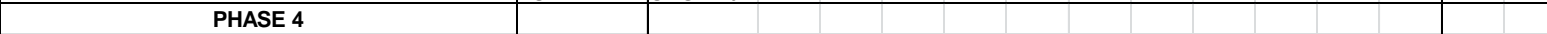 } \\
\hline \multicolumn{16}{|l|}{ Road testing commences } \\
\hline \multicolumn{16}{|l|}{ Daily drive cycles, electricity use and maintenance } \\
\hline requirements are logged & MNRE-RED & & & & & & & & & & & & & & \\
\hline \multicolumn{16}{|l|}{ Public awareness program } \\
\hline \multicolumn{16}{|l|}{ Open day' demonstrations of EV technology, } \\
\hline \multicolumn{16}{|l|}{ re-charging procedures and a tally of fuel and GHG } \\
\hline emmission savings & MNRE-RED & LTA & & $\mathrm{X}$ & & & $\mathrm{X}$ & & & & $\mathrm{X}$ & & & & \\
\hline \multirow{2}{*}{\multicolumn{16}{|c|}{ Test data collection }} \\
\hline & & & & & & & & & & & & & & & \\
\hline \multicolumn{16}{|l|}{ Driving data are transferred to database, } \\
\hline summarised on a monthly basis & MNRE-RED & & $\mathrm{X}$ & $\mathrm{X}$ & $\mathrm{X}$ & $\mathrm{X}$ & $\mathrm{X}$ & $\mathrm{X}$ & $\mathrm{X}$ & $\mathrm{X}$ & $\mathrm{X}$ & $\mathrm{X}$ & $\mathrm{X}$ & & \\
\hline \multicolumn{16}{|l|}{ Capacity training } \\
\hline Regular training is leading to full servicing proficiency & MNRE-RED & LTA & & & $X$ & & & $\mathrm{X}$ & & & $\mathrm{X}$ & & & & \\
\hline \multicolumn{16}{|l|}{ Project Analysis and Evaluation } \\
\hline Project progress evaluation & MNRE-RED & & & & & $\longrightarrow$ & & & & & & & & & \\
\hline Final project analysis and evaluation & MNRE-RED & & & & & & & & & & & & & & \\
\hline Pilot Project Decommissioning & MNRE-RED & LTA, EPC & & & & & & & & & & & & & \\
\hline \multicolumn{16}{|l|}{ Upon completion of data collection: } \\
\hline \multicolumn{16}{|l|}{$\begin{array}{l}\text { - eCars and re-charge stations may be distributed } \\
\text { amongst lead agencies and used for remaining } \\
\text { service life }\end{array}$} \\
\hline $\begin{array}{l}\text { - eCars may be auctioned and funds distributed } \\
\text { according to public service protocol }\end{array}$ & & & & & & & & & & & & & & & \\
\hline $\begin{array}{l}\text { - project assets may be re-used for another research } \\
\text { project }\end{array}$ & & & & & & & & & & & & & & & \\
\hline
\end{tabular}

